\title{
Cellular adaptation to hypoxia and reoxygenation through gene specific mRNA translation
}

Citation for published version (APA):

Magagnin, M. G. P. (2008). Cellular adaptation to hypoxia and reoxygenation through gene specific $m R N A$ translation. [Doctoral Thesis, Maastricht University]. Maastricht University. https://doi.org/10.26481/dis.20080911mm

Document status and date:

Published: 01/01/2008

DOI:

10.26481/dis.20080911mm

Document Version:

Publisher's PDF, also known as Version of record

\section{Please check the document version of this publication:}

- A submitted manuscript is the version of the article upon submission and before peer-review. There can be important differences between the submitted version and the official published version of record.

People interested in the research are advised to contact the author for the final version of the publication, or visit the DOI to the publisher's website.

- The final author version and the galley proof are versions of the publication after peer review.

- The final published version features the final layout of the paper including the volume, issue and page numbers.

Link to publication

\footnotetext{
General rights rights.

- You may freely distribute the URL identifying the publication in the public portal. please follow below link for the End User Agreement:

www.umlib.nl/taverne-license

Take down policy

If you believe that this document breaches copyright please contact us at:

repository@maastrichtuniversity.nl

providing details and we will investigate your claim.
}

Copyright and moral rights for the publications made accessible in the public portal are retained by the authors and/or other copyright owners and it is a condition of accessing publications that users recognise and abide by the legal requirements associated with these

- Users may download and print one copy of any publication from the public portal for the purpose of private study or research.

- You may not further distribute the material or use it for any profit-making activity or commercial gain

If the publication is distributed under the terms of Article $25 \mathrm{fa}$ of the Dutch Copyright Act, indicated by the "Taverne" license above, 


\section{Cellular adaptation to hypoxia and reoxygenation through gene specific mRNA translation}




\section{GROL}

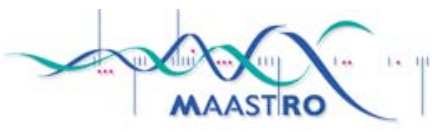

The study presented in this thesis was performed at the Department of Radiation Oncology (Maastro Lab), School for Oncology \& Developmental Biology (GROW), Maastricht University, Maastricht, The Netherlands

Printed by Drukkerij Castro in Riemst

ISBN/EAN: 978-90-9023278-2

(C) Michaël G.P. Magagnin, Maastricht, 2008

No part of this thesis may be reproduced in any form without prior written approval from the author 


\title{
Cellular adaptation to hypoxia and reoxygenation through gene specific mRNA translation
}

\author{
PROEFSCHRIFT
}

ter verkrijging van de graad van doctor aan de Universiteit Maastricht, op gezag van de Rector Magnificus, Prof. mr. G.P.M.F. Mols volgens het besluit van het College van Decanen, in het openbaar te verdedigen op donderdag 11 september 2008 om 16.00 uur

door

Michaël Gaston Pietro Magagnin 


\section{Promotores:}

Prof. dr. B.G. Wouters

Prof. dr. P. Lambin

\section{Copromotor:}

Dr. M. Koritzinsky

\section{Beoordelingscommissie:}

Prof. dr. F.C.S Ramaekers (voorzitter)

Prof. dr. B. Devreese (Universiteit Gent)

Prof. dr. J.H.A.M. Kaanders (UMC St. Radboud)

Prof. dr. E.C. Mariman

Dr. J.W. Voncken 


\section{TABLE OF CONTENTS}

\section{CHAPTER 1}

General Introduction

\section{CHAPTER 2}

Gene expression during acute and prolonged hypoxia is regulated by distinct mechanisms of translational control

CHAPTER 3

The hypoxic proteome is influenced by gene-specific changes in mRNA translation

\section{CHAPTER 4}

The mTOR target 4E-BP1 contributes to differential protein expression during normoxia and hypoxia through changes in mRNA translation efficiency

\section{CHAPTER 5}

Inhibition of 4E-BP1 sensitizes U87 glioblastoma xenograft tumors to irradiation through increased sensitivity to hypoxia induced cell death

\section{CHAPTER 6}

Proteomic analysis of gene expression following hypoxia and reoxygenation reveals proteins involved in the recovery from endoplasmic reticulum and oxidative stress

\section{CHAPTER 7}

Summary, Discussion and Future Perspectives 



\title{
Chapter 1
}

\section{General Introduction}

\author{
M.G.P. Magagnin, M. Koritzinsky and B.G. Wouters
}

Partly Published in Drug Resist Updat. 9: 185-197, 2006 


\section{INTRODUCTION}

In Europe there were an estimated 3,191,600 cancer cases diagnosed (excluding nonmelanoma skin cancers) and 1,703,000 deaths from cancer in 2006 [1]. The most common forms of cancers were breast cancer, colorectal cancer and lung cancer. Lung cancer, with an estimated 334800 deaths (19.7\% of total), was the most common cause of death from cancer, followed by colorectal (207 400 deaths), breast (131 900) and stomach (118 200) cancers. The total number of new cases of cancer in Europe appears to have increased by 300000 since 2004 [1]. Today, millions of people are living with cancer or have had cancer.

Although there are many types of cancer, they share a number of common 'hallmarks' which distinguish them from the normal cells from which they are derived [2]. This usually includes a greatly increased rate of proliferation. An isolated abnormal cell that does not proliferate more than its normal neighbours causes no significant damage, irregardless of other abnormal properties it may have. However, loss of proliferative control will give rise to a tumor or neoplasm, which is defined as a growing mass of abnormal cells. As long as the neoplastic cells remain clustered together in a single mass, the tumor is classified as benign. At this stage, a complete cure can usually be achieved by removing the tumor mass surgically. A tumor is considered a cancer only if it is malignant, that is, only if the tumor cells have acquired the ability to invade surrounding tissue. Invasiveness usually implies an ability to break loose, enter the bloodstream or lymphatic vessels and form secondary tumors, called metastases at other sites of the body. The more widely a cancer spreads, the harder it becomes to eradicate.

Cancers arising from epithelial cells are named carcinomas, those arising from connective tissue or muscle cells are named sarcomas, which both form solid tumors. Some cancers, like leukaemia, do not form solid tumors. Instead, these cancer cells involve the blood and blood-forming organs and circulate through other tissues where they grow.

Cancer cells develop as a consequence of genetic changes that are often initiated as a result of damage to the DNA. An estimated $10^{16}$ cell divisions take place in a normal human body in the course of a lifetime. Even in an environment that is free of mutagens, mutations will occur due to fundamental 
limitations on the accuracy of DNA replication, DNA repair, and cell division. Genes which when mutated stimulate cells to divide where they should not, are termed protooncogenes. These mutations have a dominant effect, and the mutant genes, known as oncogenes, are identified by their ability to drive a cell towards cancer. Other mutations, which result in loss-of-function mutations in so-called tumor suppressor genes, relieve cells of inhibitions that normally help to hold their cell numbers in check, thereby creating a risk towards cancer development. Clearly, to be cancer cells must acquire a series of changes that confer new properties on the cells as it evolves. Different cancers acquire different combinations of mutations in oncogenes and tumor suppressors which gives rise to these new properties. Nevertheless, Hanahan and Weinberg have suggested that the vast catalogue of cancer cell of genotypes is a manifestation of six essential alterations in cell physiology that collectively dictate malignant growth: self-sufficiency in growth signals, insensitivity to antigrowth signals, evading programmed cell death (apoptosis), limitless replicate potential, sustained angiogenesis and tissue invasion and metastasis. Each of these acquired capabilities during tumor development represent the successful breaching of an anticancer defence mechanism hardwired into cells and tissues [2].

However, because there are many genetic routes to the acquisition of these hallmarks, individual cancers contain unique sets of altered genes. Recent sequencing studies have suggested that the 'landscape' of mutations amongst cancers even of similar types is indeed vastly different [3]. As a result, individual cancers may behave very differently. This is especially true for the microenvironment of the tumor, which displays extreme heterogeneity amongst otherwise similar cancer types. These important differences amongst otherwise similar tumors confer unique growth, metastatic, and treatment properties on the tumor. This realization has stimulated recent efforts to develop more individualized treatment that is tailored to specific genetic or other properties of the tumor. This thesis is aimed at understanding the biological consequences of tumor hypoxia, one of the unique properties of human tumors that displays a large degree of heterogeneity amongst different tumors and which is thought to be a major contributor to patient prognosis and treatment response.

The general introduction of this thesis is divided into three separate parts. The first discusses the evidence for hypoxia in tumors and its clinical relevance. The second focuses on how tumors adapt to hypoxic stress and 
efforts aimed at targeting hypoxia tolerance in cancer. Finally, the third discusses the patterns of oxygenation (severity and duration) within tumors and their effect on the cellular hypoxic responses.

\section{TUMOR HYPOXIA AND ITS CLINICAL RELEVANCE}

Since the initial pioneering histological work of Thomlinson and Gray in 1955 that led to their discovery of hypoxia in human lung cancer [4], it has been convincingly demonstrated that the majority of solid human tumors contain regions of poor oxygenation [5, 6]. Hypoxia within solid tumors arises as a result of insufficiencies and improper functioning of the tumor vasculature which impairs the ability to deliver both oxygen and treatment to isolated regions of tumors [7-9]. The oxygen delivered is consumed as it diffuses out from the blood vessel and consequently an oxygen gradient develops, reaching complete anoxia at distances of circa 150-200 $\mu \mathrm{m}$. The limit in oxygen diffusion gives rise to what has been termed 'chronic' hypoxia. In this model, the continued proliferation of tumor cells adjacent to blood vessels, slowly pushes cells through the oxygen gradient and eventually into necrosis. However, hypoxia can also arise through transient changes in blood flow. The tumor vasculature is often immature, lacking smooth muscle cells and other structural components. Combined with high interstitial pressures in tumors, this leads to fluctuations in blood flow and/or red blood cell flux. Rapid and dramatic changes in perfusion, including complete shut down of vessels which has been experimentally demonstrated in animal tumors. Furthermore, pioneering work by Dewhirst [10] and others have shown that many tumors demonstrate cycling or periodic changes in blood flow and oxygenation. This results in a dynamically changing oxygen environment for tumor cells. Consequently these cells must endure frequent exposures to hypoxia/reoxygenation cycles.

For radiotherapy, the initial interest in hypoxia was based on the fact that hypoxic tumor cells alter the chemical reactions which take place in the DNA upon radiation such that only about one third as many lethal DNA lesions are produced in hypoxic cells compared with aerobic cells [11]. The clinical importance of hypoxia for radiotherapy has subsequently been demonstrated in trials where tumor oxygenation was measured with needle electrodes. A recent report from a multi-centre trial in head-and-neck cancer showed that in a 
multivariate Cox Proportional Hazards analysis, the hypoxic fraction was by far the most statistically significant factor explaining the variability in patient survival [12]. In this study, 5-year survival was almost constant for hypoxic fractions in the range from 0 to $20 \%$, whereas the 5 -year survival approached $0 \%$ in the most hypoxic tumors. Cells in hypoxic tumor areas have also been shown to be resistant to chemotherapy [13]. This is due in part because metabolism of the chemotherapeutic drugs in well-perfused areas of the tumors limits their ability to reach the poorly perfused hypoxic cells. Chemotherapeutic drugs may also be less active in hypoxic cells due to their comparatively low rates of proliferation.

Most recently, research efforts have concentrated on understanding the consequences of hypoxia on tumor cell biology. This has been stimulated in part by several clinical findings that implicate tumor hypoxia as a contributor to the malignant phenotype. Importantly, the prognostic value of hypoxia has been observed independent of treatment modality, even for patients treated with surgery where no 'intrinsic' resistance is expected [14]. In this cervical cancer study, hypoxia was also associated with greater lymph-vascular space involvement and parametrial infiltration. Furthermore, several clinical studies have found an association between hypoxia and metastases $[15,16]$. It has therefore been proposed that hypoxia not only modifies therapy resistance, but may also affect malignancy. Clinical efforts towards overcoming hypoxia have focused on either eliminating it, for example by breathing high oxygen gas mixtures, or by replacing oxygen with drugs that can sensitize cells to radiation in a similar way to oxygen. Unfortunately, these clinical studies have only modestly improved outcome $[17,18]$. 


\section{MECHANISMS OF ADAPTATION TO HYPOXIA}

Hypoxic conditions encountered by normal cells during development and several physiological situations activate highly regulated molecular responses designed to restore oxygen homeostasis. In non-malignant pathologies such as severe wounds and stroke, hypoxia can cause cell death and tissue malfunctioning. In these cases, the normal biological responses to hypoxia are insufficient to maintain cell function and survival.

So how does a tumor cell adapt to and survive in a nutrient deficient and low oxygen environment?

During carcinogenesis, tumor cells often become more resistant to hypoxia-induced cell death, a property that is consistent with the negative impact of hypoxia on clinical outcome. This resistance can arise, for example, through the inhibition or loss of pathways that promote cell death in response to hypoxia. This is best exemplified by the p53 pathway, which when functional can result in the rapid death of hypoxic, oncogenically transformed cells [19]. A second mechanism involves an attempt by the tumor cells to increase tumor oxygenation by stimulating angiogenesis. Persistent hypoxia in tumors can provide the basis for the 'angiogenic switch', which has been suggested as one of the key six hallmarks of cancer [2]. Neo-angiogenesis was first proposed in the 1960s and its significance in tumors and anti-cancer strategies is underscored by the discovery that growth factors such as vascular endothelial growth factor (VEGF) and platelet-derived growth factor (PDGF) are synthesized and secreted by hypoxic tumor cells via transcriptional and post-transcriptional mechanisms. Hypoxia can also decrease expression of antiangiogenic factors like thrompospodin-1 [20,21]. Finally, cancer cells become adept at regulating energy homeostasis during hypoxia where the efficiency of ATP production is impaired by the lack of oxidative phosphorylation. This regulation occurs through both increases in anaerobic glycolysis and through decreases in energy consumption via the suppression of cell proliferation and protein synthesis.

Three main pathways that influence the tolerance and behaviour of tumor cells to hypoxia have been identified and intensively studied, including the hypoxia inducible factor HIF-1 which modulates angiogenesis and two other pathways that influence both effects on energy consumption and protein 
synthesis (Figure 1).

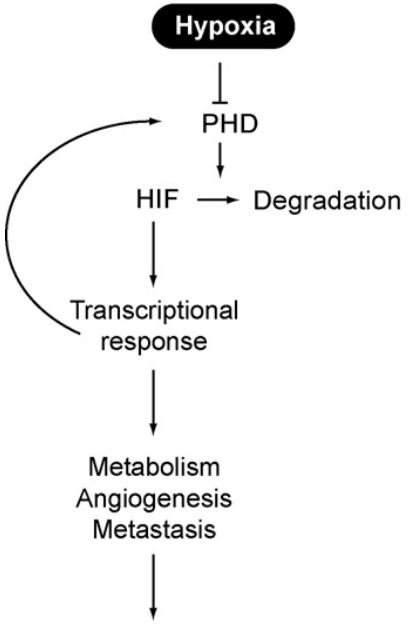

Hypoxia tolerance Tumor growth

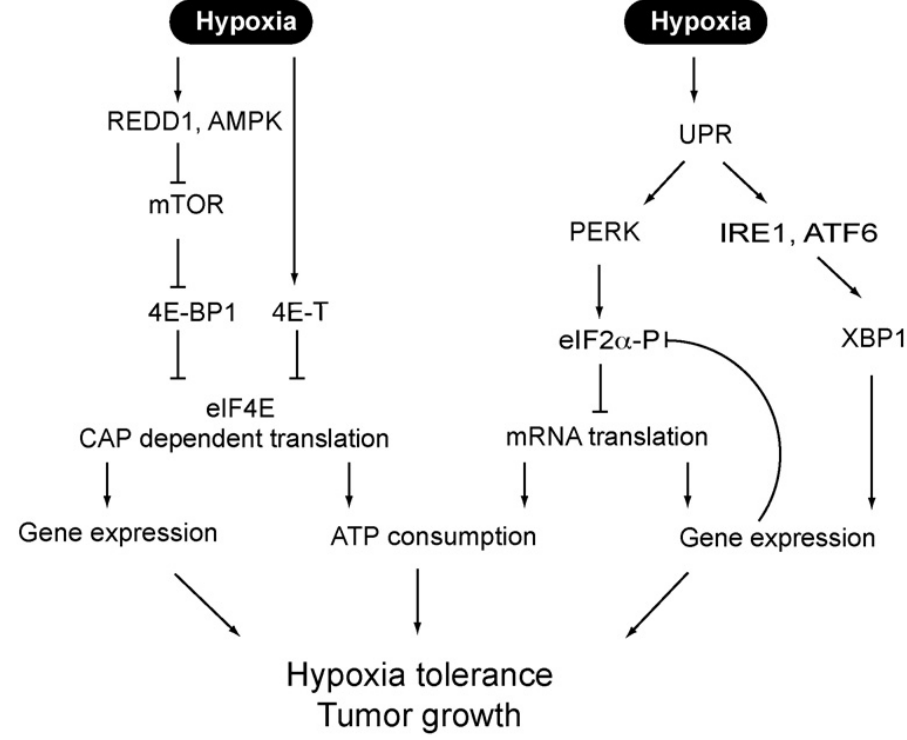

Figure 1: Cellular pathways that influence the tolerance and behaviour of tumors cells to hypoxia. Hypoxia dependent stabilisation and activation of HIF-1 mediates a transcriptional program that influences cell metabolism, angiogenesis and metastasis. Hypoxia also activates two independent pathways that inhibit mRNA translation. This inhibition is thought to influence hypoxic cell tolerance and behaviour through both effects on energy conservation and gene expression.

The understanding of this hypoxia tolerance has made it possible to develop new therapies targeted directly at the perceived important cellular responses to hypoxia, some of which are undergoing clinical evaluation (Table 1). However, it remains to be seen how effective these new therapies will be. These known pathways that control the cellular responses to hypoxia are highly dependent on both the severity of hypoxic areas in tumors (absolute levels oxygen), which spans the range from normal to anoxia and the duration of hypoxia, which is highly dynamic and characterized by both a rapid and slowly changing oxygenation levels. 
Table 1: Therapeutic targeting of HIF-1, the UPR and mRNA translation
Target
Drug
Reference

Targeting the HIF pathway

\begin{tabular}{|c|c|c|c|}
\hline HIF-1 RNAi & HIF-1 & RNAi & {$[22]$} \\
\hline Unknown & Topoisemerase I & Camptothecin & [23] \\
\hline $\begin{array}{l}\text { Blocking HIF-1 DNA binding } \\
\text { activity }\end{array}$ & HIF-1 & $\begin{array}{l}\text { Echinomycin } \\
\text { (NSC-13502) }\end{array}$ & [24] \\
\hline Translation/stability HIF-1 $\alpha$ & HSP90 & GA, 17-AAG & {$[25]$} \\
\hline Unknown & Unknown & YC-1 & [26] \\
\hline Improving HIF-PH activity & HIF-PH & Ascorbate & [27] \\
\hline Microtubule polymerization & Unknown & 2ME2 & [28] \\
\hline Blocking PTEN inhibitor & Thioredoxin-1 & $\begin{array}{l}\text { PX-12, } \\
\text { pleurotin }\end{array}$ & [29] \\
\hline Ras/MAPK activity & RAF & BAY 43-9006 & [30] \\
\hline \multicolumn{4}{|l|}{ Targeting the UPR } \\
\hline $\begin{array}{l}\text { suicide gene driven by GRP-78 } \\
\text { promotor }\end{array}$ & UPR tolerance & $\begin{array}{l}\text { HSV-tk suicide } \\
\text { gene }\end{array}$ & {$[31]$} \\
\hline Inhibiting GRP-78 transcription & GRP-78 & versipelostatin & [32] \\
\hline Inhibiting the proteasome & XBP-1 & $\begin{array}{l}\text { Proteasome } \\
\text { inhibitors }\end{array}$ & {$[33]$} \\
\hline \multicolumn{4}{|l|}{ Targeting mRNA translation } \\
\hline Inhibiting eIF2 $\alpha$ dephosphorylation & eIF $2 \alpha$ & Salubrinal & {$[34]$} \\
\hline $\begin{array}{l}\mathrm{PI} 3 / \mathrm{AKT} \text { pathway, mRNA } \\
\text { translation? }\end{array}$ & PI3K & $\begin{array}{l}\text { Wortmannin, } \\
\text { LY294002 }\end{array}$ & {$[35]$} \\
\hline mRNA translation & FRAP/mTOR & $\begin{array}{l}\text { Rapamycin, } \\
\text { CCI-779 }\end{array}$ & {$[36]$} \\
\hline
\end{tabular}




\subsection{HIF transcription factors}

The most intensely investigated molecular response to hypoxia is the activation of the transcription factor HIF-1 and its downstream targets. HIF-1 is a heterodimer composed of the hypoxia responsive subunit HIF-1 $\alpha$ and the constitutively expressed aryl hydrocarbon receptor nuclear translocator ARNT/HIF-1 $\beta$. During normoxic conditions, HIF-1 $\alpha$ is ubiquitinated by the von-Hippel Lindau (VHL) protein and targeted for degradation [37, 38].

The oxygen sensitivity of HIF- $1 \alpha$ is derived primarily from the fact that VHL protein only recognizes it when two proline residues (P402 and P564) are hydroxylated. These modifications are carried out in an oxygen-dependent reaction by one of three known HIF prolyl hydroxylases [39]. The transcriptional activity of HIF-1 is also inhibited by oxygen. This is mediated by an oxygen dependent hydroxylation of asparagine residue 803 in its Cterminal transactivation domain (C-TAD) by factor inhibiting HIF-1 (FIH) [40]. A subset of HIF-1 target genes appear less sensitive to FIH activity, possibly through utilization of an alternative oxygen-insensitive transactivation domain in the N-terminus (N-TAD) of HIF-1 $\alpha$ [41]. In addition to HIF-1 $\alpha$, two other family members have been identified, HIF-2 $\alpha$ and HIF-3 $\alpha$. HIF- $2 \alpha$ can also dimerize with HIF-1 $\beta$ and activate transcription of overlapping or distinct target genes $[42,43]$. Inhibitory PAS (IPAS/HIF-3 $\alpha$ ) contains no endogenous transactivation function but may act as a dominant negative regulator of HIF-1 [44].

HIF-1 promotes the expression of numerous genes that function to improve oxygenation through erythropoiesis and angiogenesis [45]. HIF-1 target genes also promote metabolic adaptation through regulation of glucose uptake, stimulation of glycolysis [46, 47] and through its recently reported ability to regulate the rate of cellular oxygen consumption [48]. During conditions of poor oxygenation, the generation of ATP shifts from the oxidative phosphorylation pathway in the mitochondria to the oxygen independent pathway of glycolysis in the cytoplasm. Although glycolysis is less efficient compared with oxidative phosphorylation, in the presence of sufficient glucose it can maintain ATP levels due to increases in the glycolytic enzymes. HIF-1 is a necessary mediator of this 'switch' in the cellular metabolic program, also known as the Pasteur effect [47]. In addition, HIF-1 activation is associated with an increased metastatic capacity through the 
upregulation of genes such as LOX, Met and CXCR4 [49-51]. The importance of HIF-1 in the growth and behaviour of tumors has been extensively investigated and these studies have stimulated the development of several different therapies based on targeting HIF-1 [45, 52] (Table 1). However, although many of these agents can significantly inhibit HIF-1 activity, decrease VEGF and impair xenograft growth, most of them are rather non-selective inhibitors. For example, three out of four compounds identified from a HIF-1 cell-based high-throughput screen of 2000 agents within the NCI chemical diversity set were analogues of camptothecin, a topoisomerase I inhibitor [53]. Although these compounds show an interesting mechanism for HIF-1 inhibition [23], they are likely to have other cellular effects, including activation of DNA damage responses. Due to this lack of specificity it remains difficult to define the exact contribution of HIF-1 inhibition and establish under what circumstances these agents should be used in the clinic. Several studies to develop more specific HIF-1 inhibitors and novel therapeutic drugs that target HIF-1 are underway. One of the more promising agents was derived from a two-step screening procedure of the NCI 140,000 small-molecule library [24]. The same cell-based screen discussed above was first used to identify 128 molecules capable of blocking HIF-1. These 128 compounds were then screened for their ability to block HIF-1 DNA-binding activity. This procedure identified echinomycin (NSC-13502), a small-molecule known to bind DNA in a sequence-specific fashion. This molecule was clinically investigated 20 years ago based on demonstrated pre-clinical antitumor activity [54], but minimal or no antitumor activity was reported in phase II clinical trials [55-57]. However, because no surrogate measurements of HIF activity were made in these trials, it is not clear if the lack of clinical activity is due to ineffective inhibition of HIF1 or to HIF-1 being an inappropriate target in these patients.

HIF-1 $\alpha$ has also been specifically targeted in vitro [58] and in vivo [22] using RNA interference (RNAi). In vivo, early-stage D54MG-derived gliomas were reported to be more vulnerable to HIF-1 RNAi inhibition than their latestage counterparts. Interestingly, HIF-1 $\alpha$ knockdown tumors showed no differences in vascular density compared to their wild-type counterparts, a phenomenon that was also observed in HIF-1 $\alpha$ knockout tumors derived from Ras transformed MEFs [59]. These findings may be explained by a compensatory role of the proangiogenic cytokine interleukin-8 (IL-8), which has been shown to be induced in cells lacking HIF-1 [60]. If this proves to be a general phenomenon, it poses obvious limitations to targeting HIF in tumors. A neutralizing antibody to IL-8 substantially inhibited angiogenesis and tumor 
growth in HIF-1 $\alpha$ deficient tumors, suggesting that effective inhibition of HIF1 may also require suppression of the IL-8 compensatory response [60]. It should also be emphasized that the value of targeting HIF may depend on tumor type or location. HIF-1 $\alpha$ knock-out astrocytomas, a class of oxygendependent brain tumors, showed severe necrosis, reduced growth and vessel density in a vessel-poor subcutaneous environment, but when grown in the vessel-rich brain parenchyma the phenotype was reversed [61]. Several other papers have also reported that HIF-1 deficient tumors may grow at similar or faster rates than their wild-type counterparts [62]. Similarly, overexpression of HIF-2 $\alpha$ has been shown to enhance angiogenesis, but to reduce overall tumor growth due in part to increased tumor cell apoptosis [63]. These examples illustrate that even when HIF-1 can be effectively inhibited, it is not always possible to predict the consequences for tumor growth. Thus, although targeting HIF-1 may have potential in cancer therapy, we still do not fully understand the dependence of different tumor cells on HIF-1 function.

\subsection{The Unfolded Protein Response UPR}

The endoplasmic reticulum (ER) serves as a site for protein folding, assembly, disulfide bond formation and glycosylation of newly synthesized secretory and transmembrane proteins. The protein flux into the ER is variable because it can change rapidly in response to programmes of cell differentiation, environmental conditions and the physiological state of the cell. To handle this dynamic situation, cells adjust the protein-folding capacity of the ER according to their requirements, thereby ensuring that the quality of cell-surface and secreted proteins can be maintained with high fidelity.

During conditions of ER stress such as high ER protein load or an accumulation of unfolded proteins, an evolutionarily conserved program called the unfolded protein response (UPR) is activated. Recent evidence suggests that hypoxia is also capable of activating the UPR [64-67]. Hypoxia activates both the (PKR)-like ER kinase (PERK) and the inositol-requiring protein-1 (IRE1), two of the three known UPR sensors that also include the activating transcription factor-6 (ATF6). Activation of these sensors during the UPR is thought to be mediated primarily by the dissociation of the ER chaperone immunoglobulin binding protein (BiP) from the luminal domains of PERK, IRE1 and ATF6 by preferentially binding misfolded proteins that accumulate 
in the ER lumen [68]. BiP is upregulated during hypoxia and inhibition of BiP expression results in increased cell death in cells exposed to hypoxia $[69,70]$.

PERK activation during hypoxia results in the phosphorylation at the Ser-51 residue of eukaryotic initiation factor $2 \alpha$ (eIF2 $\alpha$ ). Its phosphorylation inhibits the guanine nucleotide exchange factor eIF2B, which prevents formation of the eIF2-GTP-(Met)tRNA ternary complex and thus causes an overall inhibition of mRNA translation (Figure 2). This inhibition is thought to aid in the recovery of ER stress in part by preventing the production of new proteins. During hypoxia, the inhibition of mRNA translation may also help to conserve ATP since protein synthesis is one of the most energy consuming processes in the cell. Although phosphorylation of eIF2 $\alpha$ causes a global inhibition in mRNA translation, it paradoxically stimulates the synthesis of a subset of proteins during hypoxia including the activating transcription factor-4 (ATF4) $[64,65,71,72]$. The selective translation of ATF4 under conditions of repressed protein synthesis appears to be the result of preferentially increased translation of mRNAs that contain inhibitory upstream open reading frames (uORFs) within their 5' untranslated region (UTR) [65, 73, 74]. ATF4 mediates the activation of many downstream genes, including those involved in recovery from oxidative stress [75]. Several other genes including the ATF4 target genes CHOP and GADD34 are also preferentially translated during hypoxia [64, 65, 72]. Recently, it has been demonstrated that ER stress also triggers autophagy, which is a catabolic process for the degradation and recycling of cytosolic, long lived, or aggregated proteins and excess or defective organelles. So as the cell produces even more ER stress, this process promotes the degradation of the organelle and the damaged proteins within it [76]. In contrast to other types of autophagy, such as starvation induced autophagy, the autophagosomes that accumulate in UPR-induced yeast cells do not readily fuse with the vacuole until the stress is abolished, indicating that the sequestration of damaged ER is more important than its ultimate degradation [77]. Work by Kouroku demonstrated that PERK/eIF2 $\alpha$ phosphorylation mediates the polyglutamine-induced LC3 conversion, an essential step for autophagy formation [78]. 


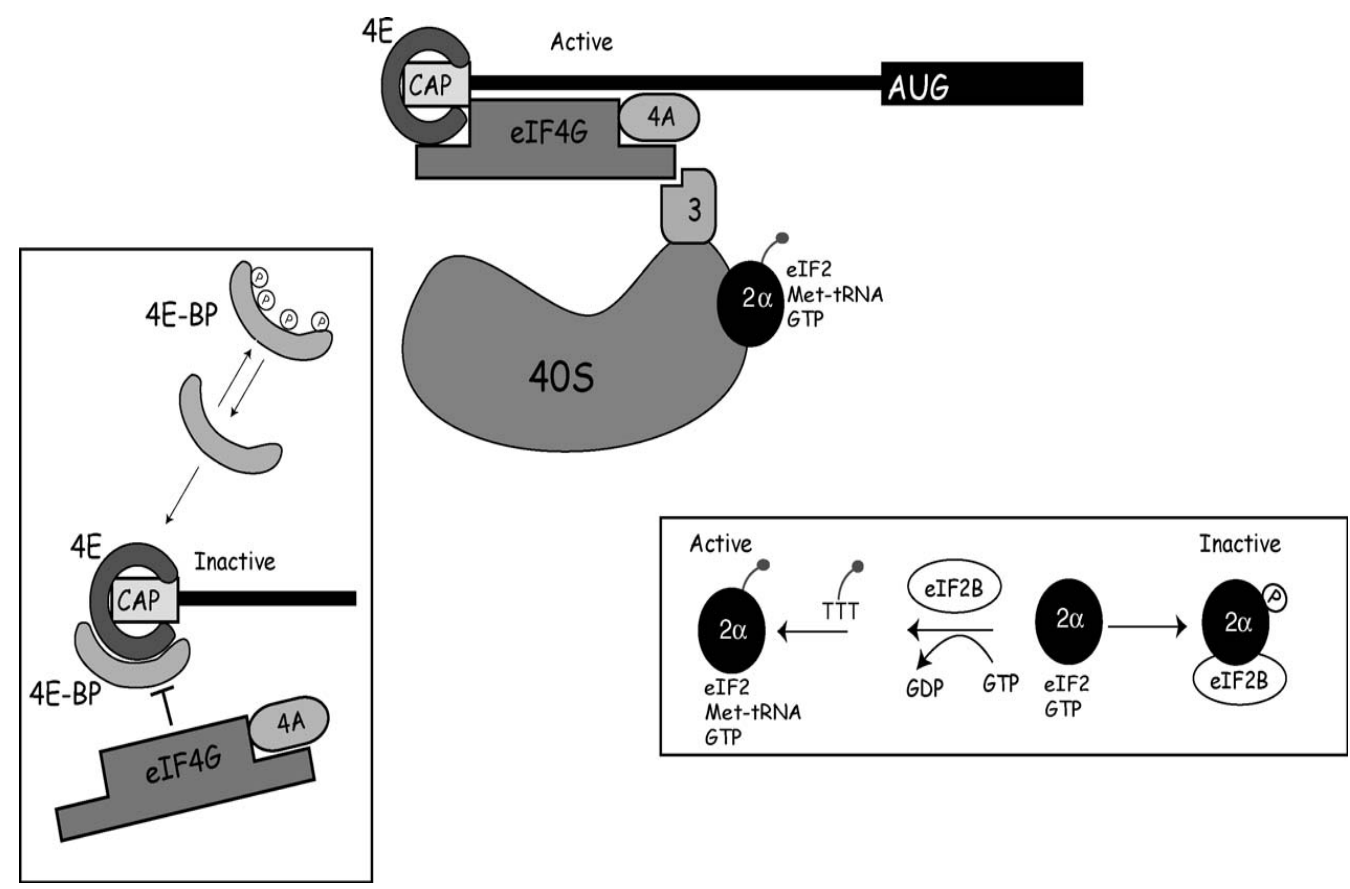

Figure 2: Control of the initiation step of mRNA translation. Initiation of translation begins following assembly of eIF4F (containing the cap-binding protein eIF4E, the scaffold protein eIF4G, and the RNA helicase eIF4A) at the m7GpppN 'cap' structure of the mRNA. Interaction with eIF3 facilitates recruitment of the small subunit of the ribosome together with the ternary complex containing eIF2/Met-tRNA/GTP. This complex then scans through the 5' UTR until it reaches the AUG start site. Here GTP is hydrolyzed releasing eIF2 and allowing recruitment of the large subunit of the ribosome. Control of initiation occurs principally at two steps. The first is through inhibition of eIF4F as a result of competitive binding of the 4E-BPs to eIF4E in their under-phosphorylated form. The second is through phosphorylation of eIF2 $\alpha$. Phosphorylation results in binding and inactivation of the GDP/GTP exchange factor eIF2B.

Other transcription factors are also induced in response to UPR activation during hypoxia. This includes NF- $\mathrm{BB}$ and Nrf2, both of which require phosphorylation of eIF2 $\alpha$ for their activation during ER stress $[79,80]$. In addition, IRE1 activation during the UPR causes the excision of a 26nucleotide intron from the mRNA coding for the X-box binding protein-1 (XBP-1) transcription factor, a necessary step in its activation [81] Collectively, these data suggest that in addition to its effect on translation, 
hypoxic activation of the UPR also leads to a significant additional transcriptional response.

The ability to phosphorylate eIF $2 \alpha$ and inhibit translation appears to be an important protective response to hypoxia since PERK knockout cells show increased cell death during hypoxic exposure [64]. These cells also produce tumors that grow much more slowly than PERK wild-type cells, an effect that has been linked to decreased hypoxia tolerance. Cells derived from a knock-in mouse expressing a non-phosphorylatable S51A mutation in eIF2 $\alpha$ show a similar phenotype [64]. A general role for the UPR in the hypoxic response is suggested by the fact that XBP-1 deficient cells also show defective tumor growth and are sensitive to hypoxia [67].

Together these data suggest that targeting the UPR in order to prevent its activation during hypoxia would be an interesting approach for therapy. A selective inhibitor of eIF $2 \alpha$ dephosphorylation (salubrinal) has been shown to protect against ER-stress [34], suggesting that this pathway can be exogenously regulated. Although there are no known specific inhibitors of the important proteins in this pathway including PERK, ATF4, IRE1 or XBP-1 that can be used clinically, efforts are underway to find such inhibitors [82]. It may also be possible to use agents that are known to stimulate ER-stress, for example through the use of proteasome inhibitors. Proteasome inhibitors that suppress the activity of IRE1 $\alpha$ rendered myeloma cells extremely sensitive to ER-stress, which was translated in increased apoptosis $[33,83]$ (Table 1).

\section{3. mTOR and eIF4F}

Hypoxia also regulates mRNA translation by inhibiting the formation of a second translation initiation complex, eIF4F. This complex contains the mRNA cap binding protein eIF4E, the scaffold protein eIF4G, and the RNA helicase eIF4A. Inhibition of eIF4F during hypoxia occurs in part through activation of the inhibitory eIF4E binding protein 4EBP1. This protein binds to eIF4E in its underphosphorylated state and prevents it from binding to eIF4G [84, 85] (Fig. $2)$. The phosphorylation of $4 \mathrm{E}-\mathrm{BP} 1$ is controlled in large part by the mammalian target of rapamycin (mTOR) kinase [86]. Several recent reports have demonstrated that mTOR activity is at least partially inhibited during hypoxia, leading to decrease 4E-BP1 phosphorylation and decreased levels of translation [65, 87-89]. 
Three upstream pathways influence mTOR activity, two of which are implicated as targets of hypoxia. These pathways signal to mTOR by altering the activity of the tuberous sclerosis complex (TSC), a negative regulator of mTOR. The first is controlled by the hypoxia inducible gene REDD1/RTP801. Its induction during hypoxia causes activation of the TSC1/TSC2 complex and inhibition of mTOR [87]. The TSC1/TSC2 complex also regulates mTOR function in response to changes in energy status. Under low energy conditions (increases in AMP) LKB1 phosphorylates and activates AMPK, which then activates the TSC1/TSC2 complex $[90,91]$. A reduction in ATP during hypoxia can thus also inhibit mTOR through this pathway [89] (Figure 3).

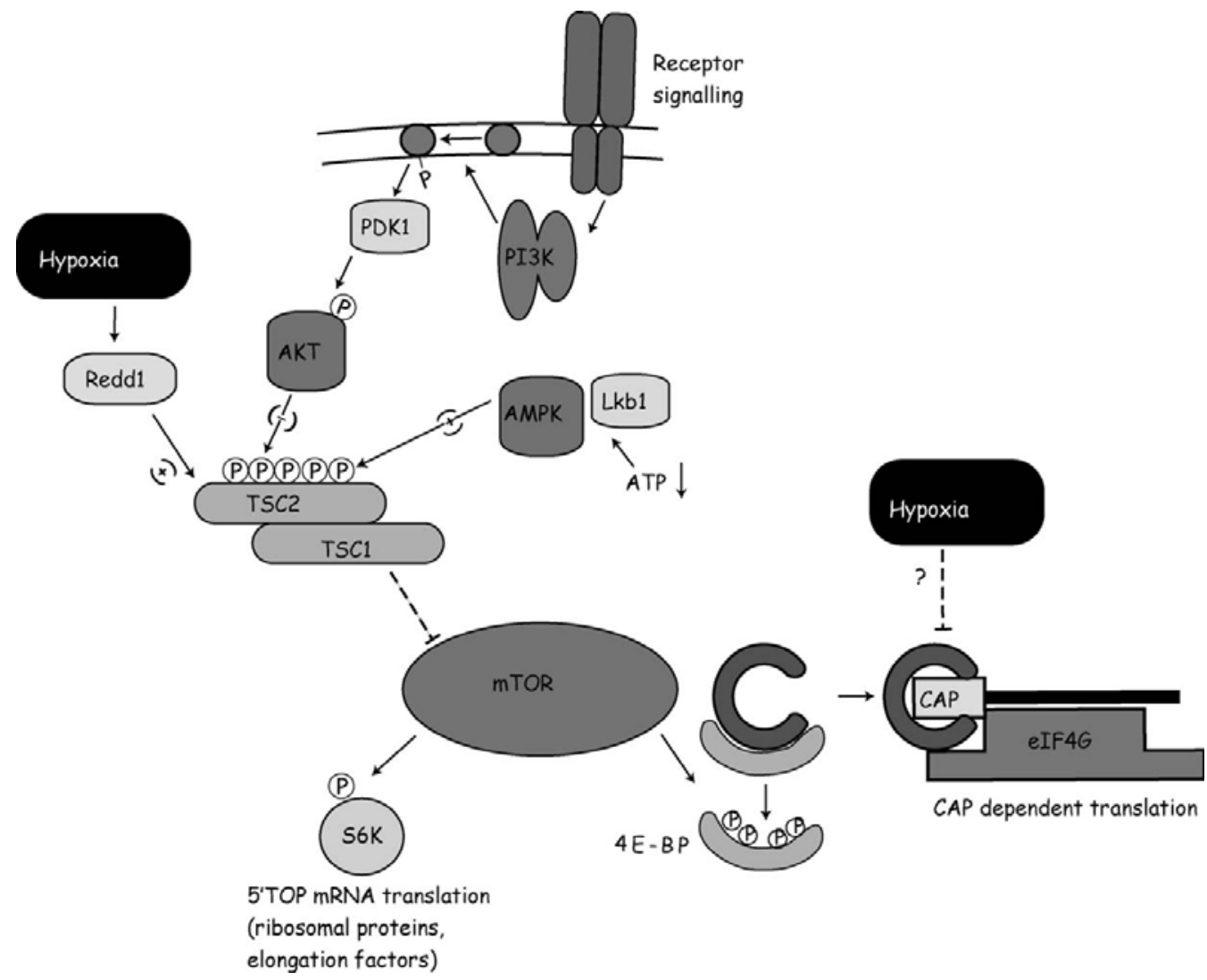

Figure 3: Control of mRNA translation through mTOR. Activation of PI3K upon growth factor receptor signaling leads to an AKT-dependent inhibitory phosphorylation of the TSC2 protein. The TSC1/TSC2 complex is a negative regulator of mTOR, and thus inhibition of TSC2 activates mTOR. Low energy levels inhibit mTOR signaling following an activating phosphorylation of TSC2 by AMPK. Phosphorylation of S6K and 4E-BP1 by mTOR promotes 
synthesis of the translational machinery and stimulates cap-dependent translation, respectively. Hypoxia inhibits mTOR and cap-dependent translation by induction of REDD1 in a TSC2dependent manner. Hypoxia may additionally inhibit cap-dependent translation through alternative mechanisms.

Inhibition of eIF4F and translation initiation during hypoxia can also occur in an mTOR independent manner. It has been shown that during hypoxia eIF4E and the eIF4E translocator protein (4E-T) redistribute from the cytoplasm to the nucleus and to distinct cytoplasmic locations consistent with P-bodies [65]. Translocation of eIF4E into either of these cellular locations makes it unavailable to participate in translation initiation. The function of eIF4E in the nucleus is not known, although $5-20 \%$ of total eIF4E is consistently found there [92]. P-bodies are recently discovered sites where mRNA is either stored or degraded and where siRNA-based silencing takes place $[93,94]$.

Similar to the situation with eIF2 $\alpha$, inhibition of mTOR and/or eIF4F during hypoxia can also selectively influence gene expression. Inhibition of eIF4F blocks 'so-called' cap dependent translation. Although the majority of genes are translated in this way, a small fraction uses alternative initiation mechanisms. These include genes containing an internal ribosome entry site (IRES), a secondary structure in the 5'UTR of the transcript that facilitates direct binding of the ribosome. Many mammalian mRNAs have been reported to contain IRES activity including a number of hypoxia regulated genes such as HIF-1 $\alpha$, BiP and VEGF [95-97], although this is still controversial [98]. Thus, IRES dependent translation might contribute to selective gene expression during hypoxia when eIF4F integrity is disrupted.

In addition to its effect on eIF4F, mTOR stimulates translation by phosphorylation and activation of S6 kinase (S6K). S6K promotes translation of a subset of mRNAs that contain terminal oligopyrimidine tract (5'TOP) sequences in their 5'UTR. This was originally thought to be due to its ability to phosphorylate the ribosomal protein S6, although this recently was shown not to be the case [99]. 5'TOP sequences are found in many components of the translational machinery, including all ribosomal proteins, and their translation is greatly stimulated by mTOR [100]. Interestingly the 5'UTR of HIF-1 $\alpha$ has also been reported to contain TOP sequence [101, 102]. 
At this point it is not yet clear what the functional consequences are of mTOR and/or eIF4F inhibition during hypoxia. As with eIF2 $\alpha$, the inhibition of mRNA translation is expected to conserve ATP and thus enable cells to maintain energy levels under hypoxia. However, substantial evidence also suggests that the cellular pathways, which regulate mRNA translation initiation through eIF4F are frequent targets for deregulation in cancer. Because eIF4E levels are limiting for cap-dependent translation in most tissues, overexpression of eIF4E in cancer cells is thought to promote the translation of a limited pool of mRNAs that encode key proteins involved in cellular growth, angiogenesis, survival and malignancy [103]. Overexpression of eIF4E in NIH 3T3 and Rat 2 fibroblasts is sufficient to cause their malignant transformation [104]. eIF4E is elevated in numerous cancers types, including bladder, head and neck, bronchioalveolar, liver, colon and breast cancers, but not in typical benign tumors and normal tissues [105]. Furthermore, transgenic mice overexpressing eIF4E show significantly increased tumorigenesis [106, 107]. In contrast to eIF4E, overexpression of 4E-BP1 blocks transformation by both eIF4E and cmyc by inhibiting cell cycle progression and increasing apoptosis [108]. Expression of a constitutively active 4E-BP1 enhances p27/Kip1 expression and represses cyclin D1 expression, which leads to cell cycle arrest of MCF7 breast cancer cells [109].

Stimulation of mRNA translation via increased eIF4F activity also occurs due to increased activation of mTOR [110]. Several genes that participate in signaling pathways upstream of mTOR are frequently altered in cancer including the PI3K/AKT pathway. Mutations in the tumor suppressor gene PTEN [111] result in deregulation of AKT and subsequent activation of mTOR and mRNA translation. Similarly, receptors such as HER2/Neu, which signal to this pathway are also frequent targets of amplification or mutation in cancer [101]. Mutations in either TSC1 or TSC2 results in formation of benign tumors called hamartomas, which consist of multiple cell types [112]. Mutations in the LBK1 tumor suppressor gene, which regulates TSC1/TSC2 in response to reductions in energy levels, causes Peutz-Jeghers syndrome (PJS) [113]. This disease is characterized by the development of hamartomas and various neoplasms, which results as a direct consequence of mTOR deregulation [114].

Oncogenic deregulation of pathways that regulate translation may result in a decreased sensitivity to hypoxia-induced changes in eIF4F. Two recent 
reports support this hypothesis $[88,115]$. Connolly et al reported that hypoxia was less effective at inhibiting mTOR and translation in transformed cells compared to normal cells suggesting that translational control during hypoxia may be lost during transformation. This finding is also supported by Kaper et al. who also found that inhibition of mTOR is cell type specific [115]. Specifically, they found that mutations in the PI3K/PTEN/TSC2 pathway suppressed the ability of hypoxia to fully inhibit mTOR. These results are clinically important given that rapamycin and its analogues are currently undergoing several clinical trials to target mTOR signaling. There is also some clinical evidence that the efficacy of rapamycin is dependent upon its ability to suppress hypoxic cell signaling [116]. Clearly much more work needs to be done to understand the functional consequences of translation inhibition through eIF4F during hypoxia, its variability in various cancer cell lines, and its potential for targeting. 


\section{PATTERNS OF TUMOR OXYGENATION - SEVERETY AND DURATION}

In the 1990s, clinical studies with oxygen electrodes and molecular markers enabled investigators to directly measure hypoxia in human tumors. These results demonstrated that solid tumors not only are poorly oxygenated, but also that oxygenation is extremely heterogeneous. The most commonly used parameter to describe hypoxia within an individual tumor has been the hypoxic fraction, defined as the percentage of hypoxic readings below an arbitrary threshold of oxygen concentration. For oxygen electrode studies, this threshold has typically been set at 2.5 or $5 \mathrm{mmHg}$. Using such arbitrary definitions, the hypoxic fraction amongst different tumors ranges from zero to $100 \%[12,117]$. Histological examinations of hypoxia in human tumors using the exogenously administered hypoxia markers pimonidazole and EF5, have demonstrated that oxygenation is also heterogeneous with respect to its spatial distribution [118120]. A common misconception is that tumors consist of central hypoxic 'cores' surrounded by better-oxygenated cells. In reality, hypoxia can be seen in all areas of the tumor and theoretically around every individual blood vessel. This fact makes it extremely difficult to spatially target treatment specifically at the hypoxic cells, for example by delivering higher radiation doses to these areas. However, the disorganized nature of the microvasculature found in most tumors does lead to spatial differences in microvessel density and perfusion and thus also to some spatial heterogeneity in the degree of hypoxia that is present.

Oxygenation within a given tumor is also highly heterogeneous with respect to oxygen concentration. Although the hypoxic fraction has been used in most studies, the oxygen electrode and marker studies clearly indicate that human tumors also contain large tumor areas exposed to more moderate hypoxia. The diffusion limit of oxygen from a functional blood vessel is determined by the vessel oxygen concentration and by the rate of oxygen metabolism in tissues. Typically this value is on the order of $150 \mu \mathrm{m}$. If vessels are spaced at distances comparable to this value, radial gradients of oxygenation develop around the vessel, which was previously referred to as diffusion-limited or 'chronic hypoxia'. Within these gradients, the oxygen concentration falls steadily from normal values at the vessel wall to anoxia on the border of tumor necrosis. As a result, cells surrounding these vessels exist at all possible levels of oxygenation (Figure 4). 

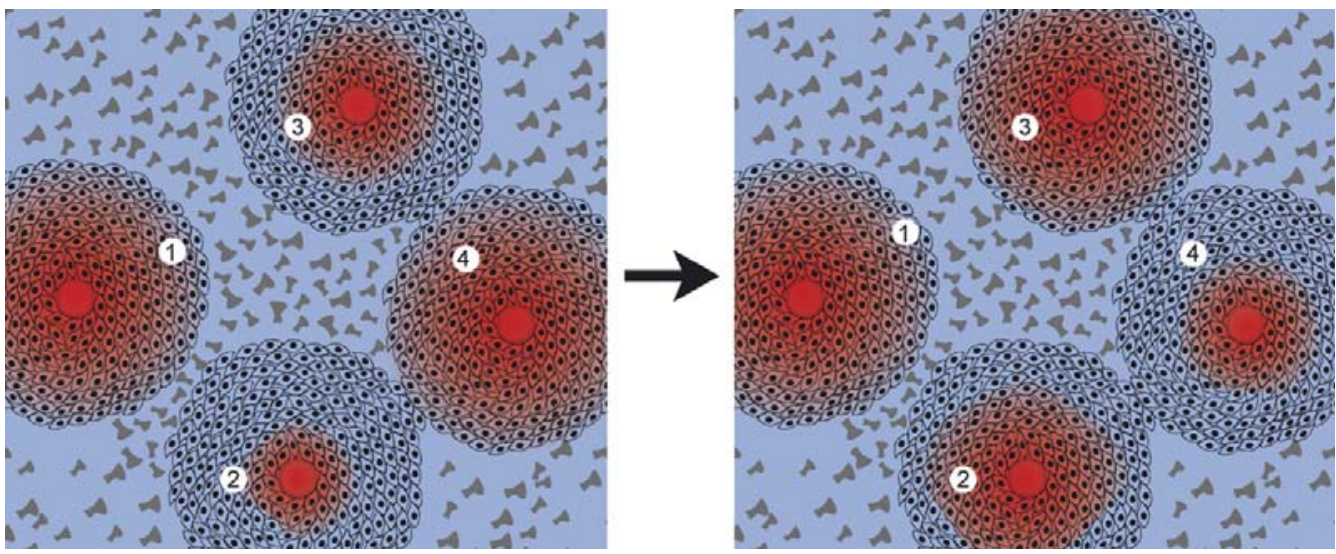

Figure 4: Dynamic oxygenation patterns and their influence on biological responses of tumor cells surrounding different blood vessels. The oxygenation status of representative regions in tumors is depicted. Well-oxygenated regions are shown in bright red and hypoxic regions in blue. Grey symbols in the blue areas represent necrotic areas. Tumor cells in areas 1-4 are all exposed to hypoxia but with different severity and/or duration. It is likely that the resulting cellular responses are different in all of these areas. (1) Stable blood flow produces a constant gradient in oxygenation surrounding this vessel. Over time, the oxygenation of individual cells decreases as they move away from the vessel, leading to what has been termed "chronic hypoxia". As cells move through this gradient, oxygen concentrations become low enough to stabilize and then fully activate HIF-1 as the PHD enzymes and subsequently FIH become inhibited. The oxygen concentrations in the peri-necrotic region are sufficiently low to fully activate both transcriptional and translational responses. However, the extended duration of hypoxia in this region may also result in activation of negative feedback loops that reduce HIF1 levels and/or eIF2 $\alpha$ phosphorylation. (2-4) Fluctuations in perfusion lead to cycling oxygen levels in cells surrounding these vessels and the development of "acute hypoxia". Cells in these areas experience fluctuations that differ in hypoxic severity and/or duration resulting in large differences in cellular response. For example, HIF-1 $\alpha$ may be degraded in area (3) but not in area (2) due to differences in the degree of reoxygenation. Also, temporary exposure to near anoxic conditions in areas (2) and (4) may be sufficient to activate the UPR, inhibit translation and induce ATF4 and XBP-1 transcriptional responses. These responses may help to prepare these cells for reoxygenation. Cells in area (3) are exposed to only moderate hypoxia and may thus lack this response. Moderate hypoxia in area (3) may also lead to activation of a different subset of HIF-1 dependent genes that are less dependent upon inhibition of FIH, which occurs at oxygen concentrations lower that that needed for HIF-1 $\alpha$ stabilisation.

Another important consideration that is expected to influence the cellular consequences of hypoxia is the duration of hypoxic exposure. The formation of gradients around perfused tumor vessels that cause the chronic hypoxia described above is expected to result in a slow, steadily decreasing 
oxygen concentration in the individual tumor cells in these gradients. As the tumor cells proliferate near the vessel, they slowly 'push' adjacent cells further away into areas of decreasing oxygenation and eventually into necrosis. It has been estimated that in murine tumors, $5-10 \mathrm{~h}$ is required for cells to migrate from one cell layer to the next [121]. If a functional vessel can support 5-10 cell layers around it, then it would require up to $100 \mathrm{~h}$ for cells to reach the outermost layer. Thus, the most hypoxic cells located furthest away from the vessel are expected to have been hypoxic for long periods of time. This theoretical example is supported by experimental studies demonstrating that hypoxic cells can exist in human tumor xenografts for up to 10 days [122]. The number of viable cells at these lowest levels of oxygenation is also expected to be influence by the tolerance of the tumor cells to hypoxia, a feature that may differ considerably in different tumors. Consequently, tumors with higher numbers of hypoxic cells may reflect an underlying molecular resistance to hypoxic exposure. The length of time that cells are exposed to different levels of hypoxia within the gradient would of course also be dependent on the proliferation rate of the tumor cells, as rapidly proliferating cells would push cells through the gradient more quickly than slowly proliferating cells. This hypothesis predicts that rapidly proliferating cells may have less pressure to select for changes that promote hypoxia tolerance, since they would not be exposed to hypoxia for as long as more slowly proliferating tumors. Experimental techniques using double hypoxic markers that allow labelling of hypoxic cells at two points in time have shown that the lifetime of hypoxic cells can vary tremendously, with half-lives ranging from 17 to $49 \mathrm{~h}$ [123].

Changes in tumor cell oxygenation are also influenced by dynamic changes in blood flow. The vasculature in tumors is susceptible to these changes in flow because it is often poorly developed, lacking smooth muscle cells and other structural components. Combined with high interstitial pressures, this can lead to rapid and dramatic changes in perfusion, including complete temporary shut down of vessels. This so-called 'acute hypoxia' can vary significantly amongst different tumors and in some cases account for a large proportion of the hypoxic cells at any given time $[122,124]$. Recent data from spontaneous and experimental animal tumors have directly shown that these perfusion changes cause large fluctuations in tumor oxygenation levels independent of the overall tumor oxygenation status. Fluctuations in flow and oxygen concentration last on average between $30 \mathrm{~min}$ and $2 \mathrm{~h} \mathrm{[10],} \mathrm{resulting} \mathrm{in}$ periodic cycling of tumor cells between different oxygen concentrations. 
Complete vasculature shut down can lead to rapid establishment of very low oxygen (anoxic) levels in a large number of cells. In summary, perfusion changes in tumors lead to significant increases in the fraction of cells exposed to hypoxia as well as the duration and severity of the hypoxic exposure.

\subsection{Oxygenation patterns and cellular hypoxic responses}

Although the heterogeneity in patterns of oxygenation is expected to have different biological and clinical implications, it has been largely overlooked in many biological and clinical studies. Relatively few studies have been conducted to assess the activation and consequences of different hypoxic response pathways as a function of hypoxic severity or duration. Nonetheless, available data demonstrate large dependencies on these factors.

\subsubsection{HIF-1}

The HIF-1 $\alpha$ transcription factor becomes stabilized at oxygen levels as high as $1-3 \%$. It is therefore expected to be present in the majority of all hypoxic cells in tumors, including many that would not have been considered as part of the hypoxic fraction in the clinical studies using oxygen electrodes. Activation of HIF-1 would also be expected in cells exposed to oxygen concentrations well above that required to cause significant increases in cell death [125]. Thus, expression and activation of HIF-1 (or its target genes) may not be a good surrogate for assessing the consequences of hypoxia on therapeutic response. This may explain results from the ARCON trial in which head and neck patients were treated with radiotherapy while breathing carbogen $(95 \%$ oxygen, $5 \% \mathrm{CO}_{2}$ ) gas to improve tumor oxygenation. In these patients, pimonidazole staining predicted benefit from carbogen, but the HIF-1 target gene carbonic anhydrase 9 (CA9) did not [119]. Several other studies confirm the relatively poor overlap between the expression of HIF-1 target genes like CA9 and pimonidazole labelling $[126,127]$. Although this may certainly be due to the contribution of hypoxia-independent regulation of these genes, it is also likely due to the different oxygen dependencies of pimonidazole and HIF-1.

Although HIF-1 is stabilized at relatively high oxygen concentrations, recent data suggest that its transcriptional activity has a more complex relationship with oxygen concentration [128]. This results from the fact that the PHD and FIH enzymes have different $\mathrm{Km}$ values for oxygen and thus 
presumably different oxygen affinities in vivo. As a result, hypoxic conditions that inhibit the PHD enzymes and thus stabilize HIF-1, may not be sufficient to inactivate FIH. In this situation, HIF-1 will only activate the subset of genes, which require only its N-TAD activity [41]. Activation of the C-TAD domain occurs only under more severe hypoxia where FIH is also inhibited. Thus, one would expect differential activation of HIF-1 target genes, and thus different cellular consequences of HIF-1 activation throughout the radial diffusion gradient surrounding blood vessels. This has potentially important consequences for therapeutic strategies aimed at targeting HIF-1.

The duration of hypoxic exposure is also expected to significantly influence HIF-1 activity. The PHD enzymes are themselves transcriptional targets of HIF-1 [129], and might thus act in a negative feedback loop to increase the breakdown of HIF-1 during prolonged hypoxia. Thus, HIF-1 dependent transcription may be highly temporal. The ability of the PHD enzymes to function in such a negative feedback loop would also be oxygen dependent, since they require some level of oxygen to function. Under severe hypoxia where oxygen concentrations are very low, increased expression of the PHD enzymes would not be expected to be able to negatively regulate HIF. A PHD negative feedback loop may explain in part the fact that HIF-1 $\alpha$ expression was found to be absent in hypoxic (pimonidazole positive) cells near peri-necrotic regions of several human tumor xenografts although the HIF-1 target gene CA9 was present [127]. Cells in these areas are expected to be those that have been hypoxic for the longest period of time, and which may have increased levels of PHD proteins. This is a further example of how specific oxygen patterns within the tumor microenvironment can influence HIF-1 responses. The lack of HIF expression in these hypoxic cells would clearly have a negative impact on HIF directed therapies.

\subsubsection{UPR}

The regulation of mRNA translation through the various mechanisms described previously is also highly influenced by hypoxic severity and duration. Phosphorylation of eIF $2 \alpha$ occurs extremely rapidly $(\sim 15 \mathrm{~min})$ during anoxia $\left(<0.02 \% \mathrm{O}_{2}\right)$, reaching a maximum after $1-2 \mathrm{~h}$ of anoxic conditions $[65,66]$. Inhibition of translation and activation of ATF4 follow similar kinetics. A decline in the level of eIF2 $\alpha$ phosphorylation is observed during longer exposures to anoxic conditions, and this is consistent with a GADD34- 
mediated negative feedback loop, which has been demonstrated to occur during the UPR [130]. Consistent with this transient eIF2 $\alpha$ phosphorylation, MEFs expressing a non-phosphorylatable mutant allele of eIF2 $\alpha$ (S51A) are only impaired in inhibition of overall mRNA translation during early $(<4 \mathrm{~h})$ exposures. Likewise, hypoxia-induced changes in gene-specific mRNA translation efficiency are dependent on eIF $2 \alpha$ phosphorylation only during early exposure times [65]. However, it is important to realize that although the direct effects of eIF $2 \alpha$ phosphorylation (i.e. altered overall and gene-specific mRNA translation efficiency) are transient, the complete cellular response is much longer lasting due to, e.g. the induction of transcriptional gene expression programs by ATF4 and other transcription factors. eIF2 $\alpha$ is phosphorylated with significantly slower kinetics during moderate hypoxia $\left(0.05-1.00 \% \mathrm{O}_{2}\right)$, and the level of phosphorylation is weaker [66]. The sensitivity of eIF2 $\alpha$

phosphorylation to both oxygen concentration and duration may also explain a recently reported study in which eIF2 $\alpha$ phosphorylation was not detected [88].

Since the IRE1 and PERK mediated arms of the UPR have not been simultaneously investigated under hypoxia, it is difficult to assess their relative levels of activation, kinetics and contribution to hypoxia resistance. Nevertheless, activation of the IRE1 mediated arm of the UPR appears to be slower than the PERK mediated pathway, since spliced XBP-1 mRNA and protein could only be detected following $24 \mathrm{~h}$ of severe hypoxia/anoxia [67]. Since both IRE1 and PERK are activated through the same mechanism, this might reflect a difference in the dependence upon BiP. Further studies are needed to assess the relative importance of IRE1 and PERK dependent pathways in hypoxia resistance and tumor growth. Both of these UPR sensors are responsible for the induction of a transcription factor (e.g. XBP-1 and ATF4), which activates a subset of the UPR genes. PERK is additionally responsible for the inhibition of overall mRNA translation during acute hypoxia, which probably serves to conserve energy as well as resulting in gene specific differential translation of the transcriptome. Therefore, targeting PERK might be expected to have a broader range of cellular effects than targeting IRE1. However, all these possible results of targeting PERK are dependent upon sensitivity to the effects of eIF2 $\alpha$ phosphorylation. This sensitivity is partly governed by the expression levels of eIF2B, which also varies amongst cell lines. 


\subsection{3. $\mathrm{mTOR}$ and $\mathrm{eIF} 4 \mathrm{~F}$}

From the present literature, it is clear that the impact of hypoxia on mTOR activity, eIF4F complex formation and translation efficiency is also highly dependent upon severity and duration of hypoxia, as well as the presence or absence of other stresses. The picture is far from clear because few studies have specifically investigated the oxygen sensitivity and (de)activation kinetics of these pathways. It also remains elusive to which extent these pathways contribute to hypoxiainduced inhibition of overall translation or whether the effects are limited to a smaller subset of genes.

During severe hypoxia, overall mRNA translation remains low in spite of the transient nature of eIF2 $\alpha$ phosphorylation. Furthermore, in contrast to short hypoxic exposures, S51A MEFs that are unable to inhibit translation through eIF2 $\alpha$, do efficiently inhibit mRNA translation during prolonged exposures $[65,66]$. These results clearly demonstrate that there is a switch of the molecular mechanism that regulates mRNA translation during prolonged exposures, from being eIF2 $\alpha$ dependent to independent. Disruption of the eIF4F complex is a candidate mechanism for this inhibition after prolonged hypoxia [65]. However, inhibition of eIF4F has also been reported to occur rapidly $(2 \mathrm{~h})$ following moderate hypoxia $(0.5 \%)$, in a cell-line dependent manner [88].

The ability of hypoxia to inhibit mTOR also shows a complex dependency with duration of hypoxia. In normal culture conditions, inhibition of mTOR is quite slow where as in serum-deprived cells it can occur extremely rapidly [89]. This may be due to an antagonistic effect of PI3K signalling on TSC2, although this has not yet been demonstrated.

Nonetheless, inhibition of mTOR in tumors is expected to differ significantly in cells exposed to hypoxia for different periods of time, and in different areas of the tumor, which may have better or worse access to nutrients. 


\section{CONCLUDING REMARKS}

Due to the complex patterns of oxygenation in human tumors and their influence on the known cellular pathways that respond to hypoxia, it is clear that a single hypoxia targeted therapy is unlikely to be effective on its own. Effective administration of HIF-1, UPR, or eIF4E/mTOR directed therapies will require some a priori knowledge not only of the amount of hypoxia expected, but also of the type of hypoxia present. From a clinical point of view this places a requirement for individualized treatment planning based on measurements or expectations of tumor hypoxia. Development of methodologies to characterize tumor oxygenation, including its temporal component, may thus hold the key to successful administration of hypoxia targeting agents. An approach that is already being pursued is the use of molecular imaging with various biomarkers associated with specific oxygenation patterns. Specific patterns of gene expression associated with the activation of different hypoxic responses could also prove to be useful. Chi et al. recently reported that a hypoxia gene-expression signature derived from exposure of cells cultured in vitro could serve as a strong predictor of clinical outcomes in breast and ovarian cancers [131]. If it becomes possible to extend this type of analysis to identify specific patterns of hypoxia in tumors, it may be possible to choose specific hypoxic-directed therapies with greater rationale. However, for this to occur a more complete understanding of the proteins regulated by different patterns of hypoxia and the contribution of individual hypoxia responses to these changes is required. A substantial effort at describing proteins and pathways regulated by HIF has occurred from many groups around the world. However, much less attention has been placed on the contribution of more recently described hypoxia response pathways that influence protein expression through changes in mRNA translation. The focus of this thesis is to investigate the mechanisms and consequences of changes in mRNA translation during hypoxia. In chapter 6 we address the presence of reactive oxygen species (ROS) in cancer cells and the effect on mRNA translation. 


\section{OUTLINE OF THIS THESIS}

The first goal of this thesis was to investigate the molecular pathways that mediate mRNA translation inhibition during hypoxia. In chapter $\mathbf{2}$ we investigated the involvement of the family of eukaryotic initiation factors (eIF2 $\alpha$ and eIF4F complex) on the inhibition of protein synthesis during hypoxia. To assess the requirement of eIF $2 \alpha$ phosphorylation for overall translation inhibition during hypoxia we examined the response of mouse embryo fibroblasts (MEFs) derived from eIF2 $\alpha$ knock-in mice containing an S51A mutation, which are defective in phosphorylation of eIF2 $\alpha$ during hypoxia. To investigate the contribution of the eIF4F complex on protein translation inhibition, we analyzed the levels of eIF4E and proteins that associate with it as an active complex (eIF4G) or as an inactive complex (4EBP1) during hypoxia. Using a sucrose gradient (polysome assays) we also analyzed the effect of hypoxia on specific gene expression by evaluating the translation efficiency for several hypoxia responsive genes.

The influence of changes in mRNA translation initiation during hypoxia on hypoxic induced gene expression was then determined (chapter 3). To evaluate the contribution of changes in mRNA abundance versus mRNA translation for each gene, DU145 prostate carcinoma cells were exposed to $4 \mathrm{~h}$ of hypoxia $\left(<0.02 \% \mathrm{O}_{2}\right)$. Efficiently translated mRNAs were isolated by sedimentation through a sucrose gradient. Affymetrix microarray technology was used to evaluate both the transcriptional and translational contribution to gene expression.

In chapter 4, we evaluated the effect of 4EBP1 expression on translation in HeLa cells during both normoxic and hypoxic conditions. In other to investigate this we generated HeLa cells stably expressing a shRNA against 4E-BP1. Using polysome assays and a 2D gel electrophoresis approach, we assessed the effects of 4E-BP1 on overall protein translation and on specific protein expression, respectively.

In chapter 5 we investigated if 4E-BP1 knock-down would demonstrate the same characteristics on tumor-growth as the overexpression of the oncogene eIF4E. We analyzed the clonogenic survival of shRNA 4EBP1 HeLa cells under different time points of hypoxia and developed U87 cells stably expressing a shRNA against 4E-BP1, which were used for our in vivo 
experiment. We monitored tumor growth and investigated the effect of 1 dose (10 Gray) of irradiation on our tumor model. Tumor sections were prepared and stained for hypoxia, proliferation and apoptosis. Immunohistochemistry was performed on tumor sections to assess differences in hypoxia, ATP levels, blood vessels density, proliferation and apoptosis between U87 tumors expressing a shRNA against 4E-BP1 and their wild type counterparts.

In chapter 6, we analyzed the effect of reoxygenation on overall protein expression using a $2 \mathrm{D}$ gel electrophoresis approach to identify specific proteins that were upregulated during reoxygenation.

Finally in chapter 7 a summary and discussion with future perspectives is presented. 


\section{REFERENCES}

[1] Ferlay, J, Autier, P, Boniol, M, Heanue, M, Colombet, M, Boyle, P. Estimates of the cancer incidence and mortality in Europe in 2006. Ann Oncol 2007;18:581-592.

[2] Hanahan, D, Weinberg, RA. The hallmarks of cancer. Cell 2000;100:57-70.

[3] Wood, LD, Parsons, DW, Jones, S, et al. The genomic landscapes of human breast and colorectal cancers. Science 2007;318:1108-1113.

[4] Thomlinson, RH, Gray, LH. The histological structure of some human lung cancers and the possible implications for radiotherapy. Br J Cancer 1955;9:539-549.

[5] Brown, JM, Wilson, WR. Exploiting tumour hypoxia in cancer treatment. Nat Rev Cancer 2004;4:437-447.

[6] Harris, AL. Hypoxia--a key regulatory factor in tumour growth. Nat Rev Cancer 2002;2:38-47.

[7] Brown, JM, Giaccia, AJ. The unique physiology of solid tumors: opportunities (and problems) for cancer therapy. Cancer Res 1998;58:1408-1416.

[8] Chaplin, DJ, Hill, SA. Temporal heterogeneity in microregional erythrocyte flux in experimental solid tumours. $\mathrm{Br} \mathrm{J}$ Cancer 1995;71:1210-1213.

[9] Sutherland, RM, Ausserer, WA, Murphy, BJ, Laderoute, KR. Tumor Hypoxia and Heterogeneity: Challenges and Opportunities for the Future. Semin Radiat Oncol 1996;6:59-70.

[10] Cardenas-Navia, LI, Yu, D, Braun, RD, Brizel, DM, Secomb, TW, Dewhirst, MW. Tumor-dependent kinetics of partial pressure of oxygen fluctuations during air and oxygen breathing. Cancer Res 2004;64:6010-6017. 
[11] Koch, CJ. Oxygen effects in radiobiology. Adv Exp Med Biol 1982;157:123-144.

[12] Nordsmark, M, Bentzen, SM, Rudat, V, et al. Prognostic value of tumor oxygenation in 397 head and neck tumors after primary radiation therapy. An international multi-center study. Radiother Oncol 2005;77:18-24.

[13] Grau, C, Overgaard, J. Effect of etoposide, carmustine, vincristine, 5fluorouracil, or methotrexate on radiobiologically oxic and hypoxic cells in a $\mathrm{C} 3 \mathrm{H}$ mouse mammary carcinoma in situ. Cancer Chemother Pharmacol 1992;30:277-280.

[14] Hockel, M, Schlenger, K, Aral, B, Mitze, M, Schaffer, U, Vaupel, P. Association between tumor hypoxia and malignant progression in advanced cancer of the uterine cervix. Cancer Res 1996;56:4509-4515.

[15] Airley, R, Loncaster, J, Davidson, S, et al. Glucose transporter glut-1 expression correlates with tumor hypoxia and predicts metastasis-free survival in advanced carcinoma of the cervix. Clin Cancer Res 2001;7:928-934.

[16] Brizel, DM, Scully, SP, Harrelson, JM, et al. Tumor oxygenation predicts for the likelihood of distant metastases in human soft tissue sarcoma. Cancer Res 1996;56:941-943.

[17] Wouters, BG, Koritzinsky, M, Chiu, RK, Theys, J, Buijsen, J, Lambin, P. Modulation of cell death in the tumor microenvironment. Semin Radiat Oncol 2003;13:31-41.

[18] Wouters, BG, Weppler, SA, Koritzinsky, M, et al. Hypoxia as a target for combined modality treatments. Eur J Cancer 2002;38:240-257.

[19] Graeber, TG, Osmanian, C, Jacks, T, et al. Hypoxia-mediated selection of cells with diminished apoptotic potential in solid tumours. Nature 1996;379:88-91.

[20] Laderoute, KR, Alarcon, RM, Brody, MD, et al. Opposing effects of hypoxia on expression of the angiogenic inhibitor thrombospondin 1 
and the angiogenic inducer vascular endothelial growth factor. Clin Cancer Res 2000;6:2941-2950.

[21] Tenan, M, Fulci, G, Albertoni, M, et al. Thrombospondin-1 is downregulated by anoxia and suppresses tumorigenicity of human glioblastoma cells. J Exp Med 2000;191:1789-1798.

[22] Li, L, Lin, X, Staver, M, et al. Evaluating hypoxia-inducible factor1alpha as a cancer therapeutic target via inducible RNA interference in vivo. Cancer Res 2005;65:7249-7258.

[23] Rapisarda, A, Shoemaker, RH, Melillo, G. Targeting topoisomerase I to inhibit hypoxia inducible factor 1. Cell Cycle 2004;3:172-175.

[24] Kong, D, Park, EJ, Stephen, AG, et al. Echinomycin, a small-molecule inhibitor of hypoxia-inducible factor-1 DNA-binding activity. Cancer Res 2005;65:9047-9055.

[25] Mabjeesh, NJ, Post, DE, Willard, MT, et al. Geldanamycin induces degradation of hypoxia-inducible factor lalpha protein via the proteosome pathway in prostate cancer cells. Cancer Res 2002;62:24782482 .

[26] Yeo, EJ, Chun, YS, Cho, YS, et al. YC-1: a potential anticancer drug targeting hypoxia-inducible factor 1. J Natl Cancer Inst 2003;95:516525.

[27] Knowles, HJ, Raval, RR, Harris, AL, Ratcliffe, PJ. Effect of ascorbate on the activity of hypoxia-inducible factor in cancer cells. Cancer Res 2003;63:1764-1768.

[28] Mabjeesh, NJ, Escuin, D, LaVallee, TM, et al. 2ME2 inhibits tumor growth and angiogenesis by disrupting microtubules and dysregulating HIF. Cancer Cell 2003;3:363-375.

[29] Welsh, SJ, Williams, RR, Birmingham, A, Newman, DJ, Kirkpatrick, DL, Powis, G. The thioredoxin redox inhibitors 1-methylpropyl 2imidazolyl disulfide and pleurotin inhibit hypoxia-induced factor 1alpha 
and vascular endothelial growth factor formation. Mol Cancer Ther 2003;2:235-243.

[30] Lee, JT, McCubrey, JA. BAY-43-9006 Bayer/Onyx. Curr Opin Investig Drugs 2003;4:757-763.

[31] Dong, D, Dubeau, L, Bading, J, et al. Spontaneous and controllable activation of suicide gene expression driven by the stress-inducible grp78 promoter resulting in eradication of sizable human tumors. Hum Gene Ther 2004; 15:553-561.

[32] Park, HR, Tomida, A, Sato, S, et al. Effect on tumor cells of blocking survival response to glucose deprivation. J Natl Cancer Inst 2004;96:1300-1310.

[33] Lee, AH, Iwakoshi, NN, Anderson, KC, Glimcher, LH. Proteasome inhibitors disrupt the unfolded protein response in myeloma cells. Proc Natl Acad Sci U S A 2003;100:9946-9951.

[34] Boyce, M, Bryant, KF, Jousse, C, et al. A selective inhibitor of eIF2alpha dephosphorylation protects cells from ER stress. Science 2005;307:935-939.

[35] Blancher, C, Moore, JW, Talks, KL, Houlbrook, S, Harris, AL. Relationship of hypoxia-inducible factor (HIF)-1alpha and HIF-2alpha expression to vascular endothelial growth factor induction and hypoxia survival in human breast cancer cell lines. Cancer Res 2000;60:71067113.

[36] Peralba, JM, DeGraffenried, L, Friedrichs, W, et al. Pharmacodynamic Evaluation of CCI-779, an Inhibitor of mTOR, in Cancer Patients. Clin Cancer Res 2003;9:2887-2892.

[37] Ivan, M, Kondo, K, Yang, H, et al. HIFalpha targeted for VHLmediated destruction by proline hydroxylation: implications for $\mathrm{O} 2$ sensing. Science 2001;292:464-468. 
[38] Jaakkola, P, Mole, DR, Tian, YM, et al. Targeting of HIF-alpha to the von Hippel-Lindau ubiquitylation complex by O2-regulated prolyl hydroxylation. Science 2001;292:468-472.

[39] Epstein, AC, Gleadle, JM, McNeill, LA, et al. C. elegans EGL-9 and mammalian homologs define a family of dioxygenases that regulate HIF by prolyl hydroxylation. Cell 2001;107:43-54.

[40] Lando, D, Peet, DJ, Gorman, JJ, Whelan, DA, Whitelaw, ML, Bruick, RK. FIH-1 is an asparaginyl hydroxylase enzyme that regulates the transcriptional activity of hypoxia-inducible factor. Genes Dev 2002;16:1466-1471.

[41] Dayan, F, Roux, D, Brahimi-Horn, MC, Pouyssegur, J, Mazure, NM. The oxygen sensor factor-inhibiting hypoxia-inducible factor-1 controls expression of distinct genes through the bifunctional transcriptional character of hypoxia-inducible factor-1alpha. Cancer Res 2006;66:3688-3698.

[42] Hu, CJ, Wang, LY, Chodosh, LA, Keith, B, Simon, MC. Differential roles of hypoxia-inducible factor 1alpha (HIF-1alpha) and HIF-2alpha in hypoxic gene regulation. Mol Cell Biol 2003;23:9361-9374.

[43] Raval, RR, Lau, KW, Tran, MG, et al. Contrasting properties of hypoxia-inducible factor 1 (HIF-1) and HIF-2 in von Hippel-Lindauassociated renal cell carcinoma. Mol Cell Biol 2005;25:5675-5686.

[44] Makino, Y, Cao, R, Svensson, K, et al. Inhibitory PAS domain protein is a negative regulator of hypoxia-inducible gene expression. Nature 2001;414:550-554.

[45] Semenza, GL. Targeting HIF-1 for cancer therapy. Nat Rev Cancer 2003;3:721-732.

[46] Mason, SD, Howlett, RA, Kim, MJ, et al. Loss of skeletal muscle HIF1alpha results in altered exercise endurance. PLoS Biol 2004;2:e288. 
[47] Seagroves, TN, Ryan, HE, Lu, H, et al. Transcription factor HIF-1 is a necessary mediator of the pasteur effect in mammalian cells. Mol Cell Biol 2001;21:3436-3444.

[48] Papandreou, I, Cairns, RA, Fontana, L, Lim, AL, Denko, NC. HIF-1 mediates adaptation to hypoxia by actively downregulating mitochondrial oxygen consumption. Cell Metab 2006;3:187-197.

[49] Erler, JT, Bennewith, KL, Nicolau, M, et al. Lysyl oxidase is essential for hypoxia-induced metastasis. Nature 2006;440:1222-1226.

[50] Pennacchietti, S, Michieli, P, Galluzzo, M, Mazzone, M, Giordano, S, Comoglio, PM. Hypoxia promotes invasive growth by transcriptional activation of the met protooncogene. Cancer Cell 2003;3:347-361.

[51] Staller, P, Sulitkova, J, Lisztwan, J, Moch, H, Oakeley, EJ, Krek, W. Chemokine receptor CXCR4 downregulated by von Hippel-Lindau tumour suppressor pVHL. Nature 2003;425:307-311.

[52] Wouters, BG, van den Beucken, T, Magagnin, MG, Lambin, P, Koumenis, C. Targeting hypoxia tolerance in cancer. Drug Resist Updat 2004; 7:25-40.

[53] Rapisarda, A, Uranchimeg, B, Scudiero, DA, et al. Identification of small molecule inhibitors of hypoxia-inducible factor 1 transcriptional activation pathway. Cancer Res 2002;62:4316-4324.

[54] Foster, BJ, Clagett-Carr, K, Shoemaker, DD, et al. Echinomycin: the first bifunctional intercalating agent in clinical trials. Invest New Drugs 1985;3:403-410.

[55] Chang, AY, Kim, K, Boucher, H, et al. A randomized phase II trial of echinomycin, trimetrexate, and cisplatin plus etoposide in patients with metastatic nonsmall cell lung carcinoma: an Eastern Cooperative Oncology Group Study (E1587). Cancer 1998;82:292-300.

[56] Muss, HB, Blessing, JA, DuBeshter, B. Echinomycin in recurrent and metastatic endometrial carcinoma. A phase II trial of the Gynecologic Oncology Group. Am J Clin Oncol 1993;16:492-493. 
[57] Wadler, S, Tenteromano, L, Cazenave, L, et al. Phase II trial of echinomycin in patients with advanced or recurrent colorectal cancer. Cancer Chemother Pharmacol 1994;34:266-269.

[58] Jensen, RL, Ragel, BT, Whang, K, Gillespie, D. Inhibition of hypoxia inducible factor-1alpha (HIF-1alpha) decreases vascular endothelial growth factor (VEGF) secretion and tumor growth in malignant gliomas. J Neurooncol 2006;78:233-247.

[59] Ryan, HE, Poloni, M, McNulty, W, et al. Hypoxia-inducible factor1alpha is a positive factor in solid tumor growth. Cancer Res 2000;60:4010-4015.

[60] Mizukami, Y, Jo, WS, Duerr, EM, et al. Induction of interleukin-8 preserves the angiogenic response in HIF-1alpha-deficient colon cancer cells. Nat Med 2005;11:992-997.

[61] Blouw, B, Song, H, Tihan, T, et al. The hypoxic response of tumors is dependent on their microenvironment. Cancer Cell 2003;4:133-146.

[62] Carmeliet, P, Dor, Y, Herbert, JM, et al. Role of HIF-1alpha in hypoxia-mediated apoptosis, cell proliferation and tumour angiogenesis. Nature 1998;394:485-490.

[63] Acker, T, Diez-Juan, A, Aragones, J, et al. Genetic evidence for a tumor suppressor role of HIF-2alpha. Cancer Cell 2005;8:131-141.

[64] Bi, M, Naczki, C, Koritzinsky, M, et al. ER stress-regulated translation increases tolerance to extreme hypoxia and promotes tumor growth. Embo J 2005;24:3470-3481.

[65] Koritzinsky, M, Magagnin, MG, van den Beucken, T, et al. Gene expression during acute and prolonged hypoxia is regulated by distinct mechanisms of translational control. Embo J 2006;25:1114-1125.

[66] Koumenis, C, Naczki, C, Koritzinsky, M, et al. Regulation of protein synthesis by hypoxia via activation of the endoplasmic reticulum kinase 
PERK and phosphorylation of the translation initiation factor eIF2alpha. Mol Cell Biol 2002;22:7405-7416.

[67] Romero-Ramirez, L, Cao, H, Nelson, D, et al. XBP1 is essential for survival under hypoxic conditions and is required for tumor growth. Cancer Res 2004;64:5943-5947.

[68] Bertolotti, A, Zhang, Y, Hendershot, LM, Harding, HP, Ron, D. Dynamic interaction of BiP and ER stress transducers in the unfoldedprotein response. Nat Cell Biol 2000;2:326-332.

[69] Koong, AC, Chen, EY, Lee, AS, Brown, JM, Giaccia, AJ. Increased cytotoxicity of chronic hypoxic cells by molecular inhibition of GRP78 induction. Int J Radiat Oncol Biol Phys 1994;28:661-666.

[70] Song, MS, Park, YK, Lee, JH, Park, K. Induction of glucose-regulated protein 78 by chronic hypoxia in human gastric tumor cells through a protein kinase C-epsilon/ERK/AP-1 signaling cascade. Cancer Res 2001;61:8322-8330.

[71] Ameri, K, Lewis, CE, Raida, M, Sowter, H, Hai, T, Harris, AL. Anoxic induction of ATF-4 through HIF-1-independent pathways of protein stabilization in human cancer cells. Blood 2004;103:1876-1882.

[72] Blais, JD, Filipenko, V, Bi, M, et al. Activating transcription factor 4 is translationally regulated by hypoxic stress. Mol Cell Biol 2004;24:7469-7482.

[73] Lu, PD, Harding, HP, Ron, D. Translation reinitiation at alternative open reading frames regulates gene expression in an integrated stress response. J Cell Biol 2004;167:27-33.

[74] Vattem, KM, Wek, RC. Reinitiation involving upstream ORFs regulates ATF4 mRNA translation in mammalian cells. Proc Natl Acad Sci U S A 2004;101:11269-11274.

[75] Harding, HP, Zhang, Y, Zeng, H, et al. An integrated stress response regulates amino acid metabolism and resistance to oxidative stress. Mol Cell 2003;11:619-633. 
[76] Yorimitsu, T, Nair, U, Yang, Z, Klionsky, DJ. Endoplasmic reticulum stress triggers autophagy. J Biol Chem 2006;281:30299-30304.

[77] Bernales, S, McDonald, KL, Walter, P. Autophagy counterbalances endoplasmic reticulum expansion during the unfolded protein response. PLoS Biol 2006;4:e423.

[78] Kouroku, Y, Fujita, E, Tanida, I, et al. ER stress (PERK/eIF2alpha phosphorylation) mediates the polyglutamine-induced LC3 conversion, an essential step for autophagy formation. Cell Death Differ 2007; 14:230-239.

[79] Cullinan, SB, Zhang, D, Hannink, M, Arvisais, E, Kaufman, RJ, Diehl, JA. Nrf2 is a direct PERK substrate and effector of PERK-dependent cell survival. Mol Cell Biol 2003;23:7198-7209.

[80] Deng, J, Lu, PD, Zhang, Y, et al. Translational repression mediates activation of nuclear factor kappa $\mathrm{B}$ by phosphorylated translation initiation factor 2. Mol Cell Biol 2004;24:10161-10168.

[81] Yoshida, H, Matsui, T, Yamamoto, A, Okada, T, Mori, K. XBP1 mRNA is induced by ATF6 and spliced by IRE1 in response to ER stress to produce a highly active transcription factor. Cell 2001;107:881-891.

[82] Feldman, DE, Chauhan, V, Koong, AC. The unfolded protein response: a novel component of the hypoxic stress response in tumors. Mol Cancer Res 2005;3:597-605.

[83] Catley, L, Tai, YT, Chauhan, D, Anderson, KC. Perspectives for combination therapy to overcome drug-resistant multiple myeloma. Drug Resist Updat 2005;8:205-218.

[84] Haghighat, A, Mader, S, Pause, A, Sonenberg, N. Repression of capdependent translation by 4E-binding protein 1: competition with p220 for binding to eukaryotic initiation factor-4E. Embo J 1995;14:57015709. 
[85] Sonenberg, N, Gingras, AC. The mRNA 5' cap-binding protein eIF4E and control of cell growth. Curr Opin Cell Biol 1998;10:268-275.

[86] Gingras, AC, Raught, B, Gygi, SP, et al. Hierarchical phosphorylation of the translation inhibitor 4E-BP1. Genes Dev 2001;15:2852-2864.

[87] Brugarolas, J, Lei, K, Hurley, RL, et al. Regulation of mTOR function in response to hypoxia by REDD1 and the TSC1/TSC2 tumor suppressor complex. Genes Dev 2004;18:2893-2904.

[88] Connolly, E, Braunstein, S, Formenti, S, Schneider, RJ. Hypoxia inhibits protein synthesis through a 4E-BP1 and elongation factor 2 kinase pathway controlled by mTOR and uncoupled in breast cancer cells. Mol Cell Biol 2006;26:3955-3965.

[89] Liu, L, Cash, TP, Jones, RG, Keith, B, Thompson, CB, Simon, MC. Hypoxia-induced energy stress regulates mRNA translation and cell growth. Mol Cell 2006;21:521-531.

[90] Corradetti, MN, Inoki, K, Bardeesy, N, DePinho, RA, Guan, KL. Regulation of the TSC pathway by LKB1: evidence of a molecular link between tuberous sclerosis complex and Peutz-Jeghers syndrome. Genes Dev 2004;18:1533-1538.

[91] Shaw, RJ, Bardeesy, N, Manning, BD, et al. The LKB1 tumor suppressor negatively regulates mTOR signaling. Cancer Cell 2004;6:91-99.

[92] Lejbkowicz, F, Goyer, C, Darveau, A, Neron, S, Lemieux, R, Sonenberg, N. A fraction of the mRNA 5' cap-binding protein, eukaryotic initiation factor 4E, localizes to the nucleus. Proc Natl Acad Sci U S A 1992;89:9612-9616.

[93] Andrei, MA, Ingelfinger, D, Heintzmann, R, Achsel, T, Rivera-Pomar, R, Luhrmann, R. A role for eIF4E and eIF4E-transporter in targeting mRNPs to mammalian processing bodies. Rna 2005;11:717-727. 
[94] Liu, J, Valencia-Sanchez, MA, Hannon, GJ, Parker, R. MicroRNAdependent localization of targeted mRNAs to mammalian P-bodies. Nat Cell Biol 2005;7:719-723.

[95] Lang, KJ, Kappel, A, Goodall, GJ. Hypoxia-inducible factor-1alpha mRNA contains an internal ribosome entry site that allows efficient translation during normoxia and hypoxia. Mol Biol Cell 2002;13:17921801.

[96] Sarnow, P. Translation of glucose-regulated protein 78/immunoglobulin heavy-chain binding protein mRNA is increased in poliovirus-infected cells at a time when cap-dependent translation of cellular mRNAs is inhibited. Proc Natl Acad Sci U S A 1989;86:5795-5799.

[97] Stein, I, Itin, A, Einat, P, Skaliter, R, Grossman, Z, Keshet, E. Translation of vascular endothelial growth factor mRNA by internal ribosome entry: implications for translation under hypoxia. Mol Cell Biol 1998;18:3112-3119.

[98] Bert, AG, Grepin, R, Vadas, MA, Goodall, GJ. Assessing IRES activity in the HIF-1alpha and other cellular 5' UTRs. Rna 2006;12:1074-1083.

[99] Ruvinsky, I, Meyuhas, O. Ribosomal protein S6 phosphorylation: from protein synthesis to cell size. Trends Biochem Sci 2006;31:342-348.

[100] Jefferies, HB, Fumagalli, S, Dennis, PB, Reinhard, C, Pearson, RB, Thomas, G. Rapamycin suppresses 5'TOP mRNA translation through inhibition of p70s6k. Embo J 1997;16:3693-3704.

[101] Laughner, E, Taghavi, P, Chiles, K, Mahon, PC, Semenza, GL. HER2 (neu) signaling increases the rate of hypoxia-inducible factor 1alpha (HIF-1alpha) synthesis: novel mechanism for HIF-1-mediated vascular endothelial growth factor expression. Mol Cell Biol 2001;21:39954004 .

[102] Schepens, B, Tinton, SA, Bruynooghe, Y, Beyaert, R, Cornelis, S. The polypyrimidine tract-binding protein stimulates HIF-1alpha IRES- 
mediated translation during hypoxia. Nucleic Acids Res 2005;33:68846894.

[103] Graff, JR, Zimmer, SG. Translational control and metastatic progression: enhanced activity of the mRNA cap-binding protein eIF4E selectively enhances translation of metastasis-related mRNAs. Clin Exp Metastasis 2003;20:265-273.

[104] Lazaris-Karatzas, A, Montine, KS, Sonenberg, N. Malignant transformation by a eukaryotic initiation factor subunit that binds to mRNA 5' cap. Nature 1990;345:544-547.

[105] De Benedetti, A, Graff, JR. eIF-4E expression and its role in malignancies and metastases. Oncogene 2004;23:3189-3199.

[106] Ruggero, D, Montanaro, L, Ma, L, et al. The translation factor eIF-4E promotes tumor formation and cooperates with c-Myc in lymphomagenesis. Nat Med 2004;10:484-486.

[107] Wendel, HG, De Stanchina, E, Fridman, JS, et al. Survival signalling by Akt and eIF4E in oncogenesis and cancer therapy. Nature 2004;428:332-337.

[108] Lynch, M, Fitzgerald, C, Johnston, KA, Wang, S, Schmidt, EV. Activated eIF4E-binding protein slows G1 progression and blocks transformation by c-myc without inhibiting cell growth. J Biol Chem 2004;279:3327-3339.

[109] Jiang, H, Coleman, J, Miskimins, R, Miskimins, WK. Expression of constitutively active 4EBP-1 enhances p27Kip1 expression and inhibits proliferation of MCF7 breast cancer cells. Cancer Cell Int 2003;3:2.

[110] Petroulakis, E, Mamane, Y, Le Bacquer, O, Shahbazian, D, Sonenberg, N. mTOR signaling: implications for cancer and anticancer therapy. $\mathrm{Br}$ J Cancer 2006;94:195-199.

[111] Li, J, Yen, C, Liaw, D, et al. PTEN, a putative protein tyrosine phosphatase gene mutated in human brain, breast, and prostate cancer. Science 1997;275:1943-1947. 
[112] Young, J, Povey, S. The genetic basis of tuberous sclerosis. Mol Med Today 1998;4:313-319.

[113] Boudeau, J, Sapkota, G, Alessi, DR. LKB1, a protein kinase regulating cell proliferation and polarity. FEBS Lett 2003;546:159-165.

[114] Kwiatkowski, DJ. Tuberous sclerosis: from tubers to mTOR. Ann Hum Genet 2003;67:87-96.

[115] Kaper, F, Dornhoefer, N, Giaccia, AJ. Mutations in the PI3K/PTEN/TSC2 pathway contribute to mammalian target of rapamycin activity and increased translation under hypoxic conditions. Cancer Res 2006;66:1561-1569.

[116] Thomas, GV, Tran, C, Mellinghoff, IK, et al. Hypoxia-inducible factor determines sensitivity to inhibitors of mTOR in kidney cancer. Nat Med 2006;12:122-127.

[117] Nordsmark, M, Overgaard, M, Overgaard, J. Pretreatment oxygenation predicts radiation response in advanced squamous cell carcinoma of the head and neck. Radiother Oncol 1996;41:31-39.

[118] Evans, SM, Hahn, SM, Magarelli, DP, Koch, CJ. Hypoxic heterogeneity in human tumors: EF5 binding, vasculature, necrosis, and proliferation. Am J Clin Oncol 2001;24:467-472.

[119] Kaanders, JH, Wijffels, KI, Marres, HA, et al. Pimonidazole binding and tumor vascularity predict for treatment outcome in head and neck cancer. Cancer Res 2002;62:7066-7074.

[120] Ljungkvist, AS, Bussink, J, Rijken, PF, Kaanders, JH, van der Kogel, AJ, Denekamp, J. Vascular architecture, hypoxia, and proliferation in first-generation xenografts of human head-and-neck squamous cell carcinomas. Int J Radiat Oncol Biol Phys 2002;54:215-228.

[121] Hirst, DG, Denekamp, J, Hobson, B. Proliferation kinetics of endothelial and tumour cells in three mouse mammary carcinomas. Cell Tissue Kinet 1982;15:251-261. 
[122] Durand, RE, Aquino-Parsons, C. Clinical relevance of intermittent tumour blood flow. Acta Oncol 2001;40:929-936.

[123] Ljungkvist, AS, Bussink, J, Kaanders, JH, et al. Hypoxic cell turnover in different solid tumor lines. Int $\mathrm{J}$ Radiat Oncol Biol Phys 2005;62:1157-1168.

[124] Lanzen, J, Braun, RD, Klitzman, B, Brizel, D, Secomb, TW, Dewhirst, MW. Direct demonstration of instabilities in oxygen concentrations within the extravascular compartment of an experimental tumor. Cancer Res 2006;66:2219-2223.

[125] Papandreou, I, Krishna, C, Kaper, F, Cai, D, Giaccia, AJ, Denko, NC. Anoxia is necessary for tumor cell toxicity caused by a low-oxygen environment. Cancer Res 2005;65:3171-3178.

[126] Mayer, A, Hockel, M, Vaupel, P. Carbonic anhydrase IX expression and tumor oxygenation status do not correlate at the microregional level in locally advanced cancers of the uterine cervix. Clin Cancer Res 2005;11:7220-7225.

[127] Sobhanifar, S, Aquino-Parsons, C, Stanbridge, EJ, Olive, P. Reduced expression of hypoxia-inducible factor-1alpha in perinecrotic regions of solid tumors. Cancer Res 2005;65:7259-7266.

[128] Pouyssegur, J, Dayan, F, Mazure, NM. Hypoxia signalling in cancer and approaches to enforce tumour regression. Nature 2006;441:437443.

[129] Berra, E, Ginouves, A, Pouyssegur, J. The hypoxia-inducible-factor hydroxylases bring fresh air into hypoxia signalling. EMBO Rep 2006;7:41-45.

[130] Novoa, I, Zeng, H, Harding, HP, Ron, D. Feedback inhibition of the unfolded protein response by GADD34-mediated dephosphorylation of eIF2alpha. J Cell Biol 2001;153:1011-1022. 
[131] Chi, JT, Wang, Z, Nuyten, DS, et al. Gene expression programs in response to hypoxia: cell type specificity and prognostic significance in human cancers. PLoS Med 2006;3:e47. 
Chapter 1 


\section{Chapter 2}

Gene expression during acute and prolonged hypoxia is regulated by distinct mechanisms of translational control

M. Koritzinsky, M.G.P. Magagnin, T. van den Beucken, R. Seigneuric, K. Savelkouls, J. Dostie, S. Pyronnet, R.J. Kaufman, S.A. Weppler, J.W.

Voncken, P. Lambin, C. Koumenis, N. Sonenberg and B.G. Wouters

EMBO J. 25: 1114-1125, 2006 


\section{ABSTRACT}

Hypoxia has recently been shown to activate the endoplasmic reticulum kinase PERK leading to phosphorylation of eIF $2 \alpha$ and inhibition of mRNA translation initiation. Using a quantitative assay we show that this inhibition exhibits a biphasic response mediated through two distinct pathways. The first occurs rapidly reaching a maximum at $1-2 \mathrm{hrs}$ and is due to phosphorylation of eIF $2 \alpha$. Continued hypoxic exposure activates a second, eIF $2 \alpha$ independent pathway that maintains repression of translation. This phase is characterized by disruption of eIF4F and sequestration of eIF4E by both its inhibitor 4E-BP1, and its transporter 4E-T. Quantitative RT-PCR analysis of polysomal RNA indicates that the translational efficiency of individual genes varies widely during hypoxia. Furthermore, the translation efficiency of individual genes is dynamic, changing dramatically during hypoxic exposure due to the initial phosphorylation and subsequent dephosphorylation of eIF2 $\alpha$. Together our data indicate that acute and prolonged hypoxia regulate mRNA translation through distinct mechanisms, each with important contributions to hypoxic gene expression. 


\section{INTRODUCTION}

The presence of hypoxic and anoxic areas in human tumors is well documented, and is prognostic for poor outcome (reviewed in [1, 2]). The clinical importance of tumor hypoxia results from its ability to protect cells against both radiation and chemotherapy and from the fact that it can provide a selection pressure for apoptotically resistant cells [3]. Furthermore, the cellular response to hypoxia causes important changes in gene expression that affect cell behavior and influence patient prognosis. There has been particular focus on changes mediated through the family of hypoxia inducible transcription factors (HIFs). HIF-1 and HIF-2 promote transcription of more than 60 putative downstream genes (for a review see [4]) that affect hypoxia tolerance, energy homeostasis, angiogenesis and tumor growth. Although the transcriptional response to hypoxia is clearly very important [5-7], tumor cells also experience short, transient exposures to hypoxia and/or anoxia that occur over time frames too fast for an effective transcriptional response. Transient changes in oxygenation occur due to the abnormal vasculature found in most tumors, characterized by immature, leaky and improperly formed vessels. Perfusion of these vessels can change dynamically in time, leading to rapid but transient episodes of severe hypoxia in the tumor cells dependent upon them $[8,9]$. Consequently post-transcriptional responses are presumably important for adaptation to cycling oxygenation in tumors.

Control of mRNA translation during hypoxia is emerging as an important cellular response to hypoxia $[10,11]$. Since protein synthesis is energy costly, inhibition of mRNA translation may represent an active response to prevent loss of energy homeostasis during hypoxia. Indeed, it has been shown that overall mRNA translation is severely but reversibly inhibited during hypoxia $[10,12,13]$ with kinetics that precede ATP depletion [14]. Furthermore, regulation of mRNA translation can have a significant and rapid impact on individual gene expression. This is because the sensitivity of individual genes to changes in overall translation varies widely and in a manner that reflects the molecular mechanisms responsible for controlling translation $[15,16]$. Regulation of gene expression through control of mRNA translation is important during various pathologies including cancer [17]. The mechanisms responsible for inhibiting translation during hypoxia are not yet fully understood. 
We have previously investigated the involvement of the endoplasmic reticulum (ER) kinase PERK in the hypoxia-induced down-regulation of protein synthesis [10]. PERK is activated as part of the evolutionarily conserved unfolded protein response (UPR) (reviewed in [18]). It phosphorylates eIF2 $\alpha$, a subunit of eIF2, which in its GTP-bound form recruits the aminoacylated tRNA to the 40S ribosomal subunit. The exchange of GDP for GTP is mediated by the guanine nucleotide exchange factor eIF2B. Ser51phosphorylated eIF2 $\alpha$ inhibits eIF2B, resulting in inhibition of translation initiation. eIF2 $\alpha$-phosphorylation results in a set of molecular events collectively termed the integrated stress response (ISR). These include the inhibition of global mRNA translation in conjunction with induced expression of the transcription factor ATF4 and its downstream target genes [19]. We showed that hypoxia rapidly activated PERK which led to reversible phosphorylation of eIF $2 \alpha[10]$. Hypoxia-induced inhibition of protein synthesis was severely attenuated in cells without functional PERK. After prolonged periods of hypoxia, PERK-deficient cells did show partial inhibition, suggesting that protein synthesis is regulated through additional mechanisms.

Another candidate mechanism for inhibiting translation during hypoxia is disruption of the cap-binding protein complex eIF4F, which consists of eIF4E, eIF4A and eIF4G (for recent reviews see [20, 21]). eIF4E participates in a protein bridge between the mRNA and the ribosome by its simultaneous interaction with the mRNA 5' cap-structure and the large scaffolding protein eIF4G, which in turn interacts with eIF3 that is bound to the 40S ribosomal subunit. eIF4E is regulated through a set of binding proteins (4E-BPs) that bind reversibly to eIF4E in their hypo-phosphorylated form, and this obstructs the interaction between eIF4E and eIF4G. The 4E-BP1 protein becomes hyperphosphorylated in response to a number of stimuli, such as insulin, hormones, growth factors, mitogens and cytokines, as a result of activation of the PI3kinase/Akt/FRAPmTOR pathway [22].

It remains unclear to what degree the lack of eIF4F assembly contributes to inhibition of translation during tumor hypoxia. Several studies have investigated the combined consequences of ischemia/reperfusion on eIF4F-related proteins in rat brains (reviewed in [23]). Proteolysis of eIF4G was reported during ischemia and reperfusion in vivo [24, 25], but not in neuronal cells cultured in vitro (NGF differentiated PC12 cells) [26]. The reports addressing the expression and phosphorylation status of eIF4E during 
ischemia are conflicting, but 4E-BP1 dephosphorylation has been demonstrated both in vivo and in vitro [25, 26]. The acuteness and complexity of ischemia/reperfusion stress and the high sensitivity of neurons to deprivation and reconstitution of both oxygen and nutrients are distinct properties of this model system and thus difficult to extrapolate to tumor hypoxia. In rat hepatocytes, 4E-BP1 becomes dephosphorylated and associates with eIF4E rapidly (15-60 min) upon mild hypoxia, but this could not explain the observed down-regulation of protein synthesis [27]. More recently it was reported that hypoxia could influence 4E-BP1 phosphorylation by affecting the activity of mTOR [28]. Serum starved and hypoxic human embryonic kidney cells failed to activate mTOR, phosphorylate 4E-BP1 and dissociate 4E-BP1 from eIF4E in response to insulin treatment. Nonetheless, it remains unknown whether hypoxia alone is sufficient to disrupt the eIF4F complex and to what extent this influences overall translation during hypoxia. Here we show that hypoxia induces a biphasic inhibition of mRNA translation characterized by transient phosphorylation of eIF $2 \alpha$ and subsequent dissociation of eIF4F. These two mechanisms operate independently of each other and both have important consequences for gene expression during hypoxia.

\section{MATERIALS AND METHODS}

\section{Cell culture}

Exponentially growing cervical carcinoma HeLa cells (American Type Culture Collection CCL-2), lung adenocarcinoma A549 cells, normal human fibroblasts (AG1522) or mouse embryo fibroblasts (MEFs) that were wild type or had a homozygous knock in mutation for eIF2 $\alpha$ (S51A) [29] were grown on glass dishes or chamber slides in DMEM media supplemented with $10 \%$ fetal calf serum (FCS). The MEF media also contained MEM non-essential amino acids and $55 \mu \mathrm{M}$ 2-mercaptoethanol (all Sigma-Aldrich). For preparation of extracts and viability assessments, see supplementary materials and methods.

\section{Hypoxic conditions}

Cells were transferred to a hypoxic culture chamber (MACS VA500 microaerophilic workstation, Don Whitley Scientific). The composition of the atmosphere in the chamber consisted of $5 \% \mathrm{H}_{2}, 5 \% \mathrm{CO}_{2}, 0.0 \% \mathrm{O}_{2}$, and residual $\mathrm{N}_{2}$. 


\section{$m^{7} G T P$ resin precipitation}

One mg of HeLa extract was incubated with $25 \mu 1$ of $\mathrm{m}^{7} \mathrm{GTP}$ sepharose resin (Amersham Biosciences) for $3 \mathrm{~h}$ at $4^{\circ} \mathrm{C}$. The resin was washed, boiled in Laemmli buffer and the polypeptides were resolved by SDS-PAGE.

\section{Western blotting}

Cell extracts were boiled in Laemmli buffer and polypeptides were resolved by SDS-PAGE and transferred onto $0.2 \mu \mathrm{m}$ nitrocellulose membranes (Amersham Corp.). For primary antibodies, see supplementary materials and methods. Detection of peroxidase-coupled secondary antibodies was performed with Enhanced Chemiluminescence (Amersham Corp.).

\section{Immunofluoresence}

Cells were fixed with $4 \%$ paraformaldehyde and permeabilised in $4 \%$ paraformaldehyde and $0.1 \%$ Triton X-100. For antibodies, see supplementary materials and methods. Cells were mounted in ProLong ${ }^{\mathrm{TM}}$ Antifade Kit (Molecular Probes) and analyzed with a Zeiss inverted LSM 410 laser scan confocal microscope.

\section{Polysomal fractionation and analysis}

Polysomal fractionation and analysis was performed as previously described [30].

\section{$R N A$ isolation and reverse transcription}

RNA isolation and RT was performed as previously described [30].

\section{Quantitative PCR analysis}

Real-time PCR was performed in either ABI 7700 or ABI 7500 (Applied Biosystems). For primers and probes, see supplementary materials and methods. Unfractionated samples were normalized by $18 \mathrm{~S}$ rRNA signal. Samples from polysome fractions were normalized by $18 \mathrm{~S}$ rRNA measured by PCR divided by $18 \mathrm{~S}$ rRNA measured by spectrometry during fractionation, corrected for loading. This facilitated correction for any differences in RNA isolation or reverse transcriptase efficiency between samples. The abundance of every gene was calculated relative to a master reference using standard curves. 


\section{RESULTS}

\section{Kinetics of translation inhibition}

To determine the effects of hypoxia on mRNA translation initiation in HeLa cells we examined the association of ribosomes with mRNA at various time points. In this assay, the number of ribosomes found within the 'polysomal' fraction of mRNA (mRNA containing 2 or more ribosomes) is a relection of $d e$ novo protein synthesis. This technique is advantageous to other methods such as ${ }^{35} \mathrm{~S}$ incorporation which requires prior amino acid starvation, a procedure that can itself influence translation initiation [31]. Figure 1A shows that at all time points examined, hypoxia causes a large decrease in polysomal mRNA and a corresponding increase in free ribosomes and ribosomal subunits. The reduction in translation is not influenced by cell death as cell viability remains above $90 \%$ following 16 hours of hypoxia (data not shown). Furthermore, the inhibition of translation is completely reversible upon reoxygenation (data not shown).

To quantitatively assess overall mRNA translation from the polysome profiles, we calculated the percentage of rRNA participating in polysomes and defined this as the overall translation efficiency. This value is reduced from $62 \%$ to $24 \%$ after one hour of hypoxia, and then recovers somewhat stabilizing at $\sim 30 \%$ (Figure 1B). The drop in translation reproducibly exhibited this biphasic response with maximum inhibition after 1 to 2 hours, followed by a small recovery. The magnitude of inhibition is comparable to that observed following complete disruption of the cellular redox environment with $1 \mathrm{mM}$ DTT (17\%) (data not shown).

Analysis of the polysome profiles in Figure 1A shows that hypoxia also causes a change in the distribution of the polysomal mRNA, with proportionally less signal in the higher molecular weight fractions. This indicates that the average number of ribosomes per mRNA transcript is also decreased during hypoxia, reflecting a reduction in translation initiation efficiency even for those transcripts that remain translated. From the polysome profiles we calculated the average number of ribosomes per translated transcript (i.e. mRNAs containing two or more ribosomes) at different time points during hypoxia (Figure 1C). The kinetics of this parameter follow in large part that of the overall translation. 
A
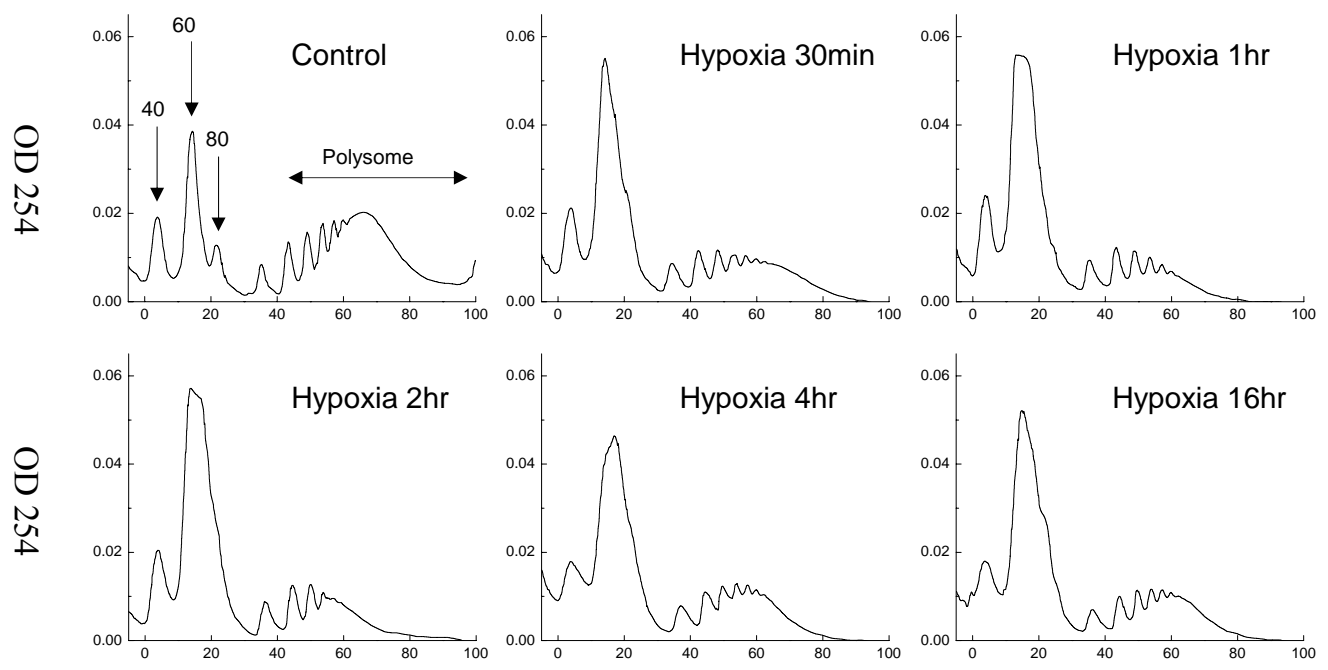

Gradient depth

Gradient depth

Gradient depth

B

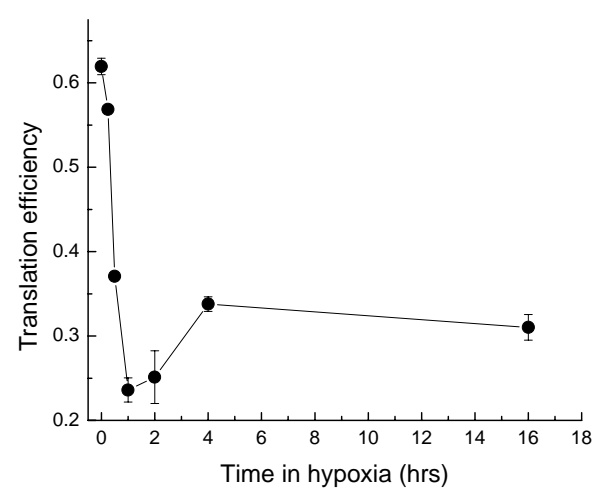

C

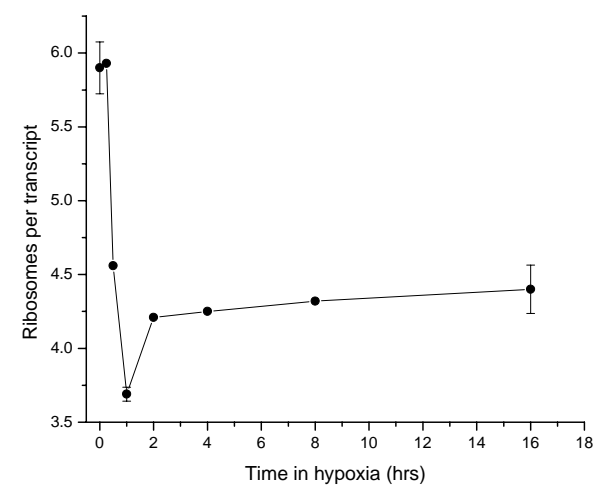

Figure 1: Hypoxia inhibits mRNA translation. HeLa cells were exposed to $0.0 \% \mathrm{O}_{2}$ for $0-16 \mathrm{~h}$ and cell lysates were separated on a sucrose gradient. (A) The optical density (OD) at $254 \mathrm{~nm}$ is shown as a function of gradient depth for each time point. Actively translated mRNA is associated with high-molecular-weight polysomes deep in the gradient. (B) Translation efficiency in HeLa cells as a function of time in $0.0 \% \mathrm{O}_{2}$. As a measure of overall translation efficiency, the relative amount of rRNA participating in polysomes was estimated. This 
fraction is proportional to the integrated area under the curve containing polysomes, as marked in (A). (C) The average number of ribosomes per mRNA in the polysomes as a function of time in $0.0 \% \mathrm{O}_{2}$. This was calculated by differential integration of the profiles in $(\mathrm{A})$.

\section{eIF $2 \alpha$ regulates translation during acute hypoxia}

The eIF $2 \alpha$ kinase PERK is at least partly responsible for protein synthesis inhibition during acute hypoxia, as measured by radioactive labeling of newly synthesized proteins [10]. Thus, we hypothesized that the rapid inhibition and subsequent partial recovery in translation is due to changes in eIF $2 \alpha$ phosphorylation. Indeed we found that the phosphorylation of eIF $2 \alpha$ is greatest after 1-2hr and then decreases by $8 \mathrm{hr}$ of hypoxia in several cell lines (Figure 2A). ATF4 protein levels also increase and then decrease during hypoxia in a manner that mirrors eIF2 $\alpha$ phosphorylation. The dynamics of eIF $2 \alpha$ phosphorylation and ATF4 protein induction thus correlate with the initial inhibition of translation and its subsequent recovery.

To assess the requirement of eIF $2 \alpha$ phosphorylation for translation inhibition during hypoxia we examined the response of mouse embryo fibroblasts (MEFs) derived from eIF2 $\alpha$ knock-in mice containing a S51A mutation [29]. As expected, these cells were defective in phosphorylation eIF2 $\alpha$ during hypoxia (Figure 2B). The translation efficiency in WT MEFs is similar to that in HeLa cells, with a rapid drop during acute hypoxia followed by a partial recovery (Figure 2C). In contrast, S51A MEFs display a substantial defect in their ability to inhibit translation during the initial phase. Nonetheless, after 16 hours of hypoxia both cell lines show a similar loss in translation efficiency. These data indicate that eIF $2 \alpha$ phosphorylation is indeed necessary for inhibition of translation during acute hypoxia, but not at later times.

When the polysome profiles are analyzed in terms of the average number of ribosomes per translated transcript, S51A MEFs exhibit an even stronger defect in their response during acute hypoxia. Despite a small but detectable drop in translation efficiency during the first 4 hours of hypoxia (Figure 2C), S51A MEFs show no decrease in the average number of ribosomes per translated transcript (Figure 2D). The same result was found in cells treated with DTT, a known activator of PERK that causes eIF2 $\alpha$ phosphorylation. In contrast, WT MEFs show a strong reduction in average ribosomes per transcript during both acute hypoxia and DTT treatment. Interestingly, after 8 hours of hypoxia the average number of ribosomes per 
translated transcript increases again towards normal levels in WT cells and is equivalent to that in S51A MEFs by 16 hours. These data provide further evidence that the inhibition of translation that occurs after acute and prolonged hypoxia are mechanistically distinct.

A
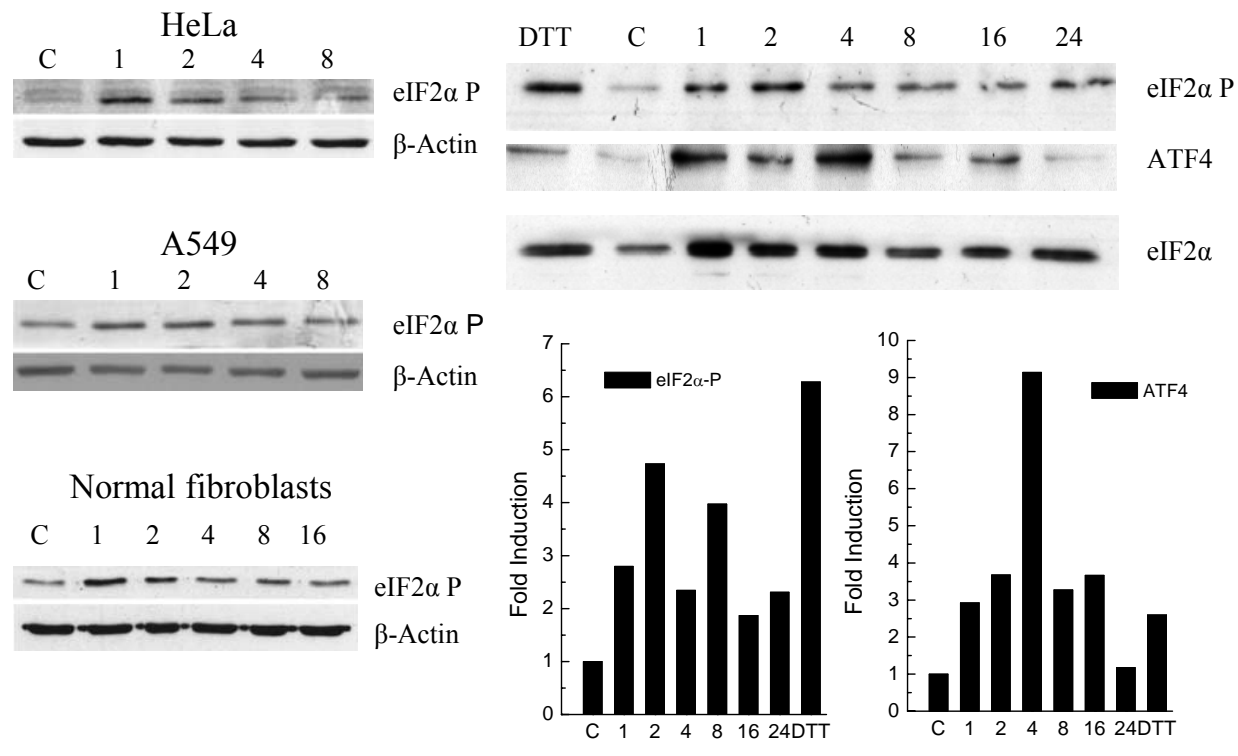

B

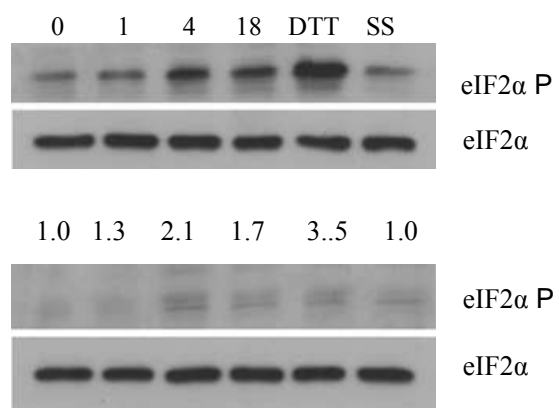


C
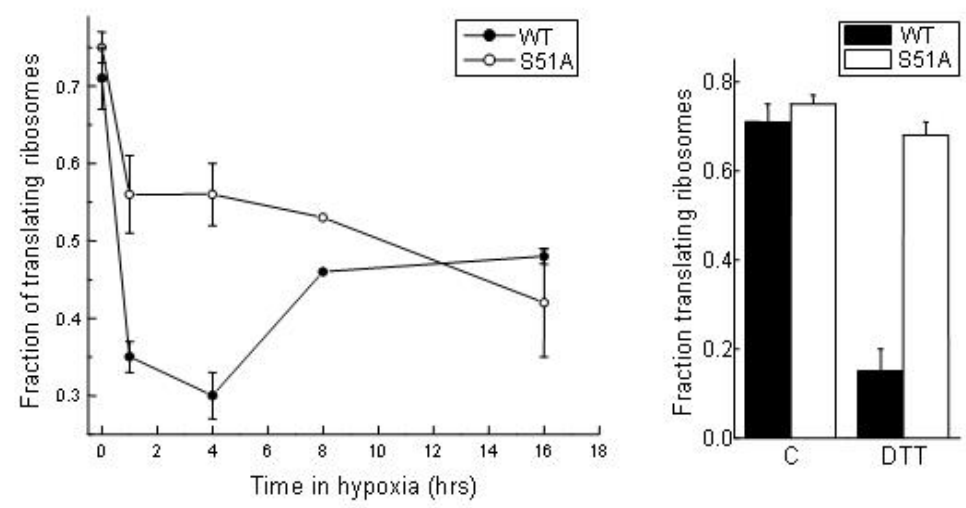

D
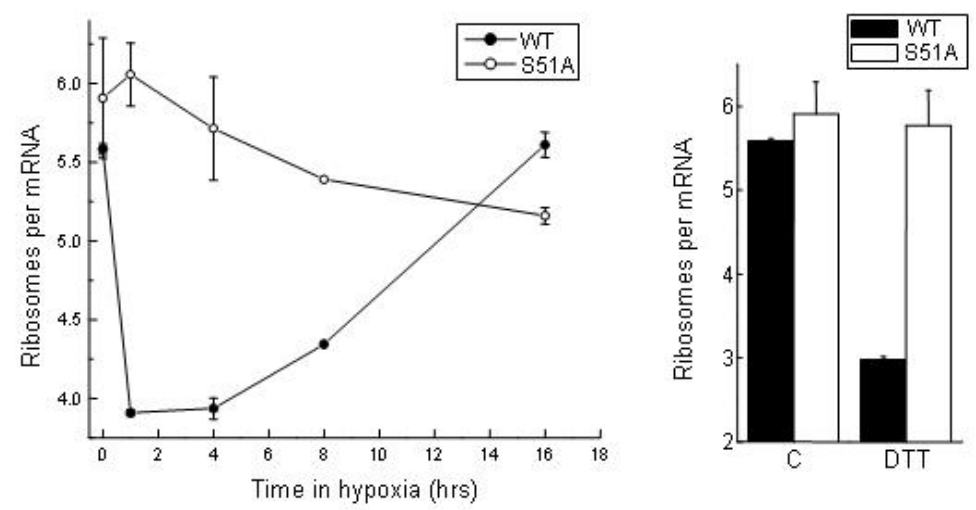

Figure 2: Inhibition of translation during acute hypoxia is dependent on eIF2 $\alpha$. HeLa cells, A549 cells, human normal fibroblasts (NF) and WT or S51A MEFs were exposed to $0.0 \% \mathrm{O}_{2}$ for $0-16 \mathrm{~h}, 1 \mathrm{mM}$ DTT or serum starvation (SS) for $1 \mathrm{~h}$. Cell lysates were separated by SDSPAGE. Immunoblots for (A) HeLa, A549 and NF or (B) MEFs were performed using antibodies against total or phosphorylated eIF2 $\alpha$, ATF4 and $\beta$-actin. In (A), optical densitometry for phosphorylated eIF $2 \alpha$ or ATF4 normalized by total eIF $2 \alpha$ is also shown. Total eIF2 $\alpha$ expression has previously been shown to be constant during hypoxia [10]. (C) Cell lysates were separated on a sucrose gradient, and OD at $254 \mathrm{~nm}$ was recorded. Translation efficiency as a function of time in $0.0 \% \mathrm{O}_{2}$ in WT and S51A MEFs was estimated as in Figure 1. (D) Average number of ribosomes per mRNA in the polysomes in WT and S51A MEFs as a function of time in $0.0 \% \mathrm{O}_{2}$ was calculated as in Figure 1. 
Disruption of the eIF4F complex during hypoxia

The assembly of the cap-binding complex eIF4F is a common control point for translation initiation and was thus a likely candidate for maintaining low rates of translation during prolonged hypoxia. We examined the levels of eIF4E and proteins that associate with it as an active complex (eIF4GI) or as an inactive complex (4E-BP1). Figure 3A shows that the levels of eIF4E do not change during hypoxia. In contrast, 4E-BP1 (Figure 3B) shows both a small induction at 8 hours and a strong dephosphorylation after 16 hours of hypoxia. This protein runs as different migrating bands representing different phosphorylation levels [32]. The fastest migrating band is substantially increased after 16 hours of hypoxia, and represents the hypo-phosphorylated 4E-BP1 which is known to have a higher affinity for eIF4E. A small decrease in the abundance of the scaffold protein eIF4GI (Figure 3C) was observed after 8 hours, consistent with a decrease in its rate of synthesis measured in microarray study using polysomal RNA (unpublished data). Overexposure of the blots indicated no reproducible changes in cleavage of eIF4G. The influence of hypoxia on 4E-BP1 phosphorylation appears to be largely independent of eIF $2 \alpha$ phosphorylation as it is not differentially affected in the WT and S51A MEFs (unpublished data). However until the relative contributions of various upstream signaling pathways to 4E-BP phosphorylation under hypoxia are better understood, it is premature to conclude that no connection between eIF2 $\alpha$ and eIF4F exists.

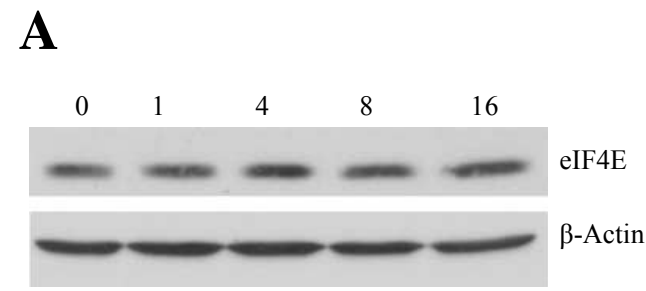

B
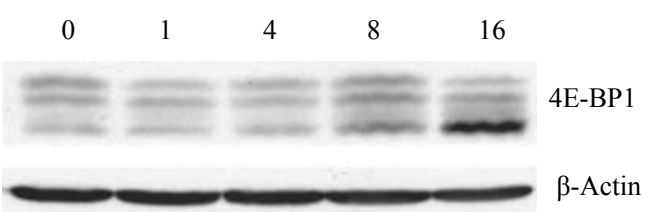

C

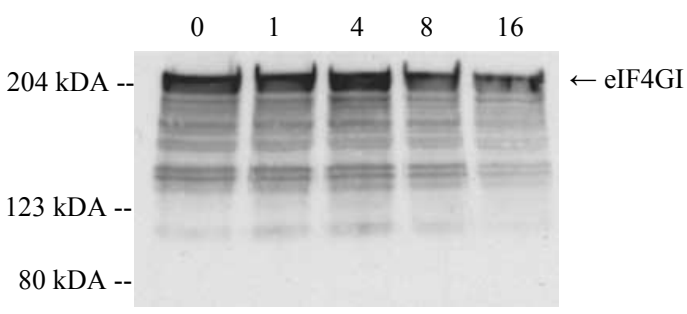


Figure 3: Expression of eIF4E, 4E-BP1 and eIF4GI during hypoxia. HeLa cells were exposed to $0.0 \% \mathrm{O}_{2}$ for $0-16 \mathrm{~h}$ and cell lysates separated by SDS-PAGE. Immunoblots were performed using antibodies against $\beta$-Actin, (A) eIF4E, (B) 4E-BP1 and (C) eIF4GI. The phosphorylation forms of 4E-BP1 have different electrophoretic mobilities and are represented by several bands on the immunoblot. Full-length eIF4GI run at about $220 \mathrm{kDa}$; the blot is overexposed to detect cleavage products.

To more strictly assess the influence of hypoxia on eIF4F, we investigated the association of eIF4E with eIF4GI and eIF4GII as well as with its inhibitor 4E-BP1 in HeLa cells. During aerobic conditions where translation is efficient, eIF4E is associated with large amounts of both eIF4GI and eIF4GII, and only a small amount of 4E-BP1 (cap lanes in Figure 4A and B). Cap-associated eIF4G migrated somewhat slower than the overall pool of eIF4G, suggesting a possible modification of this phospho-protein when bound to the cap. In contrast, after 4 or 16 hours of hypoxia there is a dramatic loss in binding to both eIF4GI and eIF4GII indicating dissociation of the eIF4F complex. At 16 hours this dissociation correlates with a large increase in binding between eIF4E and 4E-BP1, consistent with the increase in the hypophosphorylated levels of 4E-BP1 at this time. It also correlated with decreased phosphorylation of eIF4E (data not shown) at 16 hours, but the physiological significance of this remains unclear. However, although dissociation of eIF4G and eIF4E is complete after 4 hours of hypoxia, a corresponding change in eIF4E phosphorylation or eIF4E/4E-BP1 association is not seen at this time point. This suggests that a mechanism distinct from 4E-BP1 dephosphorylation may also inhibit eIF4F during hypoxia.

A

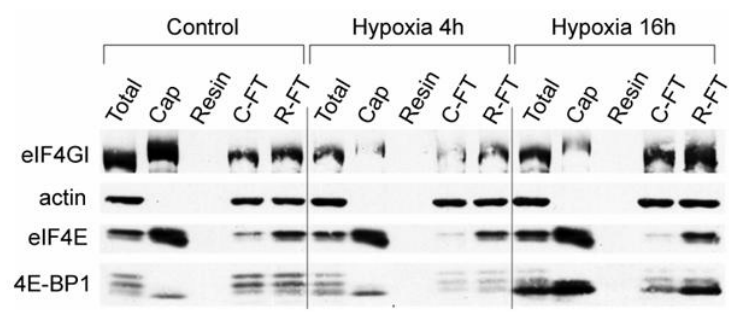

B

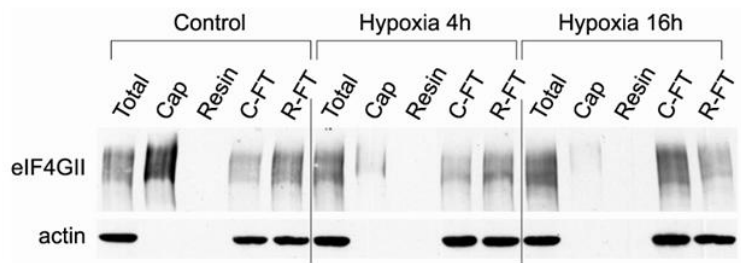


Figure 4: eIF4F is disrupted during prolonged hypoxia. HeLa cells were exposed to $0.0 \% \mathrm{O}_{2}$ for $0-16 \mathrm{~h}$ and cell lysates probed for the presence of various eIF4E complexes. Lysates were incubated with an m7-cap analogue ('Cap') or uncapped resin as a negative control. Immunoblots were performed with antibodies against actin, (A) eIF4GI, eIF4E, 4E-BP1 and (B) eIF4GII. 'Cap': proteins bound to the capped resin; 'Resin': proteins bound to the uncapped resin; 'C-FT': unbound fraction after incubation with capped resin; 'R-FT': unbound fraction after incubation with uncapped resin.

\section{Translocation of eIF4E by $4 E-T$}

A potential cause of eIF4F disruption that has not been well characterized is the translocation of eIF4E to the nucleus or to cytoplasmic bodies of mRNA processing (P-bodies). 5-20\% of eIF4E is known to localize to the cell nucleus [33]. The shuttling protein $4 \mathrm{E}-\mathrm{T}$ is the only known regulator of eIF4E localization and is capable of binding and transporting it to the cell nucleus [34]. eIF4E also colocalizes with 4E-T in P-bodies, where mRNA is degraded or stored [35]. Hypoxia caused a redistribution of both eIF4E and 4E-T from predominantly cytoplasmic staining under aerobic conditions to substantial nuclear staining during hypoxia (Figure 5A-C). This redistribution occurred progressively over time in hypoxic conditions, correlating with the gradual dephosphorylation of 4E-T (Figure 5D). In addition, hypoxic cells exhibit significant eIF4E and 4E-T staining in the peri-nuclear area which may be associated with the nuclear envelope or the endoplasmic reticulum. Interestingly, hypoxia also caused 4E-T to concentrate in peri-nuclear speckles which could represent P-bodies.

A

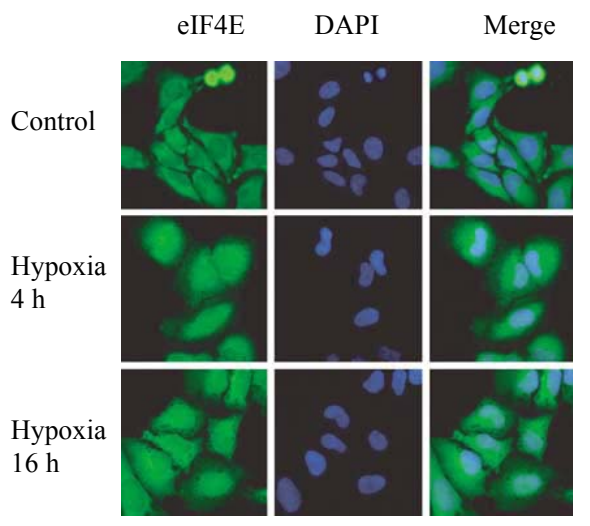

B

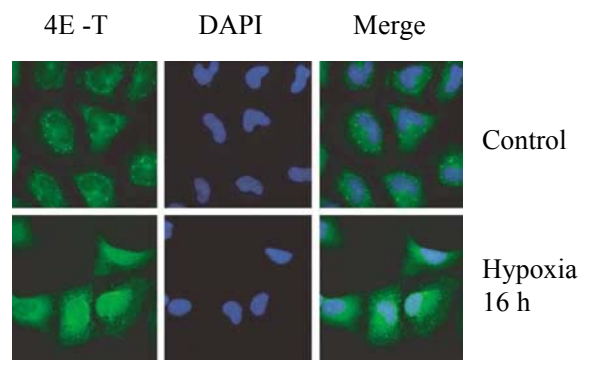


C

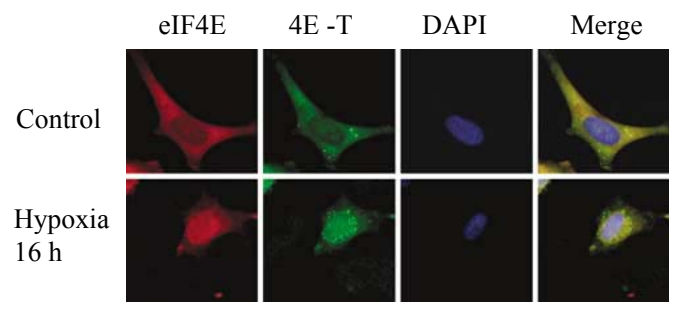

D

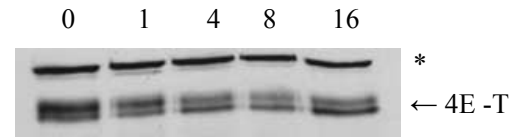

Figure 5: 4E-Tand eIF4E relocalize during hypoxia. HeLa cells were treated with $0.0 \% \mathrm{O}_{2}$ for $0-16 \mathrm{~h}$. Cells were stained with DAPI and (A) a polyclonal antibody against eIF4E, (B) a polyclonal antibody against 4E-T or (C) a monoclonal antibody against eIF4E and a polyclonal antibody against 4E-T. Cells were visualized by confocal microscopy and individual pictures merged to determine colocalization. (D) Cell lysates were separated by SDS-PAGE and immunoblots performed using antibodies against 4E-T. A crossreacting band is indicated $(*)$.

\section{Gene-specific regulation of translation}

Since translation efficiency is highly gene specific we anticipated that individual genes would show different patterns of translation efficiency during acute and prolonged hypoxia. To investigate this we fractionated polysomal mRNA and subsequently measured the mRNA abundance of individual genes by quantitative RT-PCR (Figure 6A). We first confirmed that concomitant with an increase in polysome-association, the non/sub-polysomal abundance decreased (data not shown). Subsequently we quantified both the transcript recruitment and distribution within the polysomes (expressed as the relative fraction of translated transcripts and the average number of ribosomes per translated transcript respectively).

We first measured the translational profile of the housekeeping gene $\beta-$ actin (Figure 6B). In aerobic cells it is efficiently translated with a majority of the mRNA in polysome fractions 5 and 6 . After 1 hour of hypoxia there is a marked reduction in translation as evidenced by a shift towards the lower polysome fractions, which recovers considerably by 16 hours. The drop in translation efficiency at 1 hour is due to reductions in both the relative fraction of translated mRNA as well as to a reduction in average number of ribosomes per translated transcript (Figure 6B). At later time points, only the average number of ribosomes per transcript remained low. The kinetic changes in 
translation efficiency for $\beta$-actin are similar to those observed for overall translation efficiency.

A

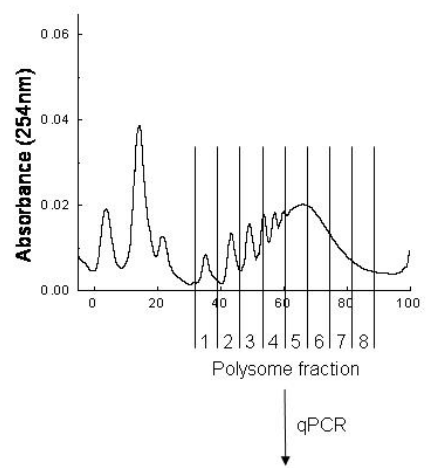

B
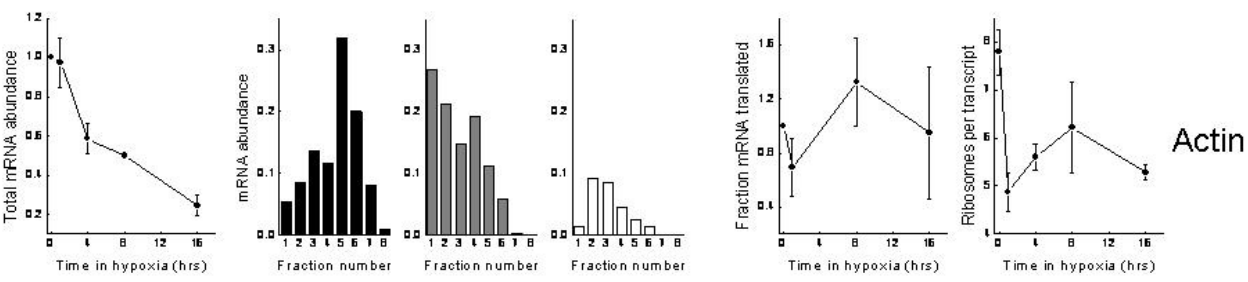

C
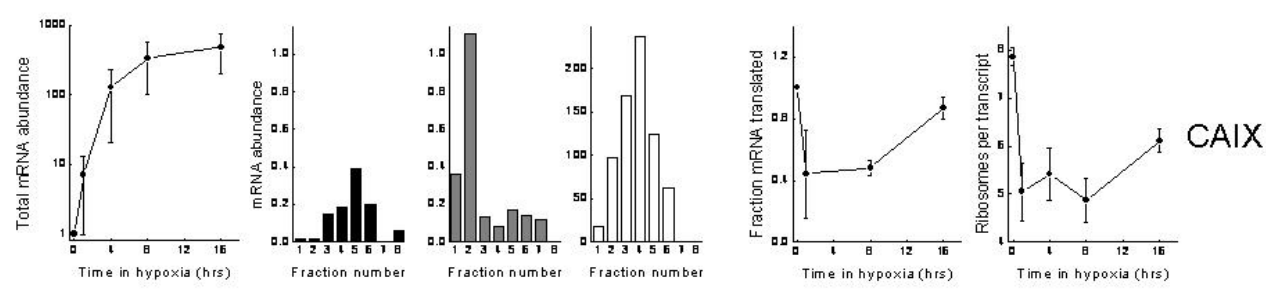

D

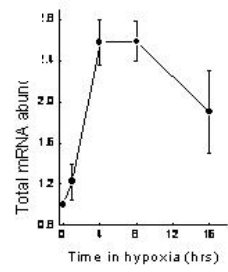

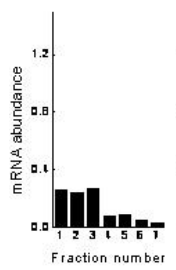
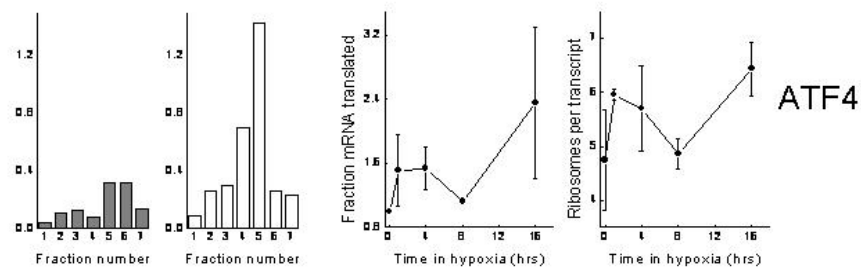
$\mathbf{E}$
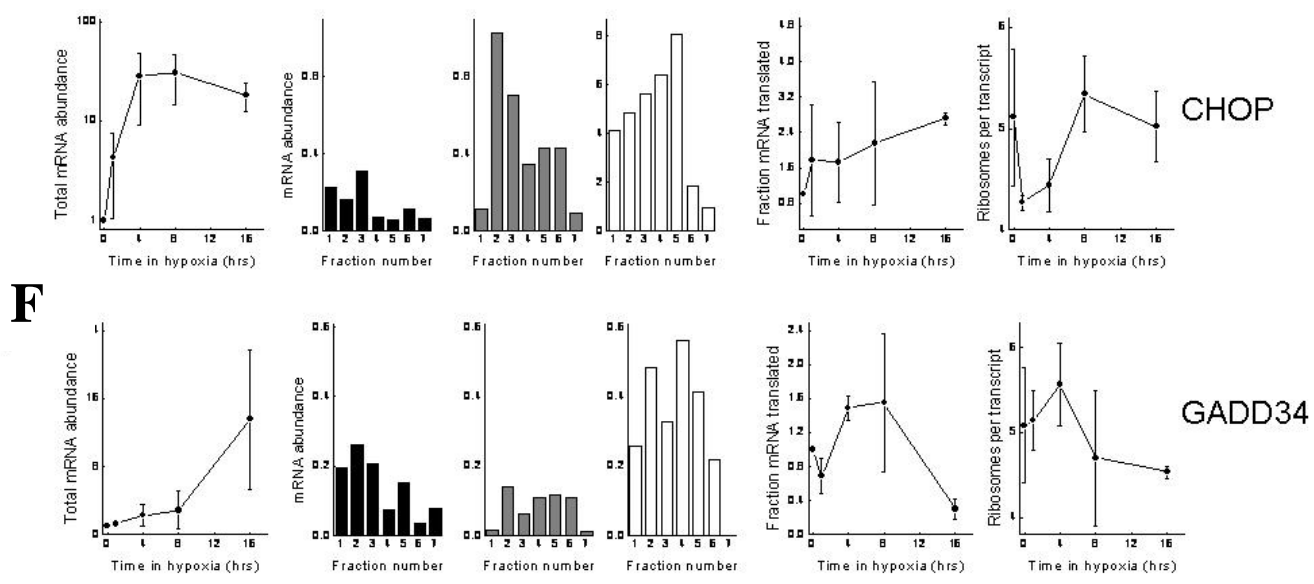

Figure 6: Gene-specific regulation of translation during hypoxia. HeLa cells were exposed to $0.0 \% \mathrm{O}_{2}$ for $0-16 \mathrm{~h}$ and cell lysates were separated on sucrose gradients. (A) Fractions were collected as indicated, RNA was isolated and reverse transcribed. Thereafter, the total mRNA abundance of (B) $\beta$-Actin, (C) CAIX, (D) ATF4, (E) CHOP and (F) GADD34 was determined using real-time quantitative PCR. The left panel shows total mRNA levels from unfractionated samples, normalized by $18 \mathrm{~S}$ rRNA signal. The following three panels use black, gray and white bars to represent the gene abundance in polysome fractions following 0,1 or $16 \mathrm{~h}$ hypoxia, respectively. The last two graphs show components of translation efficiency. This includes the relative fraction of transcripts in polysomes (i.e. corrected for total mRNA abundance) and the average number of ribosomes per mRNA. Graphs show the average from two independent experiments, and the histograms show the results from one representative experiment.

Many proteins are induced at the transcriptional level by hypoxia and we suspected that these genes might be preferentially translated during hypoxia. We investigated the translation of the HIF-1 target gene carbonic anhydrase IX (CAIX), which is important for tumor cell growth and survival during hypoxia [36]. Figure $6 \mathrm{C}$ shows a $\sim 500$ fold transcriptional induction of CAIX during hypoxia. Polysome analysis indicates that, similar to $\beta$-actin, CAIX is initially efficiently translated but severely inhibited after $1 \mathrm{hr}$ of hypoxia. A significant restoration of the polysome distribution occurs after 16 hours and thus ensures protein synthesis at this time where there is also significantly more cellular mRNA. As for $\beta$-actin, the initial inhibition of CAIX translation is due to a drop in both recruitment of the mRNA into 
polysomes and in the number of ribosomes per transcript. However, during prolonged hypoxia, the mRNA recruitment recovers and lower translation efficiency is attributed only to a small reduction in the average number of ribosomes per transcript.

ATF4 is a central transcription factor mediating the unfolded protein response (UPR) following ER stress. Both thapsigargin (which causes ER stress) and 16 hours of hypoxia result in eIF2 $\alpha$ phosphorylation and translational induction of ATF4 in a PERK dependent manner [13, 16, 37]. Under normal conditions, the translation efficiency of this gene is low with most of the mRNA found in fractions 1-3 (Figure 6D). In direct contrast to $\beta$ actin and CAIX, its translation is substantially increased during acute hypoxia, due to both increased recruitment into the polysomes and to an increase in the average number of ribosomes per transcript. In agreement with Blais and colleagues, we also observed a further increase in ATF4 translation efficiency during prolonged hypoxia [37].

An important transcriptional target of ATF4 is the C/EBP transcription factor CHOP [38], which induces cell cycle arrest and apoptosis during ER stress. Figure 6E shows that CHOP is both transcriptionally and translationally regulated by hypoxia. Translation is only moderately inhibited during acute hypoxia, as shown by a drop in average number of ribosomes per transcript. However, this reduction is much smaller than average overall reduction (Figure 1C) and the reductions observed for both $\beta$-actin and CAIX. After 16 hours of hypoxia, translation of CHOP is stimulated as indicated by a recovery in the number of ribosomes per transcript and a marked increase in the fraction translated mRNA.

Recovery from ER stress requires the GADD34 gene, which is induced in a PERK [39] and CHOP [40] dependent manner. GADD34 stimulates the activity of PP1c to dephosphorylate eIF2 $\alpha$. We found that, like CHOP, GADD34 is both transcriptionally and translationally regulated during hypoxia. Interestingly, its translation efficiency is highest after 4 hours of hypoxia, which coincides with the start of recovery from eIF $2 \alpha$ phosphorylation and overall translation inhibition (Figure 6F). In contrast, GADD34 mRNA is unable to completely bypass the translation inhibition after 16 hours. 
Gene-specific regulation of translation - dependence upon eIF $2 \alpha$

The gene specific changes in translation noted above likely reflect the underlying eIF2 $\alpha$ and eIF4F dependent mechanisms of translation control during hypoxia. We thus analysed gene-specific translation in WT and S51A MEFs to establish the dependence of individual genes on eIF2 $\alpha$ regulation (Figure 7). In contrast to the WT MEFs, the S51A MEFs show no loss in translation efficiency of $\beta$-actin or CAIX during acute hypoxia (7A and B). The loss in translation efficiency for these genes in the WT cells is similar to that observed in HeLa cells and is due primarily to a reduction in the average number of ribosomes per transcript. For both of these genes the S51A MEFs show virtually no reduction in this parameter during the acute phase of hypoxia. However, in contrast to acute hypoxia, the translation efficiency during prolonged hypoxia is similar for these two genes in both cell lines.

For ATF4, CHOP (data not shown) and GADD34 (Figure 7C), acute hypoxia causes a stimulation of translation in the WT MEFs that is similar to HeLa cells. However, the translational induction is entirely absent in the S51A MEFs. The increase in translation efficiency for GADD34 in the WT MEFs during acute hypoxia results mainly from an increase in the average number of ribosomes per transcript (Figure 7C). Cells that are defective in eIF2 $\alpha$ phosphorylation show impaired regulation of this parameter. Thus, for all genes examined, the observed changes in translation efficiency during acute hypoxia are dependent on eIF $2 \alpha$ phosphorylation.
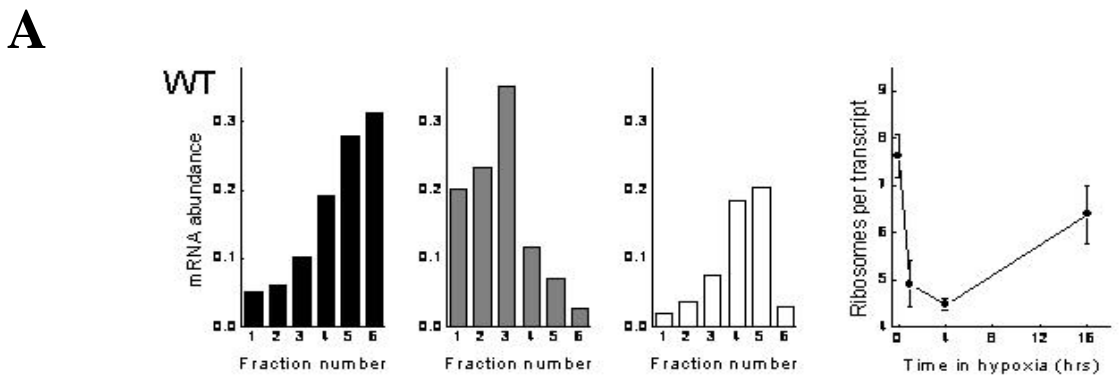

mActin
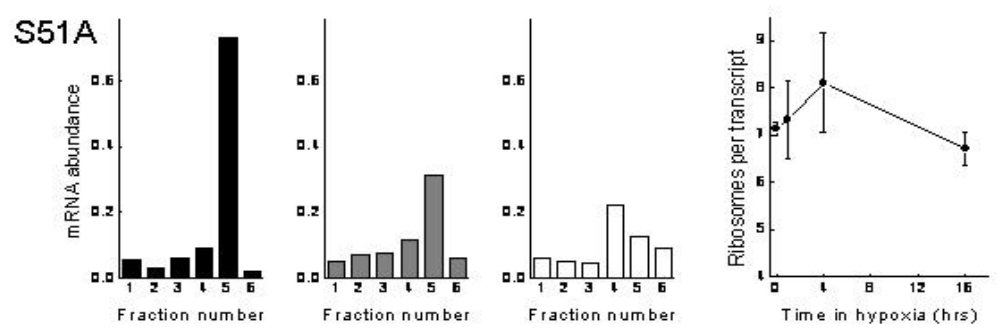

mActin 
B
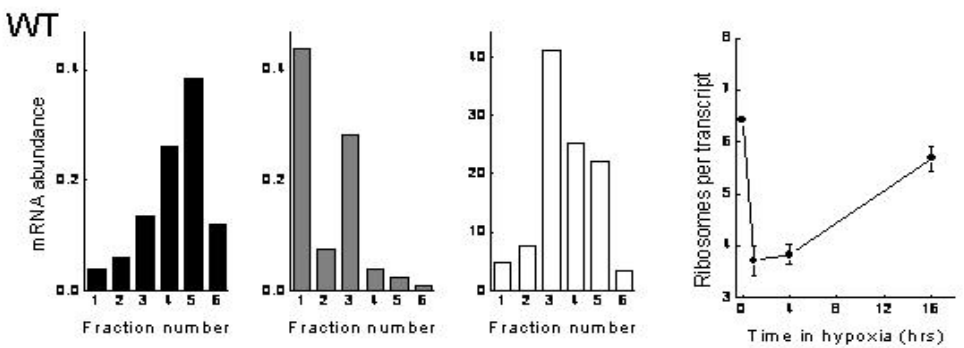

CAIX
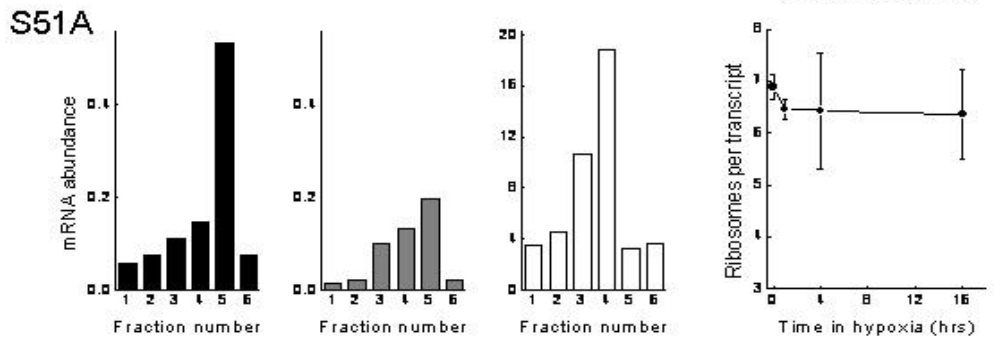

CAIX

C
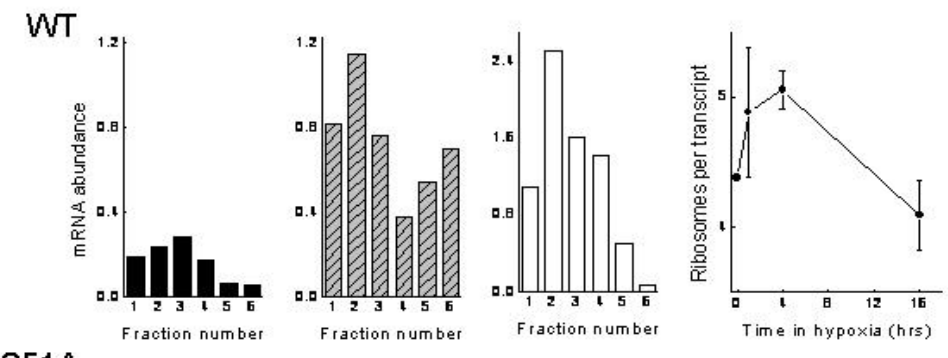

mGADD34
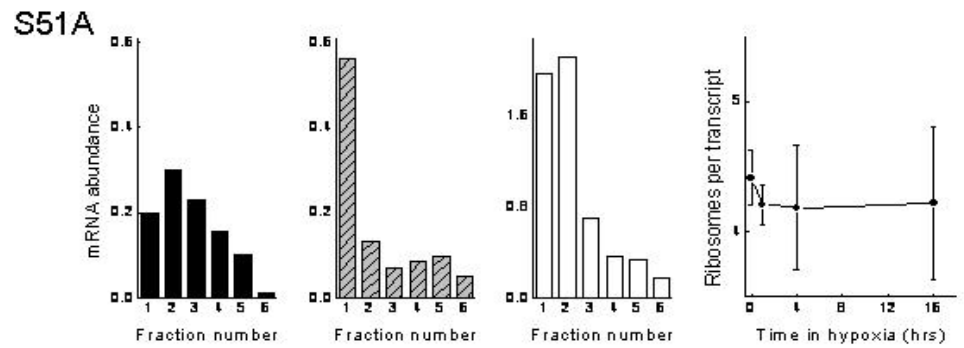

mGADD34

Figure 7: Dependence on eIF2 $\alpha-\mathrm{P}$ for gene-specific translational regulation. WT and S51A MEFs were exposed to $0.0 \% \mathrm{O}_{2}$ for $0-16 \mathrm{~h}$ and cell lysates were separated on sucrose gradients. RNA was isolated from polysome fractions and reverse transcribed. Thereafter, the abundance of (A) $\beta$-Actin, (B) CAIX and (C) GADD34 was determined using real-time quantitative PCR. The first three panels use black, solid grey, hatched grey and white bars to represent the gene abundance in polysome fractions following $0,1,4$ or $16 \mathrm{~h}$ hypoxia, 
respectively. The following graph depicts one component of translation efficiency, that is, the average number of ribosomes per mRNA.

\section{DISCUSSION}

Rapid and persistent down-regulation of protein synthesis is thought to be a means of energy preservation and to protect against the lethal effects of hypoxia $[10,11]$. Here we show that the inhibition of global mRNA translation during hypoxia exhibits a biphasic response (Figure 8).

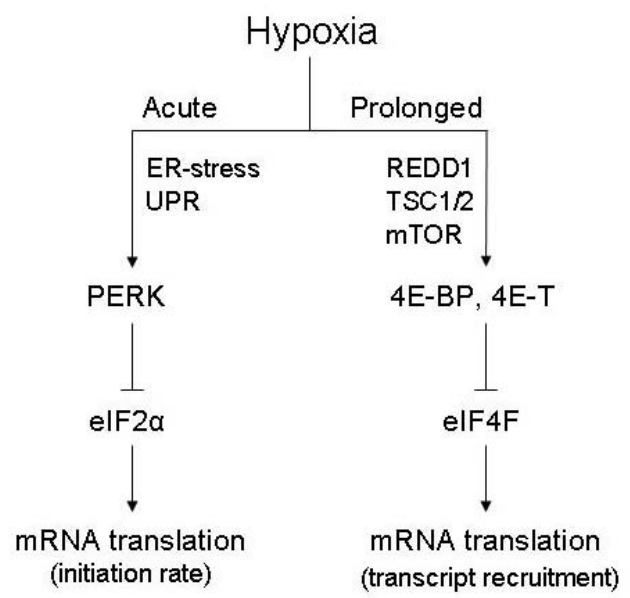

Figure 8: Model of the effects of hypoxia on overall mRNA translation. Acute hypoxia causes transient eIF $2 \alpha$ phosphorylation due to PERK activation as a part of the UPR. This results in inhibition of the rate of translation initiation. Following prolonged hypoxic conditions, activation of 4E-BP and 4E-T causes disruption of eIF4F, which inhibits the recruitment of mRNA to polysomes. Both molecular mechanisms affect specific mRNAs to varying degrees, resulting in differential gene expression.

The initial rapid inhibition (i.e. $15 \mathrm{~min}-4$ hours) is primarily dependent on eIF2 $\alpha$ phosphorylation, whereas inhibition during prolonged hypoxia is independent of eIF $2 \alpha$. Phosphorylation of eIF $2 \alpha$ under conditions of anoxia is extremely rapid, occurring almost as quickly as we can establish hypoxia in our system (15-30 min). We have previously shown that eIF2 $\alpha$ is also dephosphorylated under more moderate hypoxic conditions, although to a smaller degree and after longer times [10]. We speculate that this rapid 
response may be especially important during the acute exposures to hypoxia/anoxia that frequently occur in tumors due to the transient opening and closing of blood vessels. This rapid response may explain the importance of eIF $2 \alpha$ and ATF4 in the tolerance of cells to oxidative stress, which also occurs during hypoxia/reoxygenation cycles [19]. This hypothesis is supported by a recent study from $\mathrm{Bi}$ et al. showing that activation of the PERK-eIF2 $\alpha$ pathway during hypoxia contributes to overall tumor growth. Both human tumor cells expressing a dominant negative PERK-allele and MEFs lacking PERK or expressing the S51A eIF2 $\alpha$ produce smaller tumors with increased cell death in hypoxic areas than their wild-type counterparts [13]. Thus, although activation of eIF $2 \alpha$ phosphorylation in response to hypoxia is transient, this response appears critical for long-term cell survival within hypoxic regions of tumors.

Inhibition of translation during prolonged anoxia is associated with disruption of the mRNA cap-binding complex eIF4F and sequestration of eIF4E by both dephosphorylated 4E-BP1 and 4E-T. To our knowledge, this report is the first to show a physiological stress-induced regulation of the localization of eIF4E and its transporter 4E-T. Accumulation of eIF4E in the cell nucleus or P-bodies renders it unavailable for cytoplasmic translation. Relocalisation of eIF4E may have additional roles apart from reducing capdependent protein translation, including effects on mRNA processing, transport and degradation. Moderate hypoxia (1\%) has also been shown to effect the eIF4F complex through inhibition of mTOR [28]. However, the kinetics and relative contributions of the eIF4F pathway on inhibition of global and gene-specific translation during more moderate hypoxia remains to be determined (see below).

Analysis of mRNA distribution within polysomes at different times also revealed interesting mechanistic differences during acute and prolonged hypoxia. Acute hypoxia caused a substantial drop in the average number of ribosomes per translated transcript. This presumably results from a reduction in the rate at which ribosomal subunits can be loaded onto mRNA, since each subunit requires a new non-phosphorylated eIF $2 \alpha$ molecule. Inhibition of translation during prolonged hypoxia via eIF4F did not show this effect. Instead, translation was suppressed mainly by reducing the fraction of mRNA found within the polysomes. These results are consistent with a model in which the eIF4F cap-binding complex remains bound to the mRNA allowing 
sequential rounds of initiation by available eIF $2 \alpha$ complexes. When translation is inhibited via eIF4F, many transcripts will lack this cap binding complex and hence will not be competent to initiate translation. However, those transcripts that do contain eIF4F will be translated normally (Figure 8). A similar phenomenon has been observed for a subpopulation of mRNAs that contain 5' terminal oligopyrimidine tracts (5'TOPs), which alternate between translationally repressed and active states in response to various stimuli (reviewed in [41]). It is thus conceivable that the overall reduction in mRNA translation observed during prolonged hypoxia affects a subset of genes, such as those with 5 'TOPs, to a greater degree than others.

An important issue that arises from our study is the nature of the oxygen sensing pathways upstream of eIF $2 \alpha$ and eIF4F. Substantial evidence suggests that the oxygen sensors are largely independent of the HIF oxyen sensing pathway [42], [10]. In the case of eIF $2 \alpha$, its phosphorylation occurs in HIF independent manner. Instead it requires PERK activation [10] and is associated with activation of the unfolded protein response (UPR) in response to ER stress $[13,43]$. The upstream signaling that leads to eIF4F disruption is less clear, with perhaps both HIF dependent and independent components. Hypoxia has been shown to prevent insulin stimulation of mTOR and phosphorylation of its substrate 4E-BP1 during conditions of moderate hypoxia and serum starvation [28]. Similarly, Brugarolas and colleagues showed that induction of REDD1 during hypoxia resulted in activation of the mTOR inhibitory complex TSC1/TSC2 [44]. Since we also observe a decrease in the phosphorylation of 4E-BP1 after prolonged hypoxia, the eIF4F dependent changes in translation reported here may also be due in part to inhibition of mTOR via REDD1 and TSC1/2. However, it is unlikely that this accounts entirely for eIF4F disruption and translation inhibition during hypoxia. REDD1 is a HIF dependent gene and both mTOR inhibition and translation inhibition during hypoxia occur in HIF1 $\alpha$ knockout cells $[10,28]$. There is no evidence that inhibition of REDD1 signaling prevents the inhibition of translation during prolonged hypoxia. Furthermore, our data indicate that eIF4F disruption occurs prior to substantial binding of eIF4E to 4E-BP1. Here we have identified redistribution of eIF4E into the cell nucleus via $4 \mathrm{E}-\mathrm{T}$ as an additional mechanism for eIF4F disruption during hypoxia. Further work will be needed to establish to what degree inhibition of translation is due to suppression of mTOR/4E-BP1 phosphorylation and 4E-T activation, as well as to the requirements of HIF in both of these pathways. 
The fact that both eIF2 $\alpha$ and eIF4F independently affect translation during hypoxia has important implications for the regulation of gene expression. mRNAs preferentially translated during acute hypoxia must be less dependent on eIF $2 \alpha$ availability, while mRNAs that are actively translated during prolonged hypoxia must be less dependent on eIF4F. The translation of ATF4, which contains 2 upstream open reading frames (uORFs) in its 5'UTR is perhaps the best example of a mammalian gene that displays this type of preferential translation [16]. When eIF $2 \alpha$ availability is high, translation begins at the 5 ' most uORF and re-initiation occurs efficiently at the subsequent uORF preventing translation from the correct start codon of ATF4. When eIF2 $\alpha$ is phosphorylated, there is a higher probability of skipping the second uORF and re-initiating at the bona fide start codon [45]. Here, we found that in addition to ATF4, the downstream genes CHOP and GADD34 are also translationally induced during acute hypoxia. The S51A MEFs which are unable to phosphorylate eIF $2 \alpha$ are defective in this translational regulation. This result is consistent with a report showing that that ER stress-induced expression of GADD34 protein can be prevented by keeping eIF2 $\alpha$ dephosphorylated [46], The ability of GADD34 to bypass the inhibitory effects of eIF2 $\alpha$ phosphorylation may be responsible for its ability to provide the negative feedback necessary for dephosphorylation of eIF $2 \alpha$ and recovery from ER stress.

Our results predict that during prolonged hypoxia, gene transcripts with lower dependency on eIF4F should be preferentially translated. The translation of ATF4 and CHOP was in fact stimulated in HeLa cells after 16 hours of hypoxia when the eIF4F complex was disrupted. Preferential translation under conditions of limiting cap-binding complex activity can occur through a higher than average affinity for eIF4F [47]. Another group of mRNAs that can be translated independently of the eIF4F complex are those that contain an internal ribosomal entry site (IRES) in their 5'UTR [21, 48]. The presence of an IRES enables translation initiation under conditions where eIF4F dependent translation is inhibited. Importantly, both mouse HIF-1 $\alpha$ and VEGF have been shown to contain functional IRESes within their 5'UTR [49, 50], although their biological importance is not yet firmly established. This provides a mechanism to ensure their translation during prolonged hypoxia where eIF4F is disrupted. The mechanism responsible for the selective translation of ATF4 and CHOP during prolonged hypoxia remains to be identified. 
In conclusion, we have shown that mRNA translation is inhibited through multiple independent pathways with differing activation kinetics during hypoxia. These distinct modes of translational control influence the translation of individual genes to varying degrees and consequently can influence hypoxia regulated protein expression in complex ways. An important finding is that inhibition of translation via eIF $2 \alpha$ is transient leading to dynamic changes in the translation efficiency of genes over the first 8 hours of hypoxia. Our selected analysis of gene translation during hypoxia suggests that many genes may be differentially regulated by hypoxia. A complete survey of the genome for differentially translated genes during various exposures to hypoxia and their dependence of eIF $2 \alpha$ is possible and will undoubtedly identify novel and important hypoxia regulated proteins.

\section{ACKNOWLEGDEMENTS}

This work was financially supported by Netherlands Organization for Scientific Research (NWO), the Dutch Cancer Society (KWF Kankerbestrijding) and the Euroxy grant from the $6^{\text {th }}$ framework of the EU to B.G.W., from the Norwegian Research Council to M.K., and from grant CA94214 from the National Institutes of Health (NIH) to C.K. 


\section{REFERENCES}

[1] Wouters, BG, Weppler, SA, Koritzinsky, M, et al. Hypoxia as a target for combined modality treatments. Eur J Cancer 2002;38:240-257.

[2] Harris, AL. Hypoxia--a key regulatory factor in tumour growth. Nat Rev Cancer 2002;2:38-47.

[3] Graeber, TG, Osmanian, C, Jacks, T, et al. Hypoxia-mediated selection of cells with diminished apoptotic potential in solid tumours. Nature 1996;379:88-91.

[4] Semenza, GL. Targeting HIF-1 for cancer therapy. Nat Rev Cancer 2003;3:721-732.

[5] Tang, N, Wang, L, Esko, J, et al. Loss of HIF-1alpha in endothelial cells disrupts a hypoxia-driven VEGF autocrine loop necessary for tumorigenesis. Cancer Cell 2004;6:485-495.

[6] Ryan, HE, Lo, J, Johnson, RS. HIF-1 alpha is required for solid tumor formation and embryonic vascularization. Embo J 1998; 17:3005-3015.

[7] Leek, RD, Stratford, I, Harris, AL. The role of hypoxia-inducible factor-1 in three-dimensional tumor growth, apoptosis, and regulation by the insulin-signaling pathway. Cancer Res 2005;65:4147-4152.

[8] Cardenas-Navia, LI, Yu, D, Braun, RD, Brizel, DM, Secomb, TW, Dewhirst, MW. Tumor-dependent kinetics of partial pressure of oxygen fluctuations during air and oxygen breathing. Cancer Res 2004;64:6010-6017.

[9] Bennewith, KL, Durand, RE. Quantifying transient hypoxia in human tumor xenografts by flow cytometry. Cancer Res 2004;64:6183-6189.

[10] Koumenis, C, Naczki, C, Koritzinsky, M, et al. Regulation of Protein Synthesis by Hypoxia via Activation of the Endoplasmic Reticulum Kinase PERK and Phosphorylation of the Translation Initiation Factor eIF2alpha. Mol Cell Biol 2002;22:7405-7416. 
[11] Wouters, BG, van den Beucken, T, Magagnin, MG, Koritzinsky, M, Fels, D, Koumenis, C. Control of the hypoxic response through regulation of mRNA translation. Semin Cell Dev Biol 2005;16:487501.

[12] Erler, JT, Cawthorne, CJ, Williams, KJ, et al. Hypoxia-mediated downregulation of Bid and Bax in tumors occurs via hypoxia-inducible factor 1-dependent and -independent mechanisms and contributes to drug resistance. Mol Cell Biol 2004;24:2875-2889.

[13] Bi, M, Naczki, C, Koritzinsky, M, et al. ER stress-regulated translation increases tolerance to extreme hypoxia and promotes tumor growth. Embo J 2005;24:3470-3481.

[14] Lefebvre, VH, Van Steenbrugge, M, Beckers, V, Roberfroid, M, BucCalderon, P. Adenine nucleotides and inhibition of protein synthesis in isolated hepatocytes incubated under different pO2 levels. Arch Biochem Biophys 1993;304:322-331.

[15] Johannes, G, Carter, MS, Eisen, MB, Brown, PO, Sarnow, P. Identification of eukaryotic mRNAs that are translated at reduced cap binding complex eIF4F concentrations using a cDNA microarray. Proc Natl Acad Sci U S A 1999;96:13118-13123.

[16] Harding, HP, Novoa, I, Zhang, Y, et al. Regulated translation initiation controls stress-induced gene expression in mammalian cells. Mol Cell 2000;6:1099-1108.

[17] Holland, EC, Sonenberg, N, Pandolfi, PP, Thomas, G. Signaling control of mRNA translation in cancer pathogenesis. Oncogene 2004;23:31383144 .

[18] Schroder, M, Kaufman, RJ. The Mammalian Unfolded Protein Response. Annu Rev Biochem 2005;74:739-789.

[19] Harding, HP, Zhang, Y, Zeng, H, et al. An integrated stress response regulates amino acid metabolism and resistance to oxidative stress. Mol Cell 2003;11:619-633. 
[20] Gebauer, F, Hentze, MW. Molecular mechanisms of translational control. Nat Rev Mol Cell Biol 2004;5:827-835.

[21] Holcik, M, Sonenberg, N. Translational control in stress and apoptosis. Nat Rev Mol Cell Biol 2005;6:318-327.

[22] Hay, N, Sonenberg, N. Upstream and downstream of mTOR. Genes Dev 2004;18:1926-1945.

[23] DeGracia, DJ, Kumar, R, Owen, CR, Krause, GS, White, BC. Molecular pathways of protein synthesis inhibition during brain reperfusion: implications for neuronal survival or death. J Cereb Blood Flow Metab 2002;22:127-141.

[24] Neumar, RW, DeGracia, DJ, Konkoly, LL, Khoury, JI, White, BC, Krause, GS. Calpain mediates eukaryotic initiation factor 4G degradation during global brain ischemia. J Cereb Blood Flow Metab 1998;18:876-881.

[25] Martin de la Vega, C, Burda, J, Nemethova, M, et al. Possible mechanisms involved in the down-regulation of translation during transient global ischaemia in the rat brain. Biochem J 2001;357:819826.

[26] Martin, ME, Munoz, FM, Salinas, M, Fando, JL. Ischaemia induces changes in the association of the binding protein 4E- BP1 and eukaryotic initiation factor (eIF) $4 \mathrm{G}$ to eIF4E in differentiated PC12 cells. Biochem J 2000;351 Pt 2:327-334.

[27] Tinton, SA, Buc-Calderon, PM. Hypoxia increases the association of 4E-binding protein 1 with the initiation factor $4 \mathrm{E}$ in isolated rat hepatocytes. FEBS Lett 1999;446:55-59.

[28] Arsham, AM, Howell, JJ, Simon, MC. A novel hypoxia-inducible factor-independent hypoxic response regulating mammalian target of rapamycin and its targets. J Biol Chem 2003;278:29655-29660. 
[29] Scheuner, D, Song, B, McEwen, E, et al. Translational control is required for the unfolded protein response and in vivo glucose homeostasis. Mol Cell 2001;7:1165-1176.

[30] Koritzinsky, M, Seigneuric, R, Magagnin, MG, Beucken, T, Lambin, P, Wouters, BG. The hypoxic proteome is influenced by gene-specific changes in mRNA translation. Radiother Oncol 2005;76:177-186.

[31] Kimball, SR, Jefferson, LS. Regulation of translation initiation in mammalian cells by amino acids. In: Sonenberg N, Hershey JW, Mathews MB, editors. Translational control of gene expression, Cold Spring Harbor: Cold Spring Harbor Laboratory Press. 2000;561-579.

[32] Pause, A, Belsham, GJ, Gingras, AC, et al. Insulin-dependent stimulation of protein synthesis by phosphorylation of a regulator of 5'cap function. Nature 1994;371:762-767.

[33] Lejbkowicz, F, Goyer, C, Darveau, A, Neron, S, Lemieux, R, Sonenberg, N. A fraction of the mRNA 5' cap-binding protein, eukaryotic initiation factor 4E, localizes to the nucleus. Proc Natl Acad Sci U S A 1992;89:9612-9616.

[34] Dostie, J, Ferraiuolo, M, Pause, A, Adam, SA, Sonenberg, N. A novel shuttling protein, 4E-T, mediates the nuclear import of the mRNA 5' cap-inding protein, eIF4E. Embo J 2000;19:3142-3156.

[35] Andrei, MA, Ingelfinger, D, Heintzmann, R, Achsel, T, Rivera-Pomar, R, Luhrmann, R. A role for eIF4E and eIF4E-transporter in targeting mRNPs to mammalian processing bodies. Rna 2005;11:717-727.

[36] Robertson, N, Potter, C, Harris, AL. Role of carbonic anhydrase IX in human tumor cell growth, survival, and invasion. Cancer Res 2004;64:6160-6165.

[37] Blais, JD, Filipenko, V, Bi, M, et al. Activating transcription factor 4 is translationally regulated by hypoxic stress. Mol Cell Biol 2004;24:7469-7482. 
[38] Fawcett, TW, Martindale, JL, Guyton, KZ, Hai, T, Holbrook, NJ. Complexes containing activating transcription factor (ATF)/cAMPresponsive-element-binding protein (CREB) interact with the CCAAT/enhancer-binding protein (C/EBP)-ATF composite site to regulate Gadd153 expression during the stress response. Biochem $\mathrm{J}$ 1999;339 ( Pt 1):135-141.

[39] Novoa, I, Zeng, H, Harding, HP, Ron, D. Feedback inhibition of the unfolded protein response by GADD34-mediated dephosphorylation of eIF2alpha. J Cell Biol 2001;153:1011-1022.

[40] Marciniak, SJ, Yun, CY, Oyadomari, S, et al. CHOP induces death by promoting protein synthesis and oxidation in the stressed endoplasmic reticulum. Genes Dev 2004;18:3066-3077.

[41] Meyuhas, O, Hornstein, E. Translational control of TOP mRNAs. In: Sonenberg N, Hershey JW, Mathews MB, editors. Translational control of gene expression, Cold Spring Harbor: Cold Spring Harbor Laboratory Press. 2000;671-694.

[42] Jaakkola, P, Mole, DR, Tian, YM, et al. Targeting of HIF-alpha to the von Hippel-Lindau ubiquitylation complex by O2-regulated prolyl hydroxylation. Science 2001;292:468-472.

[43] Romero-Ramirez, L, Cao, H, Nelson, D, et al. XBP1 is essential for survival under hypoxic conditions and is required for tumor growth. Cancer Res 2004;64:5943-5947.

[44] Brugarolas, J, Lei, K, Hurley, RL, et al. Regulation of mTOR function in response to hypoxia by REDD1 and the TSC1/TSC2 tumor suppressor complex. Genes Dev 2004;18:2893-2904.

[45] Lu, PD, Harding, HP, Ron, D. Translation reinitiation at alternative open reading frames regulates gene expression in an integrated stress response. J Cell Biol 2004;167:27-33.

[46] Novoa, I, Zhang, Y, Zeng, H, Jungreis, R, Harding, HP, Ron, D. Stressinduced gene expression requires programmed recovery from translational repression. Embo J 2003;22:1180-1187. 
[47] Lawson, TG, Cladaras, MH, Ray, BK, et al. Discriminatory interaction of purified eukaryotic initiation factors $4 \mathrm{~F}$ plus $4 \mathrm{~A}$ with the $5^{\prime}$ ends of reovirus messenger RNAs. J Biol Chem 1988;263:7266-7276.

[48] Carter, MS, Kuhn, KM, Sarnow, P. Cellular internal ribosome entry site elements and the use of cDNA microarrays in their investigation. In: Sonenberg N, Hershey JW, Mathews MB, editors. Translational control of gene expression, Cold Spring Harbor: Cold Spring Harbor Laboratory Press. 2000;615-636.

[49] Lang, KJ, Kappel, A, Goodall, GJ. Hypoxia-inducible Factor-1alpha mRNA Contains an Internal Ribosome Entry Site That Allows Efficient Translation during Normoxia and Hypoxia. Mol Biol Cell 2002;13:1792-1801.

[50] Stein, I, Itin, A, Einat, P, Skaliter, R, Grossman, Z, Keshet, E. Translation of vascular endothelial growth factor mRNA by internal ribosome entry: implications for translation under hypoxia. Mol Cell Biol 1998;18:3112-3119. 
Chapter 2 


\section{Chapter 3}

The hypoxic proteome is influenced by gene-specific changes in mRNA translation

M. Koritzinsky, R. Seigneuric, M.G.P. Magagnin, T. van den Beucken, P. Lambin and B.G. Wouters

Radiother Oncol. 76: 177-186, 2005 


\section{ABSTRACT}

Hypoxia causes a rapid reduction in mRNA translation efficiency. This inhibition does not affect all mRNA species to the same extent and can therefore contribute significantly to hypoxia-induced differential protein expression. Our aim in this study was to characterize changes in gene expression during acute hypoxia and evaluate the contribution of regulation via mRNA translation on these changes. For each gene, the contribution of changes in mRNA abundance versus mRNA translation was determined. DU145 prostate carcinoma cells were exposed to 4 hours of hypoxia $(<0.02 \%$ $\mathrm{O}_{2}$ ). Efficiently translated mRNAs were isolated by sedimentation through a sucrose gradient. Affymetrix microarray technology was used to evaluate both the transcriptional and translational contribution to gene expression. Results were validated by quantitative PCR. 120 genes were more than 4-fold upregulated by hypoxia in the efficiently translated fraction of mRNA, in comparison to only 76 genes at the level of transcription. Of the 50 genes demonstrating the largest changes in translation, 11 were found to be more than 2 -fold over represented in the translated fraction in comparison to their overall transcriptional level. The gene with the highest translational contribution to its induction was CITED-2, which is a negative regulator of HIF-1 transcriptional activity. Gene-specific regulation of mRNA translation contributes significantly to differential gene expression during hypoxia. 


\section{INTRODUCTION}

The presence of hypoxic (poorly oxygenated) areas in human solid tumors is well documented [1-9]. Hypoxia causes radiation resistance and limits radiotherapy efficacy $[2-4,10,11]$. Tumor hypoxia has also been associated with a lower susceptibility to apoptosis $[12,13]$, increased angiogenesis [1417] as well as higher metastatic and invasive potential [2, 10, 18-20]. The cellular response to hypoxia which underlies its negative impact on tumor biology is believed to be due in large part to dynamic changes in gene expression.

A vast number of hypoxia-induced changes in gene expression have been described. There has been particular focus on changes mediated through the hypoxia inducible transcription factor HIF-1. HIF-1 promotes transcription of its target genes through binding a conserved hypoxia responsive element (HRE) gene promoter together with its co activator CBP/p300. More than 60 putative downstream target genes have been identified (for a review see [21]), including genes involved in glycolysis (e.g. PGK-1) [22], angiogenesis (e.g. VEGF) [23, 24], pH regulation (CA9) and survival (e.g. EPO) [25, 26]. HIF-1 is activated during hypoxia through protein stabilization of its subunit HIF-1 $\alpha$, which is targeted for ubiquitin mediated degradation by pVHL (von-Hippel Lindau) during normoxia [27].

Although the transcriptional response to hypoxia is clearly very important, cells in normal and cancerous tissue often experience short transient exposures to hypoxia which do not allow sufficient time for a productive transcriptional response [28-30]. However, a biological response to acute hypoxia is presumably required to maintain energy homeostasis and provide adaptation to the quickly changing redox microenvironment. A potentially important point for regulating gene expression that is able to respond rapidly to changes in the microenvironment is the process of mRNA translation (protein synthesis). Indeed, it has been shown that overall mRNA translation is severely but reversibly inhibited during hypoxic conditions [13, 31, 32], and this inhibition can be detected after only a few minutes of oxygen deprivation. The hypoxia-induced inhibition in mRNA translation is at least in part mediated through PERK-dependent phosphorylation of the translation initiation factor eIF2 $\alpha$ [31]. PERK is known to be activated in response to endoplasmic 
reticulum (ER) stress suggesting a possible mechanism through which oxygen activates this pathway.

Protein synthesis is the highest cellular consumer of ATP [33, 34], and thus its inhibition during hypoxia probably serves to maintain energy homeostasis. However, it is important to realize that the inhibition of global mRNA translation potentially affects different mRNA species (different genes) to highly varying degrees. This variation is based on the fact that mRNAs from different genes have different dependencies and/or affinities for the cellular translation machinery $[35,36]$. Thus while some mRNAs may be completely dependent on the translation factors that are inhibited during hypoxia, others can remain translated through alternative mechanisms and thereby bypass the overall translation block. For example, the transcription factor ATF-4 is translationally induced by ER stress in spite of PERK-dependent eIF2 $\alpha$ phosphorylation [35], and ATF-4 in turn causes transcriptional activation of a conserved gene expression program called the unfolded protein response (UPR) (reviewed in [37]). Hence, the inhibition of overall translation is a potentially powerful cellular tool for rapidly changing gene expression during hypoxia.

In this study, our aim was to evaluate the translational contribution to differential gene expression during acute hypoxia. Utilizing Affymetrix microarray technology we here show that there are significant changes in genespecific mRNA translation efficiency during hypoxia.

\section{MATERIALS AND METHODS}

\section{Cell culture and hypoxic conditions}

Exponentially growing cervical (HeLa) and prostate (DU145) carcinoma cells were seeded on glass dishes in DMEM or McCoy media with $10 \%$ foetal calf serum (FCS) (Sigma-Aldrich) and transferred to a hypoxic culture chamber (MACS VA500 microaerophilic workstation, Don Whitley Scientific, Shipley, UK). The atmosphere in the chamber consisted of $5 \% \mathrm{H}_{2}, 5 \% \mathrm{CO}_{2}$, the desired concentration of $\mathrm{O}_{2}$ and residual $\mathrm{N}_{2}$. An anoxic atmosphere was ensured by the inclusion of a catalyst in the hypoxic chamber that catalysed the conversion of $\mathrm{H}_{2}$ with any $\mathrm{O}_{2}$ to $\mathrm{H}_{2} \mathrm{O}$. 


\section{D gel electrophoresis}

Cells were washed twice with ice-cold $10 \mathrm{mM}$ Tris/250 $\mathrm{mM}$ sucrose buffer $\mathrm{pH}$ 7.0 and lysed in a $7 \mathrm{M}$ urea/2 $\mathrm{M}$ thiourea based lysisbuffer. The samples were applied to $24 \mathrm{~cm} \mathrm{pH} \mathrm{3-10} \mathrm{NL} \mathrm{IPG} \mathrm{strips} \mathrm{(Amersham} \mathrm{Biosciences).} \mathrm{Following}$ isoelectric focusing, the strips were placed on the Protean Plus Dodeca Cell (Bio-Rad Laboratories) to perform a second dimension separation using 12\% SDS-PAGE gels. The gels were stained with SYPRO Ruby dye (Bio-Rad Laboratories) and imaged on a Molecular Imager FX (Bio-Rad Laboratories).

\section{Polysomal fractionation and analysis}

Cells were treated with $0.1 \mathrm{mg} / \mathrm{ml}$ cycloheximide $(\mathrm{CHX})$ for $3 \mathrm{~min}$ at $37^{\circ} \mathrm{C}$, washed twice with ice cold PBS/CHX and harvested by scraping in lysis buffer ( $1 \%$ Triton $\mathrm{X}-100,0.3 \mathrm{M} \mathrm{NaCl}, 15 \mathrm{mM} \mathrm{MgCl} 2,15 \mathrm{mM}$ Tris $(\mathrm{pH} 7.4), 0.1 \mathrm{mg} / \mathrm{ml}$ CHX, 100 units RNAse-In (Ambion)) at $4{ }^{\circ} \mathrm{C}$. Nuclei were removed, 200ug/ml heparin was added and residual debris was removed by centrifugation. The lysate was layered on a $10 \mathrm{ml}$ continuous sucrose gradient $(20-50 \%$ sucrose in $15 \mathrm{mM} \mathrm{MgCl} 2,15 \mathrm{mM}$ Tris ( $\mathrm{pH} 7.4$ ), $0.3 \mathrm{M} \mathrm{NaCl}$ ). After $90 \mathrm{~min}$ of centrifugation at $39.000 \mathrm{rpm}$ in an SW41-Ti rotor at $4^{\circ} \mathrm{C}$, the absorbance at $254 \mathrm{~nm}$ was measured continuously as a function of gradient depth in a BioRad Laboratories UV monitor. To assess overall translation efficiency, we integrated the area under the curve that represented mRNA attached to 2 or more ribosomes, and compared this to the total area under the curve.

\section{RNA isolation}

Samples were collected in $0.55 \mathrm{M}$ final concentration of guanidinium- $\mathrm{HCl}$, subjected to 4 precipitation steps (ethanol, sodium acetate and lithium chloride), one phenol-chloroform extraction and one column extraction (RNeasy Mini Kit, Qiagen) with extensive washing in between. RNA quantity and quality was checked using the ND-1000 spectrometer (NanoDrop Technologies) and RNA Nano LabChip kit on the 2100 Bioanalyzer (Agilent) respectively.

\section{Affymetrix gene array measurements}

20 ng RNA was pooled from 3 independent experiments, representing total and highly efficiently translated RNA from aerobic and hypoxic cells. The RNA was processed according to the manufacturer's standard protocol (Affymetrix) for 2-cycle amplification. The biotin-labelled samples were hybridized to $\mathrm{HG}$ U133 Plus 2.0 chips. GCOS software (Affymetrix) was used for the absolute 
call (present, marginal, absent) of 54.675 probe sets. Intensities were filtered with a threshold of 200. Two lists of genes were generated by sorted according to (Polysomal Hypoxia)/(Polysomal Normoxia) intensity ratios or (Total Hypoxia)/(Total Normoxia) intensity ratios respectively.

\section{Quantitative PCR analysis}

The RNA was reverse transcribed using random decamers (Ambion) and MML reverse transcriptase (Sigma-Aldrich). Real-time PCR was performed in ABI 7500 (Applied Biosystems). The abundance of the following genes were detected with SYBR ${ }^{\circledR}$ Green I (Applied Biosystems) using the indicated forward and reverse primers: $\beta$-Actin: F-accatggatgatgatatcgec and Rgecttgcacatgcegg; ATF-4: F-tggccaagcacttcaaacet and Rgttgttggagggactgaccaa; DDIT3: F-ggagcatcagtccccactt and Rtgtgggattgagggtcacatc; VEGF: F-gactccggcggaagcat and R- tccgggctcggtgattta. The following genes were measured using TaqMan ${ }^{\circledR}$ Gene Expression Assays (Applied Biosystems): 18SrRNA: Hs99999901_s1 and EGLN3: Hs00222966_m1. The abundance of every gene was calculated using standard curves, and the relative gene abundances were normalized by $18 \mathrm{~S}$ signal.

\section{RESULTS}

We have reported that hypoxia results in a rapid inhibition of mRNA translation. In order to investigate the potential contribution of this inhibition on protein expression we analyzed the cellular proteome after short (1 hr) and long $(24 \mathrm{hrs})$ exposures to hypoxia. The proteome from aerobic or hypoxic HeLa cells was separated in two dimensions on the basis of charge and mass and proteins visualized by staining with SYPRO-Ruby. The early time point (1hr) was chosen to minimize the contribution of changes in transcription on protein expression. Thus, most of the changes in protein expression are due to post-transcriptional changes including the inhibition of mRNA translation which is maximal at this time. We compared the results at $1 \mathrm{hr}$ with the proteomic changes in chronically $(24 \mathrm{hrs})$ hypoxic cells, where differential gene expression was assumed to be affected by both transcriptional and posttranscriptional changes. This allowed us to assess the relative importance of post-transcriptional regulation during hypoxia. This experiment was repeated in triplicate thus producing 3 separate $2 \mathrm{D}$-gels for each condition (representative gels from each experimental condition are shown in Figure 1A). 
Proteins were matched across all gels to identify those that consistently showed changes during each of the experiments. The levels of these matched proteins during hypoxia and normoxia are plotted in Figure 1B.

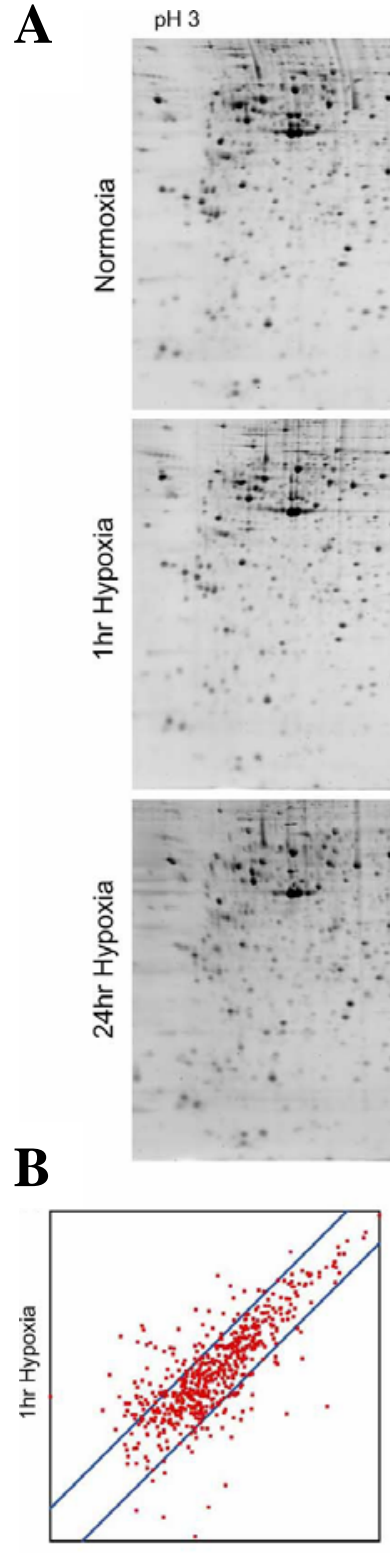

Normoxia

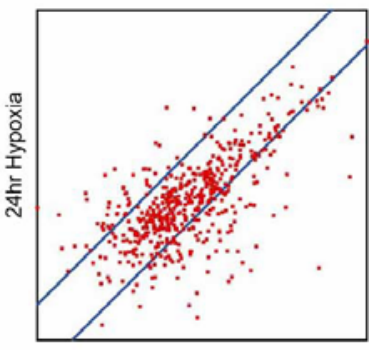

Normoxia
Figure 1: Hypoxia-induced changes in the proteome. HeLa cells were exposed to hypoxia for 0,1 or $24 \mathrm{hrs}$. Whole cell extracts were separated by 2D gel electrophoresis. (A) The resolved proteins were stained with SYPRO Ruby dye and imaged on the Molecular Imager FX (Bio-Rad). (B) The gels were analysed using PDQuest software (Bio-Rad). The relative abundance of each matched protein during normoxia vs. hypoxia was plotted with the diagonal lines representing 2-fold changes. 
Table 1 also lists the number of protein spots that showed strong consistent expression under one condition, but were not present in the other. These spots are therefore likely to represent real induced or repressed proteins, and are not a result of technical artifacts. The substantial change in the hypoxic proteome visible within 1 hour suggests that post-transcriptional events are important regulators of protein expression under these conditions.

Table 1: Hypoxia-induced changes in the proteome

\begin{tabular}{cccccc}
\hline $\begin{array}{c}\text { Hours of } \\
\text { hypoxia }\end{array}$ & $\begin{array}{c}\text { Detected } \\
\text { proteins }\end{array}$ & $\begin{array}{c}\text { Matched } \\
\text { proteins }\end{array}$ & $\begin{array}{c}>\text { 2-fold } \\
\text { change }\end{array}$ & $\begin{array}{c}\text { Present only } \\
\text { in normoxia }\end{array}$ & $\begin{array}{c}\text { Present only } \\
\text { in hypoxia }\end{array}$ \\
\hline 0 & 1440 & & & & \\
1 & 982 & 685 & 70 & 30 & 10 \\
24 & 1102 & 882 & 77 & 20 & 25 \\
\hline
\end{tabular}

Regulation of mRNA translation efficiency, which is known to occur during hypoxia, is a possible mechanism that can influence the rapid changes in protein expression shown above. To assess overall mRNA translation efficiency in DU145 cells during hypoxic conditions, we separated cell lysates on sucrose gradients and then measured RNA levels as a function of gradient depth. The resulting profiles are shown in Figure 2A. The two shallowest peaks (readily detected in the aerobic sample) represent the $40 \mathrm{~S}$ and $60 \mathrm{~S}$ ribosomal subunits respectively. The subsequent peaks represent mRNAs with increasing numbers of attached ribosomes. Efficiently translated mRNA is associated with many ribosomes (polysomes) simultaneously and therefore sediments deep in the gradient. Figure 2A demonstrates that hypoxia inhibits overall translation in DU145 cells since there is a clear reduction in the high molecular weight polysomal RNA. The percentage of ribosomes participating in translation can be determined by integrating the polysomal area and dividing by the total integrated area. The average results from three independent experiments are presented in Figure 2B. This figure shows that the fraction of ribosomes participating in translation dropped from $74 \%$ in aerobic cells to $45 \%$ after 4 hours of hypoxia. We also calculated the fraction participating in highly efficient translation (Figure 2A), which we defined as mRNA with 5 or more ribosomes. This fraction dropped from $48 \%$ to $20 \%$ after 4 hours of hypoxia.

In order to investigate the potential contribution of changes in mRNA translation on hypoxia induced gene expression, we utilized microarray 
technology. Changes in mRNA translation were assessed by isolating RNA from the highly efficiently translated polysomal fractions as depicted in Figure 2A. Transcriptional changes were assessed by isolating total mRNA from the same samples. Since this technique allowed us to evaluate both transcriptional and translational contributions to differential gene expression, we chose to measure these entities after 4 hours of hypoxia. At this time point both transcriptional and translational control of gene expression are expected to be active, and with the microarray technique we could directly compare these events. In addition to providing more information, this also allowed us to validate our results through literature comparison, since many hypoxia-induced transcriptional changes are well described. Equivalent RNA amounts from three independent experiments from cultures growing under normoxia or following 4 hours of hypoxia were pooled and then assessed using Affymetrix microarray chips containing 54,675 probe sets (including 38,500 wellcharacterized human genes).

A

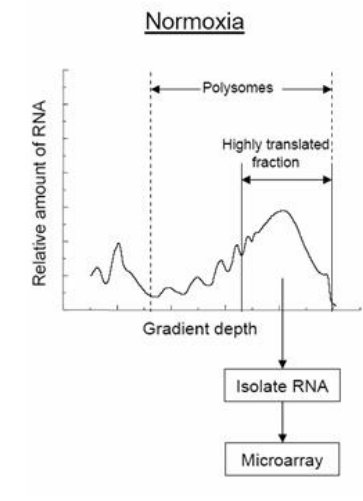

B

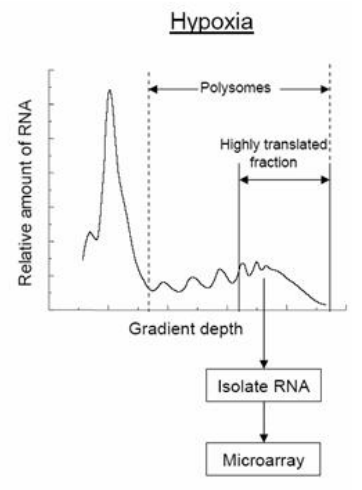

Figure 2: Hypoxia inhibits mRNA translation. DU145 cells were exposed to hypoxia for 0 or $4 \mathrm{~h}$. Whole cell extracts were separated by sedimentation through sucrose gradients. (A) Optical density (O.D.) at 254 $\mathrm{nm}$ as a function of depth in the gradient. The area representing RNA that participates in complexes containing 2 or more ribosomes is marked as 'polysomes'. RNA was isolated

for microarray and PCR analysis from the fraction indicated 'highly translated fraction'. (B) Quantification of translation efficiency as the percentage of rRNA participating in complexes of two or more ribosomes. This equals the integration of the area under the 'polysomes' part of the curve divided by the total area under the curve. The 'highly translated fraction' is also indicated. 
Figure 3 shows the scatter plots of gene intensities (log base 2) for hypoxic and aerobic samples. For all genes that demonstrate a less than 2-fold change during hypoxia, the plotted points fall within the two indicated parallel lines on these plots. Figure $3 \mathrm{~A}$ summarizes the transcriptional (total RNA) changes during hypoxia. Of the 22,332 gene probe sets that could be evaluated, $654(3 \%)$ were induced more than 2-fold during hypoxia with 76 of these increasing more than 4-fold. Changes in the highly translated RNA fraction are summarized in Figure 3B. In this highly translated fraction we found that 1082 genes $(\sim 5 \%)$ increased more than 2-fold during hypoxia with 120 of these increasing more than 4-fold. The amount of an individual gene in the highly translated mRNA fraction reflects both the total mRNA available for translation, as well as the gene's translation efficiency. However, since both the total mRNA and the highly translated fraction of mRNA are known, it is possible to calculate the relative translation efficiency for each gene on the array. This is simply equal to the signal in the highly translated fraction divided by the signal from the total cell. We calculated the translation efficiency for each gene under both aerobic and hypoxic conditions to determine those genes exhibiting the largest increases in translation efficiency. Figure 3C shows that the translation efficiency of 508 genes increased more than 2-fold with 41 of these increasing more than 3 -fold and 5 more than 4 -fold. These results demonstrate that although overall translation is inhibited during hypoxia, a significant number of genes are induced through specific increases in their translation efficiency. 


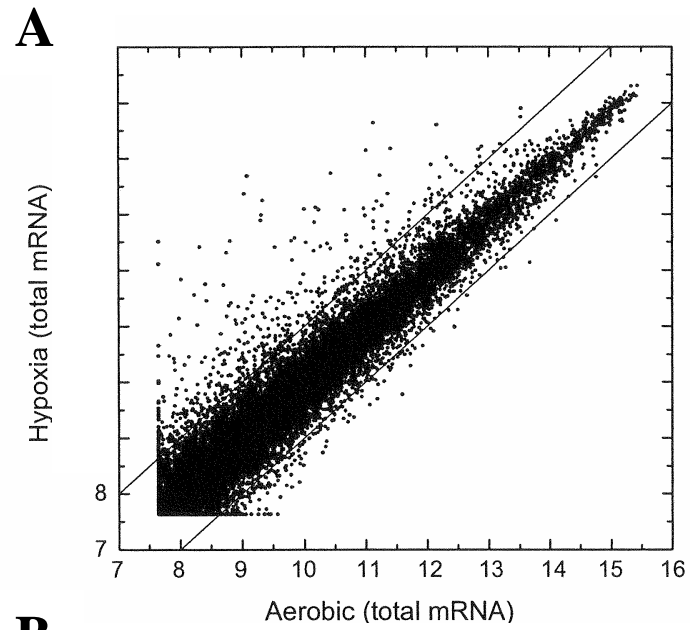

B

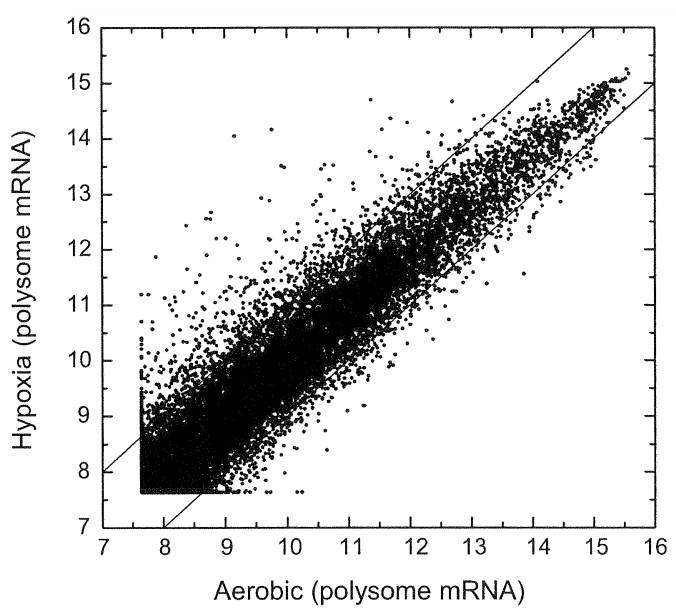

C

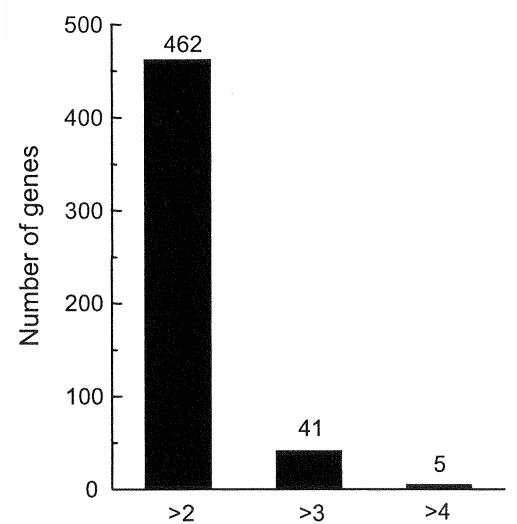

Fold increase in translational efficiency
Figure 3: Microarray signal distributions. DU145 cells were exposed to hypoxia for 0 or $4 \mathrm{~h}$. Whole cell extracts were separated by sedimentation through sucrose gradients. Equal amounts of RNA from three independent experiments were pooled. Gene-specific mRNA abundance in highly efficiently translated or unfractionated mRNA was measured using Affymetrix microarray technology. (A) and (B) Logarithm of raw (not normalized) intensities of probe sets under hypoxia vs. normoxia for total mRNA. The upper and lower diagonal lines represent the threshold for 2-fold expression changes. (A) Total, i.e. unfractionated mRNA in aerobic versus hypoxic samples. (B) mRNA with high translation efficiency in aerobic versus hypoxic samples. (C) Representation of the number of genes with hypoxia induced translation efficiency, calculated by dividing the gene abundance from the 'highly translated fraction' by that obtained from the unfractionated sample. 
Table 2 shows a ranked list of the 50 genes showing the largest increase in mRNA translation during hypoxia (derived from Figure 3B). Table 2 also lists the increase in total mRNA abundance and hence the component that can be attributed to changes in mRNA production and/or stability. The change in mRNA translation efficiency during hypoxia can be deduced by comparing these values. Of the 50 most highly induced genes, 11 demonstrated a significant contribution from changes in translation efficiency (more than 2fold increase in translation efficiency). For each of these genes, their rank within the top 50 was much higher than their rank evaluated by the increase in total mRNA levels.

Table 2: Genes most highly induced by hypoxia measured by microarray

\begin{tabular}{|c|c|c|c|c|c|c|c|c|c|}
\hline $\begin{array}{l}\text { Probe } \\
\text { Poly }\end{array}$ & $\begin{array}{l}\text { Gene } \\
\text { symbole }\end{array}$ & $\begin{array}{l}\text { Poly } \\
\text { rank }\end{array}$ & $\begin{array}{l}\text { Total } \\
\text { rank }\end{array}$ & $\begin{array}{l}\text { Ratio } \\
\text { poly }\end{array}$ & $\begin{array}{l}\text { Ratio } \\
\text { total }\end{array}$ & $\begin{array}{l}\text { Ratio } \\
\text { poly:total }\end{array}$ & $\begin{array}{l}\text { Hypoxia } \\
\text { induced }\end{array}$ & Pathway & Reference(s) \\
\hline 202934_at & $\mathrm{HK} 2$ & 1 & 2 & 30.1 & 24.6 & 1.2 & yes & HIF & {$[22,38]$} \\
\hline 221009_s_at & ANGPTL4 & 2 & 6 & 21.3 & 15.2 & 1.4 & yes & HIF & {$[39,40]$} \\
\hline 202769_at & $\mathrm{CCNG} 2$ & 3 & 1 & 16.7 & 29.4 & 0.6 & yes & HIF & {$[41,42]$} \\
\hline 209357_at & CITED2 & 4 & 42 & 16.0 & 5.4 & 3.0 & yes & HIF & {$[43,44]$} \\
\hline 217028_at & CXCR4 & 5 & 13 & 15.0 & 10.2 & 1.5 & yes & HIF & {$[38,45]$} \\
\hline 235857_at & KCTD11 & 6 & 7 & 14.6 & 14.3 & 1.0 & & & \\
\hline 218507_at & HIG2 & 7 & 30 & 13.9 & 6.7 & 2.1 & yes & HIF & {$[38,46]$} \\
\hline 204284_at & PPP1R3C & 8 & 10 & 12.1 & 12.1 & 1.0 & yes & HIF & {$[41,44]$} \\
\hline 229830_at & PDGFA & 9 & 20 & 11.7 & 8.2 & 1.4 & yes & & {$[47]$} \\
\hline 203438_at & STC2 & 10 & 9 & 11.5 & 12.9 & 0.9 & yes & HIF,UPR & {$[41,48]$} \\
\hline 227337_at & Lrp2bp & 11 & 14 & 10.8 & 10.1 & 1.1 & & & \\
\hline 242517_at & GPR54 & 12 & 5 & 10.2 & 17.2 & 0.6 & & & \\
\hline 223333_s_at & ANGPTL4 & 13 & 8 & 10.2 & 13.2 & 0.8 & yes & HIF & {$[39,40]$} \\
\hline 202887_s_at & DDIT4 & 14 & 12 & 10.1 & 11.5 & 0.9 & yes & HIF & {$[41,49]$} \\
\hline 202364_at & MXI1 & 15 & 47 & 9.6 & 5.2 & 1.8 & yes & HIF & {$[38]$} \\
\hline 209383_at & DDIT3 & 16 & 4 & 9.3 & 20.3 & 0.5 & yes & HIF,UPR & {$[50,51]$} \\
\hline 228499_at & PFKFB4 & 17 & 3 & 9.2 & 22.2 & 0.4 & yes & HIF & {$[44,52]$} \\
\hline 206424_at & CYP26A1 & 18 & 32 & 9.0 & 6.5 & 1.4 & & & \\
\hline 209201_x_at & CXCR4 & 19 & 21 & 8.6 & 8.1 & 1.1 & yes & HIF & {$[38,45]$} \\
\hline 218274_s_at & FLJ10415 & 20 & 75 & 8.4 & 4.0 & 2.1 & & & \\
\hline 212366_at & ZNF292 & 21 & 52 & 8.3 & 4.7 & 1.8 & & & \\
\hline 221567_at & NOL3 & 22 & 22 & 7.8 & 8.1 & 1.0 & & & \\
\hline 218149_s_at & ZNF395 & 23 & 62 & 7.8 & 4.3 & 1.8 & & & \\
\hline 201170_s_at & BHLHB2 & 24 & 26 & 7.5 & 7.2 & 1.0 & yes & HIF & {$[42,53]$} \\
\hline 201313_at & $\mathrm{ENO} 2$ & 25 & 67 & 7.5 & 4.1 & 1.8 & yes & & {$[44]$} \\
\hline 208763_s_at & DSIPI & 26 & 29 & 7.5 & 6.7 & 1.1 & & & \\
\hline
\end{tabular}




\begin{tabular}{llrrrrrrll} 
203574_at & NFIL3 & 27 & 24 & 7.5 & 7.7 & 1.0 & yes & & {$[41]$} \\
201466_saat & JUN & 28 & 36 & 7.5 & 6.0 & 1.2 & yes & HIF,UPR & {$[44,54,55]$} \\
205463_sat & PDGFA & 29 & 59 & 7.3 & 4.4 & 1.7 & yes & & {$[47]$} \\
202843_at & DNAJB9 & 30 & 16 & 7.3 & 9.0 & 0.8 & & UPR & {$[56]$} \\
226863_at & & 31 & 123 & 7.3 & 3.4 & 2.2 & & & \\
231798_at & NOG & 32 & 23 & 7.0 & 7.8 & 0.9 & & & \\
1554452_aaat & HIG2 & 33 & 19 & 6.8 & 8.3 & 0.8 & yes & HIF & {$[38,46]$} \\
203439_saat & STC2 & 34 & 18 & 6.8 & 8.6 & 0.8 & yes & HIF,UPR & {$[41,48]$} \\
215446_saat & LOX & 35 & 114 & 6.8 & 3.4 & 2.0 & yes & HIF & {$[38,44]$} \\
212368_at & ZNF292 & 36 & 37 & 6.7 & 5.8 & 1.2 & & & \\
202973_x_at & FAM13A1 & 37 & 68 & 6.7 & 4.1 & 1.6 & & & \\
200632_saat & NDRG1 & 38 & 17 & 6.4 & 8.9 & 0.7 & yes & HIF & {$[44,57]$} \\
241348_at & FLJ10997 & 39 & 130 & 6.3 & 3.3 & 1.9 & & & \\
1554462_aaat & DNAJB9 & 40 & 35 & 6.2 & 6.1 & 1.0 & & UPR & {$[56]$} \\
210512_saat & VEGF & 41 & 39 & 6.1 & 5.6 & 1.1 & yes & HIF,UPR & {$[22,57-59]$} \\
204285_saat & PMAIP1 & 42 & 159 & 6.1 & 3.0 & 2.0 & yes & HIF & {$[60]$} \\
209339_at & SIAH2 & 43 & 459 & 6.0 & 2.2 & 2.7 & yes & & {$[61]$} \\
211527_x_at & VEGF & 44 & 270 & 5.9 & 2.5 & 2.3 & yes & HIF,UPR & {$[22,57-59]$} \\
224610_at & RNU22 & 45 & 286 & 5.9 & 2.5 & 2.4 & & & \\
202672_s_at & ATF3 & 46 & 11 & 5.6 & 12.0 & 0.5 & & UPR & {$[62]$} \\
224797_at & ARRDC3 & 47 & 56 & 5.5 & 4.6 & 1.2 & & & \\
224741_x_at & GAS5 & 48 & 277 & 5.5 & 2.5 & 2.2 & yes & & {$[63]$} \\
219232_saat & EGLN3 & 49 & 433 & 5.4 & 2.2 & 2.4 & yes & HIF & {$[64,65]$} \\
204286_saat & PMAIP1 & 50 & 174 & 5.4 & 2.9 & 1.9 & yes & HIF & {$[60]$} \\
& & & & & & & & & \\
\hline & & & & & & & & &
\end{tabular}

As shown in Table 2, a majority of the 50 genes showing the largest changes in translation have previously been shown to be induced by hypoxia either at the mRNA or protein level. This result helps to validate the results presented here. To further validate our microarray data, we performed quantitative real-time PCR (qPCR) on several of the genes shown to be transcriptionally upregulated. The results from these validation experiments are shown in Figure 4. As a negative control, we measured the abundance of $\beta$ actin, which was not induced by hypoxia on the microarray. As expected, $\beta$ actin was also not induced when measured by qPCR. We also measured the mRNA abundance for ATF-4, EGLN3, VEGF and DDIT3. The results from the qPCR were consistent with the data from the microarray. In general, the induction factors were somewhat higher when measured by qPCR. This might be related to the fact that the gene abundance using this method is normalized 
by the abundance of $18 \mathrm{~S}$ rRNA, which may fall slightly during hypoxia. Nonetheless, the qPCR results verified the data obtained by microarray analysis.

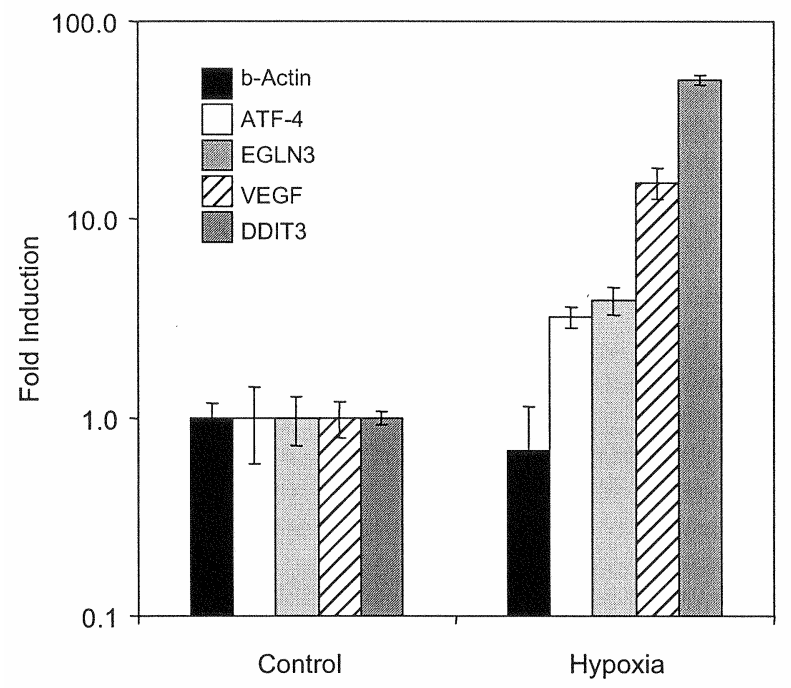

Figure 4: Microarray validation by quantitative PCR. DU145 cells were exposed to hypoxia for 0 or $4 \mathrm{~h}$. Gene-specific mRNA abundance was measured for $\beta$-Actin, ATF-4, EGLN3, VEGF and DDIT3 using quantitative real-time PCR. Gene abundance was normalized by $18 \mathrm{~S}$ rRNA signal and the induction factors were calculated using the abundance measured in three independent experiments. The standard error of the mean is shown.

\section{DISCUSSION}

There is substantial evidence that tumor oxygenation varies dynamically in time at frequencies that would be difficult to compensate for by changes in transcription. Thus, it is not clear to what degree the cellular proteome, and ultimately cell behavior, changes during acute exposures to hypoxia. To address this question we assessed the effect of both acute ( $1 \mathrm{hr})$ and chronic (24 hrs) hypoxia on the overall pool of expressed proteins. Both 1 hour and 24 hours of hypoxia clearly caused significant changes in the proteome, as demonstrated by a large number of proteins showing a greater than 2-fold change in expression. As listed in Table 1, significantly fewer protein spots were detected during hypoxia compared to normoxia, consistent with hypoxia- 
induced inhibition of mRNA translation (and transcription at later time points). Of the proteins that were detected in all conditions, approximately $10 \%$ changed their expression 2-fold or more during hypoxia. Of these, 59\% had increased expression during 1 hour hypoxia, versus 34\% after 24 hours. The results shown in Figure 1 and Table 1 demonstrate that significant changes in the proteome take place very early in the hypoxic exposure, at a time where transcriptional changes are thought to contribute to a negligible extent. These data provide evidence that a non-transcriptional mechanism is important for the changes in protein expression that occur during hypoxia. Although we argue that gene-specific mRNA translation can contribute significantly to the observed changes, other mechanisms may also be important contributors, including both mRNA and protein stabilization.

A strong suppression of mRNA translation was observed after 4 hours of hypoxia. However, the global decrease in translation efficiency assayed in this way represents the average reduction in translational efficiency for all genes. The change in translational efficiency for any particular gene under these conditions may differ significantly from this global average. This variability is thus a potentially important contribution to changes in protein expression during hypoxia. In order to evaluate this contribution we used microarrays to characterize both transcriptional and translational changes of individual genes. After 4 hours of hypoxia we found a substantially higher number of genes that showed significant increases in translation in comparison to the number showing only transcriptional changes. This is due to the fact that increased translation arises from increases in both mRNA abundance and in gene-specific translation efficiency. Importantly, these translated genes accurately reflect de novo protein production and thus are likely contributors to biological behavior. The gene found to show the largest increase in translation during hypoxia was the HIF-1 target gene hexokinase 2 (HK-2), which is involved in glucose metabolism [22]. The protein production of HK-2 increased by 30 -fold during 4 hours of hypoxia versus normoxia, while the mRNA abundance in the cells increased by 25 -fold. The interpretation of this result is that HK-2 is both transcriptionally and translationally induced, with the transcriptional component being dominant.

A majority of the genes showing the highest increases in translation have previously been shown to be targets of the HIF transcription factors (Table 2). The criteria for this annotation were non stringent and genes that 
contain putative HREs in their promoter, or that are induced by either overexpression of HIF or loss of pVHL have been included together with bona fide HIF targets. It is clear from the table that the potential influence of HIF through hypoxia-induced transcription is significant. However, the HIF target genes displayed a large spread in translation efficiency during hypoxia, ranging from 0.4 for PFKFB4 to 3.0 for CITED-2. CITED-2 was highly induced during hypoxia (number 4 on the list) with a 16-fold increase in translation and only a 5-fold increase in total mRNA. This gene product binds p300 and thereby inhibits the HIF-1-p300 interaction required for HIF-1-dependent gene transcription [43, 66]. Hypoxia has previously been shown to induce both mRNA and protein levels of CITED-2 [43], and the results presented here indicate that gene-specific up regulation of mRNA translation contributes significantly to the increased protein levels. Interestingly, the CITED-2 promoter also contains three HREs [43], indicating that it is a part of a negative feedback loop controlling expression of HIF-1 target genes. Apparently, CITED-2 mRNA is in addition able to bypass the overall repression of mRNA translation to ensure its robust expression during hypoxia.

Other genes that have a high translational component of induction include hypoxia-inducible protein 2 (HIG-2), MAX interactor 1 (MXI-1), zinc finger protein (ZNF) 292 and 395 and enolase 2 (ENO-2). As exemplified by HK-2 and CITED-2, several of the genes shown in Table 2 are induced both at the transcriptional level and through increased mRNA translation efficiency. It is conceptually not surprising that transcriptionally activated mRNA species possess the ability to be preferentially translated. Without this ability, the transcriptional induction would clearly be inefficient and result in uneconomical use of the cells limited energy sources.

The mechanistic basis for preferential translation is not well understood, although elements in the regulatory (i.e. untranslated) parts of the mRNA seem to be important. ATF-4 is an example of a gene that, paradoxically, is more efficiently translated during ER stress when global translation is inhibited through PERK-dependent eIF2 $\alpha$ phosphorylation [35]. PERK is also activated during hypoxia and necessary for at least a component of the hypoxia-induced inhibition in translation [31]. ATF-4 is thought to be translationally induced during eIF2 $\alpha$ phosphorylation because its upstream open reading frames (uORFs) in the $5^{\prime}$ untranslated region (5'UTR) of the mRNA prevent proper ribosome initiation under normal conditions [35]. Phosphorylation of eIF2 $\alpha$ makes initiation less efficient which increases the probability that ribosomes 
will read through the false uORFs and start translating at the bona fide start site. In our microarray, ATF-4 was indeed translationally induced during hypoxia, consistent with results from a previous microarray experiment performed after a longer hypoxia exposure in HeLa cells [67]. Here, we obtained an induction of 3.5 in the polysomes versus 2.3 in the totals, resulting in a poly/total ratio of 1.52 . It is also noteworthy that 8 of the 50 top induced genes listed in table 2 have been previously implicated in the UPR which requires ATF4 activation.

Gene-specific translation during hypoxia has also been reported for mouse HIF1- $\alpha$ and human VEGF. These genes have been reported to contain functional internal ribosomal entry sites (IRES) in their 5'UTR [68-71]. The presence of an IRES makes it possible for ribosomes to bind the mRNA independently of the 5' cap-structure, and therefore bypasses the requirement for certain translation factors. However, although it has been shown that the IRES-dependent translation is relatively less affected by the overall hypoxiainduced translation inhibition, it is not clear to which extent it contributes to overall protein expression and phenotype. HIF1- $\alpha$ did not appear as a translationally regulated gene on our list, perhaps indicating differences between mouse and human 5'UTRs in this gene. In contrast, VEGF was hypoxia-induced on our array and showed a poly/total ratio of 1.1 and 2.3 for two different probe sets. Many other genes had a higher contribution from changes in mRNA translation efficiency to their induction than ATF-4 and VEGF, and the molecular mechanisms responsible for this are yet to be identified.

An intriguing group of genes are those that have a large transcriptional induction, but not a corresponding increase in translation. (e.g. cyclin G2, GPR54, DDIT3, PFKFB4, ATF3). It is possible that this reflects different induction kinetics and that these genes will be efficiently translated after longer exposures to hypoxia. Our previous results have indicated that at least two distinct molecular pathways contribute to the inhibition of overall mRNA translation during acute and chronic hypoxia $[31,72]$. It is likely that a switch of molecular mechanisms can facilitate different groups of genes to be efficiently translated at different times. Another possibility is that the transcriptionally induced but translationally inhibited mRNAs produce proteins that are important in coping with the stress represented by reoxygenation. It may be important for the cells to have mRNA available to be translated as soon 
as oxygen is reintroduced and overall translation inhibition is reversed. It will thus be of interest to extend these studies of translation efficiency to cells exposed to hypoxia plus reoxygenation. Furthermore, our current results are limited to a single time point and a single oxygen concentration. It will be of interest to further evaluate the contribution of mRNA translation at a range of oxygen concentrations typical of those seen in tumors (i.e. $0.02 \%-5 \% \mathrm{O}_{2}$ ), and at different time points. The substantial change in the proteome observed as early as 1 hour after hypoxia suggests that translation control may also be important in these short exposures that may arise in vivo through transient changes in oxygenation.

In conclusion, we identified a large number of genes that demonstrate a selective ability to be translated during hypoxia exposure. Gene-specific regulation of translation therefore plays an important role in contributing to the hypoxic proteome.

\section{ACKNOWLEGDEMENTS}

This work was financially supported by Siemens, Netherlands Organization for Scientific Research (NWO) and the Dutch Cancer Society (KWF Kankerbestrijding). We thank Mieke Duysinx for technical assistance. 


\section{REFERENCES}

[1] Knocke, TH, Weitmann, HD, Feldmann, HJ, Selzer, E, Potter, R. Intratumoral pO2-measurements as predictive assay in the treatment of carcinoma of the uterine cervix. Radiother Oncol 1999;53:99-104.

[2] Hockel, M, Schlenger, K, Aral, B, Mitze, M, Schaffer, U, Vaupel, P. Association between tumor hypoxia and malignant progression in advanced cancer of the uterine cervix. Cancer Res 1996;56:4509-4515.

[3] Nordsmark, M, Overgaard, M, Overgaard, J. Pretreatment oxygenation predicts radiation response in advanced squamous cell carcinoma of the head and neck. Radiother Oncol 1996;41:31-39.

[4] Brizel, DM, Sibley, GS, Prosnitz, LR, Scher, RL, Dewhirst, MW. Tumor hypoxia adversely affects the prognosis of carcinoma of the head and neck. Int J Radiat Oncol Biol Phys 1997;38:285-289.

[5] Lartigau, E, Randrianarivelo, H, Avril, MF, et al. Intratumoral oxygen tension in metastatic melanoma. Melanoma Res 1997;7:400-406.

[6] Rofstad, EK, Maseide, K. Radiobiological and immunohistochemical assessment of hypoxia in human melanoma xenografts: acute and chronic hypoxia in individual tumours. Int J Radiat Biol 1999;75:13771393.

[7] Vaupel, P, Schlenger, K, Knoop, C, Hockel, M. Oxygenation of human tumors: evaluation of tissue oxygen distribution in breast cancers by computerized O2 tension measurements. Cancer Res 1991;51:33163322 .

[8] Runkel, S, Wischnik, A, Teubner, J, Kaven, E, Gaa, J, Melchert, F. Oxygenation of mammary tumors as evaluated by ultrasound-guided computerized-pO2-histography. Adv Exp Med Biol 1994;345:451-458.

[9] Movsas, B, Chapman, JD, Horwitz, EM, et al. Hypoxic regions exist in human prostate carcinoma. Urology 1999;53:11-18. 
[10] Brizel, DM, Dodge, RK, Clough, RW, Dewhirst, MW. Oxygenation of head and neck cancer: changes during radiotherapy and impact on treatment outcome. Radiother Oncol 1999;53:113-117.

[11] Fyles, AW, Milosevic, M, Wong, R, et al. Oxygenation predicts radiation response and survival in patients with cervix cancer. Radiother Oncol 1998;48:149-156.

[12] Graeber, TG, Osmanian, C, Jacks, T, et al. Hypoxia-mediated selection of cells with diminished apoptotic potential in solid tumours. Nature 1996;379:88-91.

[13] Erler, JT, Cawthorne, CJ, Williams, KJ, et al. Hypoxia-mediated downregulation of Bid and Bax in tumors occurs via hypoxia-inducible factor 1-dependent and -independent mechanisms and contributes to drug resistance. Mol Cell Biol 2004;24:2875-2889.

[14] Semenza, GL. Regulation of hypoxia-induced angiogenesis: a chaperone escorts VEGF to the dance. J Clin Invest 2001;108:39-40.

[15] Rofstad, EK, Danielsen, T. Hypoxia-induced metastasis of human melanoma cells: involvement of vascular endothelial growth factormediated angiogenesis. Br J Cancer 1999;80:1697-1707.

[16] Veikkola, T, Karkkainen, M, Claesson-Welsh, L, Alitalo, K. Regulation of angiogenesis via vascular endothelial growth factor receptors. Cancer Res 2000;60:203-212.

[17] Walton, HL, Corjay, MH, Mohamed, SN, Mousa, SA, Santomenna, LD, Reilly, TM. Hypoxia induces differential expression of the integrin receptors alpha(vbeta3) and alpha(vbeta5) in cultured human endothelial cells. J Cell Biochem 2000;78:674-680.

[18] Young, SD, Marshall, RS, Hill, RP. Hypoxia induces DNA overreplication and enhances metastatic potential of murine tumor cells. Proc Natl Acad Sci U S A 1988;85:9533-9537.

[19] De Jaeger, K, Kavanagh, MC, Hill, RP. Relationship of hypoxia to metastatic ability in rodent tumours. Br J Cancer 2001;84:1280-1285. 
[20] Plasswilm, L, Tannapfel, A, Cordes, N, et al. Hypoxia-induced tumour cell migration in an in vivo chicken model. Pathobiology 2000;68:99105.

[21] Semenza, GL. Targeting HIF-1 for cancer therapy. Nat Rev Cancer 2003;3:721-732.

[22] Iyer, NV, Kotch, LE, Agani, F, et al. Cellular and developmental control of $\mathrm{O} 2$ homeostasis by hypoxia-inducible factor 1 alpha. Genes Dev 1998;12:149-162.

[23] Forsythe, JA, Jiang, BH, Iyer, NV, et al. Activation of vascular endothelial growth factor gene transcription by hypoxia-inducible factor 1. Mol Cell Biol 1996;16:4604-4613.

[24] Minchenko, A, Salceda, S, Bauer, T, Caro, J. Hypoxia regulatory elements of the human vascular endothelial growth factor gene. Cell Mol Biol Res 1994;40:35-39.

[25] Semenza, GL, Wang, GL. A nuclear factor induced by hypoxia via de novo protein synthesis binds to the human erythropoietin gene enhancer at a site required for transcriptional activation. Mol Cell Biol 1992;12:5447-5454.

[26] Madan, A, Curtin, PT. A 24-base-pair sequence 3' to the human erythropoietin gene contains a hypoxia-responsive transcriptional enhancer. Proc Natl Acad Sci U S A 1993;90:3928-3932.

[27] Maxwell, PH, Wiesener, MS, Chang, GW, et al. The tumour suppressor protein VHL targets hypoxia-inducible factors for oxygen-dependent proteolysis. Nature 1999;399:271-275.

[28] Cardenas-Navia, LI, Braun, R, Lewis, K, Dewhirst, M. Comparison of fluctuations of oxygen tension in FSA, 9L, and R3230AC tumors in rats. Adv Exp Med Biol 2003;510:7-12.

[29] Cardenas-Navia, LI, Yu, D, Braun, RD, Brizel, DM, Secomb, TW, Dewhirst, MW. Tumor-dependent kinetics of partial pressure of oxygen 
fluctuations during air and oxygen breathing. Cancer Res 2004;64:6010-6017.

[30] Bennewith, KL, Durand, RE. Quantifying transient hypoxia in human tumor xenografts by flow cytometry. Cancer Res 2004;64:6183-6189.

[31] Koumenis, C, Naczki, C, Koritzinsky, M, et al. Regulation of Protein Synthesis by Hypoxia via Activation of the Endoplasmic Reticulum Kinase PERK and Phosphorylation of the Translation Initiation Factor eIF2alpha. Mol Cell Biol 2002;22:7405-7416.

[32] Kraggerud, SM, Sandvik, JA, Pettersen, EO. Regulation of protein synthesis in human cells exposed to extreme hypoxia. Anticancer Res 1995;15:683-686.

[33] Hochachka, PW, Buck, LT, Doll, CJ, Land, SC. Unifying theory of hypoxia tolerance: molecular/metabolic defense and rescue mechanisms for surviving oxygen lack. Proc Natl Acad Sci U S A 1996;93:94939498.

[34] Sutherland, R, Freyer, J, Mueller-Klieser, W, et al. Cellular growth and metabolic adaptations to nutrient stress environments in tumor microregions. Int J Radiat Oncol Biol Phys 1986;12:611-615.

[35] Harding, HP, Novoa, I, Zhang, Y, et al. Regulated translation initiation controls stress-induced gene expression in mammalian cells. Mol Cell 2000;6:1099-1108.

[36] Johannes, G, Carter, MS, Eisen, MB, Brown, PO, Sarnow, P. Identification of eukaryotic mRNAs that are translated at reduced cap binding complex eIF4F concentrations using a cDNA microarray. Proc Natl Acad Sci U S A 1999;96:13118-13123.

[37] Schroder, M, Kaufman, RJ. ER stress and the unfolded protein response. Mutat Res 2005;569:29-63.

[38] Wang, V, Davis, DA, Haque, M, Huang, LE, Yarchoan, R. Differential gene up-regulation by hypoxia-inducible factor-1alpha and hypoxia- 
inducible factor-2alpha in HEK293T cells. Cancer Res 2005;65:32993306.

[39] Belanger, AJ, Lu, H, Date, T, et al. Hypoxia up-regulates expression of peroxisome proliferator-activated receptor gamma angiopoietin-related gene (PGAR) in cardiomyocytes: role of hypoxia inducible factor 1alpha. J Mol Cell Cardiol 2002;34:765-774.

[40] Le Jan, S, Amy, C, Cazes, A, et al. Angiopoietin-like 4 is a proangiogenic factor produced during ischemia and in conventional renal cell carcinoma. Am J Pathol 2003;162:1521-1528.

[41] Leonard, MO, Cottell, DC, Godson, C, Brady, HR, Taylor, CT. The role of HIF-1 alpha in transcriptional regulation of the proximal tubular epithelial cell response to hypoxia. J Biol Chem 2003;278:4029640304.

[42] Wykoff, CC, Pugh, CW, Maxwell, PH, Harris, AL, Ratcliffe, PJ. Identification of novel hypoxia dependent and independent target genes of the von Hippel-Lindau (VHL) tumour suppressor by mRNA differential expression profiling. Oncogene 2000;19:6297-6305.

[43] Bhattacharya, S, Michels, CL, Leung, MK, Arany, ZP, Kung, AL, Livingston, DM. Functional role of p35srj, a novel p300/CBP binding protein, during transactivation by HIF-1. Genes Dev 1999;13:64-75.

[44] Sonna, LA, Cullivan, ML, Sheldon, HK, Pratt, RE, Lilly, CM. Effect of hypoxia on gene expression by human hepatocytes (HepG2). Physiol Genomics 2003;12:195-207.

[45] Staller, P, Sulitkova, J, Lisztwan, J, Moch, H, Oakeley, EJ, Krek, W. Chemokine receptor CXCR4 downregulated by von Hippel-Lindau tumour suppressor pVHL. Nature 2003;425:307-311.

[46] Denko, N, Schindler, C, Koong, A, Laderoute, K, Green, C, Giaccia, A. Epigenetic regulation of gene expression in cervical cancer cells by the tumor microenvironment. Clin Cancer Res 2000;6:480-487. 
[47] Gleadle, JM, Ebert, BL, Firth, JD, Ratcliffe, PJ. Regulation of angiogenic growth factor expression by hypoxia, transition metals, and chelating agents. Am J Physiol 1995;268:C1362-1368.

[48] Ito, D, Walker, JR, Thompson, CS, et al. Characterization of stanniocalcin 2, a novel target of the mammalian unfolded protein response with cytoprotective properties. Mol Cell Biol 2004;24:94569469.

[49] Brugarolas, J, Lei, K, Hurley, RL, et al. Regulation of mTOR function in response to hypoxia by REDD1 and the TSC1/TSC2 tumor suppressor complex. Genes Dev 2004;18:2893-2904.

[50] Carriere, A, Carmona, MC, Fernandez, Y, et al. Mitochondrial reactive oxygen species control the transcription factor CHOP-10/GADD153 and adipocyte differentiation: a mechanism for hypoxia-dependent effect. J Biol Chem 2004;279:40462-40469.

[51] Marciniak, SJ, Yun, CY, Oyadomari, S, et al. CHOP induces death by promoting protein synthesis and oxidation in the stressed endoplasmic reticulum. Genes Dev 2004;18:3066-3077.

[52] Minchenko, O, Opentanova, I, Minchenko, D, Ogura, T, Esumi, H. Hypoxia induces transcription of 6-phosphofructo-2-kinase/fructose2,6-biphosphatase-4 gene via hypoxia-inducible factor-1alpha activation. FEBS Lett 2004;576:14-20.

[53] Yoon, DY, Buchler, P, Saarikoski, ST, Hines, OJ, Reber, HA, Hankinson, O. Identification of genes differentially induced by hypoxia in pancreatic cancer cells. Biochem Biophys Res Commun 2001;288:882-886.

[54] Laderoute, KR, Calaoagan, JM, Knapp, M, Johnson, RS. Glucose utilization is essential for hypoxia-inducible factor 1 alpha-dependent phosphorylation of c-Jun. Mol Cell Biol 2004;24:4128-4137.

[55] Urano, F, Wang, X, Bertolotti, A, et al. Coupling of stress in the ER to activation of JNK protein kinases by transmembrane protein kinase IRE1. Science 2000;287:664-666. 
[56] Kurisu, J, Honma, A, Miyajima, H, Kondo, S, Okumura, M, Imaizumi, K. MDG1/ERdj4, an ER-resident DnaJ family member, suppresses cell death induced by ER stress. Genes Cells 2003;8:189-202.

[57] Hu, CJ, Wang, LY, Chodosh, LA, Keith, B, Simon, MC. Differential roles of hypoxia-inducible factor 1alpha (HIF-1alpha) and HIF-2alpha in hypoxic gene regulation. Mol Cell Biol 2003;23:9361-9374.

[58] Marjon, PL, Bobrovnikova-Marjon, EV, Abcouwer, SF. Expression of the pro-angiogenic factors vascular endothelial growth factor and interleukin-8/CXCL8 by human breast carcinomas is responsive to nutrient deprivation and endoplasmic reticulum stress. Mol Cancer 2004;3:4.

[59] Wang, GL, Jiang, BH, Rue, EA, Semenza, GL. Hypoxia-inducible factor 1 is a basic-helix-loop-helix-PAS heterodimer regulated by cellular O2 tension. Proc Natl Acad Sci U S A 1995;92:5510-5514.

[60] Kim, JY, Ahn, HJ, Ryu, JH, Suk, K, Park, JH. BH3-only protein Noxa is a mediator of hypoxic cell death induced by hypoxia-inducible factor 1alpha. J Exp Med 2004;199:113-124.

[61] Nakayama, K, Frew, IJ, Hagensen, M, et al. Siah2 regulates stability of prolyl-hydroxylases, controls HIFlalpha abundance, and modulates physiological responses to hypoxia. Cell 2004;117:941-952.

[62] Jiang, HY, Wek, SA, McGrath, BC, et al. Activating transcription factor 3 is integral to the eukaryotic initiation factor 2 kinase stress response. Mol Cell Biol 2004;24:1365-1377.

[63] Jin, K, Mao, XO, Eshoo, MW, et al. cDNA microarray analysis of changes in gene expression induced by neuronal hypoxia in vitro. Neurochem Res 2002;27:1105-1112.

[64] Appelhoff, RJ, Tian, YM, Raval, RR, et al. Differential function of the prolyl hydroxylases PHD1, PHD2, and PHD3 in the regulation of hypoxia-inducible factor. J Biol Chem 2004;279:38458-38465. 
[65] Marxsen, JH, Stengel, P, Doege, K, et al. Hypoxia-inducible factor-1 (HIF-1) promotes its degradation by induction of HIF-alpha-prolyl-4hydroxylases. Biochem J 2004;381:761-767.

[66] Freedman, SJ, Sun, ZY, Kung, AL, France, DS, Wagner, G, Eck, MJ. Structural basis for negative regulation of hypoxia-inducible factor1alpha by CITED2. Nat Struct Biol 2003;10:504-512.

[67] Blais, JD, Filipenko, V, Bi, M, et al. Activating transcription factor 4 is translationally regulated by hypoxic stress. Mol Cell Biol 2004;24:7469-7482.

[68] Lang, KJ, Kappel, A, Goodall, GJ. Hypoxia-inducible Factor-1alpha mRNA Contains an Internal Ribosome Entry Site That Allows Efficient Translation during Normoxia and Hypoxia. Mol Biol Cell 2002;13:1792-1801.

[69] Stein, I, Itin, A, Einat, P, Skaliter, R, Grossman, Z, Keshet, E. Translation of vascular endothelial growth factor mRNA by internal ribosome entry: implications for translation under hypoxia. Mol Cell Biol 1998;18:3112-3119.

[70] Akiri, G, Nahari, D, Finkelstein, Y, Le, SY, Elroy-Stein, O, Levi, BZ. Regulation of vascular endothelial growth factor (VEGF) expression is mediated by internal initiation of translation and alternative initiation of transcription. Oncogene 1998;17:227-236.

[71] Miller, DL, Dibbens, JA, Damert, A, Risau, W, Vadas, MA, Goodall, GJ. The vascular endothelial growth factor mRNA contains an internal ribosome entry site. FEBS Lett 1998;434:417-420.

[72] Wouters, BG, van den Beucken, T, Magagnin, MG, Koritzinsky, M, Fels, D, Koumenis, C. Control of the hypoxic response through regulation of mRNA translation. Semin Cell Dev Biol 2005. 


\section{Chapter 4}

The mTOR target 4E-BP1 contributes to differential protein expression during normoxia and hypoxia through changes in mRNA translation efficiency

M.G.P. Magagnin, T. van den Beucken, K. Sergeant, P. Lambin, M. Koritzinsky, B. Devreese and B.G. Wouters

Proteomics 8: 1019-1028, 2008 


\section{ABSTRACT}

Hypoxia causes a rapid and sustained inhibition in mRNA translation that is characterized by both a transient phosphorylation of eukaryotic initiation factor 2-alpha (eIF $2 \alpha$ ) and by inhibition of the mRNA cap binding protein eIF4E via activation of two distinct inhibitory proteins, the mTOR target 4E-BP1 and the eIF4E transporter 4E-T. Although the importance of eIF2 $\alpha$ phosphorylation during hypoxia has been clearly demonstrated, there is little information on the potential relevance of eIF4E regulation. We generated HeLa cells stably expressing a short hairpin interfering RNA (shRNA) against 4E-BP1 and found that despite efficient knockdown, no significant changes occurred in the overall inhibition of mRNA translation during hypoxia. However, using a proteomics approach we identified 7 proteins that were exclusively expressed in the 4EBP1 knock-down cells during both normoxic and hypoxic conditions. Further investigation of the transcriptional and translational regulation of these genes by quantitative RT-PCR indicated that the loss of 4E-BP1 causes a significant increase in the rate of protein synthesis of S100 calcium-binding protein A4 (S100A4) and transgelin 2. These 4E-BP1 regulated proteins have previously been associated with tumor cell motility, invasion and metastasis and may thus contribute to an adverse tumor phenotype. 


\section{INTRODUCTION}

The presence of poorly oxygenated (hypoxic) areas within the tumor microenvironment is well-documented [1]. Hypoxic tumors are associated with a more malignant phenotype and are more resistant to therapy as compared to better-oxygenated tumors. The adaptation to hypoxia is facilitated in large part through activation of a key regulator, hypoxia inducible factor-1 (HIF-1), which mediates transcriptional activation of genes involved in erythropoiesis, glycolysis, angiogenesis, invasion and cell survival decisions [2]. In addition to this transcriptional response, tumor hypoxia also results in a rapid drop in de novo protein synthesis [3]. Protein synthesis is the second highest cellular consumer of ATP after the $\mathrm{Na}^{+}$pump [4], and thus its inhibition during hypoxia probably serves to maintain energy homeostasis. This inhibition in overall protein synthesis occurs at the level of mRNA translation initiation [5, $6]$, a process that is regulated by a family of eukaryotic translation initiation factors (eIFs).

We have recently shown that two distinct pathways regulate mRNA translation during hypoxia. The initial phase of inhibition in protein synthesis during hypoxic exposure occurs mainly through transient phosphorylation of eIF2 $\alpha$ at serine 51 by the endoplasmic reticulum kinase PERK $[5,6]$. Although the phosphorylation of eIF $2 \alpha$ is transient, overall levels of translation remain low during prolonged hypoxia consistent with regulation of the eukaryotic initiation complex 4F. This complex consists of the eIF4E cap-binding protein, the eIF4G scaffolding protein and the ATP dependent eIF4A RNA helicase. Prolonged hypoxic exposures $(>4 \mathrm{~h})$ cause disruption of the eIF4F complex through the sequestration of eIF4E by $4 \mathrm{E}$ binding proteins (4E-BPs) and relocation of eIF4E into the nucleus and/or P-bodies by the 4E-T transporter protein [5]. There are three known 4E-BPs (4E-BP1, 4E-BP2 and 4E-BP3), with 4E-BP1 also known as PHAS-1 being the best characterized [7, 8]. 4E-BP activity is regulated by its phosphorylation status. Hypophosphorylated 4E-BP binds eIF4E, thereby preventing its association with eIF4G and thus inhibiting cap-dependent translation. Phosphorylation of 4E-BP by the mammalian target of rapamycin (mTOR) results in an abrogated interaction with eIF4E and thus stimulates translation. Hypoxia has been demonstrated to inhibit mTOR and thus promote increased binding of eIF4E to 4E-BP $[9,10]$. However, the functional consequences of hypoxia induced 4E-BP dephosphorylation remain unclear. Prevention of 4E-BP1 dephosphorylation by mTOR overexpression 
during anoxia did not cause a relief in protein synthesis inhibition [11], while 4E-BP1 knock-down models have provided some support for a role for 4E-BP1 in regulating overall translation rates during more moderately hypoxic conditions $[12,13]$. The importance of 4E-BP regulation for differential gene expression and phenotype during anoxia or hypoxia has not been addressed.

4E-BP plays an important role in the regulation of gene expression and phenotype in many other settings. In Drosophila, 4E-BP activity strongly affects fat metabolism [14]. Similarly, mice lacking 4E-BP1 show markedly smaller white fat pads and decreased blood glucose levels as compared to their wild-type counterparts, implicating 4E-BP1 as a metabolic regulator [15]. Several studies have also implicated components of the protein initiation synthesis apparatus in carcinogenesis. eIF4E induces malignant transformation when overexpressed in mammalian cells [16]. Moreover, increased levels of eIF4E are commonly found in breast, prostate and head and neck tumors, but not in benign lesions [17]. In contrast to eIF4E, overexpression of 4E-BP1 blocks transformation by both eIF4E and c-myc by inhibiting cell cycle progression and increasing apoptosis [18]. Expression of a constitutively active 4E-BP1 enhances p27/Kip1 expression and represses cyclin D1 expression, which leads to cell cycle arrest [19].

In this study, we established HeLa cells stably expressing a short hairpin interfering RNA (shRNA) against 4E-BP1 to address the contribution of $4 \mathrm{E}-\mathrm{BP} 1$ on mRNA translation and protein expression during hypoxia and normoxia. We demonstrate that although 4E-BP1 knock-down does not affect the inhibition of overall mRNA translation during severe hypoxia, the absence of 4E-BP1 stimulates specific protein expression during both normoxic and hypoxic conditions. Overall, the stable knock-down of 4E-BP1 contributes to the translational induction of specific proteins that are involved in cytoskeletal organization and invasion, which may contribute to the adverse phenotype of tumor cells. Furthermore, we demonstrate that for two of these proteins, S100 calcium-binding protein A4 (S100A4) and transgelin 2, 4E-BP1 directly regulates their translation efficiency. 


\section{MATERIALS AND METHODS}

\section{Cell culture and cell transfections}

Cervix carcinoma (HeLa) cells were grown in Dulbecco's modified Eagle's medium (Sigma) supplemented with $10 \%$ fetal bovine serum (Sigma) at $37^{\circ} \mathrm{C}$ in a $5 \% \mathrm{CO}_{2}$ incubator. HeLa cells were stably transfected with pRetroSuper [20] which was either empty (pRS) or which generated a short hairpin interfering RNA against 4E-BP1 (pRS 4E-BP1) with the following targeting sequence: gtttgagatggacatttaa. Exponentionally growing pRS HeLa and pRS 4E-BP1 HeLa cells were plated on plastic culture dishes and hypoxic treatments $\left(<0.01 \% \mathrm{O}_{2}\right)$ were performed as previously described [21].

\section{Growth curves}

HeLa cells were seeded at day 1. After day 2, 3, 4 and 5 cells were harvested using trypsin and the cell number was counted using a Coulter $\mathrm{Z}$ counter (Beckmann).

\section{Polysomal fractionation and analysis}

Experiments were performed as previously described [21].

\section{Western blot analysis}

Whole cell extracts $(40 \mu \mathrm{g})$ were resolved in 15\% SDS PAGE gels and transferred onto Hybond-Nitrocellulose membrane (Amersham Biosciences). Membranes were incubated overnight with primary antibody: 4E-BP1 (1:1000 dilution, Cell Signaling Technology) followed by incubation with horseradish peroxidase-conjugated secundary antibody (1:2000 dilution, Cell Signaling technology). Protein signals were detected using the Super Signal West Pico kit (Pierce).

\section{2-DE and image analysis}

$15 \mathrm{~cm}$ culture dishes of HeLa cells at 70\% confluence were washed twice with $5 \mathrm{~mL}$ of ice-cold $10 \mathrm{mM} / 250 \mathrm{mM}$ sucrose buffer $\mathrm{pH}$ 7.0. Cells were scraped in $1 \mathrm{~mL}$ of ice-cold Tris/Sucrose buffer and centrifuged at $400 \mathrm{~g}$ for $5 \mathrm{~min}$ at $4{ }^{\circ} \mathrm{C}$. The cells were washed again with $1 \mathrm{~mL}$ of ice-cold Tris/Sucrose buffer and centrifuged at $400 \mathrm{~g}$ for $5 \mathrm{~min}$ at $4{ }^{\circ} \mathrm{C}$. The supernatant was discarded and 200 $\mu \mathrm{L}$ 2-DE lysisbuffer (7 M urea, $2 \mathrm{M}$ thiourea, 4\% CHAPS, $0.5 \%$ IPG buffer pH 3-10 NL (Amersham Biosciences), 1\% DTT, complete EDTA-free protease inhibitor cocktail (Roche)) was added. Cells were exposed four times to a 
quick freeze-thaw lysis, and then lysates were centrifuged at $13000 \mathrm{~g}$ for 30 min at $4{ }^{\circ} \mathrm{C}$ to remove contaminants like DNA. The supernatant was collected in a cold microcentrifuge tube. Protein concentrations were determined by Bradford protein assay (Bio-Rad Laboratories) [22]. Samples were applied to $24 \mathrm{~cm}$ IPG strips pH 3-10 NL (Amersham Biosciences) by in-gel rehydration, 15 hours at $50 \mathrm{~V}$. Focusing System cycling conditions were $90 \mathrm{~min}$ at $200 \mathrm{~V}$, $90 \mathrm{~min}$ at $500 \mathrm{~V}, 2$ hours gradient step to $1000 \mathrm{~V}, 90 \mathrm{~min}$ gradient step to 8000 $\mathrm{V}$ and a final step of 6 hours at $8000 \mathrm{~V}$ with an IPGphor system (Amersham Biosciences). Following the IEF step, the strips were equilibrated for $20 \mathrm{~min}$ in equilibration buffer (6 M urea, $50 \mathrm{mM}$ Tris-HCL pH 8.8, 30\% glycerol, 2\% SDS and 1\% DTT), then treated for 20 min in the same buffer containing $2.5 \%$ iodoacetamide instead of DTT. Next, the IPG strips were placed on the Protean Plus Dodeca Cell (Bio-Rad Laboratories) to conduct a second dimension separation using $12 \%$ SDS-PAGE gels. The system was run at $150 \mathrm{~V}$ for 20 min, followed by 5 hours at $200 \mathrm{~V}$. Proteins were visualized by staining with SYPRO Ruby dye (Bio-Rad Laboratories). The 2-DE stained gels were imaged on a Molecular Imager FX (Bio-Rad Laboratories). This experiment was repeated in triplicate with a technical repeat for each condition. The resulting 2-DE protein patterns were analyzed, using PD-Quest 7.1 software (Bio-Rad Laboratories). The densities of all spots were determined with normalization based on total protein density on each of the individual gels. The reproducibility of the 2-DE gels was expressed as a correlation coefficient, which was measured between the quantities of all spots in a gel and its quantities in another biological or technical repeat from the same matchset. This correlation coefficient was always higher then 0.83 .

\section{In-gel trypsin digestion and ESI-Q-TRAP MS}

Stained protein spots of interest were excised from the gel with an automatic spot cutter (Bio-Rad Laboratories). Each gel piece was washed twice for 30 min at $30^{\circ} \mathrm{C}$ with $200 \mathrm{mM} \mathrm{NH} \mathrm{NCO}_{3}$ in $50 \% \mathrm{ACN}$ for $30 \mathrm{~min}$. After incubation, the wash solution was removed and the samples evaporated to complete dryness using a SpeedVac. For digestion, gel pieces were chilled for $60 \mathrm{~min}$ on ice in $8 \mu \mathrm{L}$ of digestion buffer containing $150 \mathrm{ng}$ modified trypsin (Promega) in $50 \mathrm{mM} \mathrm{NH}_{4} \mathrm{HCO}_{3}$. Then $5 \mu \mathrm{L}$ of digestion buffer was added and the samples were incubated overnight at $37^{\circ} \mathrm{C}$. After incubation, the supernatans was recovered and the remaining peptides were extracted from the gel by two consecutive extractions with $50 \% \mathrm{ACN} / 0.1 \% \mathrm{HCOOH}$. All the extracts were pooled and the samples were dried in a SpeedVac. The samples were resuspended in $8 \mu \mathrm{L}$ of $0.1 \% \mathrm{HCOOH}$. The peptide mixture was loaded 
and separated on a nano-HPLC system (Dionex-LC Packings) using a $75 \mu \mathrm{m}$ ID PEPMAP C18 column (Dionex) and the separated peptides were then analysed by LCMS/MS by an ESI-Q-TRAP mass spectrometer (Applied Biosystems) as previously described [23]. All searches were done using the inhouse MASCOT server and the NCBInr database limited to proteins from Homo sapiens, a 1 Da peptide and fragment mass error was tolerated and carbamidomethylation and methionine oxidation were set as variable modifications.

\section{Quantitative PCR analysis}

Experiments and normalizations were performed as previously described [5]. The abundance of the following genes were detected with SYBR Green I (Applied Biosystems) using indicated forward and reverse primers: CA-IX: Fcatcctagccetggtttttgg and R-gctcacacccctttggtt; 4E-BP1: Ftatgaccggaaattcctgatgga and R-ccgcttatcttctgggctattg; 4E-BP2: Fgtttctgttggatcgtcgcaa and R-ggagtcttcaattaaggtgcca; $\beta$-Actin: $F$ accatggatgatgatatcgec and R-gcettgcacatgccgg; 18SrRNA: Fagtcctgccctttgtacaca and R-gatccgagggectcactaaac. The following genes were measured using Taqman Gene Expression Assays (Applied Biosystems): S100A4: Hs00243202_m1, Transgelin 2: Hs00761239_s1.

\section{Transgelin 2 pulse-labeling}

Following $15 \mathrm{~min}$ starvation, cells grown on $60 \mathrm{~mm}$ dishes were incubated with $100 \mu \mathrm{Ci} 35$-S labeled methionine/cysteine (GE Healthcare) for 7, 14 or 28 min. The cells were washed in cold PBS and lysed in RIPA lysisbuffer. Total cell lysates labeled for 14 min were immunoprecipitated using a transgelin 2 antibody (Abcam). Total or immunoprecipitated cell lysates were separated on SDS-PAGE and 35S incorporation detected by autoradiography.

\section{RESULTS}

HeLa cells stably expressing a shRNA against 4E-BP1

Previously, we have shown that hypoxia regulates translation through two distinct pathways. Rapid but transient phosphorylation of eIF $2 \alpha$ is followed by sequestration of eIF4E by its inhibitor 4E-BP1 and transporter 4E-T and disruption of the eIF4F complex [5]. Figure 1A demonstrates strong dephosphorylation of 4E-BP1 after $16 \mathrm{~h}$ exposure to hypoxia. This protein 
appears as three different migrating bands $(\alpha-\gamma)$ when subjected to SDS-PAGE and western blot analysis, representing different phosphorylation states of 4E$\mathrm{BP} 1$, ranging from a fast-migrating hypophosphorylated form $(\alpha)$ to a slowmigrating hyperphosphorylated form $(\gamma)$ [7]. The hypophosphorylated band of 4E-BP1, which is known to have a higher affinity for eIF4E, is substantially increased after $16 \mathrm{~h}$ of hypoxia.

HeLa cells were transfected with a control shRNA or a shRNA directed to knock down the expression of 4EBP1. Following selection of stably expressing cell lines, total RNA was isolated for reverse transcription RT-PCR in order to characterize the transcript levels of 4E-BP1. Figure 1B shows $>10$-fold decrease in 4E-BP1 transcript expression in cells expressing a shRNA against 4E-BP1 (referred to as pRS 4E-BP1) compared to the wild type counterparts. The shRNA against 4E-BP1 has no effect on 4E-BP2 transcript levels, demonstrating the specificity of the shRNA for 4E-BP1 and absence of compensation by the homolog. Western blot analysis for 4E-BP1 expression confirmed reduced protein levels for 4E-BP1 in the pRS 4E-BP1 HeLa cells (Figure 1C). 

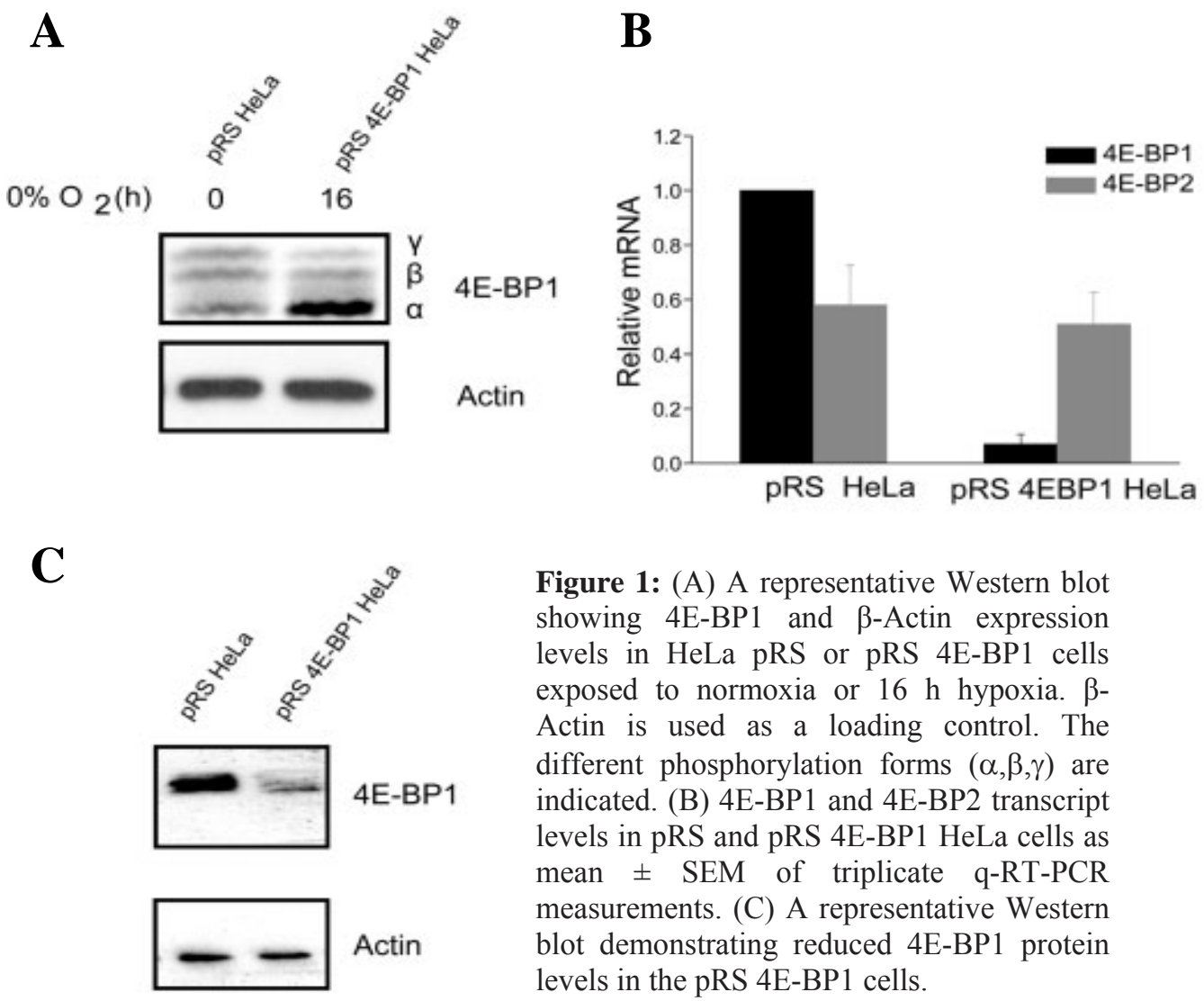

Figure 1: (A) A representative Western blot showing 4E-BP1 and $\beta$-Actin expression levels in HeLa pRS or pRS 4E-BP1 cells exposed to normoxia or $16 \mathrm{~h}$ hypoxia. $\beta$ Actin is used as a loading control. The different phosphorylation forms $(\alpha, \beta, \gamma)$ are indicated. (B) 4E-BP1 and 4E-BP2 transcript levels in pRS and pRS 4E-BP1 HeLa cells as mean \pm SEM of triplicate q-RT-PCR measurements. (C) A representative Western blot demonstrating reduced 4E-BP1 protein levels in the pRS 4E-BP1 cells.

4E-BP1 expression does not affect proliferation or overall rates of mRNA translation

Expression of a shRNA against 4E-BP1 might be expected to increase the rate of cellular proliferation through increased eIF4E activity. To test this, the growth of pRS 4E-BP1 HeLa cells was determined by counting cell number during standard cell culture. The data presented in Figure 2A show that the rate of proliferation was unaffected by the levels of 4E-BP1.

To determine the influence of 4E-BP1 on overall rates of mRNA translation in HeLa cells during normoxic and hypoxic conditions, we examined the association of ribosomes with mRNA under normal growth conditions and after $16 \mathrm{~h}$ of hypoxia. The resulting polysome profiles are shown in Figure 2B. In this assay, the first two peaks represent the 40S and 
60S ribosomal subunits, respectively. The subsequent peaks represent mRNA transcripts with increasing numbers of attached ribosomes (polysomes), which is indicative of de novo protein synthesis. The results presented in Figure $2 \mathrm{~B}$ demonstrate that hypoxia inhibits overall mRNA translation in HeLa cells, evident by a clear reduction in the high molecular weight polysomal RNA. Interestingly, knockdown of 4E-BP1 does not significantly alter the overall mRNA translation inhibition during hypoxia. The amount of ribosomal RNA participating in polysomes can be determined by integrating the fractional area under the absorbance curve which corresponds to polysomal RNA. The resulting data presented in Figure $2 \mathrm{C}$ show that the fraction of rRNA found in polysome complexes dropped from $60 \%$ in aerobic cells to $27 \%$ after $16 \mathrm{~h}$ of hypoxia, irrespective of 4E-BP1 expression levels. In summary, these results indicate that 4E-BP1 expression does not significantly influence cell proliferation and does not affect overall rates of mRNA translation during normoxic or hypoxic conditions.

\section{A}

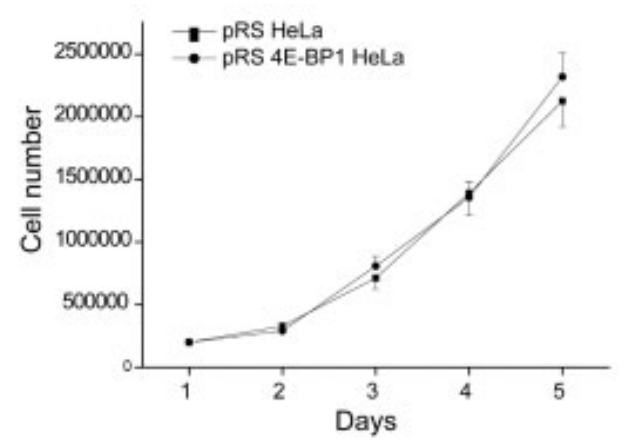

C

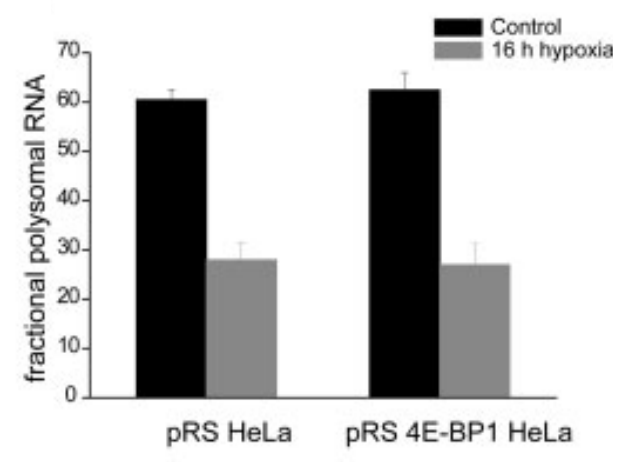




\section{B}

\section{pRS HeLa}
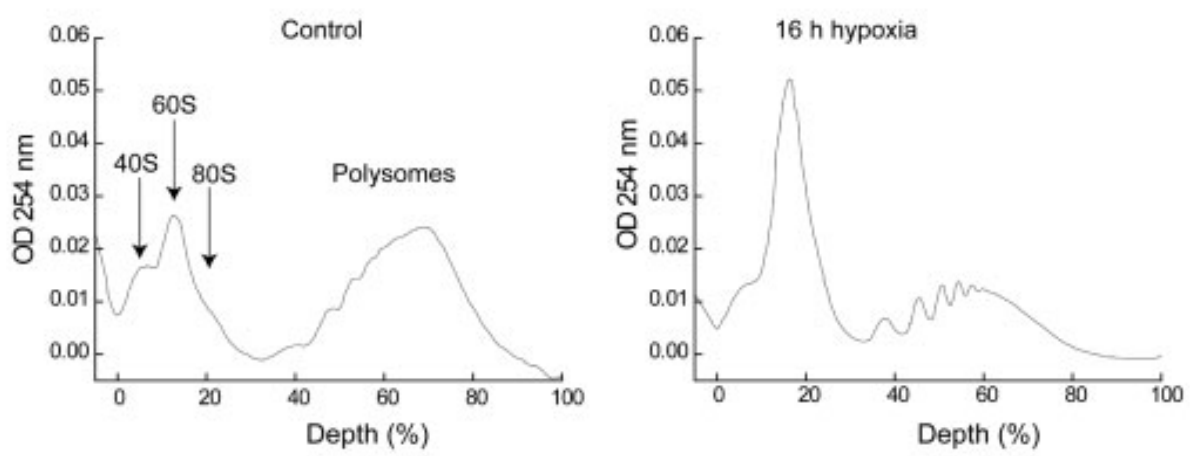

pRS 4E-BP1 Hela
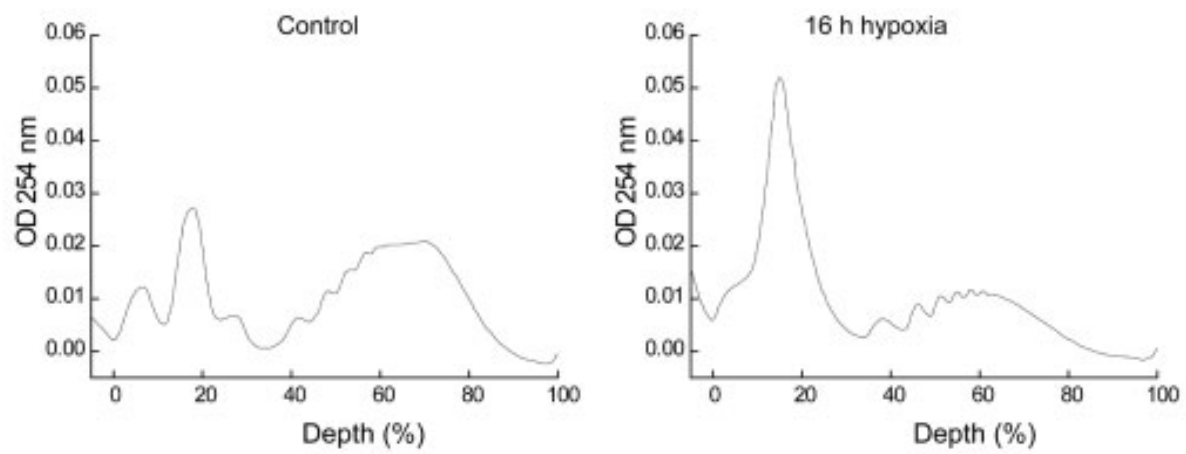

Figure 2: (A) Proliferation rates of pRS HeLa and pRS 4E-BP1 HeLa cells was monitored by counting cells following 1, 2, 3, 4, or 5 days of growth. Data represent mean 6 SEM of three independent experiments. (B) Cell lysates were sedimented through a sucrose gradient and OD at $254 \mathrm{~nm}$ was recorded as function of gradient depth. Actively translated mRNA is associated with high molecular weight polysomes in the gradient. Positions of the $40 \mathrm{~S}$ and $60 \mathrm{~S}$ ribosome subunits, 80S monosome, and polysomes are indicated. (C) The fraction of rRNA associated with polysomes is used as an estimate of overall translation efficiency. This fraction is proportional to the integrated area under the curve-containing polysomes. Data represent mean \pm SEM of two independent experiments. 
Identification of $4 \mathrm{E}-\mathrm{BP} 1$ dependent proteins

Although the data presented above indicate that 4E-BP1 expression does not affect overall mRNA translation, we hypothesized that 4E-BP1 may nonetheless affect specific protein expression. To address this we exposed wild-type and 4E-BP1 knockdown cells to normoxia or $16 \mathrm{~h}$ of hypoxia. Subsequently, proteins were isolated from the cells and separated by 2-DE. Representative gels stained with SYPRO Ruby are shown in Figure 3A. Approximately 1300 spots were detected per gel within a $\mathrm{pH}$ range of 3-10 and a molecular mass range of 10-150 kDA. In order to increase our likelihood of identifying proteins regulated by $4 \mathrm{E}-\mathrm{BP} 1$ directly at the translational level, we imposed stringent criteria for selecting spots for further MS analysis. We selected those spots that were reproducibly present in the pRS 4E-BP1 HeLa cells during both normoxic and hypoxic conditions but absent (undetectable by Sypro Ruby staining) in the wild-type pRS HeLa cells. Thus, for this first analysis, proteins that demonstrated quantitative changes in their levels (present in both wild type and 4E-BP1 knockdown cells) were not further investigated.

A

pRS HeLa

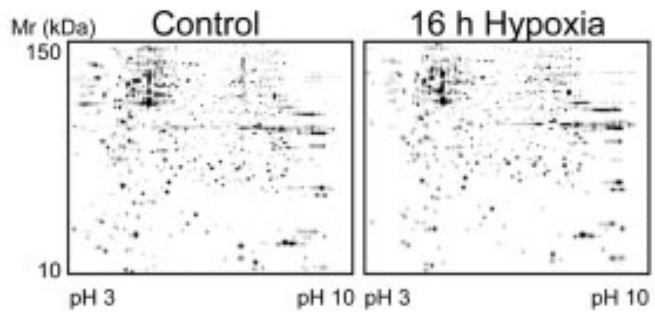

pRS 4E-BP1HeLa

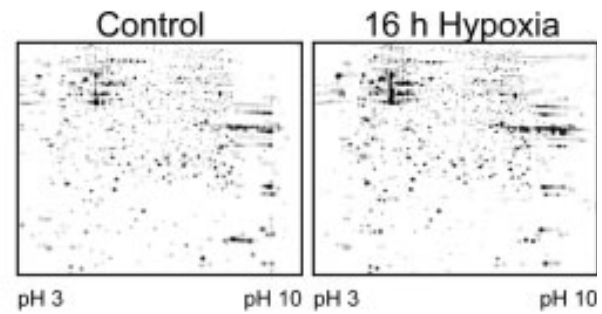


B

pRS HeLa
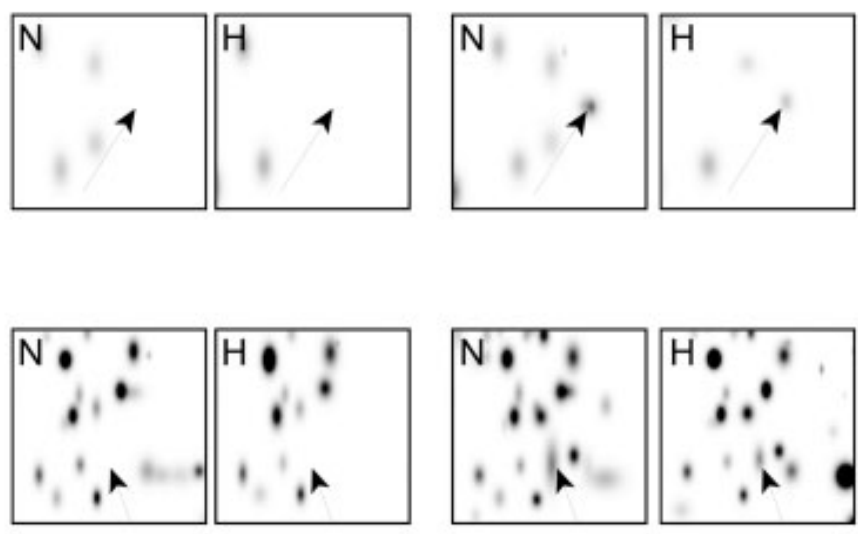

Transgelin 2
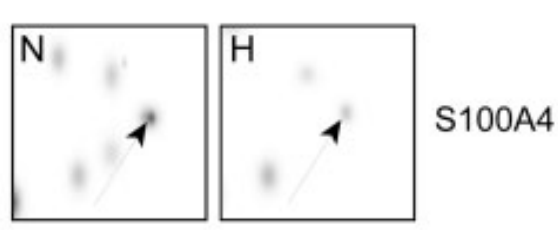

S100A4

pRS 4E-BP1 HeLa

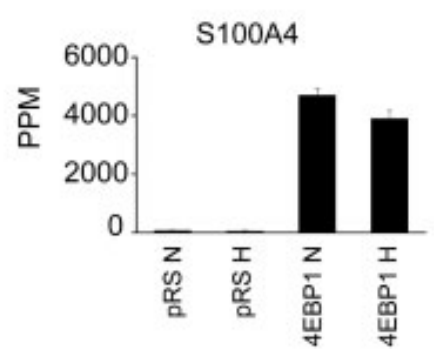

Figure 3: (A) Representative 2 D gels stained with SYPRO Ruby of pRS HeLa and pRS 4EBP1 HeLa cells exposed to normoxia or $16 \mathrm{~h}$ of hypoxia. Around 1300 spots are visible within a $\mathrm{pH}$ range of 3-10 and a molecular mass range of $10-150 \mathrm{kDa}$. (B) The insets show the expression and quantification of the protein spots identified as S100A4 and transgelin 2 during normoxic $(\mathrm{N})$ and hypoxic $(\mathrm{H})$ conditions for both cell lines.

Overall, the 2-DE gel protein spot profiles across all of the gels for both cell lines were similar. However the image analysis software PDQuest revealed the expression of a small number of proteins that were exclusively expressed in the pRS 4E-BP1 cells during both normoxia and hypoxia. Seven of these were successfully identified by ESI-Q-TRAP MS analysis followed by database searching; enolase 1, lactate dehydrogenase-B, S100A4, annexin A3, peptidylprolyl isomerise A, transgelin 2 and heat shock protein $70 \mathrm{kDA} 9 \mathrm{~B}$. The identified peptides, Swiss-Prot accession numbers, MS-MS scores, and other details of these proteins are summarized in Table 1. We chose to focus 
further mechanistic studies on two proteins, S100A4 and transgelin 2 that are described in the literature as being involved in tumor progression and invasion $[24,25]$ and which were expressed repeatedly and exclusively in cells lacking $4 \mathrm{E}-\mathrm{BP} 1$ during normoxia and hypoxia (Figure 3B).

Table 1. List of identified proteins ESI-Q-TRAP MS.

\begin{tabular}{|c|c|c|c|c|c|c|c|c|}
\hline $\begin{array}{l}\text { Swiss- } \\
\text { Prot } \\
\text { Accessi } \\
\text { on No. }\end{array}$ & $\begin{array}{c}\text { Protein } \\
\text { name }\end{array}$ & $\begin{array}{c}\text { HUG } \\
\text { O } \\
\text { Gene } \\
\text { name }\end{array}$ & $\begin{array}{c}\text { Putativ } \\
\text { e } \\
\text { functio } \\
n\end{array}$ & $\begin{array}{c}\text { Mr } \\
(\mathbf{k D a}) \\
/ \mathbf{p I}\end{array}$ & $\begin{array}{c}\text { Num } \\
\text { ber } \\
\text { of } \\
\text { pepti } \\
\text { des }\end{array}$ & $\begin{array}{c}\text { Sequ } \\
\text { ence } \\
\text { cover } \\
\text { age } \\
(\%)\end{array}$ & $\begin{array}{c}\text { MS/ } \\
\text { MS } \\
\text { score } \\
>31^{\text {a) }}\end{array}$ & $\begin{array}{c}\text { Peptide } \\
\text { sequences }\end{array}$ \\
\hline P06733 & Enolase 1 & ENO1 & $\begin{array}{c}\text { Cellular } \\
\text { metabolis } \\
\mathrm{m}\end{array}$ & $47 / 7,01$ & 1 & 3 & 33 & $\begin{array}{l}\text { R.YISPDQLAD } \\
\text { LYK.G }\end{array}$ \\
\hline P07195 & $\begin{array}{c}\text { Lactate } \\
\text { dehydroge } \\
\text { nase B }\end{array}$ & LDHB & $\begin{array}{l}\text { Cellular } \\
\text { metabolis } \\
\mathrm{m}\end{array}$ & $37 / 5,71$ & 2 & 6 & $\begin{array}{l}44 \\
43\end{array}$ & $\begin{array}{l}\text { K.IVVVTAGVR. } \\
\text { Q } \\
\text { R.GLTSVINQK. } \\
\text { L }\end{array}$ \\
\hline P26447 & $\begin{array}{l}\text { S100 } \\
\text { calcium- } \\
\text { binding } \\
\text { protein } \\
\text { A4 }\end{array}$ & $\begin{array}{l}\mathrm{S} 100 \mathrm{~A} \\
4\end{array}$ & $\begin{array}{l}\text { Calcium- } \\
\text { binding } \\
\text { protein }\end{array}$ & $12 / 5,85$ & 1 & 12 & 52 & $\begin{array}{c}\text { K.ALDVMSTFH } \\
\text { K.Y }\end{array}$ \\
\hline P12429 & $\begin{array}{c}\text { Annexin } \\
\text { A3 }\end{array}$ & $\begin{array}{c}\text { ANXA } \\
3\end{array}$ & $\begin{array}{l}\text { Calcium- } \\
\text { binding } \\
\text { protein }\end{array}$ & $36 / 5,63$ & $3^{\text {b) }}$ & 27 & $\begin{array}{l}46 \\
57 \\
38\end{array}$ & $\begin{array}{l}\text { K.LTFDEYR.N } \\
\text { K.GIGTDEFTLN } \\
\text { R.I } \\
\text { R.SEIDLLDIR.T }\end{array}$ \\
\hline P62937 & $\begin{array}{l}\text { Peptidylpr } \\
\text { olyl } \\
\text { isomerase } \\
\text { A }\end{array}$ & CYPA & $\begin{array}{l}\text { Protein } \\
\text { folding }\end{array}$ & $18 / 7,68$ & $2^{c)}$ & 33 & $\begin{array}{l}49 \\
38\end{array}$ & $\begin{array}{l}\text { K.KITIADCGQL } \\
\text {.E } \\
\text { R.VLDELTLAR. } \\
\mathrm{T}\end{array}$ \\
\hline P37802 & $\begin{array}{c}\text { Transgelin } \\
2 \\
\end{array}$ & $\begin{array}{l}\text { TAGL } \\
\text { N2 }\end{array}$ & $\begin{array}{l}\text { Cytoskele } \\
\text { tal protein }\end{array}$ & $22 / 8,41$ & 1 & 7 & 42 & $\begin{array}{l}\text { R.TLMNLGGLA } \\
\text { VAR.D }\end{array}$ \\
\hline P38646 & $\begin{array}{l}\text { Heat } \\
\text { shock } \\
\text { protein 70 } \\
\text { kDA 9B }\end{array}$ & HSPA9 & $\begin{array}{l}\text { Proliferati } \\
\text { on }\end{array}$ & $74 / 6,03$ & $1^{\text {d) }}$ & 3 & 34 & $\begin{array}{c}\text { K.DAGQISGLN } \\
\text { VLR.V }\end{array}$ \\
\hline
\end{tabular}

${ }^{a)} \mathrm{MS} / \mathrm{MS}$ score is given as $\mathrm{S}=-10 * \log (\mathrm{P})$ where $\mathrm{P}$ is the probability that the observed match is a random event.

b) 7 peptide sequences were identified, 4 had a MS/MS score $<31$.

c) 4 peptide sequences were identified, 2 had a MS/MS score $<31$.

d) 2 peptide sequences were identified, 1 had a MS/MS score $<31$. 
4E-BP1 dependent regulation of S100A4 and transgelin 2 expression

Although 4E-BP1 is directly involved in regulating mRNA translation, it could affect gene expression indirectly by e.g. by regulating the translation of a transcription factor. To address whether 4E-BP1 prevents transcription or translation of S100A4 and transgelin 2, we conducted real time quantitative RT-PCR for these two genes during normoxia or hypoxia $(16 \mathrm{~h})$ from both total cellular mRNA and from polysomal mRNA. This allows us to evaluate changes in cellular levels of mRNA as well as changes in the translation efficiency of these individual genes. As shown in Figure 4A total cellular mRNA levels of S100A4 and transgelin 2 did not significantly change following 4E-BP1 knockdown during normoxia or hypoxia. As expected, the hypoxic treatment caused a 10-fold increase in the HIF-1 target gene CA-IX in both cell lines, demonstrating the effectiveness of hypoxic treatment.

To evaluate mRNA translation and estimate de novo protein synthesis rates of these two genes, we separated lysates over sucrose gradients and collected 4 separate fractions from increasing gradient depth (Figure 4B). These 4 fractions contain mRNAs associated with an average of 2, 4, 6 and 10 ribosomes per mRNA transcript. The transcript abundance of S1004A and transgelin 2 was determined from each fraction with quantitative RT-PCR. In order to estimate the relative rate of protein production from each fraction, the mRNA abundance was multiplied by the average number of ribosomes per transcript. A relative measure of de novo protein production was estimated by summing this value from each of the 4 fractions. Figure $4 \mathrm{C}$ demonstrates that the rate of protein production of S100A4 and transgelin 2 is increased by more than 2-fold in the pRS 4E-BP1 cells during normoxia. In contrast, the hypoxia induced repression of protein production is not dependent on 4E-BP1 expression. The repression of S100A4 and transgelin 2 during hypoxia is similar to that observed for $\beta$-actin, and reflects the general decrease in cellular protein production under these conditions. Translation efficiency was determined by comparing the amount of protein production divided by the total amount of mRNA in the cell. Since the changes in mRNA abundance were negligible (Figure 4A), the observed changes in protein production (Figure 4C) were in large part a result of changes in translation efficiency (Figure 4D). The translation efficiency increased 2-fold for S100A4 and 4-fold for transgelin 2 during normoxia in the 4E-BP1 knock down compared to the wild type cells (Figure 4D). 
To validate the polysomal data and independently assess that 4E-BP1 expression directly influences protein production we measured the rates of new protein synthesis using $35 \mathrm{~S}$ methionine/cysteine labeling during normoxia for transgelin 2. Following $15 \mathrm{~min}$ starvation, cells were incubated with $35-\mathrm{S}$ labeled methionine/cysteine for 7, 14 or 28 min during normoxic exposure. Total cell lysates were separated on SDS PAGE and examined by autoradiography. Figure 4E demonstrates equal 35S labeling for both cell lines indicating no significant changes between overall rates of protein synthesis, similar to what was found by the polysomal analysis (Figure 2B). Total cell lysates labeled for $14 \mathrm{~min}$ were then immunoprecipitated using a transgelin 2 antibody. In this case, the pRS 4E-BP1 HeLa cells demonstrate a clear increase in $35 \mathrm{~S}$ incorporation for transgelin 2 , thus independently validating the increase in translation observed by polysomal mRNA analysis (Figure 4F). These data suggest that 4E-BP1 inhibits efficient mRNA translation of S100A4 and transgelin 2 during normoxia and affects protein levels during both normoxia and hypoxia.

A

Transcription
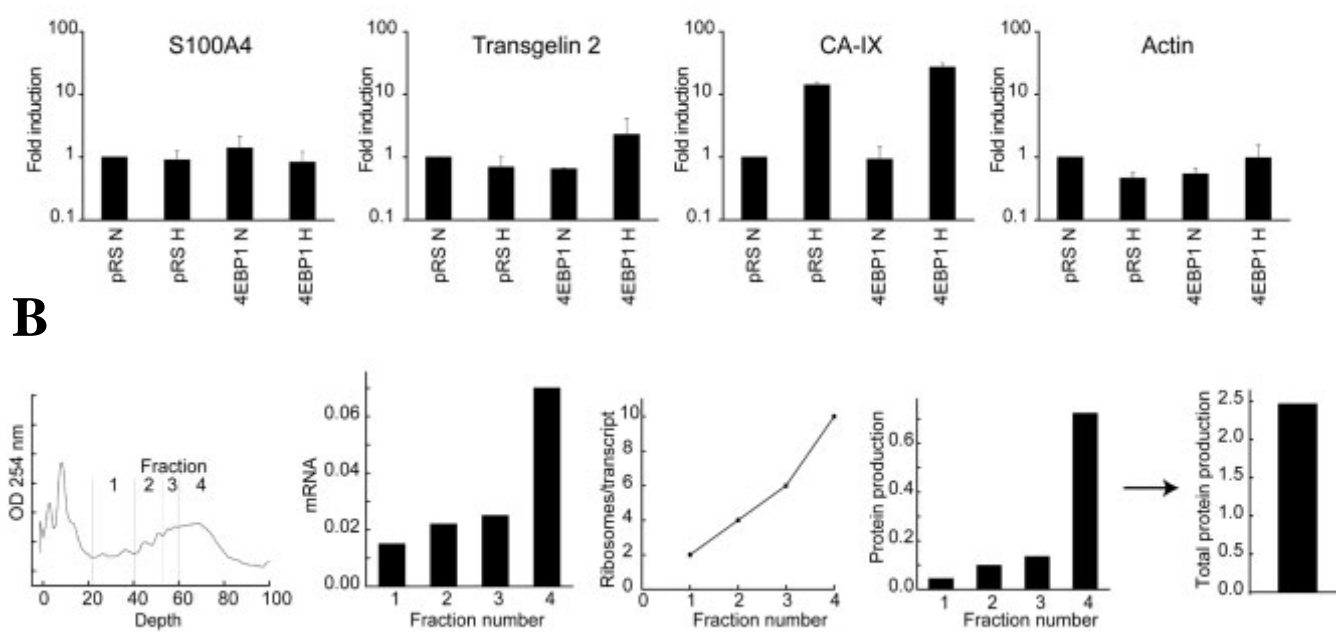
C

\section{Protein Production}

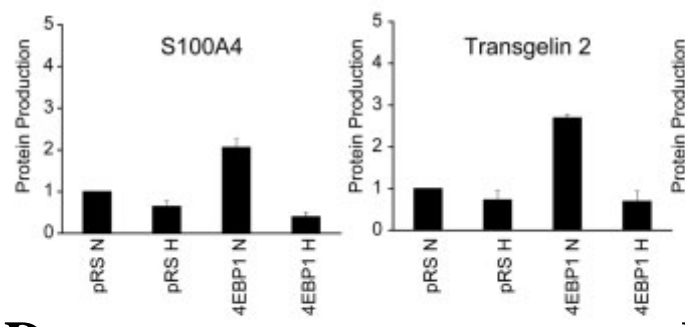

D

Translation Efficiency

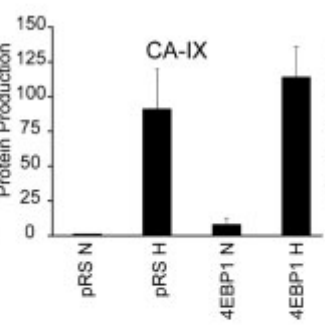

$\mathbf{E}$

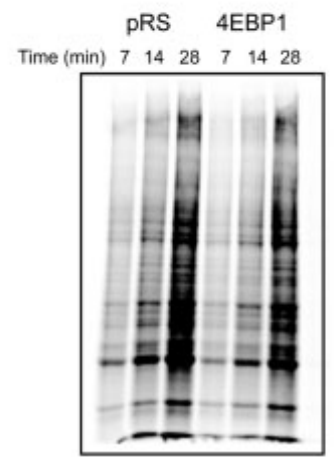

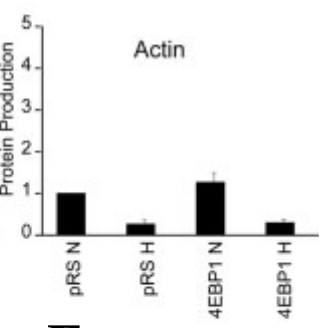

$\mathbf{F}$

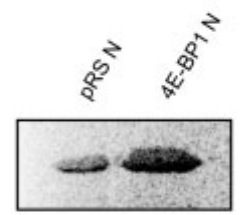

Figure 4: (A) Gene-specific transcript levels are shown for S100A4, transgelin 2, and $\beta$-Actin. CA-IX is used as a control for the hypoxic treatment. Data are normalized to 18S rRNA signal. (B) Schematic representation of the method to assess protein production. mRNA levels for genes of interest are measured in each of four separate fractions isolated at increasing depth in the gradient. The average number of ribosomes per transcript in each of the fractions is estimated based on the positions of the polysome peaks in the gradient. The amount of protein production, which reflects the de novo protein synthesis, is calculated by multiplying the mRNA levels in each fraction by the average number of ribosomes per transcript followed by summing this value in each of the four fractions. (C) Protein production was estimated as described in (B) for S100A4, transgelin 2, CA-IX, and $\beta$-Actin. (D) The relative translation efficiency is assessed by dividing the protein production by the mRNA abundance. Data represent the mean \pm SEM of two independent experiments. (E) Following 15 min starvation, cells were incubated with $100 \mathrm{mCi} 35 \mathrm{~S}$ labeled methionine/cysteine for 7, 14, or 28 min during normoxia and total cell lysates were separated on an SDS-PAGE gel and autoradiographed. (F) Total cell lysates labeled for 14 min were immunoprecipitated using a transgelin 2 antibody followed by SDS-PAGE and autoradiography. 


\section{DISCUSSION}

Previous work from us and others has demonstrated a rapid inhibition of mRNA translation during hypoxia and two distinct pathways have been implicated in this effect. The best understood is the phosphorylation and inhibition of eIF $2 \alpha$, which is responsible for a rapid inhibition of initiation during anoxia. The other is via a reduction in 4E-BP1 phosphorylation, a protein that is regulated by mTOR. Surprisingly, we show here that stable knockdown of 4E-BP1 in HeLa cells does not lead to any significant changes in overall translation, or its inhibition during hypoxia. However, using 2-DE techniques we showed that 4E-BP1 does regulate the protein levels of many different individual proteins. We identified 7 proteins that are robustly and exclusively observed in cells where 4E-BP1 had been knocked down. These proteins are involved in various cellular processes, including metabolism, invasion, protein folding and proliferation. Several of these proteins have previously been linked to cancer and/or hypoxia. The enolase 1 gene promoter contains essential binding sites for the transcription factor HIF-1 $\alpha$ [26] and lactate dehydrogenase- $\mathrm{B}$ has previously been shown to be hypoxia regulated in primary rat and chick retinal cells [27]. Peptidylprolyl isomerise A, also termed cyclophilin A, is found to be overexpressed in different cancer cells and can lead to resistance to hypoxia and cisplatin-induced cell death [28]. Similarly, overexpression of heat shock protein 70kDA 9B (also known as mortalin) has been reported to be prognostic in colorectal cancer [29].

From the seven proteins that we identified, we focused further mechanistic studies of regulation on S100A4 and transgelin 2. Both proteins have been implicated in tumor progression and invasion [24, 25] but are not known to be influenced by hypoxia. S100A4 overexpression is associated with tumor development and progression in colorectal cancer [24]. S100A4 has also been shown to act as a prognostic factor in thyroid carcinoma, where overexpression is associated with the most advanced thyroid carcinomas and lymph node metastasis [30]. A potential mechanism through which S100A4 may exert its effect on tumor progression and metastasis of some tumors is via regulation of matrix metalloproteinase-2 (MMP-2) and matrix metalloproteinase-9 (MMP-9) activity [31, 32]. Similarly, a recent study to identify tumor and tumor-associated antigens in patients with hepatocellular carcinoma (HCC) pointed to transgelin 2 as a potential diagnostic marker for HCC [25]. This protein is thought to be involved in cell proliferation and 
migration, suggesting that its overexpression may contribute to tumor progression.

We report here that 4E-BP1 expression negatively regulates the expression of S100A4 and transgelin 2 during normoxia at the level of mRNA translation initiation. Regulation of translation efficiency is increasingly being recognized as a way to control differential protein expression in response to different conditions including hypoxia [5, 21], hypoxia followed by reoxygenation [33], ionizing radiation [34] as well as by oncogenic signalling pathways [35]. Interestingly, although S100A4 and transgelin 2 are still expressed at the protein level after $16 \mathrm{~h}$ hypoxia in the 2-DE gels, the de novo synthesis of these proteins is still repressed in the pRS 4E-BP1 cells. The reduction in translation efficiency of S100A4 and transgelin 2 was similar to that of $\beta$-actin reflecting the general inhibition in protein synthesis during hypoxia. Thus, in addition to the 4E-BP1 regulation reported here, the synthesis of these proteins is subject to control by additional mechanisms during hypoxia that are similar to that observed for most cellular proteins. There are two likely candidates for this additional regulation. The first is the phosphorylation of eIF $2 \alpha$, which results in the suppression of mRNA translation initiation on a global level and thus affects the rate of synthesis for the vast majority of proteins in the cell. The second candidate is $4 \mathrm{E}-\mathrm{BP} 2$, which like 4E-BP1 is also dephosphorylated during hypoxia and capable of blocking translation initiation. Given the sensitivity of transgelin-2 and S100A4 on 4E-BP1, activation of 4E-BP2 during hypoxia may have strong inhibitor effects on the synthesis of these proteins. However, it is important to point out that the strong affect of 4E-BP1 on the regulation of these proteins during normoxia results in their continued presence in cells exposed to hypoxia for up to 16 hours.

In conclusion we have demonstrated that 4E-BP1 negatively regulates the expression of specific proteins involved in tumor progression and metastasis. This observation may contribute to the increasingly appreciated association between 4E-BP1 and malignancy. For example, an inverse correlation between 4E-BP1 expression and progression in gastrointestinal cancer has been reported [36]. In this study, higher 4E-BP1 levels were found in node-negative patients and patients without distant metastasis. Others have recently shown that phosphorylation and inhibition of 4E-BP1 correlates with poor prognosis in both tumors showing HER2/neu overexpression or 
amplification and high-grade breast tumors in which HER2/neu amplification or overexpression was not detected [37]. It will be interesting to investigate the $4 \mathrm{E}-\mathrm{BP} 1$ translational regulation of S100A4 and transgelin 2 as potential mediators of progression and treatment response in these settings.

\section{ACKNOWLEGDEMENTS}

We wish to acknowledge financial support from the Dutch Science Organization (ZonMW-NWO Top grant 912-03-047 to BW), the Dutch Cancer Society (KWF grant UM 2003-2821 to BW), and the EU $6^{\text {th }}$ framework program (Euroxy program to BW). 


\section{REFERENCES}

[1] Magagnin, MG, Koritzinsky, M, Wouters, BG. Patterns of tumor oxygenation and their influence on the cellular hypoxic response and hypoxia-directed therapies. Drug Resist Updat 2006;9:185-197.

[2] Semenza, GL. Targeting HIF-1 for cancer therapy. Nat Rev Cancer 2003;3:721-732.

[3] Kraggerud, SM, Sandvik, JA, Pettersen, EO. Regulation of protein synthesis in human cells exposed to extreme hypoxia. Anticancer Res 1995;15:683-686.

[4] Hochachka, PW, Buck, LT, Doll, CJ, Land, SC. Unifying theory of hypoxia tolerance: molecular/metabolic defense and rescue mechanisms for surviving oxygen lack. Proc Natl Acad Sci U S A 1996;93:94939498.

[5] Koritzinsky, M, Magagnin, MG, van den Beucken, T, et al. Gene expression during acute and prolonged hypoxia is regulated by distinct mechanisms of translational control. Embo J 2006;25:1114-1125.

[6] Koumenis, C, Naczki, C, Koritzinsky, M, et al. Regulation of protein synthesis by hypoxia via activation of the endoplasmic reticulum kinase PERK and phosphorylation of the translation initiation factor eIF2alpha. Molecular and cellular biology 2002;22:7405-7416.

[7] Pause, A, Belsham, GJ, Gingras, AC, et al. Insulin-dependent stimulation of protein synthesis by phosphorylation of a regulator of 5'cap function. Nature 1994;371:762-767.

[8] Poulin, F, Gingras, AC, Olsen, H, Chevalier, S, Sonenberg, N. 4E-BP3, a new member of the eukaryotic initiation factor 4E-binding protein family. J Biol Chem 1998;273:14002-14007.

[9] Arsham, AM, Howell, JJ, Simon, MC. A novel hypoxia-inducible factor-independent hypoxic response regulating mammalian target of rapamycin and its targets. J Biol Chem 2003;278:29655-29660. 
[10] Brugarolas, J, Lei, K, Hurley, RL, et al. Regulation of mTOR function in response to hypoxia by REDD1 and the TSC1/TSC2 tumor suppressor complex. Genes \& development 2004;18:2893-2904.

[11] Kaper, F, Dornhoefer, N, Giaccia, AJ. Mutations in the PI3K/PTEN/TSC2 pathway contribute to mammalian target of rapamycin activity and increased translation under hypoxic conditions. Cancer research 2006;66:1561-1569.

[12] Connolly, E, Braunstein, S, Formenti, S, Schneider, RJ. Hypoxia inhibits protein synthesis through a 4E-BP1 and elongation factor 2 kinase pathway controlled by mTOR and uncoupled in breast cancer cells. Molecular and cellular biology 2006;26:3955-3965.

[13] Koritzinsky, M, Rouschop, KM, van den Beucken, T, et al. Phosphorylation of eIF2alpha is required for mRNA translation inhibition and survival during moderate hypoxia. Radiother Oncol 2007;83:353-361.

[14] Teleman, AA, Chen, YW, Cohen, SM. 4E-BP functions as a metabolic brake used under stress conditions but not during normal growth. Genes \& development 2005;19:1844-1848.

[15] Tsukiyama-Kohara, K, Poulin, F, Kohara, M, et al. Adipose tissue reduction in mice lacking the translational inhibitor 4E-BP1. Nat Med 2001;7:1128-1132.

[16] Lazaris-Karatzas, A, Montine, KS, Sonenberg, N. Malignant transformation by a eukaryotic initiation factor subunit that binds to mRNA 5' cap. Nature 1990;345:544-547.

[17] De Benedetti, A, Harris, AL. eIF4E expression in tumors: its possible role in progression of malignancies. Int $\mathrm{J}$ Biochem Cell Biol 1999;31:59-72.

[18] Lynch, M, Fitzgerald, C, Johnston, KA, Wang, S, Schmidt, EV. Activated eIF4E-binding protein slows G1 progression and blocks transformation by c-myc without inhibiting cell growth. J Biol Chem 2004;279:3327-3339. 
[19] Jiang, H, Coleman, J, Miskimins, R, Miskimins, WK. Expression of constitutively active 4EBP-1 enhances p27Kip1 expression and inhibits proliferation of MCF7 breast cancer cells. Cancer Cell Int 2003;3:2.

[20] Brummelkamp, TR, Bernards, R, Agami, R. A system for stable expression of short interfering RNAs in mammalian cells. Science 2002;296:550-553.

[21] Koritzinsky, M, Seigneuric, R, Magagnin, MG, van den Beucken, T, Lambin, P, Wouters, BG. The hypoxic proteome is influenced by genespecific changes in mRNA translation. Radiother Oncol 2005;76:177186.

[22] Bradford, MM. A rapid and sensitive method for the quantitation of microgram quantities of protein utilizing the principle of protein-dye binding. Anal Biochem 1976;72:248-254.

[23] Sule, A, Vanrobaeys, F, Hajos, G, Van Beeumen, J, Devreese, B. Proteomic analysis of small heat shock protein isoforms in barley shoots. Phytochemistry 2004;65:1853-1863.

[24] Cho, YG, Kim, CJ, Nam, SW, et al. Overexpression of S100A4 is closely associated with progression of colorectal cancer. World $\mathrm{J}$ Gastroenterol 2005;11:4852-4856.

[25] Shi, YY, Wang, HC, Yin, YH, et al. Identification and analysis of tumour-associated antigens in hepatocellular carcinoma. Br J Cancer 2005;92:929-934.

[26] Semenza, GL, Jiang, BH, Leung, SW, et al. Hypoxia response elements in the aldolase A, enolase 1, and lactate dehydrogenase A gene promoters contain essential binding sites for hypoxia-inducible factor 1 . J Biol Chem 1996;271:32529-32537.

[27] Buono, RJ, Lang, RK. Hypoxic repression of lactate dehydrogenase-B in retina. Exp Eye Res 1999;69:685-693. 
[28] Choi, KJ, Piao, YJ, Lim, MJ, et al. Overexpressed cyclophilin A in cancer cells renders resistance to hypoxia- and cisplatin-induced cell death. Cancer research 2007;67:3654-3662.

[29] Dundas, SR, Lawrie, LC, Rooney, PH, Murray, GI. Mortalin is overexpressed by colorectal adenocarcinomas and correlates with poor survival. J Pathol 2005;205:74-81.

[30] Zou, M, Famulski, KS, Parhar, RS, et al. Microarray analysis of metastasis-associated gene expression profiling in a murine model of thyroid carcinoma pulmonary metastasis: identification of S100A4 (Mts1) gene overexpression as a poor prognostic marker for thyroid carcinoma. J Clin Endocrinol Metab 2004;89:6146-6154.

[31] Mathisen, B, Lindstad, RI, Hansen, J, et al. S100A4 regulates membrane induced activation of matrix metalloproteinase-2 in osteosarcoma cells. Clin Exp Metastasis 2003;20:701-711.

[32] Saleem, M, Kweon, MH, Johnson, JJ, et al. S100A4 accelerates tumorigenesis and invasion of human prostate cancer through the transcriptional regulation of matrix metalloproteinase 9. Proc Natl Acad Sci U S A 2006;103:14825-14830.

[33] Magagnin, MG, Sergeant, K, van den Beucken, T, et al. Proteomic analysis of gene expression following hypoxia and reoxygenation reveals proteins involved in the recovery from endoplasmic reticulum and oxidative stress $>$. Radiother Oncol 2007;83:340-345.

[34] Lu, X, de la Pena, L, Barker, C, Camphausen, K, Tofilon, PJ. Radiation-induced changes in gene expression involve recruitment of existing messenger RNAs to and away from polysomes. Cancer research 2006;66:1052-1061.

[35] Rajasekhar, VK, Viale, A, Socci, ND, Wiedmann, M, Hu, X, Holland, EC. Oncogenic Ras and Akt signaling contribute to glioblastoma formation by differential recruitment of existing mRNAs to polysomes. Mol Cell 2003;12:889-901. 
[36] Martin, ME, Perez, MI, Redondo, C, Alvarez, MI, Salinas, M, Fando, JL. 4E binding protein 1 expression is inversely correlated to the progression of gastrointestinal cancers. Int $\mathrm{J}$ Biochem Cell Biol 2000;32:633-642.

[37] Rojo, F, Najera, L, Lirola, J, et al. 4E-binding protein 1, a cell signaling hallmark in breast cancer that correlates with pathologic grade and prognosis. Clin Cancer Res 2007;13:81-89. 
Chapter 4 


\section{Chapter 5}

\section{Inhibition of 4E-BP1 sensitizes U87 glioblastoma xenograft tumors to irradiation through increased sensitivity to hypoxia induced cell death}

M.G.P. Magagnin, L. Dubois, A.H.G. Cleven, S.A. Weppler, B. Grenacher, W. Landuyt, N. Lieuwes, P. Lambin, T.A. Gorr, M. Koritzinsky, and B.G. Wouters

Submitted to Radiotherapy and Oncology 


\section{ABSTRACT}

Eukaryotic initiation factor $4 \mathrm{E}$ (eIF4E) is an essential rate-limiting factor for cap-dependent translation in eukaryotic cells. Elevated eIF4E activity is common in many human tumors and is associated with disease progression through its ability to enhance the translation of genes such as cyclin D1, c-Myc and VEGF. The growth promoting effects of eIF4E are in turn negatively regulated by $4 \mathrm{E}-\mathrm{BP} 1$. However, although 4E-BP1 harbors anti-growth activity, its expression is paradoxically elevated in some tumors. We investigated the consequences of loss of 4E-BP1 expression in HeLa and U87 cells following stable expression of a short hairpin interfering RNA (shRNA) specific for 4E$\mathrm{BP} 1$. We found that loss of 4E-BP1 expression did not significantly alter growth during optimal in vitro conditions but did accelerate the growth of U87 tumor xenografts, consistent with the growth promoting function of deregulated eIF4E. However, cells lacking 4E-BP1 were significantly more sensitive to hypoxia induced cell death in vitro. Furthermore, 4E-BP1 knockdown cells produced tumors that were more sensitive to radiation due to a reduction in the viable fraction of radioresistant hypoxic cells. Decreased hypoxia tolerance in the 4E-BP1 knockdown tumors was evident by increased levels of cleaved caspase- 3 and was associated with a reduction in ATP. These data suggest that although tumors often demonstrate increases in capdependent translation, regulation of this activity is required to facilitate energy conservation, hypoxia tolerance and tumor radioresistance. Our results suggest that targeting translational control may be an effective way to target hypoxic cells and radioresistance in metabolically hyperactive tumors. 


\section{INTRODUCTION}

Regulation of mRNA translation, the synthesis of protein from mRNA, has emerged as an important mechanism for controlling cell growth and proliferation. Several canonical signaling cascades function in part by mediating changes in mRNA translation efficiency that influence the synthesis of various proteins that are critical for cell growth, differentiation, and adaptation to cellular stress $[1,2]$. The process of translation can be divided into initiation, elongation, and termination phases, with the initiation step being rate-limiting and the most common target of regulation. Translational initiation is controlled by a large family of eukaryotic initiation factors (eIFs) [3] and for most eukaryotic mRNAs begins with the recruitment of the small ribosomal subunit (40S) to its $5^{\prime}$ cap ( $\left.\mathrm{m}^{7} \mathrm{GpppX}\right)$. This occurs via a series of interactions between the cap-binding protein eIF4E, the scaffolding protein eIF4G, the ATP-dependent RNA helicase eIF4A (collectively named the eIF4F complex) and the ribosome-associated eIF3 complex.

eIF4E availability is rate-limiting for the initiation step and is tightly controlled by a class of inhibitory proteins termed eIF4E binding proteins (4EBP1, 4E-BP2 and 4E-BP3), with 4E-BP1 being the best characterized [4, 5]. In its hypophosphorylated form, 4E-BP binds to eIF4E and prevents its association with eIF4G, thereby inhibiting cap-dependent translation. Conversely, translation is stimulated following phosphorylation of 4E-BP1 on multiple residues which stimulates dissociation from eIF4E. Changes in the availability of eIF4E differentially influence gene expression. Many growth and proliferation related proteins are encoded by mRNAs containing long and highly structured 5'UTRs, which have low translational efficiency. Examples include genes with important roles in cancer such as cyclin D1, c-Myc, VEGF and MMP9. These transcripts have been termed "weak" mRNAs and show strong sensitivity to the availability of eIF4E [6]. In contrast, "strong" mRNAs with relatively short and unstructured 5'UTRs, show less eIF4E dependency and typically code for more generally expressed and house-keeping proteins [7, 8]. Through this mechanism, malignancy-associated events are directly linked to eIF4E activity [9].

Phosphorylation and inactivation of 4E-BP1 is carried out in response to activation of the mammalian target of rapamycin complex 1 (mTORC1), which acts downstream of the PI3K/AKT and AMPK kinase signaling 
pathways. Consequently, receptor signaling in response to mitogenic stimulation leads to increased rates of cap-dependent translation in an mTOR and 4E-BP1 dependent manner [10]. In cancer, increased eIF4E activity has been reported in many tumors as a consequence of increased signaling through the $\mathrm{PI} 3 \mathrm{~K} / \mathrm{AKT} / \mathrm{mTOR}$ pathway and/or overexpression of eIF4E itself [6]. Overexpression of eIF4E is sufficient to transform cells in culture and has been reported to occur in breast, head and neck, lung, colon, non-Hodgkin's lymphoma, cervical and bladder cancers [11]. Similarly, the PI3K/AKT/mTOR pathway is commonly upregulated in many cancers through inactivation of the PTEN tumor suppressor or mutation/overexpression of various receptor tyrosine kinases $[12,13]$.

Consistent with its ability to inhibit eIF4E, 4E-BP1 has been reported to have a number of anti-proliferative and tumor suppressor functions. Overexpression of either wild-type 4E-BP1 or the dominant active mutant (A37/A46) results in enhanced translational repression and pronounced cell death following treatment with anticancer agents and decreased tumorigenicity in xenograft models [14]. 4E-BP1 has been suggested as a prognostic factor in ovarian cancer, where increased levels of phoshorylated (inactive) 4E-BP1 are associated with high-grade tumors and a poor prognosis [15]. Furthermore, we recently showed that loss of 4E-BP1 results in increased translation of S100 calcium-binding protein A4 (S100A4) and transgelin 2, proteins associated with tumor cell motility, invasion and metastasis [16]. These data support a potential tumor suppressor function for 4E-BP1. Nevertheless, there are no reports that loss of 4E-BP1 expression occurs in cancer and knockout mice lacking 4E-BP1 show no tumor predisposition [17]. In fact, it was recently reported that a large fraction of advanced breast cancers overexpress $4 \mathrm{E}-\mathrm{BP} 1$ [18].

Thus, despite its anti-growth properties, 4E-BP1 may participate in functions that are important in cancer. In this regard, we and others have recently shown that hypoxia, a frequent condition of solid tumors, inhibits mRNA translation in part through decreased mTOR signaling and disruption of the eIF4F complex [19-22]. Hypoxia associated inhibition of cap-dependent translation occurs through sequestration of eIF4E by 4E-BP1 and by the transporter 4E-T, which translocates eIF4E to the nucleus and to cytoplasmic bodies of mRNA processing (P-bodies) [21]. The aim of this study was to evaluate the biological consequences of 4E-BP1 expression on hypoxia tolerance and tumor growth. Our results indicate that inhibition of cap- 
dependent translation through 4E-BP1 is important for maintaining energy homeostasis and hypoxia tolerance.

\section{MATERIAL AND METHODS}

\section{Cell culture and cell transfections}

Cervix carcinoma (HeLa) cells and glioblastoma (U87) cells were grown in Dulbecco's modified Eagle's medium (Sigma) supplemented with 10\% fetal bovine serum (Sigma) at $37^{\circ} \mathrm{C}$ in a $5 \% \mathrm{CO}_{2}$ incubator. HeLa and $\mathrm{U} 87$ cells were stably transfected with pRetroSuper [23] which was either empty (pRS) or which generated a short hairpin interfering RNA against 4E-BP1 (pRS 4EBP1) with the following targeting sequence: gtttgagatggacatttaa.

In vitro cell growth

26000 pRS and pRS 4E-BP1 U87 cells were seeded in duplicate wells of a 24well plate. After 2-4 days of incubation under normal culture conditions, cells were washed with phosphate-buffered saline and trypsinized. Total cell numbers were enumerated using a Coulter Counter (Beckman Coulter) and normalized to the number of cells present at day 0 .

Polysomal fractionation and analysis

Experiments were performed as previously described [21].

\section{Western blot analysis}

Experiments were performed as previously described [16]. Briefly, whole cell extracts were resolved in SDS-PAGE gels and transferred onto Hybond-PVDF membranes (Amersham Biosciences). The membranes were probed overnight with antibodies directed to 4E-BP1 (Cell Signaling Technology) or $\beta$-actin (Sigma). Bound antibodies were visualized using horseradish peroxidaseconjugated secondary antibody (anti-rabbit (Cell Signaling Technology) and anti-mouse (Sigma)) and ECL luminescence (Pierce).

\section{Clonogenic survival assay}

Clonogenic survival assays were studied in pRS and pRS 4E-BP1 HeLa cells after hypoxic treatment. Cells were seeded in triplicate into $60 \mathrm{~mm}$ dishes in a range of $200-100000$ cells per dish, depending on the stringency of the treatments. Once the cells were attached, a hypoxic treatment of $0,16,24$ or 48 
$\mathrm{h}$ was applied. After hypoxia, cells were cultured at $37^{\circ} \mathrm{C}$ in a $5 \% \mathrm{CO}_{2}$ incubator for an additional 14 days. The colonies were stained with crystal violet and methanol for $1 \mathrm{~h}$ and colonies containing $\geq 50$ cells were counted. The fraction of surviving cells was normalized to the surviving fraction of the corresponding control. The clonogenic survival assays after ionizing radiation were performed in a similar set-up and cells received a single dose of 0,2 or 4 Gy.

\section{Cell viability assay}

A total of 5000 pRS and pRS 4E-BP1 U87 cells were cultured in a 96-well plate for $24 \mathrm{~h}$. The cells were exposed to either normoxia or hypoxia $(<0.01 \%$ $\mathrm{O}_{2}$ ). After 1 or 2 days of hypoxic treatment, $20 \mu \mathrm{L}$ of CellTiter $96 \mathrm{AQ}_{\text {ueous }}$ One Solution Reagent (Promega) was added directly to $100 \mu \mathrm{L}$ of culture medium and incubated for $2 \mathrm{~h}$ at $37^{\circ} \mathrm{C}$. The absorbance was measured at $490 \mathrm{~nm}$ using a 96-well plate reader (Bio-Rad Laboratories) to quantify the number of viable cells. For the ionizing radiation (IR) experiments cells received a single dose of 0,4 or 10 Gy. 72 hours post treatment the number of viable cells was evaluated as described for the hypoxic experiment.

\section{Animal experiments}

$3 \times 10^{6}$ pRS U87 and pRS 4E-BP1 U87 cells were resuspended in $100 \mu 1$ growth medium and injected subcutaneously into the lateral flank of adult NMRI-nu $(\mathrm{nu} / \mathrm{nu})$ female mice (28-32 g). Tumors were measured with a Vernier Calliper in three orthogonal diameters $\mathrm{A}, \mathrm{B}$ and $\mathrm{C}$, each corrected for thickness of the skin. Tumor volumes were calculated based on the formula A x B x C x $\pi / 6$. Once tumor volumes reached an average of $250 \mathrm{~mm}^{3}$, animals were anaesthetized with $0.1 \mathrm{ml}$ per $100 \mathrm{~g}$ body weight (b.w.) sodium pentobarbital (Nembutal; Sanofi, Belgium), placed on a lucite plate and the tumor was positioned in the irradiation field using a custom-built jig. All irradiated tumors received a single dose of $10 \mathrm{~Gy}(16 \mathrm{meV} \mathrm{e}$ ) using a Linear Accelerator (Linac Systems). When tumors reached four times the volume at the time of irradiation, animals were sacrificed and tumors were excised. The animal facilities and experiments were all performed in agreement with the national guidelines for animal welfare and approved by the Animal Ethics Committee of the University 'KU Leuven' Belgium.

\section{ATP assay}

$0.1 \mathrm{~g}$ of pRS U87 and pRS 4E-BP1 U87 tumor tissue was homogenized in 500 $\mu \mathrm{L}$ of RIPA buffer (150mM NaCl, $1 \%$ NP-40, $0.5 \%$ Na-deoxycholate, $0.1 \%$ 
SDS, 50mM Tris pH 7.5 and Complete ${ }^{\mathrm{TM}}$ (Roche) protease inhibitor cocktail). Lysates were centrifuged at $16000 \mathrm{~g}$ for $2 \mathrm{~min}$ at $4^{\circ} \mathrm{C}$ to remove contaminants like DNA. The supernatant was collected in a cold microcentrifuge tube containing 5\% trichloroacetic acid (TCA) and ATP concentrations were determined using an Adenosine 5' triphosphate (ATP) Bioluminescent Assay Kit (Sigma).

\section{Detection of hypoxic areas in tumors}

To allow assessment of the hypoxic regions within tumors, mice were injected i.p. with the hypoxic marker pimonidazole $(60 \mathrm{mg} / \mathrm{kg}$ b.w.; Hypoxyprobe-2, Chemicon) 1 hour prior to sacrifice. Tumors were excised, fixed overnight in $4 \%$ neutral buffered formaldehyde and embedded in paraffin. $5 \mu \mathrm{m}$ sections were deparaffinized in xylene, rehydrated in a graded alcohol series and finally with water. Endogenous peroxidase was quenched using $0.3 \%$ hydrogen peroxide in absolute methanol. Epitope retrieval was done by microwave treatment in the presence of $10 \mathrm{mM}$ sodium citrate $(\mathrm{pH}$ 6.0). Sections were incubated with a FITC-labeled mouse monoclonal antibody against pimonidazole (1:50 dilution, Chemicon) for $60 \mathrm{~min}$ at RT. A secondary mouse anti-FITC HRP conjugated antibody was applied (1:50 dilution, Chemicon) and staining was visualized using the DAB chromogen (Dako). Sections were rinsed and counterstained with hematoxylin (Klinipath).

\section{Immunohistochemical analysis of proliferation}

Briefly, $5 \mu \mathrm{m}$ sections were deparaffinized and incubated with mouse on mouse (MOM) blocking reagent in 10\% normal goat serum for $70 \mathrm{~min}$ at RT. A mouse monoclonal PCNA antibody (1:500 dilution, Chemicon) was applied for $30 \mathrm{~min}$ at RT. A secondary biotinylated goat anti-mouse antibody (1:500 dilution, DakoCytomation) was applied, followed by incubation with the vectastain $A B C$ kit (1:200 dilution, Vector Laboratories). Staining was visualized using DAB chromogen (Dako). Sections were rinsed and counterstained with hematoxylin (Klinipath).

\section{Visualization of blood vessels}

In order to visualize blood vessels, deparaffinized sections were incubated with rabbit polyclonal CD31 antibody (1:400 dilution, Santa Cruz) for $50 \mathrm{~min}$ at RT. A secondary biotinylated goat anti-rabbit antibody (1:500 dilution, DakoCytomation) was applied, followed by incubation with the vectastain ABC kit (1:200 dilution, Vector Laboratories). Staining was visualized using 
DAB chromogen (Dako). Sections were rinsed and counterstained with hematoxylin (Klinipath).

\section{Immunohistochemical analysis of apoptosis}

Deparaffinized sections were incubated with a rabbit cleaved caspase-3 (Asp 175) monoclonal antibody (1:100 dilution, Cell Signaling) overnight at $4^{\circ} \mathrm{C}$. A secondary PowerVision HRP anti-rabbit antibody (undiluted, Immunologic) was applied. Staining was visualized using DAB chromogen (Dako). Sections were rinsed and counterstained with hematoxylin (Klinipath).

\section{Statistical analysis}

Comparisons between cells transfected with the 4E-BP1-targeting shRNA (pRS 4E-BP1) and control cells (pRS) and ATP measurements within tumors were determined using a Student's t test. For in vivo experiments, statistical analyses were performed with a two-tailed, unpaired Mann-Whitney $U$ test. Error bars indicate standard deviations and $\mathrm{P}$ values less than 0.05 are considered statistically significant.

\section{RESULTS}

To investigate the role of 4E-BP1 on tumor growth, hypoxia tolerance and response to treatment we used previously constructed HeLa cervix carcinoma cells stably expressing an shRNA against 4E-BP1 (referred to as pRS 4E-BP1 $\mathrm{HeLa}$ ) [16]. To facilitate analysis of the role of 4E-BP1 in tumor xenografts, we also stably expressed this same shRNA or an empty vector control in glioblastoma U87 cells. The U87 cells form rapidly growing xenografts in vivo that are resistant to radiotherapy due in part to the presence of tumor hypoxia [24]. The shRNA against 4E-BP1 was effective in U87 cells as assessed by quantitative RT-PCR and similar in magnitude to that which we have previously reported in HeLa cells (Figure 1A). The shRNA against 4E-BP1 has no effect on 4E-BP2 transcript levels, demonstrating the specificity of the shRNA for 4E-BP1 and absence of compensation by the paralog. Stable knockdown of 4E-BP1 in U87 cells was also observed at the protein level and similar in magnitude to that for the previously generated HeLa cells (Figure 1B). We previously reported that stable knockdown of 4E-BP1 in HeLa cells does not alter their proliferation under standard tissue culture conditions [16]. Similarly, no effect on proliferation was observed in the U87 4E-BP1 
knockdowns compared with their wild-type controls (Figure 1C). These data suggest that under optimal growth conditions in vitro, proliferation rates are not limited by eIF4E availability.

A

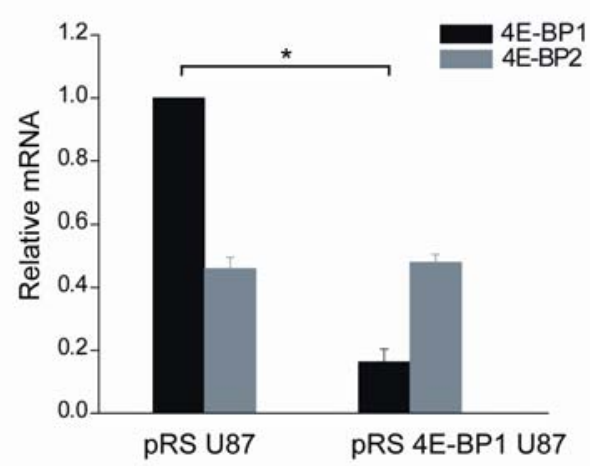

B

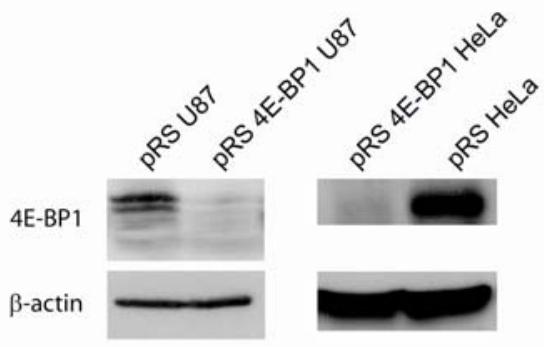

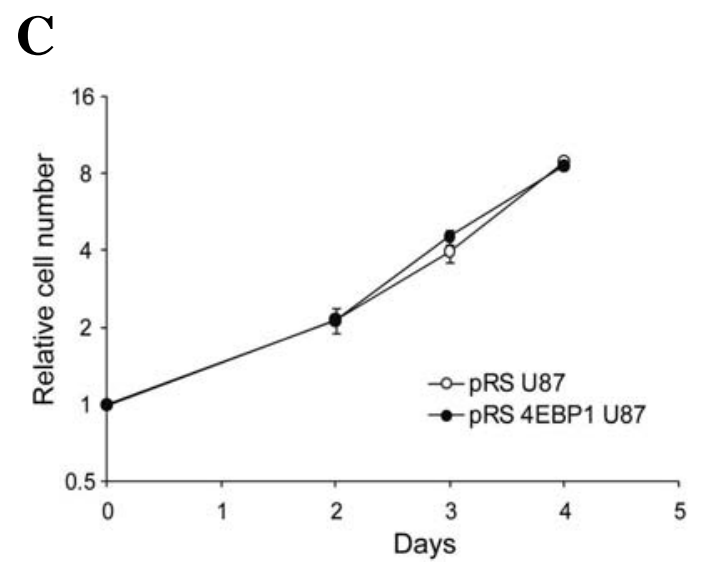

Figure 1: (A) 4E-BP1 and 4E-BP2 transcript levels in pRS and pRS 4E-BP1 U87 cells reported as mean $\pm \mathrm{SD}$ of triplicate $\mathrm{q}-\mathrm{RT}-\mathrm{PCR}$ measurements $(* \mathrm{P}<0.05$ vs control cells). (B) Western blots demonstrating reduced 4E-BP1 protein expression levels in the pRS 4E-BP1 cells. (C) Proliferation rates of pRS U87 and pRS 4E-BP1 U87 cells were monitored by counting cells following 2, 3 and 4 days of growth. Error bars represent standard deviation of the mean. Data points represent the mean $\pm \mathrm{SD}$ of triplicate measurements.

Recent reports by us and others have shown that signaling to 4E-BP1 occurs during hypoxia and is responsible for important changes in gene 
expression [16, 21, 22]. However, the consequences of this effect for hypoxia tolerance in vitro or in vivo have not been adequately addressed. We therefore assessed the tolerance of these cells to conditions of severe hypoxia $(<0.02 \%)$ that are sufficient to induce cell death [25]. Figure 2 indicates that loss of 4EBP1 significantly $(\mathrm{P}<0.05)$ reduces the tolerance of both HeLa and U87 cells to prolonged (48hr) hypoxia exposure. In the HeLa cells, hypoxia tolerance could be assessed by direct measurements of clonogenic survival (Figure 2A). However, lack of sufficient U87 colony formation in vitro necessitated the use of a less informative cell viability assay. However, a significant decrease in cell survival $(\mathrm{P}<0.05)$ was also observed in the U87 4E-BP1 knockdown cells after $48 \mathrm{~h}$ of hypoxia compared to the empty vector controls (49\% survival for pRS U87 cells versus 24\% survival for pRS 4E-BP1 U87 cells) (Figure 2B). The data from both cell lines are thus consistent and indicate an important function for 4E-BP1 in maintaining cell survival during hypoxic stress. 
A

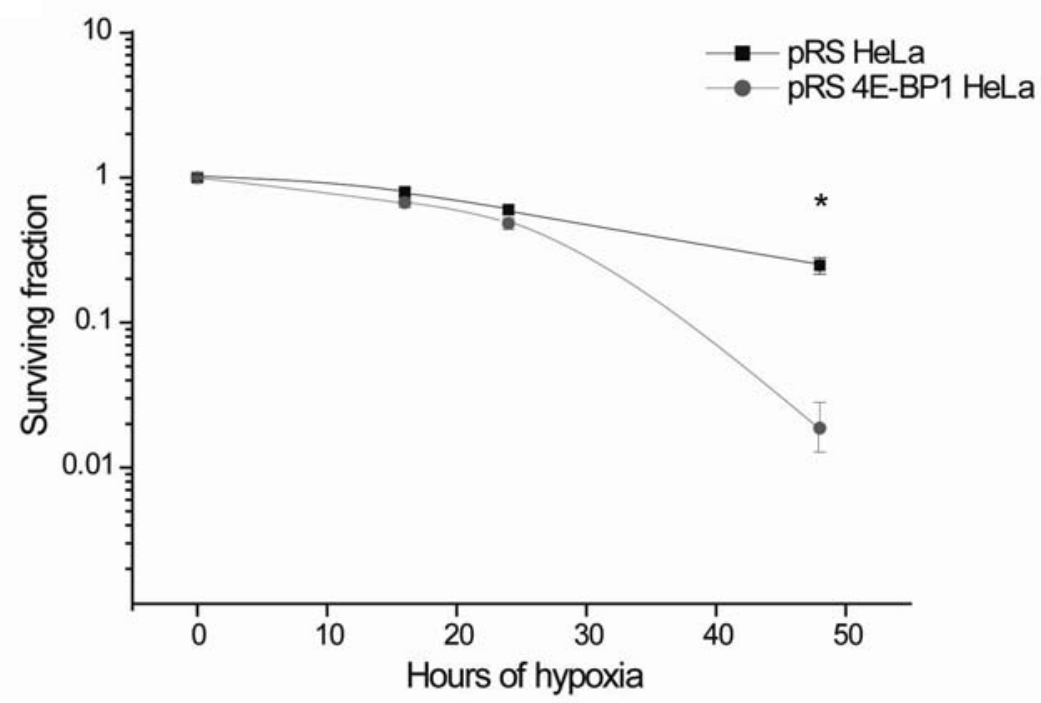

B

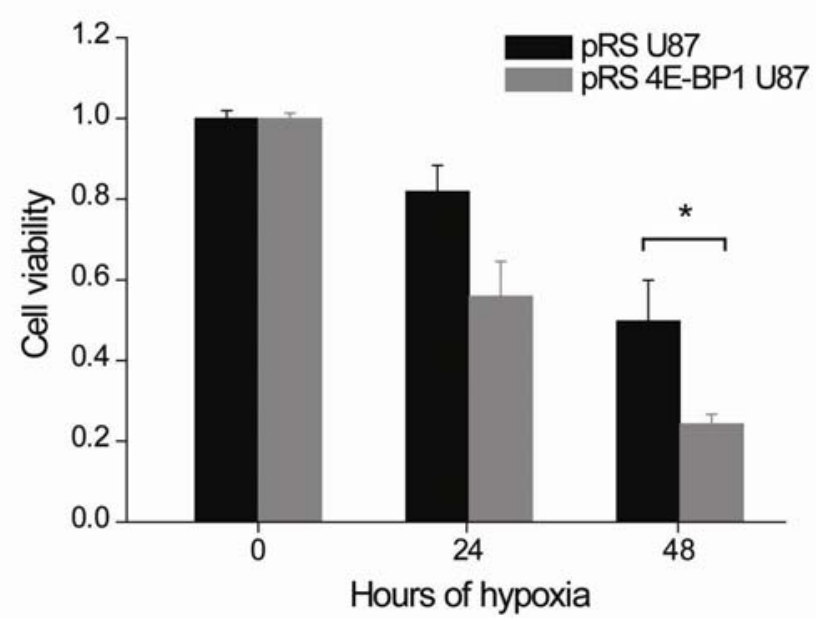

Figure 2: (A) A clonogenic survival assay was performed after pRS and pRS 4E-BP1 HeLa cells were exposed to 16,24 and 48 hours of hypoxia $(<.02 \%)$. Data points represent the mean $\pm \mathrm{SD}$ of triplicate measurements $(* \mathrm{P}<0.05$ vs control cells). (B) Cell viability assay for pRS and pRS 4E-BP1 U87 cells after 24 and 48 hours of hypoxia. Columns report the mean \pm SD of duplicate measurements ( $* \mathrm{P}<0.05$ vs control cells). 
To investigate the consequences of 4E-BP1 knock-down in tumor growth and treatment pRS U87 and pRS 4E-BP1 U87 cells were injected subcutaneously into the lateral flank of adult NMRI-nu (nu/nu) female mice. The rate of tumor growth was assessed by regular measurements of tumor size as a function of time (Figure 3A). Consistent with its role in negatively regulating eIF4E, knock-down of 4E-BP1 resulted in a small but significant ( $\mathrm{P}$ $<0.01)$ increase in growth rate. The median doubling-time determined from analysis of growth curves from individual 4E-BP1 knockdown tumors was 2.71 days compared to 4.04 days in the controls (Figure 3B). These data are in contrast with the in vitro growth results and suggest that regulation of eIF4E plays a more important role in proliferation in vivo. This is not surprising considering that features of the microenvironment, including fluctuations in oxygen, nutrient and growth factor availability all signal to 4E-BP1 via mTORC1. The data are also consistent with previous studies showing that eIF4E activity is an important contributor to tumor growth [26, 27].

The tumor microenvironment is a strong determinant of tumor response to radiotherapy. To determine if 4E-BP1 influences tumor response to radiation, tumors were irradiated with a dose of 10 Gy after they reached a size of $250 \mathrm{~mm}^{3}$. This dose resulted in a significant growth delay for both tumor types and caused little to no skin toxicity. We determined the specific growth delay which is calculated by determining the difference in time required to meet a defined tumor size relative to the doubling time of the tumor. This value is thought to closely reflect the relative number of cells killed by treatment. Interestingly, we found that the specific growth delay determined at 2, 3, or 4 times the starting tumor volume was significantly higher $(\mathrm{P}<0.01)$ in the $\mathrm{pRS}$ 4E-BP1 U87 tumors compared to the pRS U87 control tumors (Figure 3C). The response of tumors to such a large single dose is governed primarily by the fraction of viable hypoxic cells since these cells require up to three times more dose to achieve a similar level of cell kill as well-oxygenated cells. Thus, these data are consistent with a smaller number of viable hypoxic cells in the 4E-BP1 knock-down tumors. 


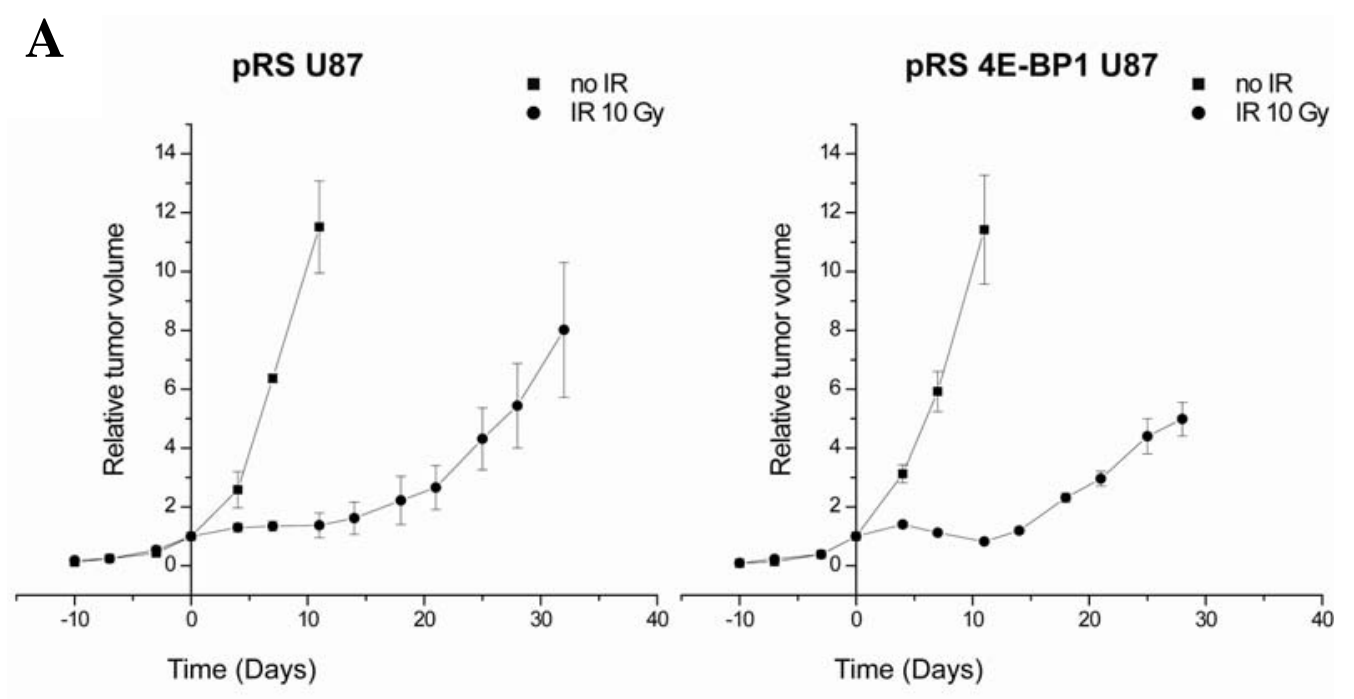

B

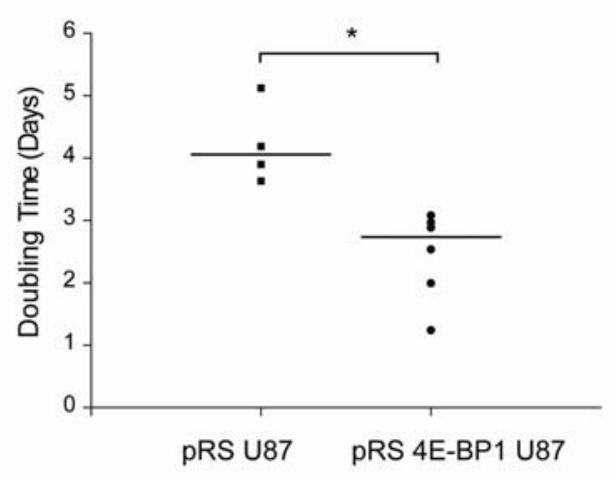

Specific growth delay

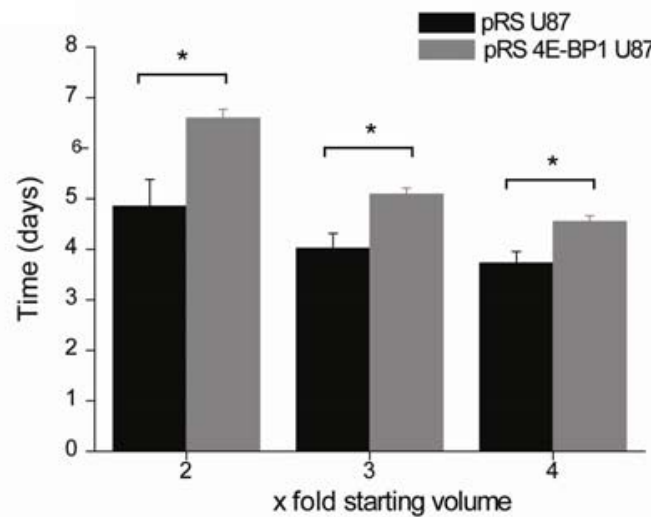

Figure 3: (A) Tumor xenografts were established and followed in immunodefecient mice before and following irradiation. A single dose of 10 Gy was administered when tumors reached a size of $250 \mathrm{~mm}^{3}$. Data shown are the average and standard deviation of from a total of 4-6 tumors in each group and are normalized to the mean size at the time of irradiation. (B) The doubling times of individual untreated pRS U87 and pRS 4E-BP1 U87 xenografts tumors were calculated $(* \mathrm{P}<0.01$ vs control tumors). (C) The specific growth delay for individual irradiated tumors from both tumor types was calculated as the time required to reach 2,3 or 4 times the starting volume divided by the time to reach the same volume in the unirradiated controls. The 4E-BP1 knockdown tumors have a significantly longer specific growth delay $(* \mathrm{P}$ $<0.01$ vs control tumors). 
The increased sensitivity of the 4E-BP1 knock-down tumors could also result from a direct effect on tumor cell radiosensitivity. This was investigated by measuring the response of both HeLa and U87 4E-BP1 knock-down and control cell lines to a range of radiation doses in vitro (Figure 4). In HeLa cells, loss of 4E-BP1 provides a small level of protection rather than sensitization to irradiation with 2 Gy or 4 Gy as measured by clonogenic survival (Figure 4A). In contrast, a growth/viability assay indicated a small but non-significant increase in radiosensitivity to doses of 4 or 10 Gy in U87 cells with stable knock-down of 4E-BP1 (Figure 4B, $\mathrm{P}=0.075$ ). Thus, although we cannot rule out a contribution of changes in radiosensitivity to the increased growth delay in the 4E-BP1 knock-down tumors, this effect is small and not consistent between the two cell lines. 
A

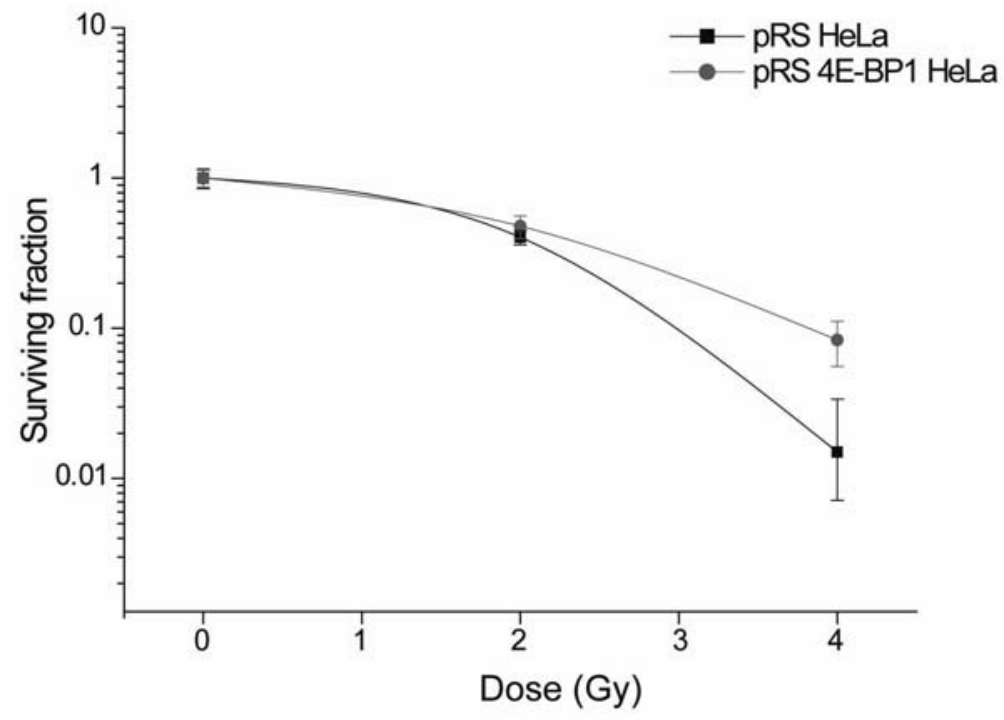

B

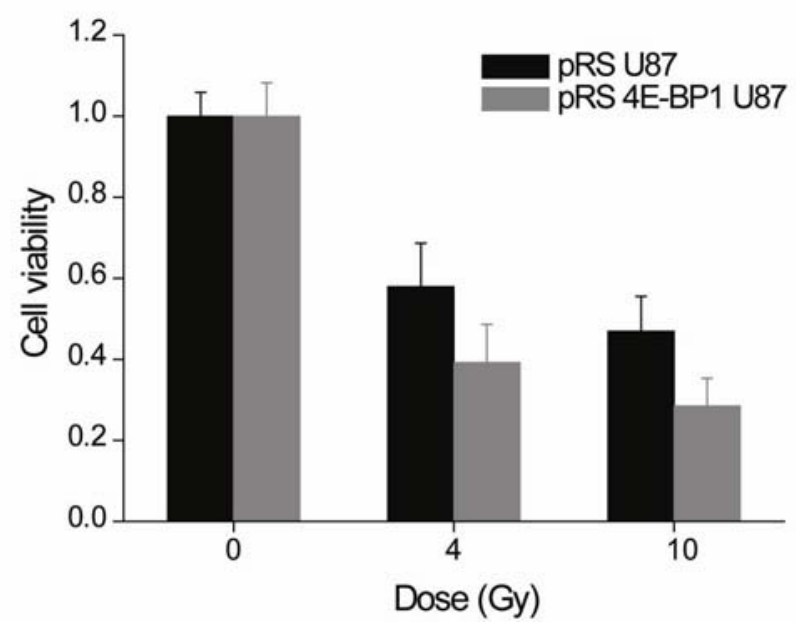

Figure 4: (A) A clonogenic survival assay was performed after HeLa pRS and pRS 4E-BP1 cells were exposed to 2 and $4 \mathrm{~Gy}$ of irradiation. Data points are the mean $\pm \mathrm{SD}$ of duplicate measurements. (B) Cell viability assay for U87 pRS and pRS 4E-BP1 cells after 4 and 10 Gy of irradiation. The mean $\pm \mathrm{SD}$ of duplicate measurements is reported. 
To investigate more directly if the increased radiosensitivity of pRS 4EBP1 U87 tumors was instead due to changes in the microenvironment we prepared tumor sections and performed immunohistochemical analyses with markers for hypoxia, blood vessel density, proliferation and apoptosis. Evaluation of the different markers was performed blindly by semi-quantitative measurement. To identify the hypoxic areas within the tumors, we used pimonidazole (PIMO) staining, which was quantified as $<10 \%$ tumor area positive, $\geq 10 \%$ and $<50 \%$ positive or $\geq 50 \%$ positive. Furthermore, the intensity of PIMO staining was indicated as weak or strong. PIMO staining was detected primarily within the peri-necrotic areas within all tumors and no significant differences in the amount or severity of hypoxia was detected between control and 4E-BP1 knock-down tumors (Table 1). Similarly, both tumor types were highly proliferative with greater than 50\% PCNA positive cells in the viable areas of the tumors. These data indicate that development of hypoxia is similar in both tumor types.

To evaluate the cellular consequences of hypoxia, we assessed blood vessel density (CD31) and apoptosis (cleaved caspase 3) within the hypoxic areas in the tumors. We did not observe any CD31-positive endothelial cells in PIMO-positive areas in parallel sections of all tumor types (Table 1). These data suggest that the hypoxia detected by PIMO staining is typical of diffusion limited hypoxia in both tumor types. Hypoxia in poorly vascularized regions develops due to gradients of oxygenation around perfused vessels and is referred to as chronic hypoxia. Overall, both tumor types demonstrated low expression of cleaved caspase-3. However, apoptosis in hypoxic regions (as indicated by positive PIMO staining) was significantly greater in the 4E-BP1 knock-down tumors compared to the control tumors (Figure 5A, Table 1). Control tumors did not demonstrate any enhancement of cleaved caspase- 3 staining in these areas compared to non-hypoxic regions, whereas caspase 3 activity was highly enriched in the hypoxic areas of 4E-BP1 knock-down tumors. These data suggest that although overall levels of hypoxia are similar in the two tumor types, the viability of hypoxic cells is lower in those tumors with knock-down of 4E-BP1. 
Table 1: Immunohistochemical analysis for pRS and pRS 4E-BP1 U87 tumors.

\begin{tabular}{|c|c|c|c|c|c|}
\hline Name & $\begin{array}{c}\text { \% PIMO } \\
\text { pos. }\end{array}$ & $\begin{array}{c}\text { Intensity } \\
\text { PIMO }^{* *}\end{array}$ & PCNA $^{*}$ & $\begin{array}{c}\text { CD31 in } \\
\text { PIMO pos. } \\
\text { area }^{*}\end{array}$ & $\begin{array}{l}\text { CASP-3 in } \\
\text { PIMO pos. } \\
\text { area }^{\$}\end{array}$ \\
\hline$p R S$ U87 & 1 & 1 & 3 & 1 & 2 \\
\hline \multirow[t]{2}{*}{$(n=3)$} & 2 & 2 & 3 & 1 & 1 \\
\hline & 3 & 2 & 3 & 1 & 1 \\
\hline$p R S 4 E-B P 1$ & 3 & 2 & 3 & 1 & 2 \\
\hline U87 & 2 & 2 & 3 & 1 & 2 \\
\hline \multirow[t]{2}{*}{$(n=4)$} & 2 & 2 & 3 & 1 & 2 \\
\hline & 1 & 1 & 3 & 1 & 2 \\
\hline $\begin{array}{l}1:<10 \% \text { tun } \\
\text { positive } \\
1: \text { weak; } 2: \\
1: \text { absent; } 2:\end{array}$ & $\begin{array}{l}\text { ng } \\
\text { sent }\end{array}$ & & & & \\
\hline
\end{tabular}

We hypothesized that the reduction in hypoxia tolerance in the 4EBP1 knockdown cells could be related to their ability to regulate energy status. ATP production is challenged during hypoxia due to the dependence on glycolysis rather than oxidative respiration. Activation of 4E-BP1 during these conditions may thus act to maintain energy levels by inhibiting protein synthesis, a large consumer of ATP. In support of this hypothesis we found that ATP levels were consistently lower in the 4E-BP1 knock-down tumors. Figure 5B shows ATP measurements derived from 4 control and 4 4E-BP1 knockdown tumors. The ATP levels in these tumors show some overlap, but in general the 4E-BP1 knockdown tumors display lower values. This did not reach significance $(\mathrm{P}=0.14)$, due in part to a single tumor in the control group that had an unusually high ATP level. If this tumor is ignored, the average difference between the two groups becomes smaller, but also reaches significance $(\mathrm{P}<0.05)$. 


\section{A}

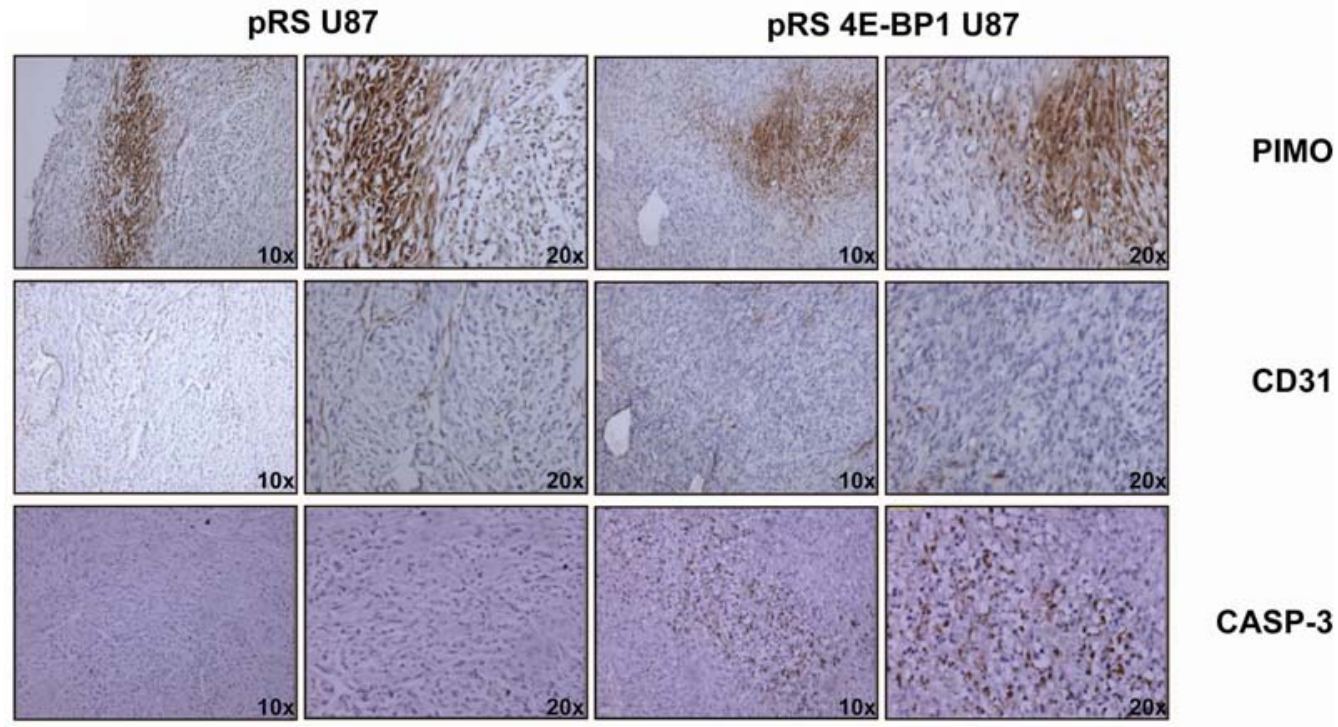

\section{B}

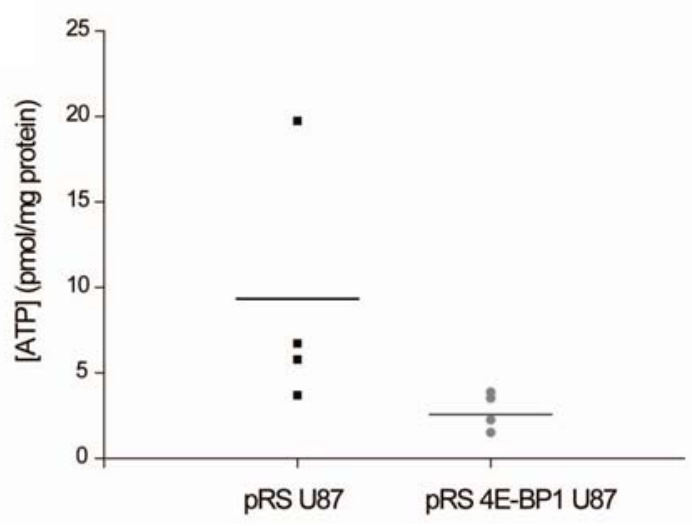

Figure 5: Tumors were scored blindly for CD31 and cleaved caspase-3 in PIMO-rich areas. (A) No CD31-positive endothelial cells in PIMO-positive areas were observed in parallel sections of all tumor types. pRS 4E-BP1 U87 tumors demonstrated cleaved caspase-3 activity, while control tumors did not demonstrated cleaved caspase- 3 activity in these hypoxic areas. (B) Concentration of ATP in pRS and pRS 4E-BP1 U87 tumors. Symbols represent measurements from individual tumors with horizontal bars indicating the mean of each group. 


\section{DISCUSSION}

The idea that translation initiation and eIF4E may be good targets for cancer therapy is not a new one. eIF4E is active in virtually all tumors, and plays a key role in promoting malignant behavior [11]. The contribution of eIF4E to malignant transformation and progression has been extensively elucidated and derives in large part from its ability to translationally regulate important growth regulatory genes. A number of trials have explored the effects of targeting eIF4E in preclinical tumor models. Antisense-RNA-mediated reduction of eIF4E suppressed both the tumorigenic and angiogenic properties of the $\mathrm{FaDu}$ head and neck cancer cells, as demonstrated by loss of capacity to grow in soft agar, reduced expression of angiogenic factors, and loss of tumorigenicity in nude mice [28]. Similarly, targeting eIF4E mRNA with an antisense RNA in cloned rat embryo fibroblasts (CREF) cells caused reversal of ras-mediated transformation and tumorigenesis [29].

Although these results are promising, the fact that eIF4E is regulated primarily through protein protein interactions makes it a poor candidate for direct drug development. An alternative approach to target its activity is through inhibition of pathways that regulate 4E-BP1. These include the $\mathrm{PI} 3 \mathrm{~K} / \mathrm{Akt} / \mathrm{mTOR}$ pathway, which plays a central role in regulating cell growth, proliferation and survival. Signaling through PI3K/Akt pathway is propagated to a diverse array of substrates, including the mammalian target of rapamycin mTOR, which promotes translation initiation through increased 4E-BP1 and ribosomal p70S6 kinase (p70S6K) phosphorylation. Rapamycin, a clinically approved mTOR inhibitor, activates 4E-BP1, which blocks eIF4E from engaging and activating the eIF4F complex. Currently, there are a number of clinical trials investigating the use of rapamycin or its analogs as new therapeutic agents. However, although 4E-BP1 clearly has anti-growth properties, its function in cancer is multi-factorial. We and others previously identified it as playing a role in the adaptation to hypoxic stress by suppressing translation initiation [16, 21, 22]. Furthermore, malignant tumors have recently been reported to maintain high levels of 4E-BP1 [18]. Here, we have demonstrated that knockdown of 4E-BP1 has opposite effects on tumor growth and response to treatment. Loss of 4E-BP1 accelerated tumor growth, as predicted by its role in negatively regulating translation but resulted in an increased tumor response to treatment with radiation. This increased response appears to result primarily from a reduced tolerance to hypoxia that was 
apparent both in vitro and in vivo. The reduction in hypoxia tolerance may be related to the inability of these cells to maintain energy homeostasis through regulation of translation initiation since the 4E-BP1 knockdown tumors also had reduced ATP levels. Remarkably, the use of 4E-Bp1 genes/proteins as hypoxia sensitive metabolic brakes seems to reflect a vital and widespread survival strategy even in healthy organisms. In hypoxia tolerant cells from embryonic fruitflies, the gene encoding the 4E-BP1 homolog is strongly induced by oxygen deprivation and its loss-of-function correlates with a poor adaptation and slowed recovery of hypoxia-challenged male Drosophila (TAG, pers. communication).

Despite the exact mechanism, these data indicate that some caution should be taken in clinical regimes that include drugs that indirectly target $4 \mathrm{E}$ BP1 in combination with radiation or other hypoxia influenced therapies [30, 31]. For example, our data suggest the possibility that by activating 4E-BP1, rapamycin could potentially increase hypoxia tolerance and radioresistance and thus offset the other benefits of inhibiting mTOR. Indeed, we have previously demonstrated some evidence for this effect in U87 tumors treated with a combination of radiation and rapamycin [24]. Despite providing a clear inhibition in tumor growth, rapamycin failed to increase the response of tumors treated with fractionated radiotherapy. Furthermore, the tumors treated with rapamycin demonstrated evidence of increased hypoxia consistent with a role of 4E-BP1 in mediating hypoxia tolerance.

Hypoxia regulates translation initiation through two distinct pathways[21, 22]. Rapid but transient eIF2 $\alpha$ phosphorylation is responsible for a rapid inhibition in translation and this is followed by sequestration of eIF4E by both 4E-BP1 and by its transporter 4E-T [21]. Tumors derived from transformed mouse embryo fibroblasts (MEFs) that are unable to inhibit translation through eIF2 $\alpha$ phosphorylation (lacking the PERK eIF2 $\alpha$ kinase or expressing the non-phosphorylateable S51A eIF2 $\alpha$ allele) form tumors that grow slowly and which have increased levels of apoptosis in hypoxic regions [20]. Interference with eIF $2 \alpha$ phosphorylation also leads directly to reduced hypoxia tolerance in vitro in both MEFs and human tumor cells [20, 32]. Thus, together with the data reported here it appears that regulation of mRNA translational during hypoxia through both eIF2 $\alpha$ and 4E-BP1 is important for hypoxia tolerance and has important implications for the tumor microenvironment. 
Tumors are known to demonstrate greatly increased rates of metabolism due to mutations in oncogenes and tumor suppressors that regulate cell growth decisions. In U87 cells, increased rates of metabolism result from mutations in the PTEN gene, which lead to increased AKT activity and cell growth [33]. Loss of 4E-BP1 in these cells presumably removes an important regulatory control on mRNA translation and thus the potential for even higher ATP consumption and/or demand. Consistent with this, we observed substantially lower overall ATP levels in the 4E-BP1 knockdown tumors compared to their wild-type controls. We hypothesize that cancer cells with elevated metabolism may become increasingly dependent on 4E-BP1 for energy homeostasis and may thus explain selection of tumors cells with high levels of this protein [18]. Consequently, targeting 4E-BP1 may be especially effective in killing hypoxic cancer cells that have sustained mutations which result in deregulated translational control. This approach is similar to the concept of 'synthetic lethality' which has been proposed for targeting of tumor cells harbouring specific mutational events. For example, treatment of repair deficient BRCA1 and BRCA2 mutant cells with Poly (ADP-ribose) polymerase (PARP) inhibitors [34] results in selective killing due to increased reliance of the PARP pathway. Changes in the reliance of metabolic pathways during hypoxia may similarly lead to vulnerabilities that can be exploited for specific cancer therapy.

In conclusion, our data provide a unique example in which targeting a gene with tumor suppressor activities can be exploited to improve cancer therapy. Our interpretation of the mechanism responsible for explaining the increased sensitivity of tumors lacking 4E-BP1 to hypoxia and irradiation is based on the inability of these cells to properly regulate ATP consumption during hypoxic conditions. We suggest that this approach may be most beneficial in cancers with mutations in signaling pathways that lead to overactivation of metabolic processes regulated by mTOR. This idea should be testable in current clinical trials targeting mTOR with rapamycin and its analogs in combination with radiotherapy. 


\section{ACKNOWLEGDEMENTS}

We wish to acknowledge financial support from the Dutch Science Organization (ZonMW-NWO Top grant 912-03-047 to BW), the Dutch Cancer Society (KWF grant UM 2003-2821 to BW), and the EU $6^{\text {th }}$ framework program (Euroxy program to PL, TAG, BGW). 


\section{REFERENCES}

[1] Dever, TE. Gene-specific regulation by general translation factors. Cell 2002;108:545-556.

[2] Magagnin, MG, Koritzinsky, M, Wouters, BG. Patterns of tumor oxygenation and their influence on the cellular hypoxic response and hypoxia-directed therapies. Drug Resist Updat 2006;9:185-197.

[3] Gingras, AC, Raught, B, Sonenberg, N. eIF4 initiation factors: effectors of mRNA recruitment to ribosomes and regulators of translation. Annu Rev Biochem 1999;68:913-963.

[4] Pause, A, Belsham, GJ, Gingras, AC, et al. Insulin-dependent stimulation of protein synthesis by phosphorylation of a regulator of 5'cap function. Nature 1994;371:762-767.

[5] Poulin, F, Gingras, AC, Olsen, H, Chevalier, S, Sonenberg, N. 4E-BP3, a new member of the eukaryotic initiation factor 4E-binding protein family. J Biol Chem 1998;273:14002-14007.

[6] De Benedetti, A, Graff, JR. eIF-4E expression and its role in malignancies and metastases. Oncogene 2004;23:3189-3199.

[7] Kozak, M. Structural features in eukaryotic mRNAs that modulate the initiation of translation. J Biol Chem 1991;266:19867-19870.

[8] Pickering, BM, Willis, AE. The implications of structured 5' untranslated regions on translation and disease. Semin Cell Dev Biol 2005;16:39-47.

[9] Graff, JR, Zimmer, SG. Translational control and metastatic progression: enhanced activity of the mRNA cap-binding protein eIF4E selectively enhances translation of metastasis-related mRNAs. Clin Exp Metastasis 2003;20:265-273.

[10] Richter, JD, Sonenberg, N. Regulation of cap-dependent translation by eIF4E inhibitory proteins. Nature 2005;433:477-480. 
[11] Thumma, SC, Kratzke, RA. Translational control: a target for cancer therapy. Cancer Lett 2007;258:1-8.

[12] Gingras, AC, Kennedy, SG, O'Leary, MA, Sonenberg, N, Hay, N. 4E$\mathrm{BP} 1$, a repressor of mRNA translation, is phosphorylated and inactivated by the Akt(PKB) signaling pathway. Genes Dev 1998;12:502-513.

[13] Neshat, MS, Mellinghoff, IK, Tran, C, et al. Enhanced sensitivity of PTEN-deficient tumors to inhibition of FRAP/mTOR. Proc Natl Acad Sci U S A 2001;98:10314-10319.

[14] Jacobson, BA, Alter, MD, Kratzke, MG, et al. Repression of capdependent translation attenuates the transformed phenotype in nonsmall cell lung cancer both in vitro and in vivo. Cancer Res 2006; 66:4256-4262.

[15] Castellvi, J, Garcia, A, Rojo, F, et al. Phosphorylated 4E binding protein 1: a hallmark of cell signaling that correlates with survival in ovarian cancer. Cancer 2006;107:1801-1811.

[16] Magagnin, MG, van den Beucken, T, Sergeant, K, et al. The mTOR target $4 \mathrm{E}-\mathrm{BP} 1$ contributes to differential protein expression during normoxia and hypoxia through changes in mRNA translation efficiency. Proteomics 2008;8:1019-1028.

[17] Tsukiyama-Kohara, K, Poulin, F, Kohara, M, et al. Adipose tissue reduction in mice lacking the translational inhibitor 4E-BP1. Nat Med 2001;7:1128-1132.

[18] Braunstein, S, Karpisheva, K, Pola, C, et al. A hypoxia-controlled capdependent to cap-independent translation switch in breast cancer. Mol Cell 2007;28:501-512.

[19] Arsham, AM, Howell, JJ, Simon, MC. A novel hypoxia-inducible factor-independent hypoxic response regulating mammalian target of rapamycin and its targets. J Biol Chem 2003;278:29655-29660. 
[20] Bi, M, Naczki, C, Koritzinsky, M, et al. ER stress-regulated translation increases tolerance to extreme hypoxia and promotes tumor growth. Embo J 2005;24:3470-3481.

[21] Koritzinsky, M, Magagnin, MG, van den Beucken, T, et al. Gene expression during acute and prolonged hypoxia is regulated by distinct mechanisms of translational control. Embo J 2006;25:1114-1125.

[22] Liu, L, Cash, TP, Jones, RG, Keith, B, Thompson, CB, Simon, MC. Hypoxia-induced energy stress regulates mRNA translation and cell growth. Mol Cell 2006;21:521-531.

[23] Brummelkamp, TR, Bernards, R, Agami, R. A system for stable expression of short interfering RNAs in mammalian cells. Science 2002;296:550-553.

[24] Weppler, SA, Krause, M, Zyromska, A, Lambin, P, Baumann, M, Wouters, BG. Response of U87 glioma xenografts treated with concurrent rapamycin and fractionated radiotherapy: possible role for thrombosis. Radiother Oncol 2007;82:96-104.

[25] Papandreou, I, Krishna, C, Kaper, F, Cai, D, Giaccia, AJ, Denko, NC. Anoxia is necessary for tumor cell toxicity caused by a low-oxygen environment. Cancer Res 2005;65:3171-3178.

[26] Wendel, HG, De Stanchina, E, Fridman, JS, et al. Survival signalling by Akt and eIF4E in oncogenesis and cancer therapy. Nature 2004;428:332-337.

[27] Wendel, HG, Silva, RL, Malina, A, et al. Dissecting eIF4E action in tumorigenesis. Genes Dev 2007;21:3232-3237.

[28] DeFatta, RJ, Nathan, CO, De Benedetti, A. Antisense RNA to eIF4E suppresses oncogenic properties of a head and neck squamous cell carcinoma cell line. Laryngoscope 2000;110:928-933.

[29] Rinker-Schaeffer, CW, Graff, JR, De Benedetti, A, Zimmer, SG, Rhoads, RE. Decreasing the level of translation initiation factor 4E with 
antisense RNA causes reversal of ras-mediated transformation and tumorigenesis of cloned rat embryo fibroblasts. Int $\mathrm{J}$ Cancer 1993;55:841-847.

[30] Reardon, DA, Quinn, JA, Vredenburgh, JJ, et al. Phase 1 trial of gefitinib plus sirolimus in adults with recurrent malignant glioma. Clin Cancer Res 2006;12:860-868.

[31] Sarkaria, JN, Schwingler, P, Schild, SE, et al. Phase I trial of sirolimus combined with radiation and cisplatin in non-small cell lung cancer. J Thorac Oncol 2007;2:751-757.

[32] Koritzinsky, M, Rouschop, KM, van den Beucken, T, et al. Phosphorylation of eIF2alpha is required for mRNA translation inhibition and survival during moderate hypoxia. Radiother Oncol 2007;83:353-361.

[33] Downes, CP, Bennett, D, McConnachie, G, et al. Antagonism of PI 3kinase-dependent signalling pathways by the tumour suppressor protein, PTEN. Biochem Soc Trans 2001;29:846-851.

[34] Farmer, H, McCabe, N, Lord, CJ, et al. Targeting the DNA repair defect in BRCA mutant cells as a therapeutic strategy. Nature 2005;434:917-921. 


\section{Chapter 6}

Proteomic analysis of gene expression following hypoxia and reoxygenation reveals proteins involved in the recovery from endoplasmic reticulum and oxidative stress

M.G.P. Magagnin, K. Sergeant, T. van den Beucken, K.M.A. Rouschop, B. Jutten, R. Seigneuric, P. Lambin, B. Devreese, M. Koritzinsky and B.G. Wouters

Radiother Oncol. 83:340-345, 2007 


\section{ABSTRACT}

Human tumors are characterized by large variations in oxygen concentration and hypoxic tumors are associated with poor prognosis. In addition, tumors are subjected to periodic changes in oxygenation characterized by hypoxia followed by reoxygenation. Cellular adaptation to hypoxia is well documented, nevertheless little is known about adaptive mechanisms to reoxygenation. Here, we investigate the changes in protein expression during reoxygenation using proteomics. HeLa cervix carcinoma cells were exposed to $4 \mathrm{~h}$ of hypoxia $\left(<0.01 \% \mathrm{O}_{2}\right)$ followed by $1 \mathrm{hr}$ of reoxygenation. The cellular proteome was examined using 2D gel electrophoresis coupled with mass spectrometry. Validation and investigation of the underlying basis for induced protein expression was investigated using western blot analysis and quantitative RTPCR. We identified proteins involved in several cellular processes that are responsible for regulating RNA metabolism, protein synthesis and degradation, including ribosomal protein $\mathrm{P} 0, \mathrm{VCP} / \mathrm{p} 97$ and FUSE binding protein 2 . Our results suggest that these newly identified proteins function in pathways that may assist in the recovery of ER stress and protein synthesis during reoxygenation. These proteins may thus be important determinants of the behaviour and survival of tumor cells to transient hypoxic exposures. 


\section{INTRODUCTION}

The consequences of lack of oxygen (hypoxia) within solid tumors has been intensively investigated over the past decade based on the observations that hypoxic tumors are more resistant to therapy, have a worse prognosis, and may be more malignant [1-4]. However, many areas within solid tumors are subjected not only to hypoxia but also to periodic changes in oxygenation characterized by hypoxia followed by reoxygenation. Reoxygenation is an important stress characterized by the production of reactive oxygen species (ROS) that cause damage to cellular macromolecules, including DNA [5]. It can be argued that any hypoxic cell that contributes to tumor repopulation or metastasis, must at one point reoxygenate and thus tolerate this stress. Consequently, it is important to consider the effects of reoxygenation on tumor biology. Nevertheless, there is little data regarding the contribution of reoxygenation to the biology within solid tumors [6].

Most studies of reoxygenation come from ischaemia-reperfusion experiments and myocardial injury where readmission of oxygenated blood into previously ischaemic myocardium can initiate a cascade of events that produce additional myocardial cell dysfunction and cell necrosis via generation of ROS [7-9]. Adaptation of solid tumors to cycles of oxygenation may promote tolerance to ROS generation during reoxygenation periods. Repeated cylces of hypoxia have been shown to select for death-resistant cells that are cross-resistant to apoptosis induced by staurosporine, azide, and cisplatin through upregulation of $\mathrm{Bcl}-\mathrm{X}_{\mathrm{L}}$, resulting in mitochondrial integrity and cell viability [10].

In this study, we used proteomic techniques to search for changes in protein expression that are specific to cells exposed to the stress of reoxygenation and identified 8 proteins. These included a number of proteins involved in protein synthesis and quality control. 


\section{MATERIALS AND METHODS}

\section{Cell culture and hypoxic conditions}

Cervix carcinoma (HeLa) cells were grown in Dulbecco's modified Eagle's medium (Sigma) supplemented with $10 \%$ fetal bovine serum (Sigma) at $37^{\circ} \mathrm{C}$ in a $5 \% \mathrm{CO}_{2}$ incubator. Exponentionally growing cells were plated on plastic culture dishes and hypoxic treatments $\left(<0.01 \% \mathrm{O}_{2}\right)$ were performed as previously described [11].

\section{2-DE and image analysis}

Briefly, $15 \mathrm{~cm}$ culture dishes of exponentionally growing HeLa cells were washed twice with ice-cold $10 \mathrm{mM} / 250 \mathrm{mM}$ sucrose buffer $\mathrm{pH} 7.0$ and lysed in $7 \mathrm{M}$ urea/2M thiourea based lysisbuffer. Cells were exposed to a quick freezethaw lysis, then lysates were centrifuged at $13000 \mathrm{~g}$ for $30 \mathrm{~min}$ at $4^{\circ} \mathrm{C}$ to remove contaminants. Protein samples were applied to $24 \mathrm{~cm}$ IPG strips $\mathrm{pH} 3-$ $10 \mathrm{NL}$ (Amersham Biosciences). Following isoelectric focusing, the strips were placed on the Protean Plus Dodeca Cell (Bio-Rad Laboratories) to perform a second dimension separation using 12\% SDS-PAGE gels. The system was run at $200 \mathrm{~V}$ for 5 hours. Proteins were visualized by staining with SYPRO Ruby dye (Bio-Rad Laboratories). The 2D stained gels were imaged on a Molecular Imager FX (Bio-Rad Laboratories). The resulting 2D protein patterns were analyzed, using PD-Quest 7.1 software (Bio-Rad Laboratories).

\section{In-gel trypsin digestion and ESI-TRAP MS}

Protein spots of interest were excised from the gel using an automatic spot cutter (Bio-Rad). After two washes with $150 \mu \mathrm{L} 200 \mathrm{mM} \mathrm{NH} \mathrm{NCO}_{3} / 50 \%$ ACN the gel plugs were completely dried using a Speedvac (Thermo Savant). To the dried gel plugs $8 \mu \mathrm{l} 50 \mathrm{mM} \mathrm{NH} \mathrm{HCO}_{3}$ containing $150 \mathrm{ng}$ trypsin (Promega) per $\mu 1$ was added and the gel pieces were kept on ice for 1 hour. Trypsin buffer was added to cover the gel plugs completely and the samples were incubated overnight at $37^{\circ} \mathrm{C}$. The peptides were extracted by two consecutive washes with $50 \% \mathrm{ACN} / 0.1 \% \mathrm{HCOOH}$ and the pooled extracts dried. The samples were resuspended in $8 \mu 10.1 \% \mathrm{HCOOH}$ and analysed using an nano-HPLC system (Dionex) hyphenated to a Q-TRAP mass spectrometer (Applied Biosystems) [12]. The MASCOT search engine was used for protein identification allowing a $1 \mathrm{Da}$ peptide mass and fragment mass tolerance. Carbamidomethylation and methionine oxidation were set as variable modification. 
Western blot analysis

Whole cell extracts $(30 \mu \mathrm{g})$ were resolved in 10\% SDS PAGE gels and transferred onto Hybond-PVDF membrane (Amersham Biosciences). Then the membranes were incubated overnight with primary antibody: VCP $(1: 1000$ dilution, Cell Signaling Technology) followed by incubation with horseradish peroxidase-conjugated secundary antibody (1:2000 dilution, Cell Signaling technology). For the preparation of nuclear and cytoplasmic protein extracts we performed a gently lysis based on a 1\% Triton X-100 lysisbuffer to isolate the cytoplasmic fraction followed by $10 \%$ glycerol lysisbuffer treatment for the nuclei. Protein signals were detected using the Super Signal West Pico kit (Pierce).

\section{Quantitative PCR analysis}

Experiments and normalizations were performed as previously described [13]. The abundance of the following genes were detected with SYBR Green I (Applied Biosystems) using indicated forward and reverse primers: RPP0: Fggcgacctggaagtccaact and R-ccatcagcaccacagcettc; CA-IX: Fcatcctagccetggtttttgg and R-gctcacacccctttggtt; 18SrRNA: Fagtccetgccetttgtacaca and R-gatccgagggectcactaaac. The following genes were measured using Taqman Gene Expression Assays (Applied Biosystems): FBP2: Hs00269352_m1 and FBP3: Hs00383472_m1.

\section{RESULTS}

To investigate the potential impact of reoxygenation on global protein expression, HeLa cells were incubated for $4 \mathrm{~h}$ of hypoxia $\left(<0.01 \% \mathrm{O}_{2}\right)$ or $4 \mathrm{~h}$ of hypoxia followed by $1 \mathrm{~h}$ of reoxygenation. Proteomic analysis of whole cell extracts from aerobic, hypoxic and reoxygenated HeLa cells was performed by two dimensional gel electrophoresis on the basis of the charge and mass followed by visualization with SYPRO-Ruby. This experiment was repeated in triplicate with a technical repeat for each condition (representative gels from each experimental condition are shown in Figure 1A). Proteins were matched across all gels to identify protein spots that were exclusively expressed during reoxygenation. The densities of the spots were determined with normalization based on total protein density on the gel. Overall, the 2D gel protein spots profiles across all of the gels from the hypoxic and reoxygenation treated and controls groups were similar. Fourteen spots were found to be expressed 
exclusively during reoxygenation, eight of which were successfully identified by analysis of ESI-TRAP MS followed by database searching. These proteins were separately involved in different cellular processes and stress response pathways (Table 1). These proteins were also expressed after $16 \mathrm{~h}$ hypoxia followed by $1 \mathrm{~h}$ reoxygenation (data not shown). In our $2 \mathrm{D}$ gels, we found $\mathrm{VCP} / \mathrm{p} 97$, FUSE binding proteins 2 and 3 (FBP2/FBP3) and ribosomal protein $\mathrm{P} 0$ (RPP0) to be expressed after reoxygenation (Figure 1B).

Table 1: List of protein spots and their identification

\begin{tabular}{|c|c|c|c|c|c|}
\hline $\begin{array}{l}\text { Swiss-Prot } \\
\text { Accession } \\
\text { No. }\end{array}$ & $\begin{array}{l}\text { Protein } \\
\text { name }\end{array}$ & $\begin{array}{l}\text { Putative } \\
\text { function }\end{array}$ & Mr(kDa)/pI & $\begin{array}{l}\text { Mass } \\
\text { Fingerprint } \\
>65\end{array}$ & $\begin{array}{l}\text { Pep } \\
\text { No. }\end{array}$ \\
\hline P55072 & $\begin{array}{l}\text { Vasolin } \\
\text { containing protein }\end{array}$ & Proteosome & $97 / 5,14$ & 252 & 8 \\
\hline Q92945 & $\begin{array}{l}\text { FUSE binding } \\
\text { protein } 2\end{array}$ & $\begin{array}{c}\text { RNA } \\
\text { metabolism }\end{array}$ & $72 / 8,02$ & 216 & 5 \\
\hline Q92946 & $\begin{array}{l}\text { FUSE binding } \\
\text { protein } 3\end{array}$ & $\begin{array}{c}\text { RNA } \\
\text { metabolism }\end{array}$ & $64 / 8,84$ & 309 & 10 \\
\hline P05388 & $\begin{array}{l}\text { Ribosomal protein } \\
\text { P0 }\end{array}$ & $\begin{array}{l}\text { Protein } \\
\text { translation }\end{array}$ & $34 / 5,72$ & 118 & 5 \\
\hline Q07244 & $\begin{array}{l}\text { Transformation } \\
\text { upregulated } \\
\text { nuclear protein }\end{array}$ & $\begin{array}{l}\text { Pre-mRNA } \\
\text { processing }\end{array}$ & $51 / 5,39$ & 71 & 5 \\
\hline O15460 & $\begin{array}{l}\text { Prolyl 4- } \\
\text { hydroxylase, } \\
\text { alpha II subunit }\end{array}$ & $\begin{array}{l}\text { Collagen } \\
\text { synthesis }\end{array}$ & $61 / 5,49$ & 215 & 6 \\
\hline P50552 & $\begin{array}{l}\text { Vasodilator- } \\
\text { stimulated } \\
\text { phosphoprotein }\end{array}$ & Cell adhesion & $40 / 9,05$ & 46 & 2 \\
\hline
\end{tabular}


A
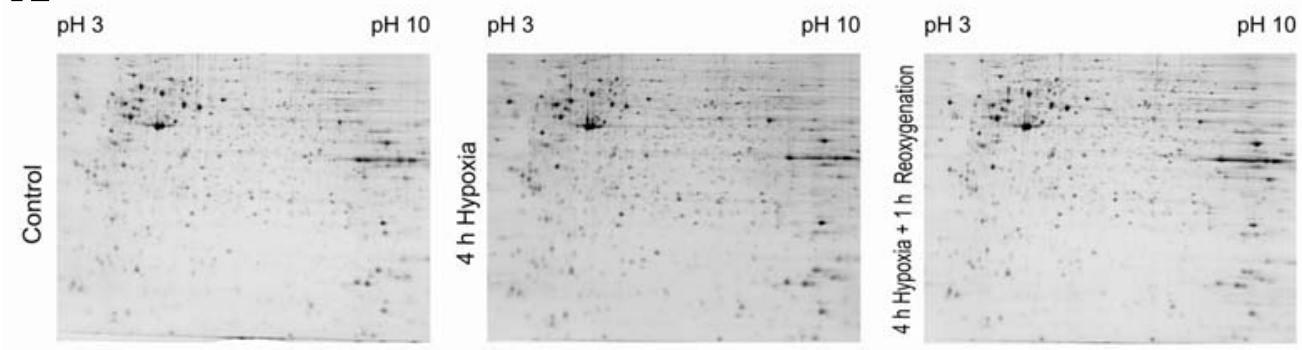

B
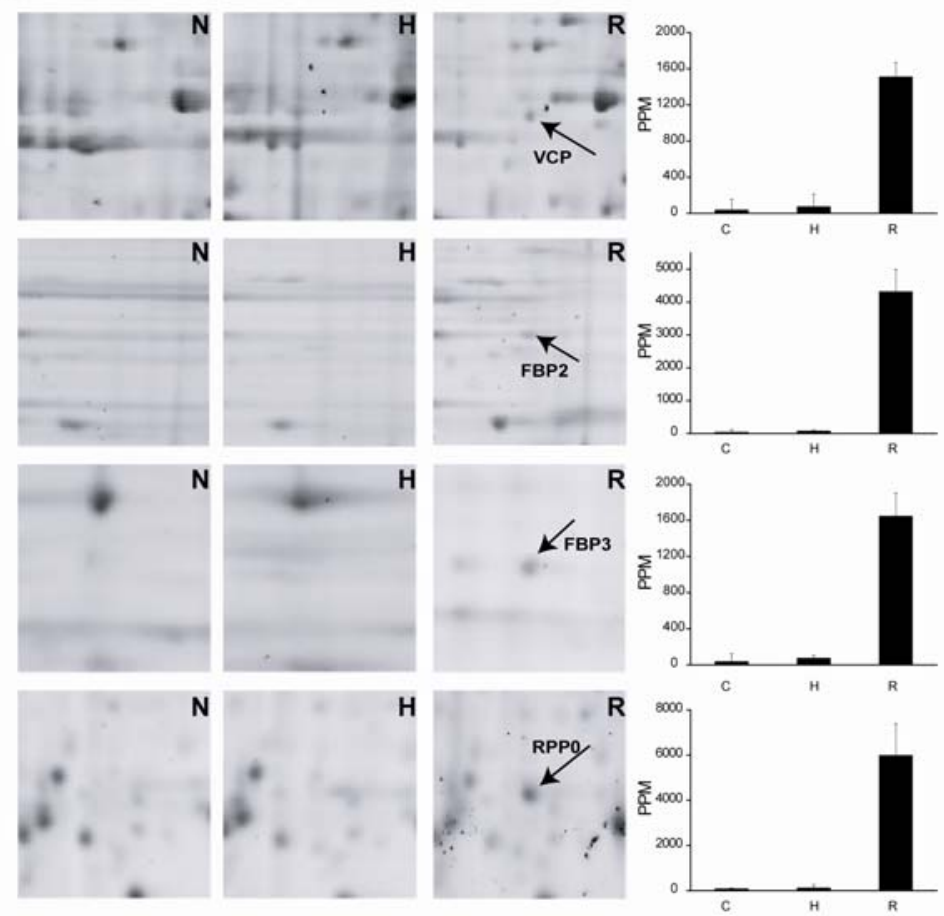

Figure 1: (A) Representative 2D gels treated with $4 \mathrm{~h}$ hypoxia or $4 \mathrm{~h}$ hypoxia followed by $1 \mathrm{~h}$ reoxygenation. Protein $(150 \mu \mathrm{g})$ was loaded on IPG strips $(24 \mathrm{~cm}, \mathrm{pH} 3-10 \mathrm{NL})$, followed by the second dimension on $12 \%$ SDS-PAGE gel, visualized with SYPR Ruby. (B) The insets show the expression and quantification of proteins listed in table 1 during normoxia $(\mathrm{N})$, hypoxia $(\mathrm{H})$ and reoxygenation $(\mathrm{R})$. 
To confirm the results found by proteomics and to determine the underlying basis for the increase in protein found during reoxygenation we evaluated the transcriptional, translational, and potentially post-translational changes in these proteins. For VCP we found no evidence of a transcriptional or translational change during hypoxia or hypoxia plus reoxygenation. Furthermore, we conducted western blot analysis using whole cell extracts from cells exposed to $4 \mathrm{~h}$ hypoxia or $4 \mathrm{~h}$ hypoxia followed by $1 \mathrm{~h}$ reoxygenation and found no significant differences in total expression levels between the different conditions (Figure 2A). This prompted us to test whether the change in VCP found in the proteomic analysis could be due to a change in the cellular distribution of VCP. We analyzed the distribution of VCP separately in nuclear and cytoplasmic protein extracts. As shown in Figure 2B, after $4 \mathrm{~h}$ hypoxia followed by $1 \mathrm{~h}$ reoxygenation we detected a significant translocation of VCP from the nucleus to the cytoplasm. This translocation of VCP was also observed after $16 \mathrm{~h}$ hypoxia followed by $1 \mathrm{~h}$ reoxygenation (data not shown). Based on this data we hypothesize that reoxygenation might primarily regulate VCP at the post-translational level.

A

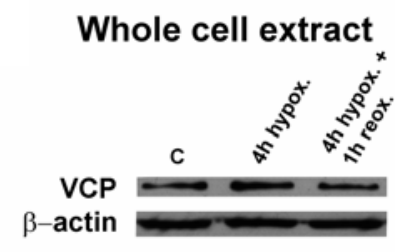

B

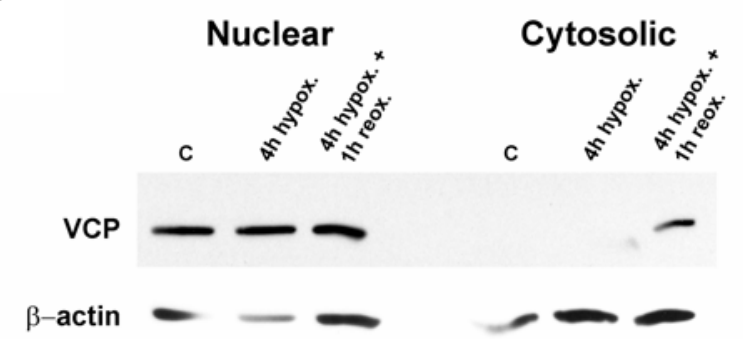

Figure 2: (A) Western blot analysis of whole cell extracts $(30 \mu \mathrm{g})$ with antibody recognizing VCP was carried out. Representative image of three independent experiments. (B) Western blot analysis for VCP using nuclear and cytoplasmic protein extracts from HeLa cells. Representative image of two independent experiments. $\beta$-Actin was used as a loading control. Histone $\mathrm{H} 3$ was used as a control for the preparation of nuclear and cytoplasmic extracts. 
To confirm the increased protein expression of FBP2, FBP3 and RPP0 during reoxygenation, we conducted experiments that would allow us to monitor both potential transcriptional and translational changes. Lysates from cells exposed to $4 \mathrm{~h}$ hypoxia or $4 \mathrm{~h}$ hypoxia followed by $1 \mathrm{~h}$ reoxygenation were separated over sucrose gradients to analyze the distribution of polysomes. The resulting profiles are shown in Figure 3A. In this assay, the first two peaks represent the $40 \mathrm{~S}$ and $60 \mathrm{~S}$ ribosomal subunits, respectively. The subsequent peaks represent mRNAs with increasing numbers of attached ribosomes (polysomes), which is a reflection of de novo protein synthesis. Figure 3A demonstrates that hypoxia inhibits overall mRNA translation in Hela cells since there is a clear reduction in the high molecular weight polysomal RNA. Interestingly, $1 \mathrm{~h}$ of reoxygenation is enough to restore overall mRNA translation to control levels. The amount of mRNA participating in translation can be determined by integrating the polysomal area and dividing by the total integrated area. The average results of two independent experiments are summarized in Figure 3B. The fraction of ribosomes participating in translation dropped from $67 \%$ in aerobic cells to $55 \%$ after $4 \mathrm{~h}$ of hypoxia and recovers after reoxygenation to $69 \%$. This drop in translation agrees with that observed during exposure to moderate hypoxia $(0.2 \%)$ in many other cell lines (Koritzinsky et al. submitted data). A more severe inhibition in translation occurs at oxygen concentrations less than $0.02 \%$, but achieving these levels of oxygenation require culture on glass petri dishes. All of our experiments were performed on plastic.

Next we performed real time quantitative RT-PCR for FBP2, FBP3 and RPP0 from both total cellular mRNA and from polysomal mRNA. This allows us to obverse both changes in transcription as well as changes in the efficiency that individual genes are translated into protein. Translation efficiency was determined by comparing the amount of mRNA found in the polysomes divided by the total amount in the cell. As shown in Figure 3C total cellular mRNA levels of FBP2, FBP3 and RPP0 did not significantly change during reoxygenation compared to hypoxia or normoxia. In comparison, hypoxic treatment caused a nine fold increase in CA-IX transcript levels. However, Figure 3D shows that the translation efficiency increased more then 2-fold for FBP2 and more then 3-fold for RPP0 during reoxygenation compared to hypoxia and normoxia. The slight increase in translation efficiency for FBP3 was not significant. These data suggest that although no changes in transcription occur for FBP2 and RPP0 during reoxygenation, the synthesis 
into protein is stimulated during reoxygenation through an increase in their translation efficiency.

A
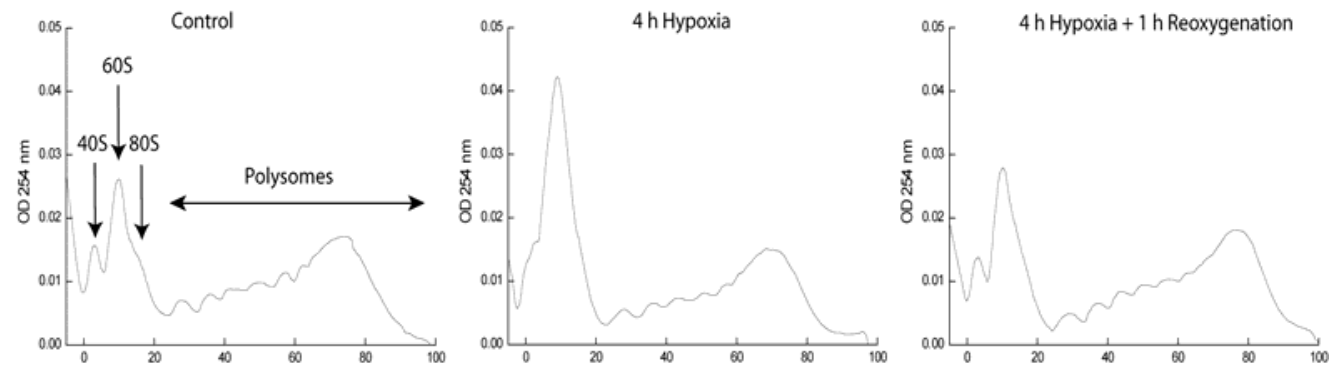

B

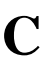

D
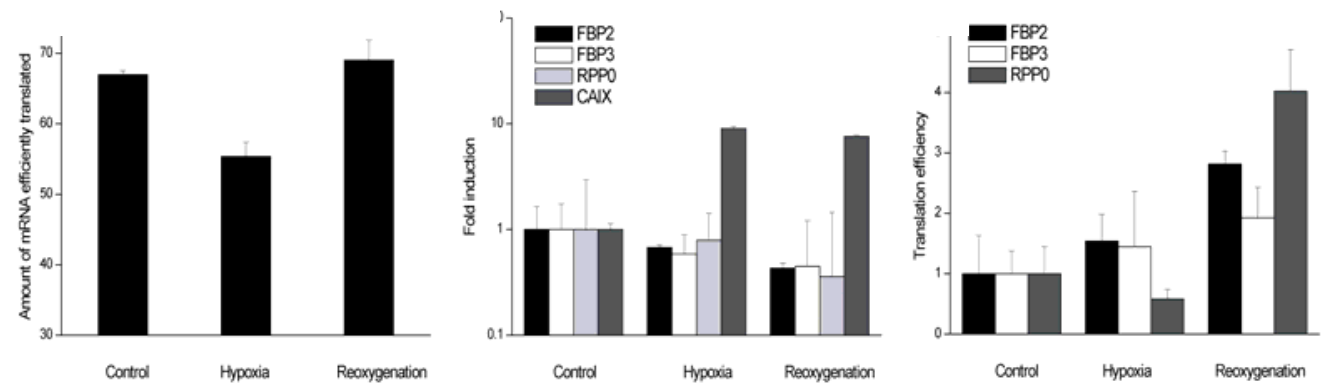

Figure 3: (A) Optical density (OD) at $254 \mathrm{~nm}$ is demonstrated as function of gradient depth for each time point. Actively translated mRNA is associated with high-molecular-weight polysomes in the gradient. (B) Amount of mRNA efficiently translated as a function of time. This fraction is proportional to the integrated area under the curve containing polysomes, as marked in (A). Gene-specific mRNA transcript levels were measured for FBP2, FBP3, RPP0 and CA-IX. Data was normalized to $18 \mathrm{~S}$ rRNA signal. (D) Relative translation efficiency was calculated for the genes of interest by dividing the signal in the polysome to the signal from the mRNA abundance. Figure 3 represents the data from two independent experiments. SEM is shown.

\section{DISCUSSION}

Our overall goal was to identify proteins that may play an important role in cellular adaptation to the stress of reoxygenation. Hypoxia/reoxygenation, generates cytotoxic reactive oxygen species which cause damage to DNA, RNA and proteins $[5,14]$ and we hypothesized that changes in individual 
protein levels may be important for adaptation to this damage. Using proteomics, we identified three proteins that are involved in different cellular processes which involve protein quality control and expression. $\mathrm{VCP} / \mathrm{p} 97$ (Cdc48 in yeast) is a hexameric ATPase of the AAA family that mediates numerous and diverse cellular functions, including endoplasmic reticulumassociated degradation (ERAD) via the ubiquitin-proteosome system (UPS) [15]. The endoplasmic reticulum (ER) serves as a site for protein folding of newly synthesized secreted and transmembrane proteins. VCP is a highly abundant protein that is required for the removal of misfolded proteins from the ER to allow their degradation by the proteosome in the cytoplasm. Loss of VCP causes polyubiquitinated cellular proteins to accumulate indicating an impaired ability to present them to the proteosome [16].

During conditions of ER stress such as the accumulation of unfolded proteins, an evolutionarily conserved program called the unfolded protein response (UPR) is activated. A number of recent reports from our group and others has demonstrated that hypoxia activates the UPR $[13,17]$ presumably in response to ER stress that occurs during hypoxic conditions. Our data here demonstrate that VCP translocates to the cytoplasm during reoxygenation, and might thereby transport unfolded proteins to the proteosome for degradation during conditions of reoxygenation where cells are recovering from hypoxia induced ER stress. We hypothesize that this effect may contribute to tumor cell survival, due to increased protein quality control and decreased cell toxicity. Interestingly, increased VCP expression levels have been associated with the recurrence of gastric carcinoma (GC) and hepatocellular carcinoma (HCC) [18, 19]. Further investigation of the function of VCP during reoxygenation, might demonstrate the potential of $\mathrm{VCP}$ as a target in cancer therapy.

Oxidative stress also results in RNA damage and incorporation of oxidized nucleotides during RNA synthesis can impair protein synthesis and other RNA functions [14]. This is interesting, given the fact that two of the other proteins we identified, FBP2 and FBP3 are involved in RNA processing. We found that the efficiency by which FBP2 is translated into protein increases by more than 2 -fold during reoxygenation. Regulation of translation efficiency is increasingly being recognized as a way to control differential protein expression in response to various conditions including hypoxia [11, 13], irradiation [20], and oncogenic signalling [21]. FBP2 (also termed KHRSP) is a member of the far-upstream element (FUSE) binding protein family that 
promotes rapid mRNA decay by recruiting the degradation machinery to AUrich elements (ARE) containing mRNAs [22]. In addition, in COS cells it has been demonstrated that FBP2 co-localizes with TIA proteins in the nucleus and migrates into TIA-enriched cytoplasmic stress granules (SG) upon oxidative stress [23]. SG have recently been described as reservoirs for untranslated mRNAs, which are either routed back to polysomes or are transferred to processing bodies in which they are degraded [24]. The presence of FBP2 in TIA-1-containing SG suggests that FBP2 contribute to these complex routing mechanisms of ARE-containing mRNAs, thereby regulating the transcription of specific mRNAs. During reoxygenation FBP2 might contribute to the degradation of oxidized RNAs, contributing to the quality control of RNA metabolism. The fact that FBP3 seems not to be regulated at the transcriptional or translational levels, indicates that FBP3 may be regulated at the protein level or through post-translational modifications during reoxygenation.

Finally, we also investigated in detail the regulation of the ribosomal protein $\mathrm{P} 0$, which is an essential component of the eukaryotic ribosomal stalk, composed of a pentameric complex of ribosomal protein $\mathrm{P} 0$ and the acidic proteins $\mathrm{P} 1$ and $\mathrm{P} 2$. This is a highly flexible structure involved in the interaction of elongation factors with the ribosome during protein synthesis [25]. We found that RPP0 is also translationally upregulated during reoxygenation. This protein may thus contribute to the restoration of protein synthesis during reoxygenation which was completely restored after only $1 \mathrm{~h}$ roxygenation (Fig. 3A). This may also lead to gene-specific changes in translation in a manner similarly reported in in S cerevisiae [26].

In summary, our results shed light on the contribution of reoxygenation on specific protein expression. The identified proteins are involved in different cellular processes that regulate protein quality control, mRNA translation and gene expression, and which may contribute to the cellular adaptation and tumor cell survival during reoxygenation. We hypothesize that during reoxygenation, these proteins act as part of a larger mechanism facilitating cellular recovery from ER stress and mRNA translational inhibition that occurs during hypoxia. Further investigation of the involvement of these proteins during reoxygenation may result in new attractive therapeutic targets. 


\section{ACKNOWLEGDEMENTS}

We wish to acknowledge financial support from the Dutch Science Organization (ZonMW-NWO Top grant 912-03-047 to BW), the Dutch Cancer Society (KWF grant UM 2003-2821 to BW), and the EU $6^{\text {th }}$ framework program (Euroxy program to BW). 


\section{REFERENCES}

[1] Fyles, A, Milosevic, M, Pintilie, M, et al. Long-term performance of interstial fluid pressure and hypoxia as prognostic factors in cervix cancer. Radiother Oncol 2006;80:132-137.

[2] Magagnin, MG, Koritzinsky, M, Wouters, BG. Patterns of tumor oxygenation and their influence on the cellular hypoxic response and hypoxia-directed therapies. Drug Resist Updat 2006;9:185-197.

[3] Nordsmark, M, Bentzen, SM, Rudat, V, et al. Prognostic value of tumor oxygenation in 397 head and neck tumors after primary radiation therapy. An international multi-center study. Radiother Oncol 2005; 77:18-24.

[4] Nordsmark, M, Loncaster, J, Aquino-Parsons, C, et al. The prognostic value of pimonidazole and tumour $\mathrm{pO} 2$ in human cervix carcinomas after radiation therapy: a prospective international multi-center study. Radiother Oncol 2006;80:123-131.

[5] Karihtala, P, Soini, Y. Reactive oxygen species and antioxidant mechanisms in human tissues and their relation to malignancies. Apmis 2007;115:81-103.

[6] Lukacova, S, Overgaard, J, Alsner, J, Horsman, MR. Strain and tumour specific variations in the effect of hypoxia on osteopontin levels in experimental models. Radiother Oncol 2006;80:165-171.

[7] Hansen, PR. Role of neutrophils in myocardial ischemia and reperfusion. Circulation 1995;91:1872-1885.

[8] Ma, XL, Weyrich, AS, Lefer, DJ, Lefer, AM. Diminished basal nitric oxide release after myocardial ischemia and reperfusion promotes neutrophil adherence to coronary endothelium. Circ Res 1993;72:403412.

[9] Simpson, PJ, Lucchesi, BR. Free radicals and myocardial ischemia and reperfusion injury. J Lab Clin Med 1987;110:13-30. 
[10] Dong, Z, Wang, J. Hypoxia selection of death-resistant cells. A role for Bcl-X(L). J Biol Chem 2004;279:9215-9221.

[11] Koritzinsky, M, Seigneuric, R, Magagnin, MG, van den Beucken, T, Lambin, P, Wouters, BG. The hypoxic proteome is influenced by genespecific changes in mRNA translation. Radiother Oncol 2005;76:177186.

[12] Devreese, B, Vanrobaeys, F, Van Beeumen, J. Automated nanoflow liquid chromatography/tandem mass spectrometric identification of proteins from Shewanella putrefaciens separated by two-dimensional polyacrylamide gel electrophoresis. Rapid Commun Mass Spectrom 2001;15:50-56.

[13] Koritzinsky, M, Magagnin, MG, van den Beucken, T, et al. Gene expression during acute and prolonged hypoxia is regulated by distinct mechanisms of translational control. Embo J 2006;25:1114-1125.

[14] Li, Z, Wu, J, Deleo, CJ. RNA damage and surveillance under oxidative stress. IUBMB Life 2006;58:581-588.

[15] Woodman, PG. p97, a protein coping with multiple identities. J Cell Sci 2003;116:4283-4290.

[16] Wojcik, C, Yano, M, DeMartino, GN. RNA interference of valosincontaining protein ( $\mathrm{VCP} / \mathrm{p} 97)$ reveals multiple cellular roles linked to ubiquitin/proteasome-dependent proteolysis. J Cell Sci 2004;117:281292.

[17] Bi, M, Naczki, C, Koritzinsky, M, et al. ER stress-regulated translation increases tolerance to extreme hypoxia and promotes tumor growth. Embo J 2005;24:3470-3481.

[18] Yamamoto, S, Tomita, Y, Hoshida, Y, et al. Expression level of valosin-containing protein is strongly associated with progression and prognosis of gastric carcinoma. J Clin Oncol 2003;21:2537-2544. 
[19] Yamamoto, S, Tomita, Y, Nakamori, S, et al. Elevated expression of valosin-containing protein (p97) in hepatocellular carcinoma is correlated with increased incidence of tumor recurrence. J Clin Oncol 2003;21:447-452.

[20] Lu, X, de la Pena, L, Barker, C, Camphausen, K, Tofilon, PJ. Radiation-induced changes in gene expression involve recruitment of existing messenger RNAs to and away from polysomes. Cancer Res 2006;66:1052-1061.

[21] Rajasekhar, VK, Viale, A, Socci, ND, Wiedmann, M, Hu, X, Holland, EC. Oncogenic Ras and Akt signaling contribute to glioblastoma formation by differential recruitment of existing mRNAs to polysomes. Mol Cell 2003;12:889-901.

[22] Gherzi, R, Lee, KY, Briata, P, et al. A KH domain RNA binding protein, KSRP, promotes ARE-directed mRNA turnover by recruiting the degradation machinery. Mol Cell 2004;14:571-583.

[23] Rothe, F, Gueydan, C, Bellefroid, E, Huez, G, Kruys, V. Identification of FUSE-binding proteins as interacting partners of TIA proteins. Biochem Biophys Res Commun 2006;343:57-68.

[24] Anderson, P, Kedersha, N. RNA granules. J Cell Biol 2006.

[25] Gonzalo, P, Lavergne, JP, Reboud, JP. Pivotal role of the P1 N-terminal domain in the assembly of the mammalian ribosomal stalk and in the proteosynthetic activity. J Biol Chem 2001;276:19762-19769.

[26] Rodriguez-Gabriel, MA, Remacha, M, Ballesta, JP. Phosphorylation of ribosomal protein $\mathrm{P} 0$ is not essential for ribosome function but can affect translation. Biochemistry 1998;37:16620-16626. 


\title{
Chapter 7
}

Summary, Discussion and Future Perspectives

\author{
M.G.P. Magagnin
}




\section{SUMMARY AND DISCUSSION}

Poor oxygenation (hypoxia) influences important physiological and pathological conditions, including development, ischemia, stroke, and cancer. Hypoxia within solid tumors arises as a result of insufficiencies and improper functioning of the tumor vasculature, which negatively impacts treatment response. A series of measurements of $\mathrm{pO}_{2}$ values in primary and metastatic tumors of the cervix, breast, head-and-neck and rectum [1-3] have shown that patients with poorer tumor oxygenation exhibit a significantly lower probability of 5-year survival than patients with better-oxygenated tumors. These findings are supported by more recent studies of head-and-neck tumors and soft tissue sarcomas, and strongly suggest that hypoxia fundamentally alters tumor physiology to a more aggressive phenotype [4].

This appears at first glance to be paradoxical, since hypoxia is a condition unfavourable to cell growth and in many situations can even directly stimulate cell death. The resolution of this paradox lies in our understanding of the biological consequences of hypoxia for the tumor as a whole. In the past decade we have become aware of many important biological changes that occur when cells lack oxygen and the potential contribution of these pathways to the malignant phenotype of tumors. This biological response to hypoxia is capable of promoting metastasis, angiogenesis and selection of cells with diminished apoptotic potential. The inhibition or loss of pathways that promote cell death in response to hypoxia (e.g. p53 pathway) provide the basis for the selection of cells which have increased hypoxia tolerance [5].

A general mechanism of adaptation, which received a lot of attention in research during the past decade, is the activation of a conserved transcriptional program mediated in large part by the hypoxia inducible factors termed HIFs, which modulates the expression of numerous genes involved in various processes such as angiogenesis and glucose metabolism.

In this thesis, we have investigated the rapid and sustained inhibition in mRNA translation which seems to be another mechanism that contributes to hypoxia tolerance. Since protein synthesis is extremely energy costly, the inhibition of mRNA translation may act as a cellular survival mechanism by conserving energy demand during hypoxia in which energy production is inefficient. However, the inhibition of overall mRNA translation paradoxically 
induces the expression of certain proteins that are essential for the adaptation to the hypoxic stress. We have focused on understanding how hypoxia inhibits overall protein synthesis and on determining which specific proteins are translationally regulated during hypoxia. Furthermore, we have investigated specific changes in protein expression during reoxygenation and their potential contribution to the adaptation of the tumor cell to this stress.

mRNA translation is regulated by a family of translation initiation factors The first goal of this thesis was to investigate how the inhibition of overall mRNA translation during hypoxia is regulated. In chapter 2 we demonstrated that the inhibition of global mRNA translation during hypoxia exhibits a biphasic response, which is regulated at the level of translation initiation. The initial rapid inhibition is primarily dependent on eukaryotic inititiation factor $2 \alpha$ (eIF $2 \alpha$ ) phosphorylation, whereas inhibition during prolonged hypoxia is independent of eIF $2 \alpha$. Phosphorylation of eIF $2 \alpha$ under conditions of anoxia $\left(<0.02 \% \mathrm{O}_{2}\right)$ is extremely rapid, occurring almost as quickly as we can establish hypoxia in our system (15-30 min). Recently, we demonstrated that the inhibition of mRNA translation during acute hypoxia $\left(0.2 \% \mathrm{O}_{2}\right)$ also depends on eIF $2 \alpha$ phosphorylation. Clonogenic survival assays demonstrated that the disruption of eIF $2 \alpha$ phosphorylation increased the sensitivity to hypoxia and anoxia [6].

We speculate that this rapid response may be especially important during acute exposures to hypoxia/anoxia that frequently occur in tumors due to the transient opening and closing of blood vessels. This rapid response may explain the importance of eIF2 $\alpha$ and ATF4 in the tolerance of cells to oxidative stress, which also occurs during hypoxia/reoxygenation cycles [7]. This hypothesis is supported by another study demonstrating that activation of the PERK-eIF2 $\alpha$ pathway during hypoxia contributes to overall tumor growth [8]. Human tumor cells expressing a dominant-negative PERK allele as well as MEFs lacking PERK or expressing the S51A eIF2 $\alpha$ produce smaller tumors with increased cell death in hypoxic areas than their WT counterparts [8]. Thus, although activation of eIF $2 \alpha$ phosphorylation in response to hypoxia is transient, this response appears critical for long-term cell survival within hypoxic regions of tumors. Disruption of eIF2 $\alpha$ phosphorylation might therefore be a potential target for hypoxia-directed molecular cancer therapy. 
Furthermore, in chapter 2 we demonstrated that the inhibition of translation during prolonged anoxia is associated with disruption of the mRNA cap-binding complex eIF4F and sequestration of eIF4E by both dephosphorylated 4E-BP1 and 4E-T. After $4 \mathrm{~h}$ or $16 \mathrm{~h}$ hypoxia, there is a dramatic loss in binding of eIF4E to both eIF4GI and eIF4GII, indicating dissociation of the eIF4F complex. At $16 \mathrm{~h}$, this dissociation correlates with a large increase in binding between eIF4E and 4E-BP1, consistent with the increase in the hypophosphorylated levels of 4E-BP1 at this time. Exposure to $16 \mathrm{~h}$ of hypoxia also caused a redistribution of both eIF4E and 4E-T from the cytoplasm to the nucleus and to P-bodies. Mammalian $\mathrm{P}$ bodies are cytoplasmic foci enriched with $5^{\prime} \rightarrow 3^{\prime}$ mRNA degrading enzymes where mRNA is degraded or stored [9]. Furthermore, microRNAs (miRNAs) which mediate translational repression and/or mRNA degradation at the posttranscriptional level accumulate in P-bodies [10]. Accumulation of eIF4E in the cell nucleus or P-bodies renders it unavailable for cytoplasmic translation. The initial phosphorylation and subsequent dephosphorylation of eIF2 $\alpha$ during hypoxic exposure changed the translation efficiency of individual genes such as ATF4 and CHOP.

In conclusion, we demonstrated in chapter 2 that mRNA translation is inhibited through multiple independent pathways with different activation kinetics during hypoxia. These different mechanisms of translational control influence the translation of individual genes to varying degrees and consequently can influence hypoxia-regulated protein expression in complex ways. An important finding is that inhibition of translation via eIF $2 \alpha$ is transient, leading to dynamic changes in the translation efficiency of genes over the first $8 \mathrm{~h}$ of hypoxia. Our selected analysis of gene translation during hypoxia suggests that many genes may be differentially regulated by hypoxia.

Microarrays can be applied as a tool to assess both transcriptional and translational changes during hypoxia

In chapter 2 we demonstrated that although hypoxia causes a rapid reduction in overall mRNA translation, not all mRNA species are affected to the same extent. Therefore, mRNA translation efficiency can contribute significantly to hypoxia-induced differential protein expression. In chapter 3 we characterized changes in gene expression in DU145 prostate carcinoma cells during acute hypoxia (4 h hypoxia) and evaluated the contribution of regulation via mRNA translation on these changes. An Affymetrix approach was used to evaluate 
both the transcriptional and translational contribution to gene expression for each gene. To assess the translational contribution to gene expression we separated cell lysates on sucrose gradients and then we measured RNA levels as function of gradient depth. Efficiently translated mRNA is associated with many ribosomes (polysomes) simultaneously and therefore sediments deep in the gradient. Thus, it is possible to separate mRNAs that are efficiently translated (mRNAs with more than 4 ribosomes) from mRNAs that are not or not efficiently translated. 120 genes were than 4-fold upregulated by hypoxia in the efficiently translated fraction of mRNA, in comparison to only 76 genes at the level of transcription. The gene that demonstrated the largest increase in translation during hypoxia was the HIF-1 target gene hexokinase 2 (HK-2), which is involved in glucose metabolism [11]. In conclusion, these data provide evidence that translational regulation plays an important role in contributing to the changes in protein expression that occur during hypoxia and highlights the importance of examining gene regulatory events that occur posttranscriptionally.

Loss of the tumor suppressor $4 E-B P 1$ contributes to an adverse phenotype through specific protein expression

In chapter 2 we demonstrated that inhibition of cap dependent translation during hypoxia is promoted via activation of two distinct inhibitory proteins, the mTOR target 4E-BP1 and the eIF4E transporter 4E-T, which disrupts the eIF4F complex. In chapter 4 we generated HeLa cells stably expressing a short hairpin interfering RNA (shRNA) against 4E-BP1 to assess the contribution of 4E-BP1 expression on changes in mRNA translation during hypoxia. We found that 4E-BP1 expression did not alter overall levels of mRNA translation during normoxia or hypoxia. However, using a proteomics approach we identified 7 proteins that were exclusively expressed in the 4EBP1 knock-down cells during both normoxic and hypoxic conditions. Further investigation of the transcriptional and translational regulation of these genes by quantitative RT-PCR indicated that the loss of 4E-BP1 causes a significant increase in the rate of protein synthesis of S100 calcium-binding protein A4 (S100A4) and transgelin 2. S100A4 overexpression is associated with tumor development and progression in colorectal cancer [12]. S100A4 has also been shown to act as a prognostic factor in thyroid carcinoma, where overexpression is associated with the most advanced thyroid carcinomas and lymph node metastasis [13]. Recently, a study to identify tumor and tumor-associated 
antigens in patients with hepatocellular carcinoma (HCC) pointed to transgelin 2 as a potential diagnostic marker for HCC [14]. Thus, these 4E-BP1 regulated proteins have previously been associated with tumor cell motility, invasion and metastasis and may thus contribute to an adverse tumor phenotype.

Several of the other 4E-BP1 dependent proteins that we identified have previously been associated with cancer and/or hypoxia. These include enolase 1 , lactate dehydrogenase-B, peptidylprolyl isomerase A and heat shock protein $70 \mathrm{kDA} 9 \mathrm{~B}$. The enolase 1 gene promoter contains essential binding sites for the transcription factor HIF-1 $\alpha$ [15] and lactate dehydrogenase-B has previously been shown to be hypoxia regulated in primary rat and chick retinal cells [16]. Peptidylprolyl isomerise A (also termed cyclophilin A) has been reported to be overexpressed in different cancer cells and can lead to resistance to hypoxia and cisplatin-induced cell death [17]. Similarly, overexpression of heat shock protein 70kDA 9B (also termed mortalin) has been reported to be prognostic in colorectal cancer [18]. These observations support a growing cooperative role between transcriptional (primarily HIF) and translational control mechanism during hypoxia that are relevant to cancer.

\section{Loss of 4E-BP1 sensitizes U87 tumors to hypoxia and irradiation}

In chapter 5 we demonstrated that the loss of 4E-BP1 expression in HeLa cells results in decreased clonogenic survival after hypoxic treatment. We hypothesized that this is due to inefficient energy conservation (4E-BP1 loss) during hypoxia, together with a compromised energy production due to the lack of oxygen. To investigate if 4E-BP1 knock-down may demonstrate a similar phenotype as cells overexpressing eIF4E, we injected nude mice with U87 glioblastoma cells stably expressing a shRNA against 4E-BP1 (referred to as pRS 4E-BP1 U87). We demonstrated that pRS 4E-BP1 U87 tumors grow faster than their wild type counterparts, which was expected based on the hypothesis that the loss of 4E-BP1 results in activation of eIF4E, which would profoundly affect cellular growth properties [19]. However, a single dose of 10 Gy resulted in a larger growth delay in the pRS 4E-BP1 U87 cells as compared to the pRS U87. Immunohistochemical analysis of tumor sections implies that this sensitivity to irradiation is due to decreased hypoxia in pRS 4E-BP1 U87 tumors. We hypothesize that the pRS 4E-BP1 tumors are more sensitive to hypoxia due to increased ATP consumption. Indeed, ATP measurements clearly demonstrated lower energy levels in the pRS 4E-BP1 tumors cells. 
Tumors are known to demonstrate greatly increased rates of metabolism due to mutations in oncogenes and tumor suppressors that regulate cell growth decisions. In U87 cells, increased rates of metabolism result from pTEN gene mutations, which lead to increased Akt activity and cell growth. Loss of 4EBP1 in these cells removes an important regulatory control on mRNA translation and thus the potential for even higher ATP consumption and demand. Our data suggest that cancer cells with elevated metabolism may become increasingly dependent on 4E-BP1 for energy homeostasis during hypoxia. Consequently, targeting this gene can specifically kill hypoxic tumor cells due to their inability to regulate metabolism. This approach is similar to the concept of 'synthetic lethality' which has been proposed for targeting of tumor cells harbouring specific mutational events. For example, treatment of repair defecient BRCA1 and BRCA2 mutant cells with Poly (ADP-ribose) polymerase (PARP) inhibitors [20] results in selective killing due to increased reliance of the PARP pathway. BRCA1 and BRCA2 are important for DNA double-strand break repair by homologous recombination [21], and mutations in these genes predispose to breast and other cancers [22]. PARP is an enzyme involved in base excision repair, a key pathway in the repair of DNA singlestrand breaks [23]. Loss of BRCA1 or BRCA2 profoundly sensitizes cells to the inhibition of PARP enzymatic activity, resulting in chromosomal instability, cell cycle arrest and subsequent apoptosis.

\section{Cancer cells adapt to reoxygenation through specific protein expression}

Human tumors are characterized by large variations in oxygen concentration and patients with the most hypoxic tumors have a poor prognosis. Furthermore, tumors are subjected to periodic changes in oxygenation characterized by hypoxia followed by reoxygenation. Cellular adaptation to hypoxia is well documented, nevertheless little is known about adaptive mechanisms to reoxygenation or their importance. In chapter 6 we investigated the changes in protein expression that occur during reoxygenation using proteomics. HeLa cells were exposed to $4 \mathrm{~h}$ of hypoxia $\left(<0.01 \% \mathrm{O}_{2}\right)$ followed by $1 \mathrm{hr}$ of reoxygenation. We identified proteins involved in several cellular processes that are responsible for regulating RNA metabolism, protein synthesis and degradation, including ribosomal protein $\mathrm{P} 0$ (RPP0), vasolin containing protein (VCP/p97) and FUSE binding protein 2 (FBP2). Reoxygenation causes damage to DNA, RNA, proteins and lipids trough the activation of reactive oxygen 
species (ROS). We speculate that the proteins induced by reoxygenation serve to allow adaptation to this stress.

VCP is a highly abundant protein that is required for the removal of misfolded proteins from the ER to allow their degradation by the proteosome in the cytoplasm. Our data demonstrated that VCP translocates to the cytoplasm during reoxygenation, and might thereby transport unfolded proteins to the proteosome for degradation during conditions of reoxygenation where cells are recovering from hypoxia induced ER stress.

As mentioned before, oxidative stress also results in RNA damage and incorporation of oxidized nucleotides during RNA synthesis, which can impair protein synthesis and other RNA functions [24]. This is interesting, given the fact that FBP2 is involved in RNA processing. FBP2 (also termed KHRSP) is a member of the far-upstream element (FUSE) binding protein family that promotes rapid mRNA decay by recruiting the degradation machinery to AUrich elements (ARE) containing mRNAs [25]. We found that the efficiency by which FBP2 is translated into protein increases by more than 2-fold during reoxygenation. We found that RPP0 is also translationally upregulated during reoxygenation. This protein may thus contribute to the restoration of protein synthesis during reoxygenation which was completely restored after only $1 \mathrm{~h}$ roxygenation.

In summary, these results shed light on the contribution of reoxygenation on specific protein expression. We suggest that this effect may contribute to tumor cell survival, due to increased protein quality control and decreased cell toxicity and as such these proteins or their regulators would be interesting new therapeutic targets to explore. 


\section{FUTURE PERSPECTIVES}

It is clear that cancer is not a single disease but a collection of disorders each with their own prognosis and wide range of causes. However, all tumors are characterized by common properties including deregulated cell growth. This deregulation is caused in part by elevated rates of metabolism including increased rates of protein synthesis causing high levels of growth factors and proteins with oncogenic potential. This is often associated with a loss of control over the regulation of protein synthesis, which seems to occur primarily at the level of mRNA translation initiation. Consequently, translation initiation factors have been found to be deregulated in numerous types of cancers [26].

Currently, a variety of novel therapeutics targeting cap-dependent translation are being developed as a mechanism for cancer treatment [27]. Our data demonstrated that eIF $2 \alpha$ targeting might be a good therapeutic approach, because the loss of eIF2 $\alpha$ phosphorylation renders tumor cells sensitive to hypoxia and causes significant changes in gene expression. The most straightforward way of targeting eIF $2 \alpha$ would be to inhibit the kinase PERK which is responsible for its phosphorylation during hypoxia. Indeed, based in part upon the work presented in this thesis, new inhibitors are being developed by at least two different pharmaceutical companies.

We also demonstrated that the loss of the tumor suppressor 4E-BP1 results in the translation of specific mRNAs whose products promote tumorigenesis. Further investigation is required to define the clinical importance of S100A4 and transgelin 2 in hypoxic tumors. It would be particularly interesting to examine the clinical evidence for co-ordinated expression these proteins with eIF4E, which is often overexpressed in cancer. Furthermore, the possible contribution of S100A4 and transgelin 2 to an adverse tumor phenotype might be assessed by expressing a stable knock-down for both proteins. The metastatic potential of cells expressing a shRNA against S100A4 could be addressed both in vitro and in vivo.

Energy levels and tumor metabolism are also interesting future targets for therapy in cancer. A balance between ATP production and ATP consumption may be considered important if the tumor cell wants to contribute to tumor growth. In our study, the loss of two tumor suppressor genes (pTEN and 4E-BP1) in U87 tumors which both influence energy demand results in 
reduced hypoxia tolerance. Interestingly, this finding sheds extra light on a new way of cancer therapy that has been presented previously [20].

Finally, data presented in this thesis highlight the potential importance of reoxygenation stress as regulators of cell phenotype through changes in gene expression. Considering the available data for VCP and FBP2 it might be interesting to further investigate their contribution to the adaptation to reoxygenation. An important first step will be to target these proteins (eg. produce stable knock-downs for each of these proteins) and determine the sensitivity to hypoxia or reoxygenation. Furthermore, the use of a ROS inducer like the estrogen derivative 2-ME, which causes an accumulation of cellular superoxide, might be used to further increase cytotoxicity in vitro during normoxia or hypoxia in cells that express a stable knock-down for VCP and FBP2. VCP is a very abundant protein and might be difficult to knock-down, so an alternative might be to knock-down one of its co-factors. In vivo experiments should also be conducted to monitor tumor growth between cells that express a VCP or FBP2 knock-down compared to their WT counterparts. Tumors could be treated with irradiation, a ROS inducer or with drugs that are known to influence tumor oxgyenation.

This thesis sheds light on the importance of mRNA translational regulation during hypoxia tumorigenesis, and potentially during therapy. Using both in vitro and in vivo approaches, we have demonstrated for the first time the true importance and potential of manipulating control of mRNA translation during hypoxia. We reported that the loss of translational control (eIF2 $\alpha$ or 4EBP1) resulted in increased sensitivity of different tumor cells to hypoxia. Furthermore, although the loss of translational control (4E-BP1 loss) resulted in faster growing tumors, these tumors demonstrated increased sensitivity to irradiation through increased hypoxic cell death. These data suggest that therapeutic drugs that specifically target different members of the family of translational initiation factors have the potential to improve the treatment of cancer. The work in this thesis also addressed the importance of cellular responses to reoxygenation and we demonstrated that cancer cells adapt to this stress through specific mRNA translation. Our work has uncovered a tantalizing list of potential stress response proteins that are likely to be important mediators of tuomor cell function and survival. Further investigation of these reoxygenation specific genes may reveal new therapeutic targets which may be used to sensitize tumors to the stress of reoxygenation. Given the recent 
understanding of the important and frequent changes in oxygenation that occur in tumors, this future work is particularly exciting.

In conclusion, this thesis has highlighted the importance of cellular adaptation to hypoxia and reoxygenation through gene specific mRNA translation and may open new therapeutic windows for cancer treatment. 


\section{REFERENCES}

[1] Hockel, M, Knoop, C, Schlenger, K, et al. Intratumoral pO2 predicts survival in advanced cancer of the uterine cervix. Radiother Oncol 1993;26:45-50.

[2] Hockel, M, Schlenger, K, Aral, B, Mitze, M, Schaffer, U, Vaupel, P. Association between tumor hypoxia and malignant progression in advanced cancer of the uterine cervix. Cancer Res 1996;56:4509-4515.

[3] Vaupel, P, Thews, O, Kelleher, DK, Hoeckel, M. Oxygenation of human tumors: the Mainz experience. Strahlenther Onkol 1998;174 Suppl 4:6-12.

[4] Vaupel, P, Hoeckel, M. Predictive power of the tumor oxygenation status. Adv Exp Med Biol 1999;471:533-539.

[5] Graeber, TG, Osmanian, C, Jacks, T, et al. Hypoxia-mediated selection of cells with diminished apoptotic potential in solid tumours. Nature 1996;379:88-91.

[6] Koritzinsky, M, Rouschop, KM, van den Beucken, T, et al. Phosphorylation of eIF2alpha is required for mRNA translation inhibition and survival during moderate hypoxia. Radiother Oncol 2007;83:353-361.

[7] Harding, HP, Zhang, Y, Zeng, H, et al. An integrated stress response regulates amino acid metabolism and resistance to oxidative stress. Mol Cell 2003;11:619-633.

[8] Bi, M, Naczki, C, Koritzinsky, M, et al. ER stress-regulated translation increases tolerance to extreme hypoxia and promotes tumor growth. Embo J 2005;24:3470-3481.

[9] Andrei, MA, Ingelfinger, D, Heintzmann, R, Achsel, T, Rivera-Pomar, R, Luhrmann, R. A role for eIF4E and eIF4E-transporter in targeting mRNPs to mammalian processing bodies. RNA 2005;11:717-727. 
[10] Jackson, RJ, Standart, N. How do microRNAs regulate gene expression? Sci STKE 2007;2007:re1.

[11] Iyer, NV, Kotch, LE, Agani, F, et al. Cellular and developmental control of $\mathrm{O} 2$ homeostasis by hypoxia-inducible factor 1 alpha. Genes Dev 1998;12:149-162.

[12] Cho, YG, Kim, CJ, Nam, SW, et al. Overexpression of S100A4 is closely associated with progression of colorectal cancer. World J Gastroenterol 2005;11:4852-4856.

[13] Zou, M, Famulski, KS, Parhar, RS, et al. Microarray analysis of metastasis-associated gene expression profiling in a murine model of thyroid carcinoma pulmonary metastasis: identification of S100A4 (Mts1) gene overexpression as a poor prognostic marker for thyroid carcinoma. J Clin Endocrinol Metab 2004;89:6146-6154.

[14] Shi, YY, Wang, HC, Yin, YH, et al. Identification and analysis of tumour-associated antigens in hepatocellular carcinoma. Br J Cancer 2005;92:929-934.

[15] Semenza, GL, Jiang, BH, Leung, SW, et al. Hypoxia response elements in the aldolase A, enolase 1, and lactate dehydrogenase A gene promoters contain essential binding sites for hypoxia-inducible factor 1 . J Biol Chem 1996;271:32529-32537.

[16] Buono, RJ, Lang, RK. Hypoxic repression of lactate dehydrogenase-B in retina. Exp Eye Res 1999;69:685-693.

[17] Choi, KJ, Piao, YJ, Lim, MJ, et al. Overexpressed cyclophilin A in cancer cells renders resistance to hypoxia- and cisplatin-induced cell death. Cancer Res 2007;67:3654-3662.

[18] Dundas, SR, Lawrie, LC, Rooney, PH, Murray, GI. Mortalin is overexpressed by colorectal adenocarcinomas and correlates with poor survival. J Pathol 2005;205:74-81. 
[19] Lazaris-Karatzas, A, Montine, KS, Sonenberg, N. Malignant transformation by a eukaryotic initiation factor subunit that binds to mRNA 5' cap. Nature 1990;345:544-547.

[20] Farmer, H, McCabe, N, Lord, CJ, et al. Targeting the DNA repair defect in BRCA mutant cells as a therapeutic strategy. Nature 2005;434:917-921.

[21] Tutt, A, Ashworth, A. The relationship between the roles of BRCA genes in DNA repair and cancer predisposition. Trends Mol Med 2002;8:571-576.

[22] Wooster, R, Weber, BL. Breast and ovarian cancer. N Engl J Med 2003;348:2339-2347.

[23] Hoeijmakers, JH. Genome maintenance mechanisms for preventing cancer. Nature 2001;411:366-374.

[24] Li, Z, Wu, J, Deleo, CJ. RNA damage and surveillance under oxidative stress. IUBMB Life 2006;58:581-588.

[25] Gherzi, R, Lee, KY, Briata, P, et al. A KH domain RNA binding protein, KSRP, promotes ARE-directed mRNA turnover by recruiting the degradation machinery. Mol Cell 2004;14:571-583.

[26] Pandolfi, PP. Aberrant mRNA translation in cancer pathogenesis: an old concept revisited comes finally of age. Oncogene 2004;23:31343137.

[27] Thumma, SC, Kratzke, RA. Translational control: a target for cancer therapy. Cancer Lett 2007;258:1-8. 
Samenvatting 


\section{SAMENVATTING}

(voor referenties zie hoofdstuk 7)

Laag zuurstofgehalte (hypoxie) beïnvloedt belangrijke fysiologische en pathologische condities, zoals ontwikkeling, ischemie, beroertes en kanker. Hypoxie in solide tumoren ontstaat door insufficienties en onjuiste werking van het tumor bloedvatenstelsel, dat de therapie negatief beïnvloedt. Een reeks van zuurstofmetingen in primaire en gemetastaseerde tumoren van de baarmoederhals, borst, hoofd, nek en rectum (1-3) hebben aangetoond dat patiënten met een lager zuurstofgehalte in de tumor een significante lagere waarschijnlijkheid van 5 jaar overleving hebben dan patiënten met tumoren met een hoger zuurstofgehalte. Deze bevindingen zijn verder nog bevestigd door meer recentere studies over hoofd- en nektumoren en sarcomas, en suggereren sterk dat hypoxie fundamenteel de tumor fysiologie verandert tot een aggressiever fenotype (4).

Dit lijkt op het eerste zicht paradoxaal, gezien hypoxie een conditie is die ongunstig is voor celgroei en in vele omstandigheden zelfs rechtstreeks celdood stimuleert. De oplossing voor dit paradox ligt in het begrijpen van de onderliggende biologische effecten van hypoxie in de tumor als een geheel. Gedurende de voorbije decennia zijn we bewust geraakt van de vele belangrijke biologische veranderingen die zich voordoen wanneer cellen een zuurtsof tekort hebben en de potentiële contributie van deze veranderingen tot het kwaadaardig fenotype van deze tumoren. Het biologisch antwoord op hypoxie is in staat metastases, angiogenese (aanmaak nieuwe bloedvaten) en de selectie van cellen met een verminderde apoptotische (geprogrammeerde celdood) capaciteit te promoten. Het blokkeren of verliezen van cascades die celdood promoten als antwoord op hypoxie (vb. de p53 cascade) ligt aan de basis voor de selectie van cellen met verhoogde tolerentie tot hypoxie (5).

Een algemeen aanpassingsmechanisme, dat heel veel aandacht kreeg in de onderzoekswereld gedurende de laatste decennia, is de activatie van een transcriptie programma dat in grote delen geleid wordt door hypoxie induceerbare factoren, genaamd HIFs. Deze factoren beïnvloeden de expressie van vele genen die een invloed hebben in verschillende processen zoals angiogenese en glucose metabolisme. 
In deze thesis, hebben we de snelle en continue inhibitie in mRNA translatie (eiwitaanmaak) bestudeerd, hetgene een ander mechanisme is dat ook leidt tot tolerentie tegen hypoxie. Eiwitaanmaak kost enorm veel energie, zodat deze verhindering in eiwitaanmaak kan fungeren als een overlevingsmechanisme gedurende hypoxie. Ondanks de verhindering van eiwitaanmaak, worden er toch eiwitten aangemaakt die noodzakelijk zijn voor de overleving gedurende hypoxie. Wij hebben onderzocht hoe hypoxie eiwitaanmaak verhindert en welke eiwitten toch gemaakt worden tijdens hypoxie. Verder hebben we ook de veranderingen in eiwitaanmaak gedurende reoxygenatie bestudeerd alsook hun invloed op overleving tijdens deze vorm van stress.

Deze thesis wijst op het belang van de regulatie van eiwitsynthese gedurende tumor hypoxie en waarschijnlijk ook gedurende de therapie. Door het gebruik van in vitro en in vivo modellen, hebben we voor de eerste keer het echte belang aangetoond van het manipuleren van eiwitaanmaak gedurende hypoxie. We hebben gerapporteerd dat het verlies van eIF2 $\alpha$ of $4 \mathrm{E}-\mathrm{BP} 1$ resulteert in verhoogde gevoeligheid tot hypoxie van verschillende tumorcellen. Verder leidt het verlies van 4E-BP1 tot sneller groeiende tumoren, die een verhoogde gevoeligheid vertoonden aan bestraling door verhoogde celdood door hypoxie. Deze data suggereren dat therapeutische medicijnen die specifiek translatie initiatie factoren aanvallen, potentieel hebben om de kanker therapie te verhogen. Het werk in deze thesis heeft ook de belangen van cellulaire antwoorden tijdens reoxygenatie bestudeerd en wij hebben aangetoond dat kankercellen zich aanpassen aan deze stress door specifieke eiwitaanmaak. Ons werk heeft verschillende eiwitten geïdentificeerd die hoogstwaarschijnlijk belangrijk zijn voor tumor celfunctie en overleving.

Toekomstig onderzoek van deze specifieke reoxygenatie eiwitten zou deze eiwitten kunnen identificeren als mogelijke nieuwe doelwitten om tumoren overgevoelig te maken aan reoxygenatie. Als men denkt over het belang en de frequentie waarmee veranderingen in zuurstofgehalte in tumoren zich voordoen, is toekomstig onderzoek zeer interessant.

Om te besluiten, heeft deze thesis de belangen van de cellulaire aanpassing tot hypoxie en reoxygenatie door specifieke eiwitaanmaak aangetoond en ook een nieuwe deur geopend voor het behandelen van kanker. 


\section{Dankwoord}




\section{DANKWOORD}

Ik zou graag Prof. Philippe Lambin willen bedanken, die mij de mogelijkheid gaf om een doctoraat te doen binnen de capgroep Maastro.

Ik zou graag mijn co-promotor Dr. Marianne Koritzinsky willen bedanken.

Ik zou ook graag Prof. Brad Wouters willen bedanken om al zijn constructieve kritiek gedurende de voltooiing en de verwezenlijking van dit doctoraat.

De leden van de beoordelingscommissie, te weten Prof. dr. Frans Ramaekers (voorzitter), Prof. dr. Bart Devreese, Prof. dr. Hans Kaanders, Prof. dr. Edwin Mariman en dr. Willem Voncken, wil ik bedanken voor hun tijd en de interesse die zij hebben besteed aan het beoordelen van mijn thesis.

Graag zou ik Prof. Dr. B. Devreese en dr. Kjell Sergeant bedanken voor hun hulp met de massa spectrometrie. Die maand die ik bij jullie heb doorgebracht in Gent, heeft ons twee mooie artikelen opgeleverd.

Al mijn collega's van het Maastro Lab zou ik ook graag bedanken. Vooral ludwig en Natasja voor hun hulp met het laatste artikel.

Verder will ik Younan, Twan en Barry bedanken voor al die mooie uitstapjes die we gedaan hebben. Ik hoop dat we dit in de toekomst blijven doen.

Verder wil ik mijn twee paranimfen en beste vrienden David en Jan bedanken om mij vandaag hier bij te staan.

In het bijzonder wil ik mijn ouders bedanken. Jullie waren er altijd om mij steunen en stimuleren in alles wat ik deed. Bedankt om altijd in mij te blijven geloven.

As last but certainly not least, Mhaie Mhaie. Bedankt voor al je steun en liefde, ik hoop dat we nog vele jaren van elkaar kunnen genieten. 


\section{Curriculum Vitae}




\section{CURRICULUM VITAE}

Michaël Gaston Pietro Magagnin was born on January $7^{\text {th }}, 1978$ in Luik, Belgium. In 1996, he completed high school, with science mathematics as his main subject, at the Onze-Lieve Vrouwe College in Tongeren, Belgium. In 2002, he graduated as an Engineer in Biochemistry from the Katholieke Hogeschool Limburg (KHLIM) in Diepenbeek, Belgium. In September 2002 he joined the Department of Human Biology (NUTRIM), Maastricht University, as a Research Technician. In September 2003 he became a $\mathrm{PhD}$ student at the Department of Radiation Oncology (GROW) under the supervision of Prof. dr. B.G. Wouters and Prof. dr. P. Lambin. In January 2008, he started to work as a Clinical Research Associate (CRA) at Pharmaceutical Product Development (PPD) in Brussels, Belgium. 


\section{List of Publications}




\section{LIST OF PUBLICATIONS}

[1] Wouters, BG, van den Beucken, T, Magagnin, MGP, Lambin, P, Koumenis, C. Targeting hypoxia tolerance in cancer. Drug Resist Updat 2004;7:25-40.

[2] Koritzinsky, M, Seigneuric, R, Magagnin, MGP, van den Beucken, T, Lambin, P, Wouters, BG. The hypoxic proteome is influenced by genespecific changes in mRNA translation. Radiother Oncol 2005;76:177186.

[3] Wouters, BG, van den Beucken, T, Magagnin, MGP, Koritzinsky, M, Fels, D, Koumenis, C. Control of the hypoxic response through regulation of mRNA translation. Seminars in cell \& developmental biology 2005;16:487-501.

[4] Corpeleijn, E, van der Kallen, CJ, Kruijshoop, M, Magagnin, MGP, de Bruin, TW, Feskens, EJ, Saris, WH, Blaak, EE. Direct association of a promoter polymorphism in the CD36/FAT fatty acid transporter gene with Type 2 diabetes mellitus and insulin resistance. Diabet Med 2006;23:907-911.

[5] Koritzinsky, M, Magagnin, MGP, van den Beucken, T, Seigneuric, R, Savelkouls, K, Dostie, J, Pyronnet, S, Kaufman, RJ, Weppler, SA, Voncken, JW, Lambin, P, Koumenis, C, Sonenberg, N, Wouters, BG. Gene expression during acute and prolonged hypoxia is regulated by distinct mechanisms of translational control. The EMBO journal 2006;25:1114-1125.

[6] Magagnin, MGP, Koritzinsky, M, Wouters, BG. Patterns of tumor oxygenation and their influence on the cellular hypoxic response and hypoxia-directed therapies. Drug Resist Updat 2006;9:185-197.

[7] Koritzinsky, M, Rouschop, KM, van den Beucken, T, Magagnin, MGP, Savelkouls, K, Lambin, P, Wouters, BG. Phosphorylation of eIF2alpha is required for mRNA translation inhibition and survival during moderate hypoxia. Radiother Oncol 2007;83:353-361. 
[8] Magagnin, MGP, Sergeant, K, van den Beucken, T, Rouschop, KM, Jutten, B, Seigneuric, R, Lambin, P, Devreese, B, Koritzinsky, M, Wouters, BG. Proteomic analysis of gene expression following hypoxia and reoxygenation reveals proteins involved in the recovery from endoplasmic reticulum and oxidative stress. Radiother Oncol 2007;83:340-345.

[9] Seigneuric, R, Starmans, MH, Fung, G, Krishnapuram, B, Nuyten, DS, van Erk, A, Magagnin, MGP, Rouschop, KM, Krishnan, S, Rao, RB, Evelo, CT, Begg, AC, Wouters, BG, Lambin, P . Impact of supervised gene signatures of early hypoxia on patient survival. Radiother Oncol 2007;83:374-382.

[10] van den Beucken, T, Magagnin, MGP, Savelkouls, K, Lambin, P, Koritzinsky, M, Wouters, BG. Regulation of Cited2 expression provides a functional link between translational and transcriptional responses during hypoxia. Radiother Oncol 2007;83:346-352.

[11] Magagnin, MGP, van den Beucken, T, Sergeant, K, Lambin, P, Koritzinsky, M, Devreese, B, Wouters, BG. The mTOR target 4E-BP1 contributes to differential protein expression during normoxia and hypoxia through changes in mRNA translation efficiency. Proteomics 2008;8:1019-1028.

[12] Magagnin, MGP, Dubois, L, Cleven, AHG, Weppler, SA, Grenacher, B, Landuyt, W, Lieuwes, N, Lambin, P, Gorr, TA, Koritzinsky, M, Wouters, BG. Inhibition of 4E-BP1 sensitizes U87 glioblastoma xenograft tumors to irradiation through increased sensitivity to hypoxia induced cell death. (submitted to Radiother Oncol) 


\section{List of Abbreviations}




\section{LIST OF ABBREVIATIONS}

$\begin{array}{ll}\text { ARE } & \text { AU-Rich Element } \\ \text { ARNT } & \text { Aryl Hydrocarbon Receptor Nuclear Translocator } \\ \text { ATF6 } & \text { Activation Transcription Factor 6 } \\ \text { ATP } & \text { Adenosine Triphosphate } \\ \text { BiP } & \text { Immunoglobulin Binding Protein } \\ \text { CA-9 } & \text { Carbonic Anhydrase-9 } \\ \text { CHX } & \text { Cycloheximide } \\ \text { CITED-2 } & \text { Cbp/p300 Interacting Transactivator Domain-2 } \\ \text { C-TAD } & \text { C-Terminal Transactivation Domain } \\ \text { DMEM } & \text { Dulbecco's Modified Eagle's Medium } \\ \text { DNA } & \text { Deoxyribonucleic Acid } \\ \text { DTT } & \text { Dithiothreitol } \\ \text { DU145 } & \text { Prostate Carcinoma } \\ \text { eIF2 } \alpha & \text { Eukaryotic Initiation Factor 2 } \alpha \\ \text { eIF4E } & \text { Eukaryotic Initiation Factor 4E } \\ \text { 4E-BP1 } & \text { 4E-Binding Protein 1 } \\ \text { EPO } & \text { Erythropoietin } \\ \text { ER } & \text { Endoplasmatic Reticulum } \\ \text { ERAD } & \text { Endoplasmic Reticulum Associated Degradation } \\ \text { ESI } & \text { Electrospray Ionisation } \\ \text { 4E-T } & \text { 4E-Transporter } \\ \text { FBP } & \text { FUSE Binding Protein } \\ \text { FUSE } & \text { Far Upstream Element } \\ \text { GC } & \text { Gastric Carcinoma } \\ \text { GTP } & \text { Guanidine Triphosphate } \\ \text { HCC } & \text { Hepatocellular Carcinoma } \\ \text { HeLa } & \text { Cervical Carcinoma } \\ \text { HIF-1 } & \text { Hypoxia Inducible Factor-1 } \\ \text { HIG-2 } & \text { Hypoxia Inducible Protein-2 } \\ \text { HK-2 } & \text { Hexokinase 2 } \\ \text { HPLC } & \text { High Performance Liquid Chromatography } \\ \text { HRE } & \text { Hypoxia Response Element } \\ \text { IEF } & \text { Isoelectric Focusing } \\ \text { IL-8 } & \text { Interleukin-8 } \\ \text { IRE-1 } & \text { Inositol-Requiring Protein-1 } \\ \text { IRES } & \text { Internal Ribosomal Entry Sites } \\ & \end{array}$




$\begin{array}{ll}\text { MEF } & \text { Mouse Embryonic Fibroblast } \\ \text { MMP } & \text { Matrix Metalloproteinase } \\ \text { Mr } & \text { Molecular Weight } \\ \text { (m)RNA } & \text { (Messenger) Ribonucleic Acid } \\ \text { MS } & \text { Mass Spectrometry } \\ \text { mTOR } & \text { Mammalian Target of Rapamycin } \\ \text { N-TAD } & \text { N-Terminal Transactivation Domain } \\ \text { PARP } & \text { Poly (ADP-Ribose) Polymerase } \\ \text { PBS } & \text { Phosphate Buffered Saline } \\ \text { PCR } & \text { Polymerase Chain Reaction } \\ \text { PDGF } & \text { Platelet-Derived Growth Factor } \\ \text { PERK } & \text { (PKR)-like ER Kinase } \\ \text { PHD } & \text { Prolyl Hydrolase } \\ \text { pRS } & \text { pRetroSuper } \\ \text { pVHL } & \text { von-Hippel Lindau Protein } \\ \text { RNAi } & \text { RNA Interfering } \\ \text { ROS } & \text { Reactive Oxygen Species } \\ \text { RPP0 } & \text { Ribosomal Protein P0 } \\ \text { S100A4 } & \text { S100 Calcium-Binding Protein A4 } \\ \text { SDS } & \text { Sodium Dodecyl Sulphate } \\ \text { SG } & \text { Stress Granules } \\ \text { shRNA } & \text { Short Hairpin RNA } \\ \text { TCA } & \text { Trichloroacetic Acid } \\ \text { TOP } & \text { Terminal Oligopyrimidine } \\ \text { TSC } & \text { Tuberous Sclerosis Complex } \\ \text { uORF } & \text { Upstream Open Reading Frame } \\ \text { UPR } & \text { Unfolded Protein Response } \\ \text { UPS } & \text { Ubiquitin Proteasome System } \\ \text { VCP } & \text { Vasolin Containing Protein } \\ \text { VEGF } & \text { Vascular Endothelial Growth Factor } \\ \text { XBP-1 } & \text { X-Box Binding Protein-1 } \\ & \\ & \end{array}$

